\title{
Retro-nasal aroma release and satiation
}

Citation for published version (APA):

Ruijschop, R. M. (2009). Retro-nasal aroma release and satiation. [Doctoral Thesis, Maastricht University]. Maastricht University. https://doi.org/10.26481/dis.20090702rr

Document status and date:

Published: 01/01/2009

DOI:

10.26481/dis.20090702rr

Document Version:

Publisher's PDF, also known as Version of record

\section{Please check the document version of this publication:}

- A submitted manuscript is the version of the article upon submission and before peer-review. There can be important differences between the submitted version and the official published version of record.

People interested in the research are advised to contact the author for the final version of the publication, or visit the DOI to the publisher's website.

- The final author version and the galley proof are versions of the publication after peer review.

- The final published version features the final layout of the paper including the volume, issue and page numbers.

Link to publication

\footnotetext{
General rights rights.

- You may freely distribute the URL identifying the publication in the public portal. please follow below link for the End User Agreement:

www.umlib.nl/taverne-license

Take down policy

If you believe that this document breaches copyright please contact us at:

repository@maastrichtuniversity.nl

providing details and we will investigate your claim.
}

Copyright and moral rights for the publications made accessible in the public portal are retained by the authors and/or other copyright owners and it is a condition of accessing publications that users recognise and abide by the legal requirements associated with these

- Users may download and print one copy of any publication from the public portal for the purpose of private study or research.

- You may not further distribute the material or use it for any profit-making activity or commercial gain

If the publication is distributed under the terms of Article $25 \mathrm{fa}$ of the Dutch Copyright Act, indicated by the "Taverne" license above, 


\title{
RETRO-NASAL AROMA RELEASE
}

\author{
AND
}

SATIATION 
Cover design: R.M. Goethals

Cover photos: T. Picard and D. Guglielmo

Lay-out: R.M. Goethals

Printed by: $\quad$ GVO Drukkers \& Vormgevers B.V. | Pons en Looijen, Ede

(c) 2009, R.M.A.J. Ruijschop

Retro-nasal aroma release and satiation

Thesis Maastricht University - 164 p. - with ref. - with summary in Dutch

Rianne Ruijschop (Rianne.Ruijschop@nizo.nl)

ISBN 978-90-9024360-3

Key words: Retro-nasal aroma stimulation; Flavour; Satiation; APcI-MS; MS-NOSE;

Olfactometry 


\section{RETRO-NASAL AROMA RELEASE}

\section{AND}

\section{SATIATION}

\section{PROEFSCHRIFT}

ter verkrijging van de graad van doctor aan de Universiteit Maastricht, op gezag van de Rector Magnificus, Prof. mr. G.P.M.F. Mols

volgens het besluit van het College van Decanen, in het openbaar te verdedigen op donderdag 2 juli 2009 om 14.00 uur

door

Rianne Maria Anna Josephina Ruijschop 


\section{Promotores:}

Prof. dr. M.S. Westerterp-Plantenga

Prof. dr. ir. C. de Graaf (Wageningen Universiteit)

\section{Copromotor:}

Dr. A.E.M. Boelrijk (Danone Research Medical Nutrition)

\section{Beoordelingscommissie:}

Prof. dr. ir. R.P. Mensink (voorzitter)

Prof. dr. med. T. Hummel (University of Dresden Medical School, Germany)

Prof. dr. ir. A.M.W.J. Schols

Prof. dr. A.J. Taylor (University of Nottingham, United Kingdom)

Prof. dr. K.R. Westerterp
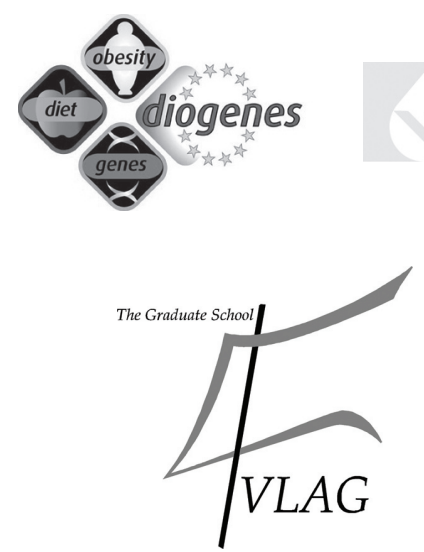

The research described in this thesis was financially supported by the Dutch Dairy Association (NZO) and the pan-European programme DiOGenes. DiOGenes is the acronym of the project "Diet, Obesity and Genes" supported by the European Community (Contract no. FOOD-CT-2005-513946), http://www.diogenes-eu.org/. The research was part of the Collective Research Dairy Nutrition and Health Programme carried out by NIZO food research for the Dutch dairy industry. The studies presented in this thesis were performed within NUTRIM School for Nutrition, Toxicology and Metabolism, which participates in the Graduate School VLAG (Food Technology, Agrobiotechnology, Nutrition and Health Sciences), accredited by the Royal Netherlands Academy of Arts and Sciences. 


\section{Contents}

\section{Chapter 1}

General Introduction

\section{Chapter 2}

Retro-nasal aroma release depends on both subject and product differences:

A link to food intake regulation?

\section{Chapter 3}

Effects of retro-nasal aroma release on satiation

\section{Chapter 4}

Effects of ingredient-related aroma cues on satiation and food intake

\section{Chapter 5}

Acute effects of complexity in aroma composition on satiation and food intake

\section{Chapter 6}

Effects of aroma-texture congruency within dairy custard on satiation and food intake

\section{Chapter 7}

Effects of bite size and duration of oral processing on retro-nasal aroma release - features contributing to meal termination

\section{Chapter 8}

General Discussion

Summary

Samenvatting

Dankwoord 


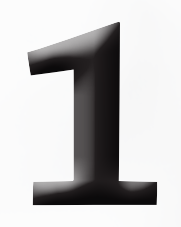

General Introduction 
The epidemic of obesity gives rise to the design of foods for suppression of appetite. Adopting a multidisciplinary approach that combines principles from the sensory science of flavours and texture, gastrointestinal physiology and ingredient technology could bring engineering of such food products within reach. The ultimate aim is to develop good tasting food products that may induce an increased level of satiation, preventing consumers from overeating.

This thesis focuses on the possibility of using sensory triggers, in particular aroma, for inducing or increasing satiation. The relative importance of different aroma concepts for satiation has been studied, using a novel approach of mass-spectrometry in combination with olfactometry.

\section{A GLOBAL NEED FOR SUSTAINED WEIGHT MANAGEMENT}

The prevalence of overweight and obesity, and associated co-morbidities, is increasing significantly. The World Health Organization (WHO) projects that worldwide by 2015, approximately 2.3 billion adults will be overweight and more than 700 million will be obese. The fundamental cause of obesity and overweight is an energy imbalance between energy consumed and energy expended. Global increase in overweight and obesity is attributable to a number of factors, including a global shift towards increased energy intake. In addition, there is a trend towards decreased physical activity associated with increasingly sedentary lifestyles ${ }^{(1)}$.

Advising individuals to choose healthier diets with less energy, and to increase their level of exercise, to prevent energy imbalance, has proven insufficient to deal with the epidemic of overweight. The human body exerts a strong defence against undernutrition and weight loss, but applies a much weaker resistance to overconsumption and weight gain. This means that weight gain by overconsumption may occur despite the best efforts to prevent it ${ }^{(2)}$. Therefore, conventional weight management (dietary intervention, physical activity, behavioural therapy) often results in shortterm successes only; sustained weight maintenance is difficult to achieve ${ }^{(3)}$. Hence, alternative weight reduction strategies are explored.

Various weight management approaches can be adopted with different modes of action, from boosting diet-induced thermogenesis and fat oxidation ${ }^{(4)}$, inhibiting protein breakdown ${ }^{(5)}$, and blocking intestinal fat absorption ${ }^{(6)}$, to regulating mood (linked to food consumption) ${ }^{(7)}$, suppressing appetite and enhancing satiety ${ }^{(8)}$.

\section{APPETITE CONTROL}

The biological drive to eat can be linked with the satiating power or efficiency of food or food ingredients. Food brings about this effect by mediating certain processes that can be roughly classified as either sensory, cognitive, post-ingestive or post-absorptive. These processes activate physiological and biochemical mechanisms in the body. 
Collectively these processes have been referred to as the satiety cascade, consisting of processes related to satiation (intra-meal satiety) and satiety (inter-meal satiety) ${ }^{(2,}$ 9). Food-related stimuli can affect all phases of the satiety cascade. In Figure 1.1 this 'satiety cascade' is depicted along with the meal intake cycle.

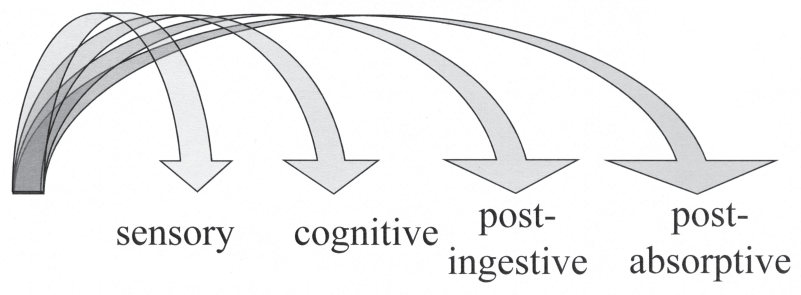

Inter-meal interval

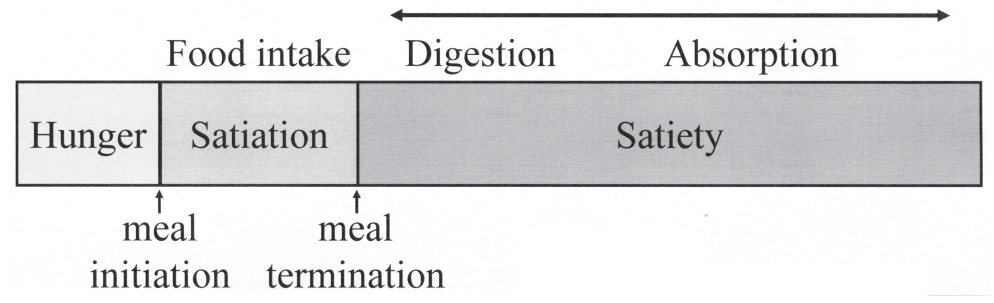

Figure 1.1 Schematic overview of a food intake cycle and satiety cascade with related terminology (adapted from 2).

Satiation (intra-meal satiety) is associated with fullness and termination of food intake during meals. It develops during meal intake and ultimately brings the period of eating to an end. Satiation, therefore, reduces hunger and limits the amount of energy consumed during a meal ${ }^{(2,10)}$. Satiety (inter-meal satiety), on the other hand, occurs after meal termination. It is the state of satiety that delays the onset of the next meal and may reduce food consumption at the next eating occasion ${ }^{(2)}$. Satiation and satiety are distinct but interrelated factors that influence both the type and amount of food consumed.

Even before the food touches the mouth, physiological signals are generated by the sight and the smell of food. These events constitute the cephalic phase of appetite. Cephalic-phase responses are generated throughout the gastrointestinal tract and one of their prime functions is to prepare the body for effective food digestion. During and immediately after eating, signals from the oral cavity and gastrointestinal tract, which are processed towards the brain, exert major control over appetite. Flavour and mouth feel qualities of food give rise to hedonic responses via opioidergic and aminergic neural pathways ${ }^{(11-12)}$. Food-induced gastrointestinal effects that decrease appetite include gastric distension, intestinal nutrient presence, hormone release and post-absorptive appearance of food metabolites in the circulation. These peripheral events lead to an activation of multiple pathways and networks within the central nervous system. Proteins, fats and carbohydrates generate different sets of physiological responses with 
different effects on the intensity and duration of satiety. Many studies have shown that proteins are the macronutrients that provide the most satiation per kilo joule $(\mathrm{kJ})$, followed by carbohydrates and fats ${ }^{(13-16)}$. Not only the macronutrient composition of food, but also the overall energy density and food texture influence meal size and postmeal satiety ${ }^{(2)}$.

Currently marketed food products that are claimed to suppress appetite often contain active ingredients, such as the fat emulsion Olibra ${ }^{\mathrm{TM}}$ or the Korean pine nut oil PinnoThin ${ }^{\mathrm{TM}}$, which are aimed at later phases of the satiety cascade, e.g. the postingestive and post-absorptive stage ${ }^{(8,17)}$. This thesis focuses on the possibility of using sensory triggers, particularly aroma, for inducing or increasing satiation. These sensory triggers take part in the early phases of the satiety cascade at the interface between satiation and satiety, and contribute to the process of meal termination.

\section{UNDERSTANDING OF SENSORY SATIATION}

Sensory modalities

Human perception of food aroma and texture during consumption is a complex process, in which taste, mouth feel, vision, olfaction, the trigeminal system and even auditory signals contribute to the total appreciation of a food product ${ }^{(18-20)}$. When food is eaten, it is subjected to changes in temperature, mechanical deformation and effects caused by saliva, such as dilution and enzymatic breakdown of certain food ingredients, such as starch ${ }^{(21)}$. Non-volatile compounds that are responsible for the basic tastes diffuse into the saliva and subsequently reach the gustatory receptors. Furthermore, during oral processing and after swallowing, volatile aroma compounds are released from the food matrix and are able to flow to the olfactory epithelium (i.e. retro-nasal aroma release), where they interact with olfactory receptors. During food intake, the different senses interact in a non-linear way. Cross-modal phenomena, in which aroma influences the perception of the taste or texture (and vice versa) of a food product, have been described ${ }^{(20,22-26)}$. Aroma-taste interactions are most prominent for sweetness and congruent aromas like strawberry and include both synergistic and antagonistic effects ${ }^{(20)}$. Additionally, perceived properties like thickness and creaminess may be enhanced by congruent aromas ${ }^{(25)}$. Moreover, perceived aroma intensity is decreased with increasing firmness of the food that is consumed ${ }^{(20,26)}$.

The orbitofrontal cortex in the human brain is an important site where representations of the various sensory properties of food converge. The orbitofrontal cortex is also the region where the short-term sensory-specific control of appetite and ingestion are regulated ${ }^{(27)}$. Sensory effects, generated by the sensory properties of food, are probably among the most important factors leading to satiation and meal termination ${ }^{(28)}$. 


\section{Relevance of sensory satiation}

Sensory satiation refers to the decrease in pleasantness of a food after it is eaten compared with the decrease in pleasantness of foods that were tasted but not eaten to satiation. Sensory satiation already occurs within 2 minutes after the start of consumption, when there has been little opportunity for digestion and absorption ${ }^{(29)}$. The duration of sensory satiation is unknown. A number of studies show that drops in liking persist for more than one hour after consumption ${ }^{(28)}$. Factors that interrupt continued exposure, i.e. distractors introduced during a meal (e.g. watching TV, conversation with friends during dining) or variety in food and sensory properties, delay the development of sensory satiation ${ }^{(30-32)}$. This implies that, when a food is eaten, introducing another food with different sensory properties slows the decline in desire to eat and increases the total amount of food consumed. Increasing the variety of sensorily distinct foods that are almost identical in composition can increase food and energy intake and alter energy balance in the short to medium term ${ }^{(33)}$.

Sensory satiation depends more on the sensory stimulation accompanying eating and less on absorptive events after consuming these foods ${ }^{(28-29,34-36)}$. However, sensory perception is able to influence physiological and metabolic mechanisms underlying appetite regulation.

To a large extent, satiation and satiety are conditioned (learned) responses. Sensory signals are mostly unconsciously learned to be associated with the metabolic consequences of food products (e.g. 37). This phenomenon is called flavour-nutrient learning (cf. 37-39). The term 'flavour' refers to the combined perception of aroma, taste and mouth feel at the time of food consumption ${ }^{(40)}$. Alterations in flavour preference, food intake and presumably satiation can occur following repeated exposure to flavourfood combinations ${ }^{(37,41)}$. These effects can also be macronutrient-specific, e.g. proteinspecific hungers, provided that the previous meal was low in that macronutrient ${ }^{\text {(e.g. } 42 \text {. }}$. Alternatively, modified sham feeding (MSF) can provoke cephalic and metabolic responses due to sensory signals. MSF implies oral exposure to food that is chewed, but not eaten ${ }^{(43-44)}$. Physiological responses observed during MSF are increased salivation and flow of digestive gastric and pancreatic juices, a rise in plasma ghrelin and insulin levels, and a decrease in blood glucose ${ }^{(45-46)}$. Rather than enhancing satiation or satiety, cephalic responses appear to reflect and favour appetitive and consummatory behaviours; i.e. they prime the body for smooth ingestion (salivation) and effective breakdown of food (digestive juices) and safeguard against perturbations of homeostasis (by limiting post-prandial hyperglycaemia). However, oro-sensory exposure to lipids or glucose is also reported to stimulate the transfer of intestinally present triglycerides into the circulation ${ }^{(47-48)}$. Both of these responses could potentially contribute to satiation. Moreover, Smeets et al. ${ }^{(49-51)}$ showed that oral stimulation with fat, using a MSF technique, induces anticipatory responses to food that affects sensory satiation, 
satiety, desire to eat, metabolites, and energy expenditure up to 1 hour after the sham fed meal.

\section{AROMA PERCEPTION}

Ortho- vs. retro-nasal olfaction

Aroma stimuli can reach the olfactory epithelium through two pathways: via the nose, during sniffing (referred to as ortho-nasal olfaction), and via the mouth, during food consumption (referred to as retro-nasal olfaction) (Figure 1.2) ${ }^{(52)}$.

Ortho-nasal olfaction processes stimuli from the external environment, which travel through the anterior nares towards the olfactory mucosa during sniffing. In contrast, during oral processing and after swallowing, volatile aroma molecules are released from the food matrix and they reach the nasal cavity through the pharynx, stimulating receptors in the olfactory cleft. This pathway for aroma perception is defined as retronasal olfaction.

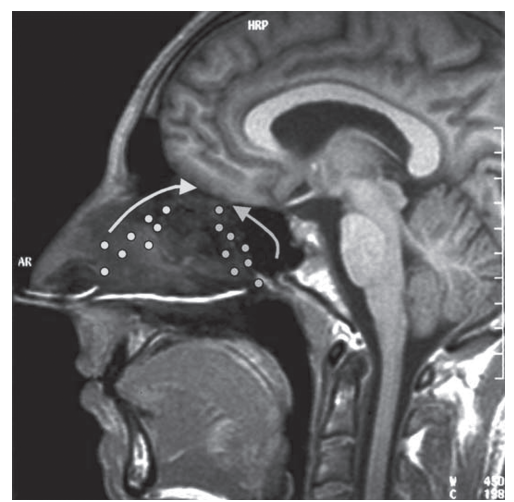

Figure 1.2 A magnetic resonance image (MRI) showing placement of the nasal cannulae at the external nares to achieve orthonasal delivery, and at the retro-pharynx, to achieve retro-nasal delivery. Dots and arrows depict the idealised distribution and flow direction of odourants delivered orthonasally (via the external nares) or retro-nasally (via the retro-pharynx) (Reprinted from 53, with permission from Elsevier).

Differences in airflow patterns through the two pathways and aroma absorption across the mucosa may determine differences in ortho- and retro-nasal aroma perception ${ }^{(52,54-}$ 55). For example, differences in perceived aroma thresholds ${ }^{(56)}$, cross-modal interactions of aroma and texture ${ }^{(20,25)}$ and neural aroma processing ${ }^{(53)}$, are reported to account for perceptual differences in ortho- and retro-nasal olfaction. Ortho-nasal aroma thresholds are observed to be significantly lower than retro-nasal aroma thresholds. Correspondingly, the concentration of aroma reaching the olfactory cleft through the retro-nasal pathway is usually much higher than during ortho-nasal perception of aromas due to salivation, warming and mastication during food consumption ${ }^{(56)}$. Aroma stimuli have also shown to increase the intensities of perceived thickness 
and creaminess, but only when the (butter) aroma was presented retro-nasally ${ }^{(25)}$. This enhancement is most pronounced when aroma presentation is coincided with swallowing, inducing retro-nasal aroma olfaction.

Differences in texture can also lead to differences in perceived aroma intensity. Visschers et al. ${ }^{(20)}$ show that the perceived intensity of aroma decreases with increasing firmness of the food that is consumed. The aroma and texture stimuli were presented separately, using an olfactometer. However, these cross-modal interactions did not depend on ortho- or retro-nasal aroma presentation and perception. In addition, the neural processing of aroma is influenced by the pathway for aroma perception. Small et al. ${ }^{(53)}$ investigated response patterns to ortho- and retro-nasal olfaction at a centralnervous level, by using functional magnetic resonance imaging (fMRI). They report that aroma perception is greater to a food aroma (chocolate) compared to a non-food aroma (lavender). Its processing may be related to differential reward circuits for food, but not non-food aromas ${ }^{(57)}$. Ortho-nasal olfaction appears to correlate to the anticipatory phase in food reward, whereas retro-nasal olfaction is related to the consummatory phase, receipt of a reward.

\section{Engineering retro-nasal aroma perception}

The ability to administer aroma stimuli to subjects separately from other stimuli from the food matrix (associated with other ingredients, textures and tastes) enables investigation of the relative importance of aroma stimuli for perception. Both atmospheric pressure chemical ionization-mass spectrometry (APcI-MS) and olfactometry have proven to be of great importance in measuring as well as mimicking aroma release. The release of aromas during food consumption can be measured and adjusted, using APcI-MS technology ${ }^{(58-59)}$. On the other hand, tailored olfactometer equipment, originally developed for medical purposes, is finding more and more applications in aroma research ${ }^{(20,25,60)}$. Olfactometry can be applied to deliver specific, well-defined aroma profiles consisting of a single aroma component or a mixture of multiple aroma components. As described by Visschers et al. ${ }^{(20)}$, delivering food-related aroma stimuli to subjects via an olfactometer involves fine-tuning of many parameters, such as the initial concentration of the aroma component(s) in a suitable solution, volatility and partitioning of the aroma component(s) from the solvent into the air flow, air dilution factor of the olfactometer, aroma pulse timing, and aroma pulse length. Delivery of aroma stimuli in a manner that reflects aroma release during food intake is complex. For retro-nasal aroma delivery, a tube of approximately 9 centimetres in length is cut from a sterile silicon suction catheter ${ }^{(52)}$. The tube is placed inside the nose, such that the opening is in the epi-pharynx. For aroma stimulation the tube is connected to the outlet of the olfactometer. The olfactometer delivers aroma stimuli, which are embedded into a constant flow of odourless, humidified air of controlled temperature (total flow $8 \mathrm{~L} / \mathrm{min}, 60 \%$ relative humidity, $40^{\circ} \mathrm{C}$ ). 
It has been demonstrated that the aroma profile that is generated with the olfactometer closely resembles the concentration of volatiles in the oro-nasal cavity measured in individuals during ingestion of a specific food product ${ }^{(59,61)}$. The used approach is based on data from in vivo studies with real-time measurement of aroma release, using APcI-MS. This enables the design of complete aroma release profiles that mimic those obtained by in vivo measurement during food consumption ${ }^{(20)}$ (Figure 1.3). The combination of mass-spectrometry and olfactometry provides a unique and novel approach to investigate the role of aroma for perception.

\section{Food consumption}

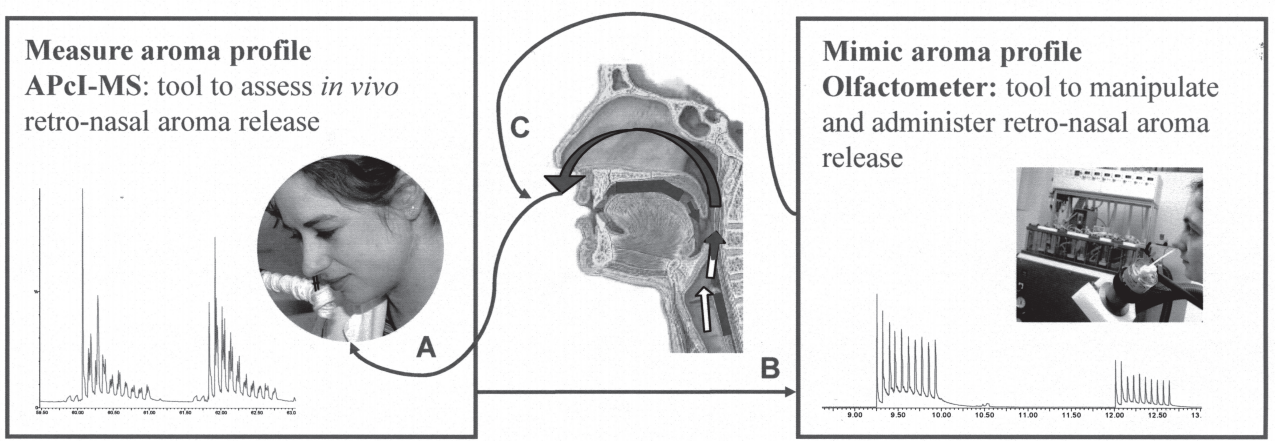

Figure 1.3 Illustration of the used approach to deliver specific, well-defined aroma profiles that mimic those obtained during food consumption. The release of aromas during food consumption is measured, using APcI-MS technology (A). Using a computer-controlled stimulator based on air dilution olfactometry, complete aroma release profiles are designed that mimic those obtained by applying APcI-MS technology (B). Specific, well-defined aroma profiles are retro-nasally delivered to the subject, while combined with the taste and mouth feel sensation of the non-aromatised food product in the mouth $(C)$.

\section{AROMA AS CANDIDATE TRIGGER FOR SATIATION}

During the consumption of a meal, aroma molecules reach the olfactory epithelium retro-nasally. Activation of brain areas by a retro-nasally sensed food odour is associated with the perception of food that is consumed and is hypothesised to contribute to satiation ${ }^{(53)}$, i.e. sensory-related satiation. The extent of sensory stimulation may therefore be related to meal termination ${ }^{(29,36)}$.

From previous work, it is known that the physical structure of a food that is consumed is important for the extent of retro-nasal aroma release during consumption ${ }^{(62-65)}$. This is because the texture of the food has an influence on the breakdown and oral processing in the mouth. (Soft) solid foods like cheese have a more complex texture and therefore require more extensive chewing and swallowing, resulting in a relative long and high retro-nasal aroma release. On the other hand, consumption of liquid food results in a relatively short and more spiked, limited retro-nasal aroma release ${ }^{(59,}$ 
66). These differences may (partly) explain why people become more satiated by a (soft) solid food compared to a beverage ${ }^{(67-71)}$. Additionally, subject differences in retro-nasal aroma stimulation are of importance for the extent of retro-nasal aroma release during consumption ${ }^{(72)}$. These subject differences are factors that are likely not controlled by the individual, such as saliva production, nasal anatomy, and oral processing habits ${ }^{(72-76)}$. Moreover, the aroma quality (e.g. ingredient-related aroma cues, complexity in aroma composition and congruency in aroma and texture) is a more food product related property with respect to the extent of retro-nasal aroma stimulation. Furthermore, bite size and duration of oral processing have been suggested to be of importance for the extent of retro-nasal aroma stimulation, from both the subject and food product point of view.

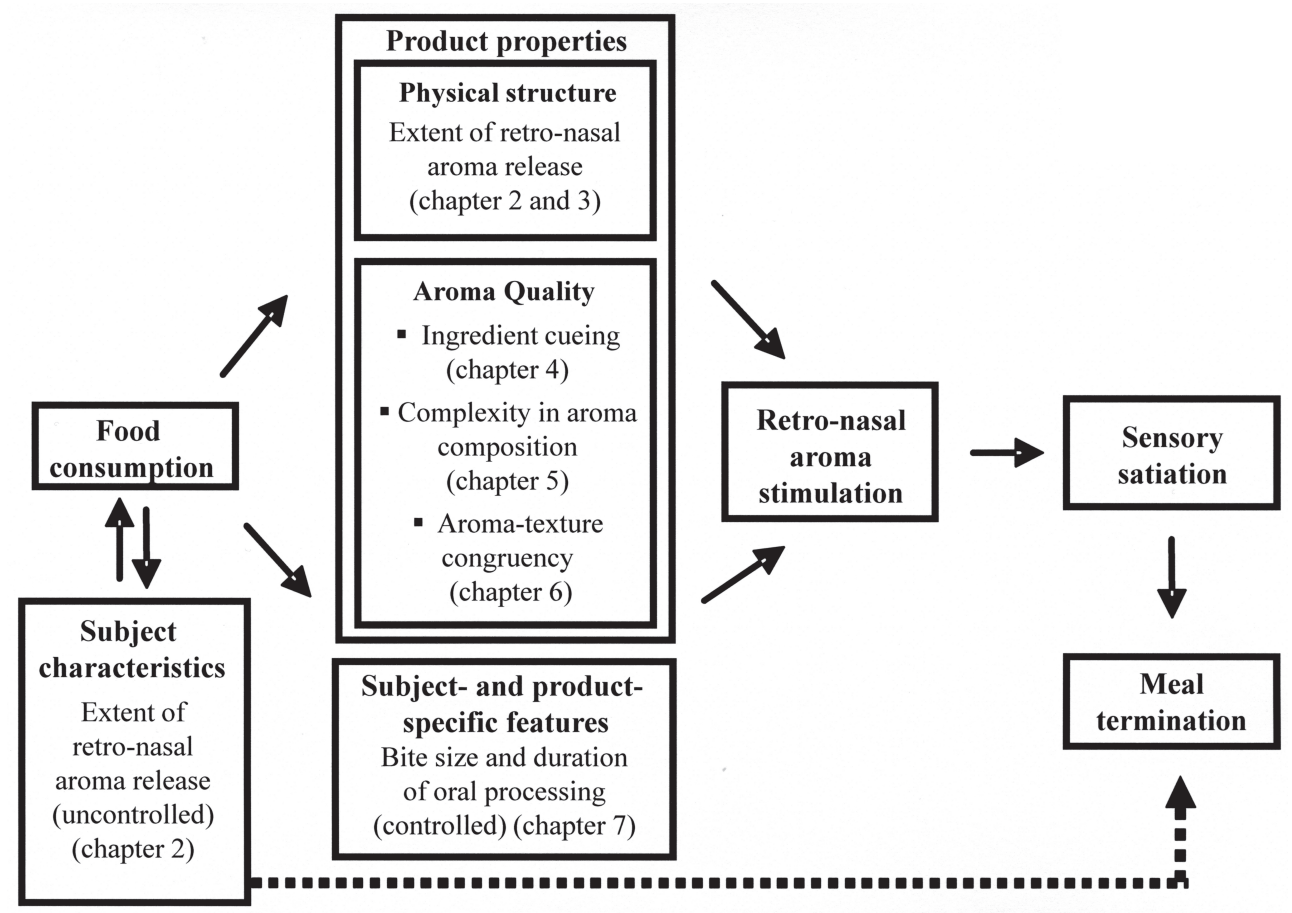

Figure 1.4 Schematic representation of features that are suggested to contribute to the extent of retro-nasal aroma stimulation and sensory satiation, from both the subject and food product point of view.

Retro-nasal aroma stimulation is hypothesised to induce sensory satiation and thereby to provoke meal termination. Therefore, differences in the extent of retro-nasal aroma stimulation during consumption are thought to be responsible for subject or food product differences in sensory satiation and food intake. Figure 1.4 gives an overview of some of the features that are suggested to contribute to the extent of retro-nasal 
aroma stimulation and subsequently sensory satiation, from both the subject and food product point of view. Tailoring these features may lead to a higher quality and/or quantity of retro-nasal aroma stimulation, which in turn may lead to enhanced feelings of satiation and ultimately contribute to a decrease in food intake.

\section{RATIONALE AND CONTENTS OF THIS THESIS}

It is hypothesised that differences in the extent of retro-nasal aroma release during consumption may be one of the reasons that people vary in their satiation characteristics, due to differences in perceived intensity, duration or quality of retro-nasal aroma stimulation. Therefore, the effect of retro-nasal aroma release on satiation and food intake is studied, from both the subject and food product point of view (Figure 1.4).

First, the question is addressed whether subjects can be segmented based on their extent of retro-nasal aroma release, using real-time APcI-MS, and whether this depends on the type of food product they consume. To this end, in vivo retro-nasal aroma release is assessed for food products, which varied in texture from (semi-)liquid to solid. Ultimately, the aim is to determine whether subject differences in the extent of retro-nasal aroma release are linked to subject differences in sensory satiation and food intake behaviour (Chapter 2). A higher extent of retro-nasal aroma release may result in more sensory stimulation, which in turn may lead to increased feelings of satiation and decreased food intake. Obviously, the level of sensory stimulation depends on the timed-release of the aromas and thereby differs for different food structures and compositions. After all, the physical structure of a food product that is consumed is important for the extent of retro-nasal aroma release during consumption. It is hypothesised that relative prolonged retro-nasal aroma release, as observed in solid foods, is an important factor in generating an enhanced level of satiation compared to the level resulting from consuming a (iso-energetic and iso-volumetric) beverage. Therefore, it is assessed whether a beverage becomes more satiating when the retronasal aroma release profile coincides with the profile of a (soft) solid food (Chapter 3 ). To a large extent, satiation and satiety are conditioned (learned) responses. Sensory signals are mostly unconsciously learned to be associated with the metabolic consequences of food products. It is investigated whether specific aroma stimuli, which subjects do not consciously recognise, are able to cue for satiation. It is hypothesised that ingredient-related aroma cues at sensory detection threshold may contribute to satiation, because of unconsciously learned responses, or due to unconsciously perceiving the aroma cues for the macronutrients (Chapter 4). Moreover, it is assessed whether a single exposure to an aroma, complex in composition, may contribute to satiation, because of increased sensory stimulation due to concurrent exposure to multiple aroma components cueing for similar sensory perception. Assuming that the total amount of exposure to a food's sensory properties determines the total decline 
in desire to eat, it is hypothesised that increased sensory stimulation from a more complex aroma further reduces the desire to eat and enhances satiation (Chapter 5). Comparably, increased sensory stimulation from a food product congruent in aroma and texture is expected to further reduce desire to eat, because of concurrent sensory exposure to multiple sensory modalities cueing for similar sensory perception (i.e. creaminess). Using a regimen of a fixed preload followed by an ad libitum meal of the creamy custard, the effects of four possible aroma combinations (either congruent or incongruent with creamy texture) on the amount of ad libitum food intake are tested in a two-by-two full-factorial design. It is hypothesised that satiation and food intake are affected by the level of congruency as well as by variation of successive exposure to aroma-texture combinations (Chapter 6).

In addition to product and (uncontrolled) subject features, the effect of bite size and duration of oral processing on the extent of retro-nasal aroma release is investigated. It is hypothesised that consuming food, either in multiple small bite sizes or with a longer duration of oral processing may evoke substantial longer oral processing per gram consumed and an increase in transit time in the oral cavity. This is expected to result in a higher cumulative retro-nasal aroma stimulation, which in turn may lead to increased feelings of satiation and decreased food intake (Chapter 7).

Chapter 8 discusses the implications of this research and provides suggestions for application in food product development.

\section{ACKNOWLEDGEMENTS}

Part of this chapter has been published in Ruijschop, R.M.A.J., Burseg, K.M.M., Lambers, T.T., \& Overduin, J. (2009) Designing foods to induce satiation - a flavour perspective. In: McClements, D.J., \& Decker, E.D. (Eds.), Designing functional foods: Understanding, measuring and controlling food structure breakdown and nutrient absorption for the development of health-promoting foods. Cambridge: Woodhead Publishing Ltd \& CRC Press LLC (in press).

\section{REFERENCES}

1. International Obesity Task Force (IOTF). Retrieved 29-09-2008, from http:// www.iotf.org.

2. Blundell, J.E., \& King, N.A. (1996) Overconsumption as a cause of weight gain: behavioural-physiological interactions in the control of food intake (appetite). In: James, P., Bouchard, C., \& Bray, G. (Eds.), The origins and consequences of obesity (pp. 138-158). Chichester: Wiley.

3. Westerterp-Plantenga, M.S., Lejeune, M.P.G.M., Nijs, I., van Ooijen, M., \& Kovacs, E.M.R. (2004) High protein intake sustains weight maintenance after body weight loss in humans. Int. J. Obes. Relat. Metab. Disord. 28: 57-64. 
4. St-Onge, M-P., \& Bosarge, A. (2008) Weight-loss diet that includes consumption of medium-chain triacylglycerol oil leads to a greater rate of weight and fat mass loss than does olive oil. Am. J. Clin. Nutr. 87: 621-626.

5. Hill, A.J., Peikin, S.R., Ryan, C.A., \& Blundell, J.E. (1990) Oral administration of proteinase inhibitor II from potatoes reduces energy intake in man. Physiol. Behav. 48: 241-246.

6. Heck, A.M., Yanovski, J.A., \& Calis, K.A. (2000) Orlistat, a new lipase inhibitor for the management of obesity. Pharmacotherapy 20: 270-279.

7. Rogers, P.J. (1995) Food, mood and appetite. Nutr. Res. Rev. 8: 243-269.

8. Diepvens, K., Soenen, S., Steijns, J., Arnold, M., \& Westerterp-Plantenga, M.S. (2007) Long-term effects of consumption of a novel fat emulsion in relation to body-weight management. Int. J. Obes. 31: 942-949.

9. Blundell, J.E. (1999) The control of appetite: basic concepts and practical implications. Schweiz. Med. Wochenschr. 129: 182-188.

10. Blundell, J.E., Lawton, C.L., Cotton, J.R., \& Macdiarmid, J.I. (1996) Control of human appetite: Implications for the intake of dietary fat. Annu. Rev. Nutr. 6: 285-319.

11. Kirkham, T.C., \& Cooper, S.J. (1991) Opioid peptides in relation to the treatment of obesity and bulimia. In: Bloom, S.R. \& Burnstock, G. (Eds.), Peptides: A Target for New Drug Development (pp. 284). London: IBC.

12. Drewnowski, A. (1992) Food preferences and the opioid peptide system. Trends Food Sci. Technol. 3: 97-99.

13. De Castro, J.M. (1987) Macronutrient relationships with meal patterns and mood in the spontaneous feeding behavior of humans. Physiol. Behav. 39: 561-569.

14. De Graaf, C., Hulshof, T., Weststrate, J.A., \& Jas, P. (1992) Short-term effects of different amounts of protein, fats, and carbohydrates on satiety. Am. J. Clin. Nutr. 55: 33-38.

15. Stubbs, R.J. (1995) Macronutrient effects on appetite. Int. J. Obes. 19: S11-S19.

16. Westerterp-Plantenga, M.S., Pasman, W.J., Yedema, M.J.W., \& Wijckmans-Duijsens, N.E.G. (1996) Energy intake adaptation of food intake to extreme energy densities of food by obese and non-obese women. Eur. J. Clin. Nutr. 50: 401-407.

17. Hughes, G.M., Boyland, E.J., Williams, N.J., Mennen, L., Scott, C., Kirkham, T.C., Harrold, J.A., Keizer, K.G., \& Halford, J.C. (2008) The effect of Korean pine nut oil (PinnoThin) on food intake, feeding behaviour and appetite: a double-blind placebo-controlled trial. Lipids Health Dis. 7: 6.

18. Shepherd, R. (1995) Psychological aspects of food choice. Food Sci. Technol. Today 9: 178-182. 
19. Meiselman, H.L. (1996) The contextual basis for food acceptance, food choice and food intake: the food, the situation and the individual. In: Meiselman, H.L., \& MacFie, H.J.H. (Eds.), Food choice, acceptance and consumption (pp. 239-263). London: Blackie Academic \& Professional.

20. Visschers, R.W., Jacobs, M.A., Frasnelli, J., Hummel, T., Burgering, M., \& Boelrijk, A.E.M. (2006) Cross-modality of texture and aroma perception is independent of orthonasal or retro-nasal stimulation. J. Agric. Food Chem. 54: 5509-5515.

21. De Wijk, R.A., \& Prinz, J.F. (2005) The role of friction in perceived oral texture. Food Qual. Pref. 16: 121-123.

22. Pfeiffer, J.C., Hort, J., Hollowood, T.A., \& Taylor, A.J. (2006) Taste-aroma interactions in a ternary system: a model of fruitiness perception in sucrose/acid solutions. Percept. Psychophys. 68: 216-227.

23. Hort, J., \& Hollowood, T.A. (2004) Controlled continuous flow delivery system for investigating taste-aroma interactions. J. Agric. Food Chem. 52: 4834-4843.

24. Stevenson, R.J., Prescott, J., \& Boakes, R.A. (1999) Confusing tastes and smells: how odours can influence the perception of sweet and sour tastes. Chem. Senses 24: 627-635.

25. Bult, J.H.F., de Wijk, R.A., \& Hummel, T. (2007) Investigations on multimodal sensory integration: texture, taste, and ortho- and retronasal olfactory stimuli in concert. Neurosci. Lett. 411: 6-10.

26. Weel, K.G., Boelrijk, A.E.M., Alting, A.C., van Mil, P.J.J.M., Gruppen, H., Voragen, A.G.J., Burger, J.J., \& Smit, G. (2002) Flavor release and perception of flavored whey protein gels: perception is determined by texture rather than by release. $J$. Agric. Food Chem. 50: 5149-5155.

27. Rolls, E.T. (2004). Smell, taste, texture, and temperature multimodal representations in the brain, and their relevance to the control of appetite. Nutr. Rev. 62: S193-S204.

28. Sorensen, L.B., Moller, P., Flint, A., Martens, M., \& Raben, A. (2003) Effect on sensory perception of foods on appetite and food intake: a review of studies on humans. Int. J. Obes. Relat. Metab. Disord. 27: 1152-1166.

29. Hetherington, M., Rolls, B.J., \& Burley, V.J. (1989) The time course of sensoryspecific satiety. Appetite 12: 57-68.

30. Hetherington, M.M., Foster, R., Newman, T., Anderson, A.S., \& Norton, G. (2006) Understanding variety: tasting different foods delays satiation. Physiol. Behav. 87: 263-271.

31. Brunstrom, J.M., \& Mitchell, G.L. (2006) Effects of distraction on the development of satiety. Br. J. Nutr. 96: 761-769.

32. Romer, M., Lehrner, J., van Wymelbeke, V., Jiang, T., Deecke, L., \& Brondel, L. (2006) Does modification of olfacto-gustatory stimulation diminish sensoryspecific satiety in humans? Physiol. Behav. 87: 469-477. 
33. Stubbs, R.J., Johnstone, A.M., Mazlan, N., Mbaiwa, S.E., \& Ferris, S. (2001) Effect of altering the variety of sensorially distinct foods, of the same macronutrient content, on food intake and body weight in men. Eur. J. Clin. Nutr. 55: 19-28.

34. Snoek, H.M., Huntjens, L., van Gemert, L.J., de Graaf, C., \& Weenen, H. (2004) Sensory-specific satiety in obese and normal-weight women. Am. J. Clin. Nutr. 80: 823-831.

35. Rolls, B.J., Rowe, E.A., \& Rolls, E.T. (1982) How sensory properties of food affect human feeding behaviour. Physiol. Behav. 29: 409-417.

36. Hetherington, M.M., \& Boyland, E. (2007) Short-term effects of chewing gum on snack intake and appetite. Appetite 48: 397-401.

37. Gibson, E.L., \& Brunstrom, J.M. (2007) Learned influences on appetite, food choice and intake: Evidence in human beings. In: Cooper, S.J., \& Kirkham, T.C. (Eds.), Progress in brain research: Appetite and body weight-- Integrative systems and the development of anti-obesity drugs (pp. 271-300). London: Elsevier.

38. Booth, D.A., Lee, M., \& McAleavey, C. (1976) Acquired sensory control of satiation in man. Br. J. Psychol. 67: 137-147.

39. Mobini, S., Chambers, L.C., \& Yeomans, M.R. (2007) Effects of hunger state on flavour pleasantness conditioning at home: flavour-nutrient learning vs. flavourflavour learning. Appetite 48: 20-28.

40. Taylor, A.J. (1996) Volatile flavor release from foods during eating. Crit. Rev. Food Sci. Nutr. 36: 765-784.

41. Yeomans, M.R. (2006) The role of learning in development of food preferences. In: Shepherd, \& R., Raats, M. (Eds.), Psychology of food choice (pp. 93-112). Wallingford, Oxford: CABI.

42. Gibson, E.L., Wainwright, C.J., \& Booth, D.A. (1995) Disguised protein in lunch after low-protein breakfast conditions food-flavor preferences dependent on recent lack of protein intake. Physiol. Behav. 58: 363-371.

43. Robertson, M.D., Jackson, K.G., Williams, C.M., Fielding, B.A., \& Frayn, K.N. (2001) Prolonged effects of modified sham feeding on energy substrate mobilization. Am. J. Clin. Nutr. 73: 111-117.

44. Arosio, M., Ronchi, C.L., Beck-Peccoz, P., Gebbia, C., Giavoli, C., Cappiello, V., Conte, V., \& Peracchi, M. (2004) Effects of modified sham feeding on ghrelin levels in healthy human subjects. J. Clin. Endocrinol. Metab. 89: 5101-5104.

45. Broberg, D.J., \& Bernstein, I.L. (1989) Preabsorptive insulin release in bulimic women and chronic dieters. Appetite 13: 161-169.

46. Power, M.L., \& Schulkin, J. (2008) Anticipatory physiological regulation in feeding biology: cephalic phase responses. Appetite 50: 194-206.

47. Mattes, R.D. (2002) Oral fat exposure increases the first phase triacylglycerol concentration due to release of stored lipid in humans. J. Nutr. 132: 3656-3662. 
48. Robertson, M.D., Parkes, M., Warren, B.F., Ferguson, D.J., Jackson, K.G., Jewell, D.P., \& Frayn, K.N. (2003) Mobilisation of enterocyte fat stores by oral glucose in humans. Gut 52: 834-839.

49. Smeets, A.J.P.G., \& Westerterp-Plantenga, M.S. (2006) Oral exposure and sensory-specific satiety. Physiol. Behav. 89: 281-286.

50. Smeets, A.J.P.G., \& Westerterp-Plantenga, M.S. (2006) Satiety and substrate mobilization after oral fat stimulation. Br. J. Nutr. 95: 795-801.

51. Smeets, A.J.P.G., Lejeune, M.P., \& Westerterp-Plantenga, M.S. (2008) Effects of oral fat perception by modified sham feeding on energy expenditure, hormones and appetite profile in the postprandial state. Br. J. Nutr. 101: 1360-1368.

52. Negoias, S., Visschers, R., Boelrijk, A., \& Hummel, T. (2008) New ways to understand aroma perception. Food Chem. 108: 1247-1254.

53. Small, D.M., Gerber, J.C., Mak, Y.E., \& Hummel, T. (2005) Differential neural responses evoked by orthonasal versus retro-nasal odorant perception in humans. Neuron 47: 593-605.

54. Mozell, M.M. (1970) Evidence for a chromatographic model of olfaction. J. Gen. Phys. 56: 46-63.

55. Kent, P.F., Mozell, M.M., Youngentob, S.L., \& Yurco, P. (2003) Mucosal activity patterns as a basis for olfactory discrimination: comparing behavior and optical recordings. Brain Res. 981: 1-11.

56. Burdach, K.J., Kroeze, J.H., \& Koster, E.P. (1984) Nasal, retronasal, and gustatory perception: An experimental comparison. Percept. Psychophys. 36: 205-208.

57. Berridge, K.C. (1996) Food reward: brain substrates of wanting and liking. Neurosci. Biobehav. Rev. 20: 1-25.

58. Taylor, A.J., Linforth, R.S.T., Harvey, B.A., \& Blake, A. (2000) Atmospheric pressure chemical ionisation mass spectrometry for in vivo analysis of volatile flavour release. Food Chem. 71: 327-338.

59. Weel, K.G.C., Boelrijk, A.E.M., Burger, J.J., Gruppen, H., Voragen, A.G.J., \& Smit, G. (2003) A protocol for measurement of in vivo aroma release from beverages. $J$. Food Sci. 68: 1123-1128.

60. Heilmann, S., \& Hummel, T. (2004) A new method for comparing orthonasal and retronasal olfaction. Behav. Neurosc. 118: 412-419.

61. de Kok, P.M.T., Boelrijk, A.E.M., de Jong, C., Burgering, M.J.M., \& Jacobs, M.A. (2006) MS-nose flavour release profile mimic using an olfactometer. In: Bredie, W., \& Petersen, M.A. (Eds.), Developments in Food Science; Flavour Science, Recent Advances and Trends. London: Elsevier 43: 585-599.

62. Linforth, R.S.T., Baek, I., \& Taylor, A.J. (1999) Simultaneous instrumental and sensory analysis of volatile release from gelatine and pectin/gelatine gels. Food Chem. 65: 77-83. 
63. Cook, D.J., Linforth, R.S.T., \& Taylor, A. (2003) Effects on hydrocolloid thickeners on the perception of savory flavors. J. Agric. Food Chem. 51: 3067-3072.

64. Lethuaut, L., Weel, K.G., Boelrijk, A.E., \& Brossard, C.D. (2004) Flavor perception and aroma release from model dairy desserts. J. Agric. Food Chem. 52: 3478-3485.

65. van Ruth, S.M., de Witte, L., \& Uriarte, A.R. (2004) Volatile flavor analysis and sensory evaluation of custard desserts varying in type and concentration of carboxymethyl cellulose. J. Agric. Food Chem. 52: 8105-8110.

66. Brauss, M.S., Balders, B., Linforth, R.S.T., Avison, S., \& Taylor, A.J. (1999) Fat content, baking time, hydration and temperature affect flavour release from biscuits in model-mouth and real systems. Flavour Fragr. J. 14: 351-357.

67. Haber, G.B., Heaton, K.W., Murphy, D., \& Burroughs, L.F. (1977) Depletion and disruption of dietary fibre. Effects on satiety, plasma-glucose, and serum-insulin. Lancet 2: 679-682.

68. Mattes, R.D., \& Rothacker, D. (2001) Beverage viscosity is inversely related to postprandial hunger in humans. Physiol. Behav. 74: 551-557.

69. Mattes, R. (2005) Soup and satiety. Physiol. Behav. 83: 739-747.

70. Tsuchiya, A., Almiron-Roig, E., Lluch, A., Guyonnet, D., \& Drewnowski, A. (2006) Higher satiety ratings following yoghurt consumption relative to fruit drink or dairy fruit drink. J. Am. Diet. Assoc. 106: 550-557.

71. Zijlstra, N., Mars, M., de Wijk, R.A., Westerterp-Plantenga, M.S., \& de Graaf, C. (2008) The effect of viscosity on ad libitum food intake. Int. J. Obes. 32: 676-683.

72. Buettner, A., Beer, A., Hanning, C., Settles, M., \& Schieberle, P. (2002) Physiological and analytical studies on flavor perception dynamics as induced by eating and swallowing process. Food Qual. Pref. 13: 497-504.

73. Buettner, A., Beer, A., Hanning, C., \& Settles, M. (2001) Observation of the swallowing process by application of videofluoroscopy and real-time magnetic resonance imaging-consequences for retro-nasal aroma stimulation. Chem. Senses 26: 1211-1219.

74. Brown, W.E., Dauchel, C., \& Wakeling, I. (1996) Influence of chewing efficiency on texture and flavour perceptions of food. J. Texture Stud. 27: 433-450.

75. Wright, K.M., Sprunt, J., Smith, A.C., \& Hills, B.P. (2003) Modeling flavor release from a chewed bolus in the mouth. Part 1. Mastication. Int. J. Food Sci. Technol. 38: 351-360.

76. Pionnier, E., Chabanet, C., Mioche, L., Le Quere, J.L., \& Salles, C. (2004) 1. In vivo aroma release during eating of a model cheese: relationships with oral parameters. J. Agric. Food Chem. 52: 557-564. 


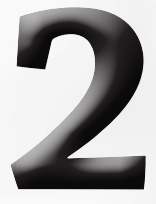

\title{
Retro-nasal aroma release depends on both subject and product differences: A link to food intake regulation?
}

\author{
Ruijschop, R.M.A.J., Burgering, M.J.M., \\ Jacobs, M.A., \& Boelrijk, A.E.M.
}

Chemical Senses (2009) in press doi:10.1093/chemse/bjp011 


\section{ABSTRACT}

It is hypothesised that differences in the extent of retro-nasal aroma release during consumption may be 1 of the reasons that people vary in their satiation characteristics. Using real-time atmospheric pressure chemical ionization-mass spectrometry (APcIMS), in vivo retro-nasal aroma release was determined for 30 subjects consuming 9 different food products, varying in physical structure (i.e., (semi-)liquid and solid food products). Additionally, for a subset of the subjects ad libitum food intake was measured. Retro-nasal aroma release intensity and profile morphology appeared to be subject specific and relatively independent of the type of food product subjects consumed. A subject who was observed as having a relatively high retro-nasal aroma release intensity for a (semi-)liquid food product also appeared to have a relatively high retro-nasal aroma release intensity for a solid food product. However, for all subjects, there were absolute differences between food products in the extent of retro-nasal aroma release comparing (semi-)liquid and solid food products. This implies that the extent of retro-nasal aroma release is a valid physiological feature that characterises any individual. Interestingly, a negative trend was observed between extent of retronasal aroma release and amount of ad libitum food intake $(P=0.07)$. This may have implications for the regulation of food intake.

Key words: APcI-MS; Flavour; Olfactometry; Oral processing; Retro-nasal aroma stimulation; Satiation 


\section{INTRODUCTION}

Aroma is an important property that contributes to sensory perception of a food product ${ }^{(1)}$. It is likely that sensory effects, including aroma stimuli, contribute to a large extent to satiation, resulting in meal termination ${ }^{(2-3)}$. During the consumption of a meal, aroma molecules reach the olfactory epithelium either orthonasally (perceived as originating from the external world) or retro-nasally (perceived as arising from the mouth) ${ }^{(4-5)}$. The brain response, that is, neural brain activation, to a retro-nasally sensed food odour signals the perception of food and is suggested to be related to satiation (6). Retro-nasal aroma stimulation is mainly related to the event of swallowing, when a small volume of air is exhaled immediately after swallowing, the so-called 'swallow breath'. It is assumed that this pulse should contain the major part of food volatiles that have been released from the food product prior to swallowing, and should therefore elicit a retro-nasal aroma pulse ${ }^{(7-8)}$.

From previous work, it is known that the physical structure of a food that is consumed is important for the extent of retro-nasal aroma release during consumption (9-12). Additionally, subject differences are known to be important for the extent of retro-nasal aroma release. These subject differences are factors that are likely to be uncontrolled by a person, for example, saliva production, nasal anatomy, and oral processing habits (13-17).

It is hypothesised that differences in the extent of retro-nasal aroma release during consumption may be 1 of the reasons that people vary in their satiation characteristics, due to differences in perceived intensity or duration of sensory stimulation.

The aim of the present study was to investigate whether subjects can be segmented based on their extent of retro-nasal aroma release using real-time atmospheric pressure chemical ionization-mass spectrometry (APcI-MS) and whether this depends on the type of food product they consume. Ultimately, based on this segmentation, the aim was to determine whether subject differences in the extent of retro-nasal aroma release can be linked to subject differences in sensory satiation and perhaps food intake behaviour.

\section{SUBJECTS AND METHODS}

\section{Subjects}

Thirty healthy subjects ( 13 men and 17 women) aged 18-65 years living in Wageningen (The Netherlands) and surroundings were recruited from an existing database for consumer studies. Subjects did not have any previous experience with APcI-MS measurements. The subjects included normal-weight, overweight, and obese subjects, with a body mass index (BMI) varying between 18 and $32 \mathrm{~kg} \mathrm{~m}^{-2}$. BMI was calculated as body weight $(\mathrm{kg}$ ) divided by height $(\mathrm{m})$ squared. Body weight was measured without wearing shoes using a calibrated scale that was accurate to $0.1 \mathrm{~kg}$ (Inventum, Veenendaal, 
The Netherlands). At the same time without wearing shoes, height was measured with a wall-mounted stadiometer (Microtoise mabo 4116, Brevete, France).

Subjects' degrees of dietary restraint were determined using the Dutch translation of the 3-Factor Eating Questionnaire (TFEQ) ${ }^{(18)}$. Based on the outcome of the TFEQ, these subjects showed no dietary restraint (i.e., scores $\leq 9$ ), no disinhibition (i.e., emotional eating) (i.e., scores $\leq 8$ ), and no physiological hunger (i.e., scores $\leq 8$ ). Subject characteristics, including TFEQ scores, are summarised in Table 2.1. Subjects were fully informed about the course of the APcI-MS measurement.

Table 2.1 Characteristics of the 30 subjects who participated in this study ${ }^{a}$

\begin{tabular}{lcccc}
\hline & \multicolumn{2}{c}{ Women $(\mathrm{n}=17)$} & \multicolumn{2}{c}{ Men $(\mathrm{n}=13)$} \\
\cline { 2 - 5 } & $\begin{array}{c}\text { Normal weight } \\
(\mathrm{n}=10)\end{array}$ & $\begin{array}{c}\text { Overweight } \\
(\mathrm{n}=7)\end{array}$ & $\begin{array}{c}\text { Normal weight } \\
(\mathrm{n}=7)\end{array}$ & $\begin{array}{c}\text { Overweight } \\
(\mathrm{n}=6)\end{array}$ \\
\hline Age (years) & $43 \pm 13$ & $49 \pm 14$ & $31 \pm 8$ & $59 \pm 12$ \\
$\mathrm{BMI}\left(\mathrm{kg} \mathrm{m}^{-2}\right)$ & $22 \pm 3$ & $28 \pm 2$ & $23 \pm 2$ & $27 \pm 2$ \\
TFEQ $^{b}$ & & & & \\
Factor 1 (cognitive restraint) & $5 \pm 2$ & $7 \pm 2$ & $4 \pm 3$ & $6 \pm 2$ \\
Factor 2 (disinhibition) & $3 \pm 1$ & $3 \pm 1$ & $4 \pm 1$ & $3 \pm 1$ \\
Factor 3 (hunger) & $3 \pm 2$ & $4 \pm 2$ & $3 \pm 2$ & $2 \pm 1$ \\
\hline
\end{tabular}

${ }^{a}$ Mean \pm SD.

bTFEQ: Three-Factor Eating Questionnaire. The value of factors 1, 2 and 3 is in the range of 0 to 18; 0 to 13 , and 0 to 14 , respectively. A higher value indicates more restraint, disinhibition or physiological hunger. All values are below medians that are usual.

\section{Food products}

Subjects consumed 9 different food products, varying in physical structure (i.e., liquid, semi-liquid, and solid food products). All food products were commercially available. In the category liquid food products, the subjects consumed a strawberry-flavoured dairy beverage (Fristi, RiedelDrinks, Friesland Foods, Meppel, The Netherlands). In the category semi-liquid food products, the subjects consumed banana-flavoured custard (private label Albert Heijn Zaandam, The Netherlands) and raspberry pudding (Mona, Campina, Woerden, The Netherlands). In the category solid food products, the subjects consumed cheese-flavoured crackers (TUC, LU, General Biscuits Nederland B.V., Danone, Breda, The Netherlands), milk, and dark (extra bitter) chocolate (private label Albert Heijn Zaandam, The Netherlands), young and aged (Gouda type) cheese (private label Albert Heijn Zaandam, The Netherlands), and winegums (candy) (Red Band, LEAF Holland B.V., Oosterhout, The Netherlands). 
Measurement of the extent of retro-nasal aroma release with APcI-MS technology

To detect the aroma compounds with the highest response in retro-nasal aroma release, all food products were measured separately. Aroma compounds in the air released from the artificial mouth were monitored by on-line sampling by an Atmospheric Pressure Chemical Ionization Gas-Phase Analyzer attached to a VG Quattro II mass spectrometer (MS-Nose; Micromass UK Ltd., Manchester, United Kingdom) ${ }^{(19-23)}$. Compounds were ionized by a $3.0 \mathrm{kV}$ discharge (source and probe temperatures were $80^{\circ} \mathrm{C}$ ) and scanned for $\mathrm{m} / \mathrm{z} 50-250 . \mathrm{m} / \mathrm{z}$ values (i.e., the ion mass-charge ratio of a specific aroma component) with the highest response were selected (Table 2.2). In vivo retro-nasal aroma release was assessed in exhaled breath of the 30 subjects for 9 food products in triplicate in a fixed volume and size (i.e., mouthful consumption; Table 2.2).

Table 2.2 Food products consumed in a fixed volume and size with their $\mathrm{m} / \mathrm{z}$-value with the highest response in APcI-MS measurement

\begin{tabular}{lcccc}
\hline Product & Category & $\begin{array}{c}\text { Serving per } \\
\text { measurement }\end{array}$ & $\begin{array}{c}\text { Volume / size } \\
\text { per serving }\end{array}$ & $\begin{array}{c}\text { Ion mass } \\
(\mathrm{m} / \mathrm{z} \text { value })\end{array}$ \\
\hline $\begin{array}{l}\text { Young Gouda type cheese } \\
\text { Aged Gouda type cheese }\end{array}$ & $\begin{array}{c}\text { Solid } \\
\text { Solid }\end{array}$ & $\begin{array}{c}1 \text { piece } \\
1 \text { piece }\end{array}$ & $\begin{array}{c}\text { 2x1x1 cm; } 8 \mathrm{~g} \\
2 \mathrm{x} 1 \mathrm{x} 1 \mathrm{~cm} ; 8 \mathrm{~g} \\
\text { two halves }\end{array}$ & 73 \& 89 \\
Cheese-flavoured cracker & Solid & 1 piece & $73 \& 87$ \\
piled up; $4.5 \mathrm{~g}$ & 87 \\
Mark chocolate & Solid & 1 piece & $6.5 \mathrm{~g}$ & 87 \\
Strawberry-flavoured & Solid & 1 piece & $6.5 \mathrm{~g}$ & $117 \& 131$ \\
dairy beverage & Liquid & 1 sip & $17 \mathrm{~mL}$ & $131 \& 145$ \\
Banana-flavoured custard & Semi-liquid & 1 spoon & $20 \mathrm{~g}$ & $71 \& 131$ \\
Raspberry pudding & Semi-liquid & 1 spoon & $20 \mathrm{~g}$ & $83 \& 117$ \\
Winegum candy & Solid & 1 piece & $5 \mathrm{~g}$ & \\
\hline
\end{tabular}

Subjects breathed in and out through the nose. One nostril was placed over a small disposable plastic tube, allowing them to breathe, drink, and eat normally. Aroma compounds in the air released from the breath of subjects were monitored by online sampling part of the exhaled air directly into the APcI-MS via the tube. The air was sampled $(75 \mathrm{~mL} / \mathrm{min})$ through a capillary tube $(0.53 \mathrm{~mm}$ internal diameter, heated to $\left.100^{\circ} \mathrm{C}\right)$. The compounds were monitored in selected ion mode $(0.08 \mathrm{~s}$ dwell on each ion), in 2 independent sets. The cone voltage used was $20 \mathrm{~V}$.

Subjects were free to use their own natural eating habits during the experiments (without any chewing protocol). Between food products, the mouth was rinsed with water. Blank experiments were recorded before the consumption of food products with water following the same protocol.

Acetone, present in human breath, was measured at $m / z 59(19 \mathrm{~V})$ as an indicator for 
the breathing pattern ${ }^{(24)}$. The area of the resulting breath peaks in the aroma signal was taken as a measure of in vivo retro-nasal aroma release. Different parameters could be extracted from each individual retro-nasal aroma release curve, characterising the extent of retro-nasal aroma release, that is, $\mathrm{T}_{-1 / 2}, \mathrm{~T}_{\max }, \mathrm{T}_{1 / 2}, \mathrm{I}_{\max }$, and Area Under Curve (AUC) (Figure 2.1). Because we were interested in comparative retro-nasal aroma release between subjects, expression of the extent of retro-nasal aroma release in arbitrary units (AU) was sufficient to analyze differences ${ }^{(21)}$.

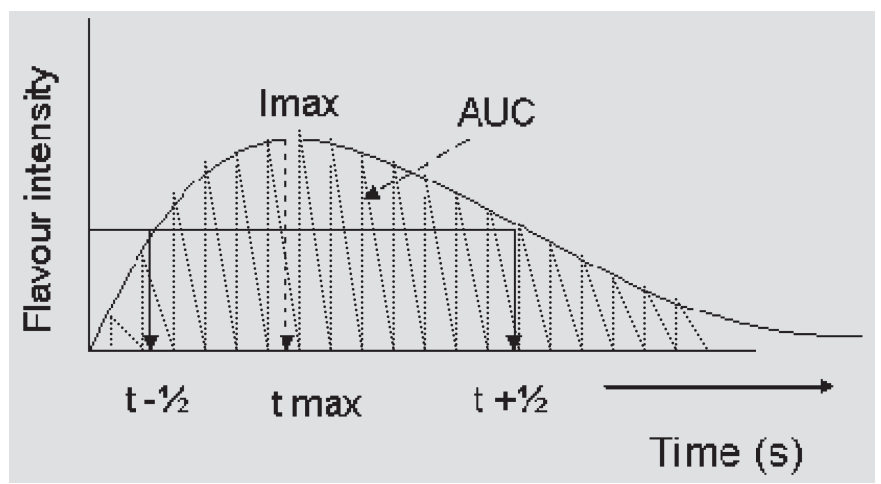

Figure 2.1 Schematic representation of a retro-nasal aroma release curve and its characteristic parameters $\left(I_{\max }\right.$ : maximum intensity [AU], $T_{\max }$ : time at which maximal intensity occurs [min], AUC: total area under the curve [AU], $T_{-1 / 2}$ : time at which half of the maximal intensity occurs, before reaching maximum intensity [min], $\mathrm{T}_{1 / 2}$ : time at which half of the maximal intensity occurs, after reaching maximum intensity $[\mathrm{min}])$.

\section{Measurement of ad libitum food intake}

In a subsequent study for a subset of 15 subjects ( 8 men and 7 women; aged 20-30 years; BMI 20-30 $\mathrm{kg} \mathrm{m}^{-2}$ ), the effect of retro-nasal aroma release intensity on food intake was investigated using a similar approach as described in Ruijschop et al. (3). The aim was to investigate if people became more or less satiated if they were more or less aroma stimulated than normal. For the 15 subjects their natural retro-nasal aroma release for the given food product had already been assessed using APcI-MS technology. Subsequently, in a double-blind placebo-controlled randomised crossover full factorial design, each subject was, on separate days, administered his or her own natural aroma release profile, a 4 times higher concentrated, and a 4 times lower concentrated aroma release profile using a computer-controlled stimulator based on air dilution olfactometry (OM4, Burghart, Wedel, Germany). The profiles were produced with generic cheese aroma (Givaudan, Naarden, The Netherlands) and administered in a retro-nasal fashion (i.e., approximately $9 \mathrm{~cm}$ in length of a silicon tube (suction catheter CH 10, D-Care B.V., Houten, The Netherlands) was placed into the subjects' lower meatus of the right nasal cavity) while the subjects consumed a cold, fusilli 
tricolore pasta (AH private label Albert Heijn Zaandam, The Netherlands), which was boiled in salty water (100 g pasta boiled in $10 \mathrm{~g}$ salt per liter water). After retro-nasal aroma stimulation ad libitum food intake of young-matured Gouda type cheese (AH private label Albert Heijn Zaandam) was measured. The total amount of young matured cheese consumed per subject during his or her 3 test days was calculated, and this amount served as measure for ad libitum young-matured cheese intake.

\section{Data analysis}

To assess the extent of retro-nasal aroma release, different food products $(n=9)$ were evaluated in triplicate, that is, on 3 test occasions $(n=3)$, by all subjects $(n=30)$ in a crossover design.

\section{Descriptive (qualitative) data analysis}

The triplicate measurements of the characteristic retro-nasal aroma release parameters $\left(\mathrm{T}_{\max }, \mathrm{I}_{\max }\right.$, and $\left.\mathrm{AUC}\right)$ for each subject per food product were averaged. This was allowed, because test occasion did not explain a significant part of the variance regarding differences in the extent of retro-nasal aroma release. The mean values of the characteristic parameters of the retro-nasal aroma release curve were standardised for each individual food product, by division of the average value by the standard error. This type of standardisation was necessary because all food products had a different magnitude of the characteristic retro-nasal aroma release parameters. The set of data obtained was evaluated by regular statistical means, such as descriptive statistics. In addition, food products and subjects were grouped together in a regular Principal Component Analysis (PCA) projection. Furthermore, Hierarchical Cluster Analysis was applied using Ward's method with the calculation of Euclidean distances among morphology $\left(\mathrm{I}_{\max }\right.$ and $\mathrm{T}_{\max }$ ) and intensity $\left(\mathrm{I}_{\max }\right.$ and $\mathrm{AUC}$ ) of the retro-nasal aroma release curve.

\section{Analytical (quantitative) data analysis}

Because all food products had a different magnitude of the characteristic retro-nasal aroma release parameters, and it was noticed that the data set was not normally distributed, nonparametric statistical testing was applied to the raw data for the mean value of the triplicate measurements for each subject per food product. To this end, the Spearman rank correlation coefficient was calculated for $\mathrm{T}_{\text {max }}, \mathrm{I}_{\text {max }}$, and AUC across subjects to assess whether subjects could be characterised with respect to their extent of retro-nasal aroma release irrespective of the type of food product consumed.

After ranking the mean value of the triplicate measurements across subjects for each food product for both $\mathrm{I}_{\max }$ and AUC, the sum of both ranks across subjects for each food product was obtained. When adding the sum of both ranks across subjects for each 
food product, a final rank for $\mathrm{I}_{\max }$ and AUC combined was calculated with respect to retro-nasal aroma release intensity across subjects for all food products. In summary: Final rank $=\Sigma\left[\left(\Sigma \text { (rank } \mathrm{I}_{\max } \text { and rank AUC }\right)_{\text {across subjects for each food product }}\right)$ across subjects for each food product].

For the morphology of the retro-nasal aroma release profile, the sum of ranks for $I_{\max }$ and $\mathrm{T}_{\max }$ across subjects for each food product and subsequently all food products (final rank) was calculated similarly.

Additionally, the extent of the ranked retro-nasal aroma release was linked to subject characteristics, like age and BMI, and food intake behaviour.

Statistical analysis was performed with Statistica (1999, StatSoft Inc., Tulsa, OK, United States). P values $<0.05$ were considered as being statistically significant.

\section{RESULTS}

\section{Validity of response of selected $\mathrm{m} / \mathrm{z}$ signal}

Selected aroma compounds detected in the range of $\mathrm{m} / \mathrm{z}$ 20-250 (Table 2.2), that is, aroma compounds with the highest response showed comparable retro-nasal aroma release profiles for a specific food product. For example, the standardised retro-nasal aroma release parameters $\left(\mathrm{T}_{\max }, \mathrm{I}_{\max }\right.$, and AUC) for $\mathrm{m} / \mathrm{z} 131$ and $\mathrm{m} / \mathrm{z} 145$ for bananaflavoured custard appeared to be highly correlated $\left(\mathrm{R}^{2}=0.8 ; \mathrm{P}<0.001, \mathrm{R}^{2}=0.9 ; \mathrm{P}<\right.$ $0.001, \mathrm{R}^{2}=0.9 ; \mathrm{P}<0.001$, for $\mathrm{T}_{\max }, \mathrm{I}_{\max }$, and $\mathrm{AUC}$, respectively). Other food products showed comparable results. Therefore, the same retro-nasal aroma release profile was measured, irrespective of the $\mathrm{m} / \mathrm{z}$ value taken (data not shown). Hence, it was appropriate to select $\mathrm{m} / \mathrm{z}$ values with the highest response for a specific food product for the in vivo retro-nasal aroma release measurements.

\section{Within-subject reproducibility in the extent of retro-nasal aroma release}

Irrespective of the time of measurement, for a specific food product, test occasion did not explain part of the variance regarding differences in the extent of retro-nasal aroma release. The serving number did not affect the magnitude of the characteristic retro-nasal aroma release parameters during consumption of, for example, a spoon of banana-flavoured custard or a piece of aged cheese (respectively, for banana-flavoured custard Friedman analysis of variance (ANOVA): $\mathrm{P}=0.99$ for $\mathrm{T}_{\max }, \mathrm{P}=0.98$ for $\mathrm{I}_{\max }, \mathrm{P}=$ 0.88 for AUC and for aged cheese Friedman ANOVA: $\mathrm{P}=0.39$ for $\mathrm{T}_{\max }, \mathrm{P}=0.90$ for $\mathrm{I}_{\max }$, $\mathrm{P}=0.65$ for $\mathrm{AUC}$ ). In summary, the extent of retro-nasal aroma release that was evoked in subjects during consumption of a specific food product appeared to be reproducible with respect to retro-nasal aroma release intensity and profile morphology.

\section{Subject differences affecting the extent of retro-nasal aroma release}

Subjects differed in the extent of retro-nasal aroma release regarding intensity $\left(\mathrm{I}_{\max }\right.$ 
and AUC) and morphology ( $\mathrm{I}_{\max }$ and $\mathrm{T}_{\max }$ ) of the retro-nasal aroma release profile. As illustrated by Figure 2.2 different types of retro-nasal aroma release patterns were identified. Representatives of 2 groups are shown: a group of subjects with a maximum retro-nasal aroma release after swallowing, that is, retro-nasal aroma release likely through the swallow breath ${ }^{(7-8)}$ (Figure 2.2 A), and a group of subjects with an earlier maximum retro-nasal aroma release immediately after starting chewing, that is, retronasal aroma release likely through the velopharyngeal portal, because the velum is intermittently open during oral processing (14) (Figure 2.2 B1). In addition, within 1 group of subjects with the same retro-nasal aroma release pattern large differences were observed in retro-nasal aroma release intensity among subjects (Figure 2.2 B2). The extent of retro-nasal aroma release that was evoked in subjects during consumption of a specific food product appeared to be reproducible with respect to retro-nasal aroma release intensity and profile morphology (Friedman ANOVA: $\mathrm{P}>0.05$ ).

Release after swallowing Release immediately after starting chewing

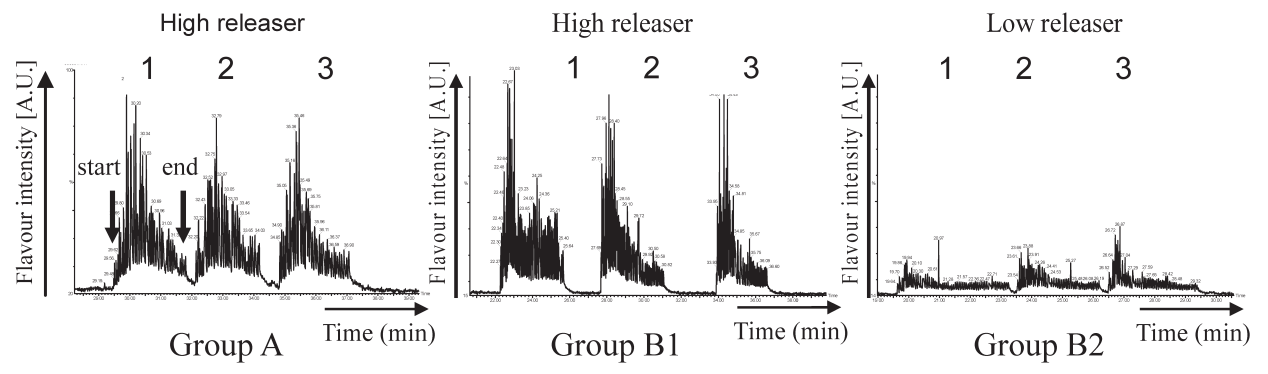

Figure 2.2 Illustration of the two different groups regarding the morphology and intensity of the retro-nasal aroma release profile. Examples given for aged cheese. (1, 2, and 3 stand for the triplicate measurements). Start and end of a single retro-nasal aroma release curve are depicted with arrows. For each retro-nasal aroma release curve the characteristic retro-nasal aroma release parameters $\left(\mathrm{T}_{\max }, \mathrm{T}_{+1 / 2}, \mathrm{I}_{\max }\right.$ and $\left.\mathrm{AUC}\right)$ can be extracted, similarly as represented in Figure 2.1.

To investigate whether subjects could be grouped based on their retro-nasal aroma release profiles, subjects were segmented based on the extent of their retro-nasal aroma release intensity ( $\mathrm{I}_{\max }$ and AUC) ("high vs. low-medium releasers") and the morphology of their retro-nasal aroma release curve $\left(\mathrm{I}_{\max }\right.$ and $\mathrm{T}_{\max }$ ) ("early vs. late releasers") after consumption of solid and (semi-)liquid food products, respectively.

With respect to the extent of retro-nasal aroma release intensity, a number of subjects showed relatively low-to-medium retro-nasal aroma release intensities, whereas other subjects displayed relatively high retro-nasal aroma release intensities after consumption of solid and (semi-)liquid food products. As well as the intensity of their retro-nasal aroma release, subjects could also be segmented on the morphology of their retro-nasal aroma release curve. However, segmentation was only possible using the 
APcI-MS data obtained after consumption of solid food products. This was an expected result, because the morphology of these curves contained more information than the data obtained after consumption of a (semi-)liquid food product. (Semi-)liquid food products have a relatively short transit time in the oral cavity, and therefore, hardly any oral processing is needed to swallow them. Consumption of (semi-)liquid food products thus resulted in relatively short and spiked retro-nasal aroma release patterns, which were difficult to segment based on morphology of the retro-nasal aroma release curve. With respect to solid food products, a number of subjects showed a relatively early start of retro-nasal aroma release, that is, maximal intensity $\left(\mathrm{I}_{\max }\right)$ occurred relatively fast. Conversely, other subjects showed a relatively late start of retro-nasal aroma release. Physiological differences in timing and performance of mastication and swallowing are attributed to be responsible for these differences ${ }^{(14)}$.

\section{Product differences affecting the extent of retro-nasal aroma release}

Apart from subject differences in the extent of retro-nasal aroma release, product differences were also factors important for the extent of retro-nasal aroma release. Figure 2.3 illustrates the differences in the extent of retro-nasal aroma release during consumption of a solid (i.e., aged cheese) compared with a liquid (i.e., strawberryflavoured dairy beverage) food product.
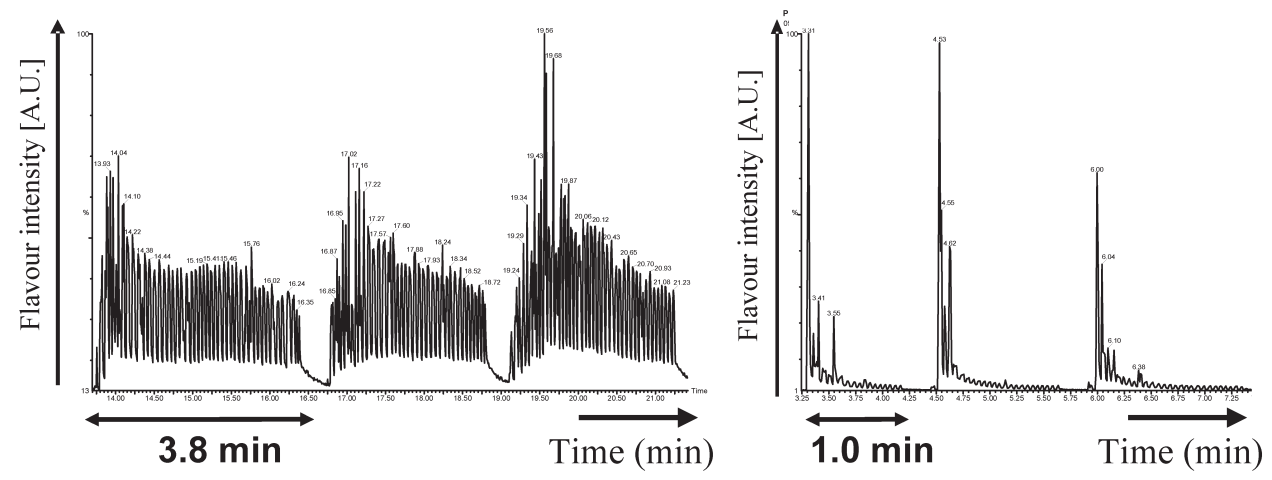

Figure 2.3 Example of 1 subject illustrating the differences in the extent of retro-nasal aroma stimulation between the consumption of 3 times 1 mouthful (on average $8 \mathrm{~g}$ per mouthful) of aged cheese (solid food product; left) and 3 times 1 sip (on average $17 \mathrm{~mL}$ per sip) of strawberry-flavoured dairy beverage (liquid food product; right), measured by in vivo APcI-MS. For each retro-nasal aroma release curve the characteristic retro-nasal aroma release parameters $\left(\mathrm{T}_{\max }, \mathrm{T}_{+1 / 2}, \mathrm{I}_{\max }\right.$ and AUC) can be extracted, similarly as represented in Figure 2.1.

Solid food products required considerable chewing and swallowing, due to their firmer texture. Consequently, most subjects had an immediate and prolonged retro- 


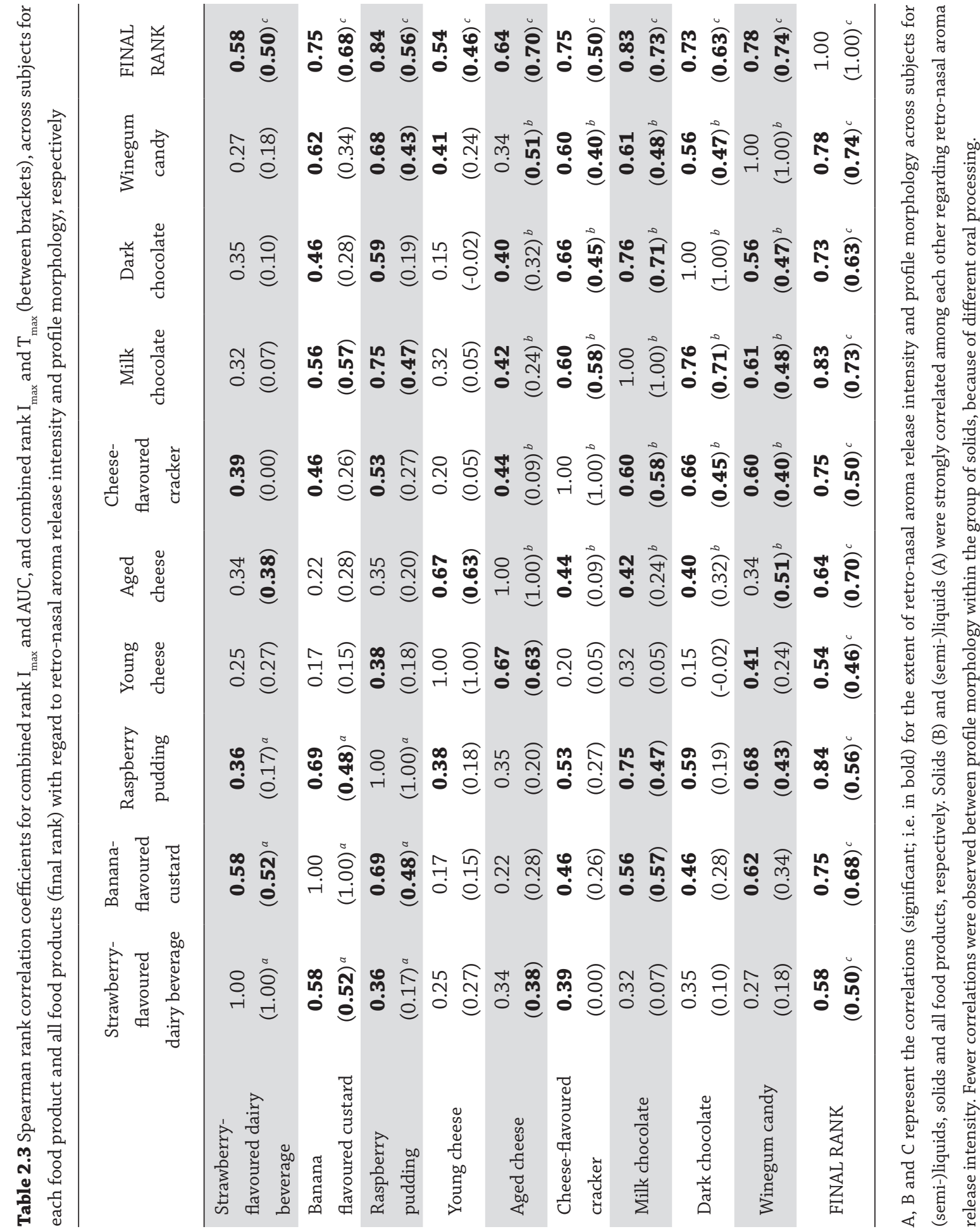


nasal aroma release. In contrast to consumption of solid food products, during the consumption of (semi-)liquid food products, most subjects had a short and spiked retro-nasal aroma release pattern. Intensity levels differed between the subjects. PCA projection supported these observations (data not shown).

Characterisation of subjects and food products based on the extent of retro-nasal aroma release

Spearman rank correlation coefficient showed that for the 9 food products, evaluated on 3 test occasions by all subjects, $I_{\max }$ and AUC were significantly correlated (data not shown). Therefore, it was justified to calculate a combined rank as the sum of both parameters.

After ranking the mean value of the triplicate measurements across subjects for each food product for both $\mathrm{I}_{\max }$ and AUC, the sum of both ranks across subjects for each food product was obtained. The sum of the combined rank $\mathrm{I}_{\max }$ and AUC across subjects for each food product led to a final rank for $\mathrm{I}_{\max }$ and AUC combined across subjects for all food products.

Spearman rank correlation coefficient across subjects showed that all food products were correlated (i.e., final rank), although solid and (semi-)liquid food products were strongly correlated among each other with respect to retro-nasal aroma release intensity (e.g., a correlation between cheese-flavoured cracker and milk chocolate and a correlation between banana-flavoured custard and raspberry pudding) (Table 2.3). The only exception was young cheese, which as a solid food product was only correlated to a minority of solid food products, namely, aged cheese and winegum candy.

The morphology of the retro-nasal aroma release profile (in particular explained by $\mathrm{T}_{\max }$, i.e., time at which $\mathrm{I}_{\max }$ occurred) was quite different between (semi-)liquid and solid food products (Table 2.4). Solid food products required a longer duration of oral processing compared with (semi-)liquid food products before swallowing. Spearman rank correlation coefficients for combined rank $\mathrm{I}_{\max }$ and $\mathrm{T}_{\max }$ across subjects for each food product, and all food products (final rank) were less consistent in characterising subjects based on the profile morphology of their retro-nasal aroma release (Table 2.3). All food products were correlated among each other (i.e., final rank), albeit fewer correlations were observed between profile morphology within the group of solid food products (e.g., a correlation between aged cheese and winegum candy), because of different oral processing.

Effects of the extent of retro-nasal aroma release on food intake behaviour

Additionally, for half of the subjects, showing no dietary restraint (Table 2.1), ad libitum food intake data of young matured cheese were available. 
Table 2.4 Morphology (mean values) of retro-nasal aroma release profiles for the 30 subjects consuming 9 different food products in triplicate

\begin{tabular}{lccccc}
\hline Food product & $\begin{array}{c}\text { Mean } \mathrm{T}_{\max }{ }^{a} \\
(\mathrm{~min})\end{array}$ & $\begin{array}{c}\text { Minimum } \\
\mathrm{T}_{\max }{ }^{a}(\mathrm{~min})\end{array}$ & $\begin{array}{c}\text { Maximum } \\
\mathrm{T}_{\max }{ }^{a}(\mathrm{~min})\end{array}$ & $\begin{array}{c}\text { Standard } \\
\text { error }(\mathrm{min})\end{array}$ & $\begin{array}{c}\text { Food } \\
\text { matrix }\end{array}$ \\
\hline $\begin{array}{l}\text { Strawberry-flavoured } \\
\text { dairy beverage }\end{array}$ & 0.083711 & 0.002000 & 0.381000 & 0.064102 & \\
$\begin{array}{l}\text { Banana-flavoured } \\
\text { custard }\end{array}$ & 0.134111 & 0.010000 & 0.353000 & 0.081199 & $\begin{array}{c}\text { (Semi-) } \\
\text { liquid }\end{array}$ \\
$\begin{array}{l}\text { Raspberry pudding } \\
\text { Cheese-flavoured }\end{array}$ & 0.191045 & 0.001000 & 0.547000 & 0.113245 & \\
cracker & 0.405844 & 0.008000 & 1.213998 & 0.194112 & \\
Milk chocolate & 0.620766 & 0.076000 & 1.652000 & 0.321189 & \\
$\begin{array}{l}\text { Dark chocolate } \\
\text { Young cheese }\end{array}$ & 0.672543 & 0.238998 & 1.720001 & 0.321654 & Solid \\
Aged cheese & 0.705489 & 0.021000 & 2.457000 & 0.493131 & \\
Winegum candy & 0.762844 & 0.043000 & 1.989000 & 0.381746 & \\
\hline
\end{tabular}

There is a distinct difference in (semi-)liquid and solid food products for $\mathrm{T}_{\max }$ (i.e. time at which maximal intensity occurs [minutes]).

${ }^{a} \mathrm{~T}_{\text {max }}$ : time at which maximal intensity occurs (minutes).

When the total amount of cheese consumed ad libitum during the three test sessions in the satiation experiment was compared with the extent of the ranked retro-nasal aroma release for these subjects (Table 2.3), a trend was observed that subjects who had a higher extent of retro-nasal aroma release tended to consume less (Spearman rank correlation coefficient $=-0.5 ; \mathrm{P}=0.07$ ) (Figure 2.4 ).

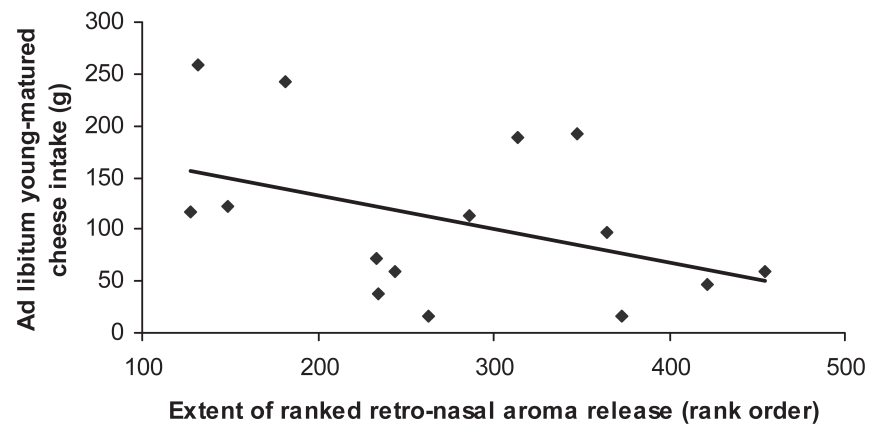

Figure 2.4 The total amount of young-matured cheese consumed ad libitum by 15 subjects after aroma stimulation using olfactometry in relation to their extent of ranked retro-nasal aroma release (i.e. final rank $=\Sigma\left[\left(\Sigma\left(\text { rank } I_{\max } \text { and rank AUC) }\right)_{\text {across subjects for each food product }}\right)\right.$ across subjects for each food product]). 
This result was even significant for the test session in the satiation experiment in which subjects were delivered a 4 times lower concentrated retro-nasal aroma release profile compared with their own natural retro-nasal aroma release profile (Spearman rank correlation coefficient $=-0.6 ; \mathrm{P}=0.03$ ).

This may have implications for the regulation of food intake. However, BMI was not directly correlated to the extent of the ranked retro-nasal aroma release (Spearman rank correlation coefficient $=0.1 ; \mathrm{P}>>0.05$ ). Notably, it appeared that age was positively correlated to $\mathrm{T}_{\max }$ (time at which $\mathrm{I}_{\max }$ occurred). Particularly, for solid food products like dark chocolate and winegum candy, $\mathrm{T}_{\max }$ was later when subjects were older (Spearman rank correlation coefficient $=0.4 ; \mathrm{P}<0.05$ for both dark chocolate and winegum candy).

\section{DISCUSSION}

In vivo retro-nasal aroma release was assessed for 30 subjects consuming 9 different food products that varied in texture from (semi-)liquid to solid using APcI-MS technology. Selection of specific $\mathrm{m} / \mathrm{z}$ signals (thus a specific aroma compound) (Table 2.2) did not cause any response bias regarding the obtained retro-nasal aroma release profiles. This implies that aroma release data obtained for a single aroma compound ( 1 specific $\mathrm{m} / \mathrm{z}$ value) are a good predictor for the relative release of other aroma compounds (other $\mathrm{m} / \mathrm{z}$ values) in order to characterise subjects. Furthermore, the extent of retro-nasal aroma release that was evoked in subjects during consumption of each of the 9 individual food products appeared to be reproducible with respect to retro-nasal aroma release intensity and profile morphology (Figures 2.2 and 2.3).

In the present study, the extent of retro-nasal aroma release depended on both subject and product differences. Therefore, it can be concluded that a subject who was observed as having a relatively high retro-nasal aroma intensity for a (semi-)liquid food product (e.g., strawberry-flavoured dairy beverage), also appeared to have a relatively high intensity for a solid food product (e.g., dark chocolate) (Table 2.3). Subjects can thus be characterised based on their extent of retro-nasal aroma release, independent of the type of food product they consumed. However, there were absolute differences between food products in the extent of retro-nasal aroma release comparing (semi-) liquid and solid food products (Figure 2.3). Differences in structure and composition of the food product and the oral processing it evoked are thought to be responsible for these differences ${ }^{(9-12)}$. Among (semi-)liquid food products (strawberry-flavoured dairy beverage, banana-flavoured custard, and raspberry pudding), in vivo retro-nasal aroma release profiles were comparable and correlated. These types of food matrices apparently did not evoke significant differences in oral processing and subsequently in retro-nasal aroma release. The observed similarity in retro-nasal aroma release profiles for the selection of (semi-)liquid food products enables future measurements to characterise a person's extent of retro-nasal aroma release based on 1 (semi-)liquid 
food product. With respect to solid food products, this was more complicated. Among solid food products, there are larger differences in matrix structures compared with (semi-)liquid food products, evoking significant differences in oral processing and subsequently in retro-nasal aroma release.

The demonstrated subject and product differences with respect to the extent of retro-nasal aroma release may be 1 of the reasons that people vary in their satiation characteristics and may have implications for the regulation of food intake. It is known that the extent of sensory stimulation may be related to meal termination ${ }^{(25-26)}$. Liquid foods appear to be less satiating than (soft) solid foods ${ }^{(27-30)}$. Differences in the extent of retro-nasal aroma release due to differences in structure and composition and the oral processing it evokes may be responsible for this effect ${ }^{(9-12)}$. Additionally, subject differences in oral processing parameters, like salivary flow rate, nasal anatomy, bite size, and eating speed may have an effect on the extent of retro-nasal aroma release ${ }^{(13-}$ 17). The development of mathematical models for aroma release during consumption of liquid, semi-liquid, and solid food products is ongoing, including both physico-chemical and physiological parameters $\left.{ }^{(e . g, g}, 31-32\right)$.

In the present study, a negative trend was observed between the extent of retro-nasal aroma release and total amount of ad libitum food intake. The brain response, that is, neural brain activation, to a food odour sensed retro-nasally signals the perception of food, which is hypothesised to be related to satiation ${ }^{(6)}$. Limited extent of retro-nasal aroma release may result in less sensory stimulation, which in turn may lead to decreased feelings of satiation and increased food intake. The current findings tend to support the hypothesis that subject differences in the extent of retro-nasal aroma release are linked to subject differences in sensory satiation and food intake behaviour. This assumption is even strengthened by the result of the session in the satiation experiment, in which subjects were aroma stimulated with a 4 times lower concentrated retro-nasal aroma release profile. Here, a subject's original extent of in vivo retro-nasal aroma release, while eating normally, was negatively related to the amount of ad libitum food consumed in the aroma-stimulated satiation experiment. Due to the preload ad libitum setting of the satiation experiment ${ }^{(3)}$, it was expected that the aroma stimulation (preload) would affect the amount of ad libitum food intake, as a result of the development of sensory satiation. This may act upon a possible relationship between a subject's extent of in vivo retro-nasal aroma release and amount of ad libitum food intake. From the 3 different aroma intensities, the least concentrated aroma stimulation was envisaged to hardly affect ad libitum young-matured cheese consumption in terms of sensory satiation. Indeed, we found that under this condition, a significant negative correlation appeared between a subject's original extent of in vivo retro-nasal aroma release and amount of ad libitum food intake. However, a follow-up study with a larger subject population is needed to ultimately demonstrate an immediate, significant effect of the extent of retro-nasal aroma release on food intake behaviour. 
The results of the present study are promising and will serve as input for upcoming studies that investigate the role of retro-nasal aroma release in satiation, both from food products and subject point of view. Ultimately, the aim is to develop food products containing triggers that are able to regulate food intake behaviour. Examples of applications could be the development of food products with an increase of aftertaste, an increase or lingering of aroma release via flavour delivery systems or encapsulation technology, or the development of long chewable food structures in beverages that evoke substantial oral processing and an increase in transit time in the oral cavity. These applications may lead to a more efficient retro-nasal aroma release and sensory stimulation, which in turn may affect satiation and food intake behaviour.

\section{ACKNOWLEDGEMENTS}

We acknowledge Wageningen Centre for Food Sciences (now Top Institute Food and Nutrition) for putting their consumer panel at our disposal for subject recruitment. We also thank Jan van Riel and Annereinou Dijkstra for their skillful assistance with the measurements.

This work was done within DiOGenes. DiOGenes is the acronym of the project "Diet, Obesity and Genes" supported by the European Community (Contract no. FOODCT-2005-513946). The Parties of the project are listed on the web-site of the project: http://www.diogenes-eu.org/.

Special acknowledgement is made to the Dutch Dairy Association for co-financing this project.

\section{REFERENCES}

1. Meilgaard, M., Civille, G.V., \& Carr, B.T. (1999) Sensory evaluation techniques (pp. 7-8). $3^{\text {rd }}$ ed. Boca Raton, FL: CRC Press.

2. Sorensen, L.B., Moller, P., Flint, A., Martens, M., \& Raben, A. (2003) Effect on sensory perception of foods on appetite and food intake: a review of studies on humans. Int. J. Obes. Relat. Metab. Disord. 27: 1152-1166.

3. Ruijschop, R.M.A.J., Boelrijk, A.E.M., de Ru, J.A., de Graaf, C., \& WesterterpPlantenga, M.S. (2008) Effects of retro-nasal aroma release on satiation. Br. J. Nutr. 99: 1140-1148.

4. Murphy, C., Cain, W.S., \& Bartoshuk, L.M. (1977) Mutual action of taste and olfaction. Sens. Processes 1: 204-211.

5. Rozin, P. (1982) Taste-smell confusions and the duality of the olfactory sense. Percept. Psychophys. 31: 397-401.

6. Small, D.M., Gerber, J.C., Mak, Y.E., \& Hummel, T. (2005) Differential neural responses evoked by orthonasal versus retro-nasal odorant perception in humans. Neuron 47: 593-605. 
7. Land, D.G. (1994) Perspectives on the effects of interactions on flavour perception: an overview. In: McGorrin, R.J., \& Leland, J. (Eds.), Flavor-food interactions (pp. 2-11). Washington: ACS: ACS Symposium Series 633.

8. Buettner, A., \& Schieberle, P. (2000) Exhaled odorant measurement (EXOM) - a new approach to quantify the degree of in-mouth release of food aroma compounds. Lebensm-Wiss. Technol. 33: 553-559.

9. Linforth, R.S.T., Baek, I., \& Taylor, A.J. (1999) Simultaneous instrumental and sensory analysis of volatile release from gelatine and pectin/gelatine gels. Food Chem. 65: 77-83.

10. Cook, D.J., Linforth, R.S.T., \& Taylor, A. (2003) Effects on hydrocolloid thickeners on the perception of savory flavors. J. Agric. Food Chem. 51: 3067-3072.

11. Lethuaut, L., Weel, K.G., Boelrijk, A.E., \& Brossard, C.D. (2004) Flavor perception and aroma release from model dairy desserts. J. Agric. Food Chem. 52: 3478-3485.

12. van Ruth, S.M., de Witte, L., \& Uriarte, A.R. (2004) Volatile flavor analysis and sensory evaluation of custard desserts varying in type and concentration of carboxymethyl cellulose. J. Agric. Food Chem. 52: 8105-8110.

13. Brown, W.E., Dauchel, C., \& Wakeling, I. (1996) Influence of chewing efficiency on texture and flavour perceptions of food. J. Texture Stud. 27: 433-450.

14. Buettner, A., Beer, A., Hanning, C., \& Settles, M. (2001) Observation of the swallowing process by application of videofluoroscopy and real-time magnetic resonance imaging-consequences for retro-nasal aroma stimulation. Chem. Senses 26: 1211-1219.

15. Buettner, A., Beer, A., Hanning, C., Settles, M., \& Schieberle, P. (2002) Physiological and analytical studies on flavor perception dynamics as induced by eating and swallowing process. Food Qual. Pref. 13: 497-504.

16. Wright, K.M., Sprunt, J., Smith, A.C., \& Hills, B.P. (2003) Modeling flavor release from a chewed bolus in the mouth. Part 1. Mastication. Int. J. Food Sci. Technol. 38: 351-360.

17. Pionnier, E., Chabanet, C., Mioche, L., Le Quere, J.L., \& Salles, C. (2004) 1. In vivo aroma release during eating of a model cheese: relationships with oral parameters. J. Agric. Food Chem. 52:.557-564.

18. Westerterp-Plantenga, M.S., Rolland, V., Wilson, S.A.J., \& Westerterp, K.R. (1999) Satiety related to $24 \mathrm{~h}$ diet-induced thermogenesis during high protein/ carbohydrate versus high fat diets, measured in a respiration chamber. Eur. J. Clin. Nutr. 53: 495-502.

19. van Ruth, S.M., Roozen, J.P., \& Cozijnsen, J.L. (1994). Comparison of dynamic headspace in mouth model systems for flavour release from rehydrated bell pepper cuttings. In: Maarse, H., \& van der Heij, D.G. (Eds.), Trends in flavour research (pp. 59-64). Amsterdam: Elsevier Science. 
20. Taylor, A.J., \& Linforth, R.S.T. (1996) Flavour release in the mouth. Trends Food Sci. Tech. 7: 444-448.

21. Taylor, A.J., Linforth, R.S.T., Harvey, B.A., \& Blake, A. (2000) Atmospheric pressure chemical ionisation mass spectrometry for in vivo analysis of volatile flavour release. Food Chem. 71: 327-338.

22. Weel, K.G.C., Boelrijk, A.E.M., Burger, J.J., Gruppen, H., Voragen, A.G.J., \& Smit, G. (2003) A protocol for measurement of in vivo aroma release from beverages. $J$. Food Sci. 68: 1123-1128.

23. Weel, K.G.C., Boelrijk, A.E.M., Burger, J.J., Verschueren, M., Gruppen, H., Voragen, A.G.J., \& Smit, G. (2004). New device to stimulate swallowing and in vivo aroma release in the throat from liquid and semi-liquid food systems. J. Agric. Food Chem. 52: 6564-6571.

24. Weel, K.G.C., Boelrijk, A.E.M., Alting, A.C., van Mil, P.J.J.M., Burger, J.J., Gruppen, H., Voragen, A.G.J., \& Smit, G. (2002) Flavor release and perception of flavoured whey protein gels: perception is determined by texture rather than by release. J. Agric. Food Chem. 50: 5149-5155.

25. Hetherington, M., Rolls, B.J., \& Burley, V.J. (1989) The time course of sensoryspecific satiety. Appetite 12: 57-68.

26. Hetherington, M.M., \& Boyland, E. (2007) Short-term effects of chewing gum on snack intake and appetite. Appetite 48: 397-401.

27. Haber, G.B., Heaton, K.W., Murphy, D., \& Burroughs, L.F. (1977) Depletion and disruption of dietary fibre. Effects on satiety, plasma-glucose, and seruminsulin. Lancet 2: 679-682.

28. Mattes, R.D., \& Rothacker, D. (2001) Beverage viscosity is inversely related to postprandial hunger in humans. Physiol. Behav. 74: 551-557.

29. Mattes, R. (2005) Soup and satiety. Physiol. Behav. 83: 739-747.

30. Tsuchiya, A., Almiron-Roig, E., Lluch, A., Guyonnet, D., \& Drewnowski, A. (2006) Higher satiety ratings following yoghurt consumption relative to fruit drink or dairy fruit drink. J. Am. Diet. Assoc. 106: 550-557.

31. Normand, V., Avison, S., \& Parker, A. (2004) Modeling the kinetics of flavour release during drinking. Chem. Senses 29: 235-245.

32. Trelea, I.C., Atlan, S., Déléris, I, Saint-Eve, A., Marin, M., \& Souchon, I. (2008) Mechanistic mathematical model for in vivo aroma release during eating of semiliquid foods. Chem. Senses 33: 181-192. 


\section{Effects of retro-nasal aroma release on satiation}

Ruijschop, R.M.A.J., Boelrijk, A.E.M., de Ru, J.A., de Graaf, C., \& Westerterp-Plantenga, M.S.

British Journal of Nutrition (2008) 99: 1140-1148 doi:10.1017/S0007114507837482 


\section{ABSTRACT}

It is suggested that the brain response of a food odour sensed retro-nasally is related to satiation. The extent of retro-nasal aroma release during consumption depends on the physical structure of a food, i.e. solid foods generate a longer, more pronounced retro-nasal aroma release than liquid foods. The aim of this study was to investigate if a beverage becomes more satiating when the retro-nasal aroma release profile coincides with the profile of a (soft) solid food. In a double-blind placebo-controlled randomised cross-over full factorial design, twenty-seven healthy subjects (fourteen males and thirteen females; aged 16-65 years; BMI 19-37 $\mathrm{kg} \mathrm{m}^{-2}$ ) were administered aroma profiles by a computer-controlled stimulator based on air dilution olfactometry. Profile A consisted of a profile that is obtained during consumption of normal beverages. Profile B is normally observed during consumption of (soft) solids. The two profiles were produced with strawberry aroma and administered in a retro-nasal fashion, while the subjects consumed a sweetened milk drink. Before, during and after the sensory stimulation, appetite profile measurements were performed. Subjects felt significantly more satiated if they were aroma stimulated with profile $B(P=0.04)$. After stimulation with sweet strawberry aroma, there was a significant decrease in desire to eat sweet products $(P=0.0001)$. In conclusion, perceived satiation was increased by altering the extent of retro-nasal aroma release.

Key words: Satiation; Retro-nasal aroma stimulation; Flavour; Olfactometry 


\section{INTRODUCTION}

In man, satiation is to a large extent obtained by sensory effects, generated through the smell, taste, colour, temperature and texture of food. It is likely that these factors contribute to the inhibition of eating while finishing a course or a meal ${ }^{(1)}$. There are quantitative reports that not all food types result in the same intensity or duration of sensory stimulation ${ }^{(2,3)}$. The extent of sensory stimulation may be related to meal termination. Liquid foods appear to be less satiating than (soft) solid foods ${ }^{(4-7)}$. Differences in structure and composition of the food may be (partly) responsible for this effect.

In view of the obesity problem one of the targets is to develop foods that combine liking with limited food intake, by enhancing satiation signals. In this respect, the role of aroma as a sensory trigger in satiety mechanisms is of interest ${ }^{(8-9)}$.

During the consumption of a meal, aroma molecules either reach the olfactory epithelium orthonasally (perceived as originating from the external world) or retronasally (perceived as arising from the mouth) ${ }^{(10-11)}$. The brain response, i.e. neural brain activation to a retro-nasally sensed food odour is signalling the perception of food ${ }^{(12)}$. The latter is hypothesised to be related to satiation. From previous work, it is known that the physical structure of a food that is consumed is important for the extent of retronasal aroma release during consumption ${ }^{(13-16)}$. Additionally, interpersonal differences are important for retro-nasal aroma release efficiency. These are factors that are likely

(a)

\section{Consumption of 3 pieces}

of aged cheese

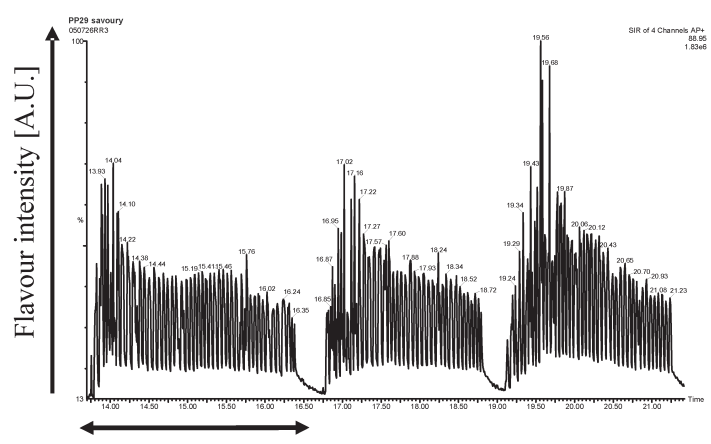

$3.8 \mathrm{~min}$ (b)

Consumption of 3 sips of dairy drink

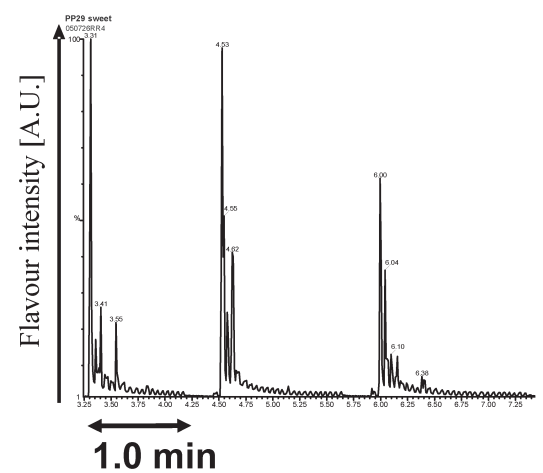

Figure 3.1 Example of one subject, taken from Ruijschop et al. ${ }^{(22)}$, illustrating the differences in the extent of retro-nasal aroma stimulation between (a) the consumption of three times one mouthful (on average $8 \mathrm{~g}$ per mouthful) of cheese ((soft) solid food) and (b) three times one sip (on average 17 $\mathrm{mL}$ per sip) of beverage (liquid food), measured by in vivo atmospheric pressure chemical ionisationMS technology ${ }^{(23,24)}$. Since this illustration is comparison-wise, expression of the flavour intensity in arbitrary units (A.U.) is sufficient to analyse differences ${ }^{(25)}$. As appears from the triplicate measurement, people are reproducible in the morphology and intensity of their aroma release profile. 
uncontrolled by a person, e.g. saliva production, nasal anatomy and oral processing habits ${ }^{(17-21)}$. The present study focuses on differences in food characteristics related to the extent of retro-nasal aroma release that they evoke. It appeared that there was a relatively much longer retro-nasal aroma release profile when consuming cheese instead of a beverage (Figure 3.1). (Soft) solid foods like cheese have a more complex texture and therefore require more extensive chewing and swallowing, resulting in a relative long and high retro-nasal aroma release profile. On the other hand, consumption of liquid food results in a relatively short and more spiked, limited retro-nasal aroma release pattern ${ }^{(22-24)}$. These differences may be one of the reasons why people become more satiated by a (soft) solid food compared to a beverage ${ }^{(4-7)}$.

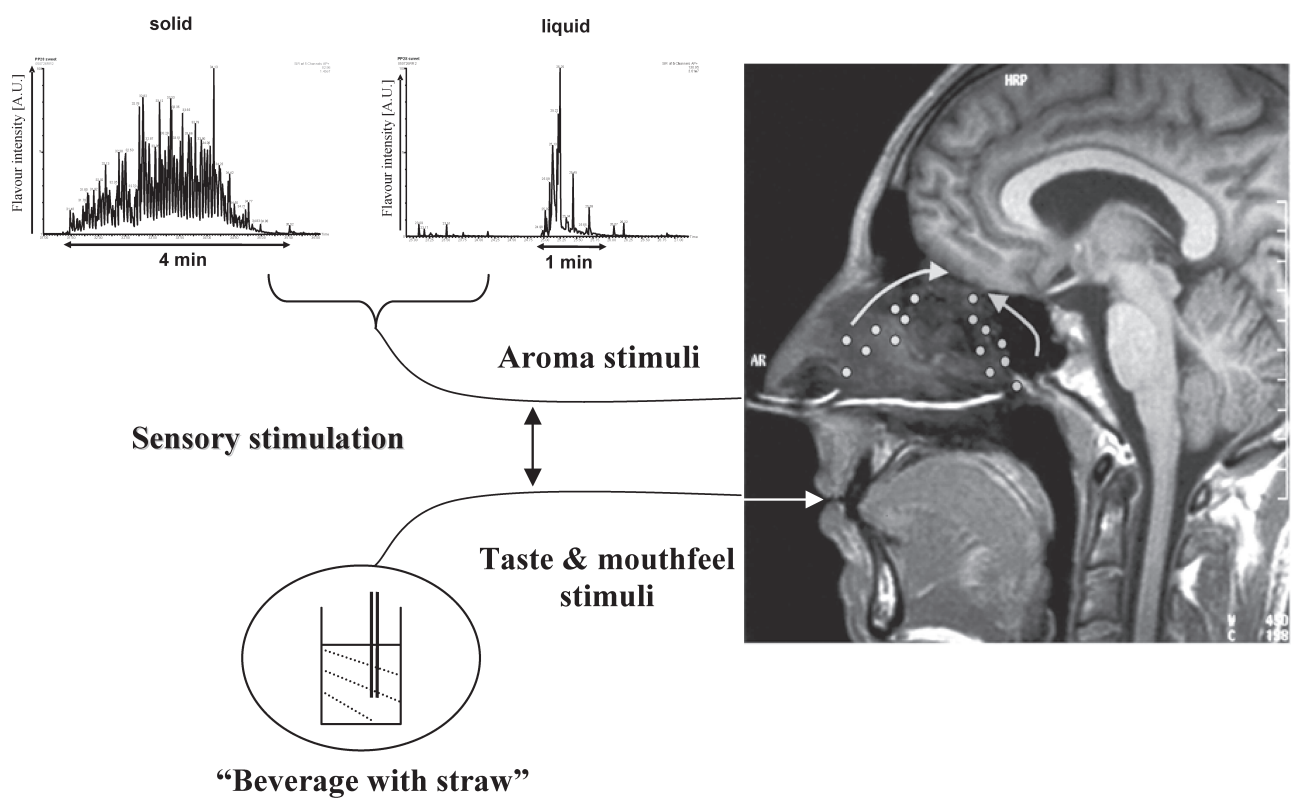

Figure 3.2 Schematic representation of the approach used in the present study. Using a computercontrolled stimulator based on air dilution olfactometry, aroma stimuli can be administered in a retro-nasal fashion separately from other stimuli, such as taste and mouthfeel. An MRI image showing placement of the nasal cannulae at the external nares to achieve orthonasal delivery, and at the retro-pharynx, to achieve retro-nasal delivery. Dots and arrows depict the idealised distribution and flow direction of odourants delivered orthonasally (via the external nares) or retro-nasally (via the retropharynx). Reprinted from Small et al. ${ }^{(12)}$, with permission from Elsevier. All aroma release profiles which were retro-nasally delivered in the nose were combined with the taste and mouthfeel sensation of a sweetened milk drink in the mouth. A.U., arbitrary units.

In order to study this hypothesis, the effect of the extent of retro-nasal aroma stimulation on food intake and satiation was investigated. Using a computer-controlled stimulator based on air dilution olfactometry, aroma stimuli can be administered separately from 
other stimuli, such as different ingredients, textures and tastes (Figure 3.2). Hence, the relative importance of aroma stimuli apart from other stimuli on the short-term appetite profile and subsequent energy intake in normal-weight and overweight men and women was investigated. The aim of the present study was to determine whether a beverage becomes more satiating when the retro-nasal aroma release profile coincides with the profile of a (soft) solid food.

\section{SUBJECTS AND METHODS}

\section{Subjects}

Twenty-seven healthy subjects (fourteen men and thirteen women) aged 18-65 years living in Ede and surroundings were recruited through the local newspapers. The subjects included normal-weight, overweight and obese subjects, with a BMI of 19-37 $\mathrm{kg} \mathrm{m}^{-2}$. BMI was calculated as body weight (kg) divided by height (m) squared. Body weight was measured without wearing shoes using a calibrated scale which was accurate to $0.1 \mathrm{~kg}$ (Inventum, Veenendaal, The Netherlands). At the same time without wearing shoes, height was measured with a wall-mounted stadiometer (Microtoise mabo 4116, Brevete, France).

Table 3.1 Characteristics of the 27 subjects who participated in this study ${ }^{a}$

\begin{tabular}{|c|c|c|c|c|}
\hline & \multicolumn{2}{|c|}{$\begin{array}{l}\text { Normal-weight } \\
\quad(\mathrm{n}=19)\end{array}$} & \multicolumn{2}{|c|}{$\begin{array}{c}\text { Overweight } \\
(\mathrm{n}=8)\end{array}$} \\
\hline & Mean & SD & Mean & SD \\
\hline Age (years) & 44 & 15 & 44 & 8 \\
\hline BMI $\left(\mathrm{kg} \mathrm{m}^{-2}\right)$ & 22 & 3 & 29 & 3 \\
\hline \multicolumn{5}{|l|}{ TFEQ $^{\mathrm{b}}$} \\
\hline Factor 1 (cognitive restraint) & 5 & 2 & 5 & 3 \\
\hline Factor 2 (disinhibition) & 4 & 2 & 5 & 2 \\
\hline Factor 3 (hunger) & 3 & 2 & 4 & 3 \\
\hline
\end{tabular}

${ }^{a}$ Mean \pm SD.

b TFEQ: Three-Factor Eating Questionnaire. The values of factors 1, 2 and 3 are in the range of 0 to 18 ; 0 to 13 , and 0 to 14 , respectively. A higher value indicates more restraint, disinhibition or physiological hunger. All values are below medians that are usual.

Subjects' degrees of dietary restraint were determined using the Dutch translation of the Three-Factor Eating Questionnaire ${ }^{(26)}$. Based on the outcome of the Three-Factor Eating Questionnaire subjects were selected with low scores on dietary restraint (i.e. scores $\leq 9$ ), disinhibition (i.e. emotional eating) (i.e. scores $\leq 8$ ) and physiological hunger (i.e. scores $\leq 8$ ). In addition, based on self-report, subjects were not allergic to, nor did they have an aversion to, any of the food ingredients used in the present 
study. Subject characteristics, including Three-Factor Eating Questionnaire scores, are summarised in Table 3.1. Subjects were fully informed about the course of the test day and gave their written, informed consent. To prevent response-bias the participants were given no information about the hypothesis and nature of the predictions of the experiment. They were only aware of the fact that the study was about sensory stimulation and satiety. The study was approved by the Medical Ethical Committee of Wageningen University.

\section{Preparation of products}

Sweetened milk drink

For the preparation of the sweetened milk drink, 10\% sucrose (Suiker Unie, Oud Gastel, The Netherlands) and six droplets (i.e. $0.36 \mathrm{~mL}$ in total) of pink food colour (Städter $\mathrm{GmbH}$, Grünberg, Germany) were added to 1 litre of semi-skimmed (1.5\% fat) pasteurized milk (private label, Albert Heijn Zaandam, The Netherlands). The metabolisable energy of 1 litre of sweetened milk drink was $3.7 \mathrm{MJ} ; 15.4 \%$ of energy as fat, $68.6 \%$ as carbohydrate and $15.4 \%$ as protein.

\section{Sweetened strawberry-flavoured milk drink}

In order to prepare the sweetened strawberry-flavoured milk drink, $10 \%$ sucrose (Suiker Unie), $60 \mathrm{mg}$ strawberry aroma ${ }^{(27)}$ and six droplets (i.e. $0.36 \mathrm{~mL}$ in total) of pink food colour (Städter $\mathrm{GmbH}$ ) were added to 1 litre of semi-skimmed (1.5\% fat) pasteurized milk (private label, Albert Heijn Zaandam). The metabolisable energy and macronutrient composition of the sweetened strawberry-flavoured milk drink were similar to the sweetened milk drink (1 litre, $3.7 \mathrm{MJ} ; 15.4 \%$ of energy as fat, $68.6 \%$ as carbohydrate and $15.4 \%$ as protein).

\section{Strawberry aroma}

The strawberry aroma used was the standard flavour of the COST 921 action ${ }^{(27)}$, designed and supplied by Givaudan (Geneva, Switzerland), which contains fifteen components including ethyl butyrate (90 mg/g), methyl dihydrojasmonate (5 mg/g), methyl cinnamate (24 mg/g), vanillin ( $5 \mathrm{mg} / \mathrm{g}$ ), ethyl hexanoate $(50 \mathrm{mg} / \mathrm{g})$, benzyl acetate (2 $\mathrm{mg} / \mathrm{g})$, g-decalactone (20 mg/g), hexanal (1 mg/g), cis-3-hexenol (15 mg/g), b-ionone $(1 \mathrm{mg} / \mathrm{g})$, ethyl iso-pentanoate $(10 \mathrm{mg} / \mathrm{g})$, methyl anthranilate $(1 \mathrm{mg} / \mathrm{g})$, furaneol (5 $\mathrm{mg} / \mathrm{g})$, styrallyl acetate $(1 \mathrm{mg} / \mathrm{g})$, cis-3-hexenyl acetate $(5 \mathrm{mg} / \mathrm{g})$, and triacetin $(795$ $\mathrm{mg} / \mathrm{g}$ ) as a solvent. Prior to use in the olfactometer, the strawberry flavour was diluted 1000-fold in propylene glycol (Sigma-Aldrich Chemie GmbH, Germany).

\section{Chocolate milk drink}

Commercially available semi-skimmed ( $1.5 \%$ fat) UHT chocolate milk drink was used 
(Bonomel, Albert Heijn Zaandam, The Netherlands). The metabolisable energy of 1 litre of chocolate milk drink was $3.0 \mathrm{MJ} ; 17.7 \%$ of energy as fat, $63.7 \%$ as carbohydrate and $18.6 \%$ as protein.

\section{Aroma stimulation}

The strawberry aroma was administered by means of a tailored computer-controlled four-channel olfactometer based on air-dilution olfactometry (OM4; Burghart, Wedel, Germany). As already described by Visschers et al. ${ }^{(28)}$, delivering food-related aroma stimuli via an olfactometer to subjects involves a variety of parameters and matching the aroma stimuli to such a level that can be genuinely related to food is a complex process. The approach that was used is based on the knowledge of measuring aroma release in vivo in real time using atmospheric pressure chemical ionization-MS (APcIMS) ${ }^{(24,29-31)}$. In practice, the Teflon tubing outlet of the olfactometer is directly attached to the APcI-MS inlet capillary. In this way, the timing and intensity of the aroma pulses generated by the olfactometer are matched with in vivo flavour release profiles of food products that initially were measured with the APcI-MS sampling the nose of a human subject. It was demonstrated that indeed the aroma profile that was generated with the olfactometer closely resembles the concentration of volatiles in the nose space measured for an individual subject eating or drinking a specific product. This enables the design of complete aroma release profiles that mimic those obtained by in vivo experiments during the consumption of foods ${ }^{(28)}$.

In the current set-up, the air flow out of the olfactometer was kept constant at 8 litres/min so as to be as close as possible to natural aroma release conditions during consumption. A complete aroma time-intensity release profile was administered by the olfactometer consisting of multiple aroma pulses. The aroma release curve that resembles the consumption of a liquid food (i.e. aroma profile A - Figure 3.3) was delivered as a profile of three consecutive pulses, each lasting $3 \mathrm{~s}$, with interpulse intervals of $1 \mathrm{~s}$. The odourised-dilution air flow ratios, i.e. the amount of odour-enriched air $\mathrm{v}$. the amount of odourless air for the three pulses within the profile were 4:4, 2:6, 1:7, with a total odour + dilution air flow of 8 litres $/ \mathrm{min}$. The aroma concentration in the delivered air corresponds linearly to the fraction of the total flow for flow rates up to 4 litres/min in each aroma vessel. The second aroma profile (i.e. aroma profile B - Figure 3.3), mimicking the consumption of a (soft) solid food like Dutch Gouda cheese, varied only in the number of delivered consecutive pulses. In this profile ten pulses were delivered. The two aroma profiles thus primarily differed in length of the aroma release curve and not in concentration (height). Both profiles were designed in such a way that the envelope of the aroma pulses mimics the reflux of air that occurs during and after swallowing. Each subject received both aroma profiles with the same concentration of the strawberry aroma in a fully randomised order. For retro-nasal odour delivery, approximately $9 \mathrm{~cm}$ in length of a silicon tube (suction catheter $\mathrm{CH}$ 
10; D-Care B.V., Houten, The Netherlands) was placed into the lower meatus of the right nasal cavity. Anterior rhinoscopy was performed to exclude major pathology. Introduction of the tubing to the nose was tolerated well by all subjects without causing congestion, epistaxis or mucus discharge. Subjects waited for $15 \mathrm{~min}$, in which they could relax and familiarise with the tubing. To what extent a subject felt comfortable was also recorded. The silicon tube was connected to the olfactometer while the subject was sitting straight up in a chair, enabling concurrent consumption of a beverage.

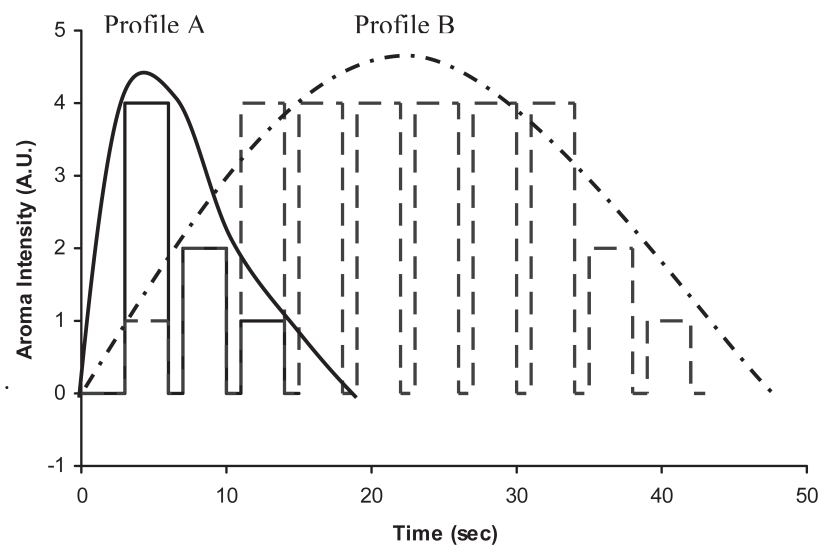

Figure 3.3 Aroma release profiles delivered by olfactometer in the reference (i.e. liquid, profile A,-) and manipulated (i.e. (soft) solid, profile B,--) aroma stimulation. Since the present study is comparison-wise, expression of the flavour intensity in arbitrary units (A.U.) is sufficient to analyse differences ${ }^{(25)}$. The smoothed lines indicate the perceived aroma intensity, which is a continuous envelope.

Subjects were connected to the olfactometer for $10 \mathrm{~min}$. The duration of aroma stimulation depended on the type of aroma stimulation they received. Both aroma stimulations consisted of ten aroma release profiles, starting every minute. All ten aroma release profiles which were retro-nasally delivered in the nose were combined with the taste and mouthfeel sensation of a sweetened milk drink (10 mL) in the mouth. During one complete aroma stimulation experiment, every subject received ten such milk samples (100 $\mathrm{mL}$ in total), which were served at $7 \pm 1^{\circ} \mathrm{C}$.

A specific protocol was established for the timing of aroma delivery. As $10 \mathrm{~mL}$ is a normal quantity to be consumed in one sip, subjects were instructed to consume the entire sweetened milk sample in one sip using a straw. The aroma was delivered $3 \mathrm{~s}$ after the instruction to consume the sweetened milk sample. No specific instruction with regard to breathing was given. With the exception of strong breath intake through the nose, the total air flow of 8 litres/min from the olfactometer ensures delivery of the aroma to the olfactory epithelium. During the experiments, the subjects were closely 
observed in order to verify compliance with the protocol.

To prevent adaptation to the delivered aroma, the delay between the measurements amounted to a minimum of 17 s (i.e. the time interval between two successive aroma release profiles). Within this time interval, a continuous constant flow of clean air was maintained. After aroma stimulation, the silicon tube was removed and subjects went to another room for the remaining part of the experiment.

\section{Experimental design}

Separately, in order to prevent response-bias, additional sensory data were obtained to investigate whether the difference in the two aroma release profiles was large enough to be perceived as being different. Therefore, after the satiation experiments, a triangle test was performed with the subjects who participated in the study. Based on these results, it could be checked whether the intervention was successful.

For the satiation experiments, each subject visited the test location twice in the morning. Between each visit there was a time interval of 1 week. Before starting the experiment, daily dietary energy requirements were calculated individually by multiplying the BMR by an activity index of 1.75 . The BMR was calculated according to the equation of Harris and Benedict ${ }^{(32)}$. Subjects were asked to consume $10 \%$ of the daily dietary energy requirements for breakfast at home, which varied per person from 836.8 to $1464.4 \mathrm{~kJ}$ (from 200 to $350 \mathrm{kcal}$ ). In addition, the subjects were requested to consume the same type and amount of breakfast when visiting the laboratory the second time. Based on this individually standardised breakfast, subjects visited the laboratory every time with comparable feelings of hunger and satiety. This was confirmed by a baseline measurement before the start of the aroma stimulation.

In a double-blind placebo-controlled randomised crossover full factorial design subjects were administered two different aroma profiles using an olfactometer set-up as described earlier. Before, during and after the sensory stimulation, appetite profile measurements were performed. After sensory stimulation actual beverage intake of the sweetened strawberry-flavoured milk drink was measured. In addition, liking of the sweetened strawberry-flavoured milk drink $v$. the chocolate milk drink was measured. The design of a test day is represented schematically in Figure 3.4.

\section{Sensory evaluation of the aroma profiles}

A triangle test was performed in order to investigate whether the difference in the two aroma profiles was large enough to be perceived as being different. Using the olfactometer (OM4; Burghart), twenty-five subjects received four triangles each in a retro-nasal fashion. These triangles consisted of three stimuli, i.e. either two liquid (profile A) and one (soft) solid (profile B) aroma release profile or two (soft) solid (profile B) and one liquid (profile A) aroma release profile in a fully randomised order. Subjects were asked to pick out the odd stimulus. 


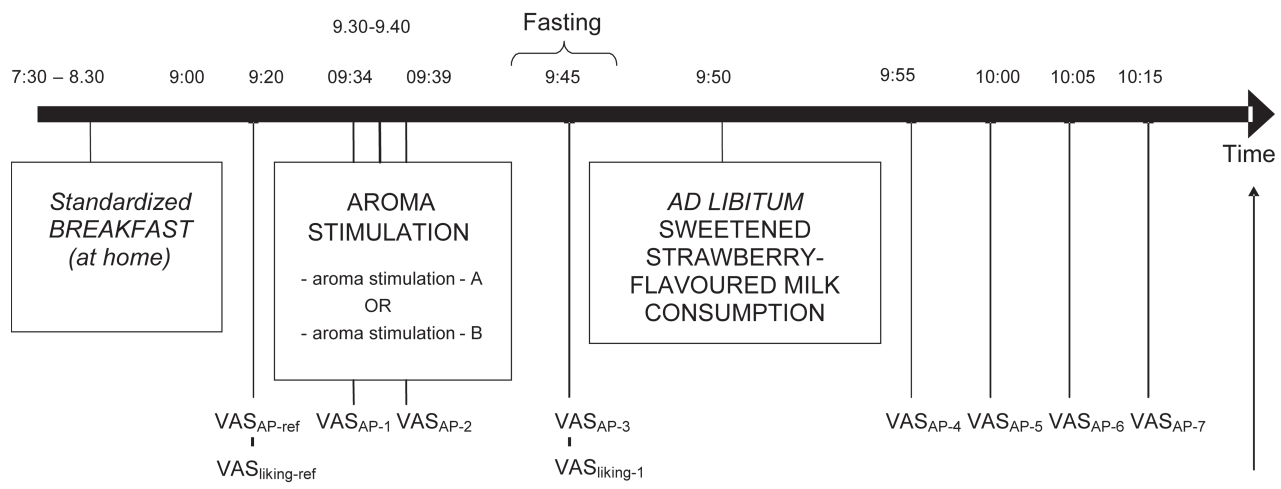

Figure 3.4 Overview of the test day protocol. Subjects came twice to the laboratory, a week apart, and received either the reference (i.e. liquid) aroma stimulation-A or the manipulated (i.e. (soft) solid) aroma stimulation-B in a fully randomised order. Appetite profiles were recorded on a $100-\mathrm{mm}$ visual analogue scale (VAS) at regular time-points $\left(\mathrm{VAS}_{\mathrm{AP}-\mathrm{ref}}\right.$ to $\left.\mathrm{VAS}_{\mathrm{AP}-\mathrm{f}}\right)$. To determine possible sensoryspecific satiety effects, hedonic ratings were recorded for the sweetened strawberry-flavoured milk drink and the chocolate milk drink on a $100 \mathrm{~mm}$ VAS $\left(\mathrm{VAS}_{\text {liking-ref }}\right.$ and $\mathrm{VAS}_{\text {liking- } 1}$ ). In addition, $5 \mathrm{~min}$ after the subjects had been aroma stimulated, the amount of sweetened strawberry-flavoured milk consumed ad libitum was measured.

\section{Data analysis of triangle test}

The number of correct responses (i.e. correctly identified odd stimuli) and total responses of the triangle test were counted. Data were treated as though there were 100 individual judges, instead of four replicates from twenty-five judges. To check if this was statistically valid, the possibility of non-independent judgements among replications was tested. The proportions of correct decisions between the replicates were not significantly different. Therefore, the data could be combined and the combined data may be analysed without reference to the individual replications ${ }^{(33)}$.

It was determined if the number correct for the number tested (i.e. 100) was equal to or larger than the number indicated in the suitable statistical table (i.e. forty-two), i.e. the minimum number of correct responses required for significant difference at a significance level of $\alpha=0.05^{(34)}$.

\section{Measurements}

\section{Short-term appetite profile}

The appetite profile, i.e. ratings of hunger, fullness, satiety, desire to eat, and thirst were recorded on a 100-mm visual analogue scale (VAS) (anchored for each with "not at all" and "very much") at regular time-points before, during and after both the aroma stimulation and the ad libitum beverage intake (see $\mathrm{VAS}_{\mathrm{AP}}$ - Figure 3.4). In addition, at the same time-points desire to eat sweet products and desire to eat savoury products 
were recorded on 100-mm VAS anchored with "not at all" and "very much". In Dutch language the exact wording for recording of the appetite profile ratings was: "Hoeveel honger heeft $\mathrm{u}$ ?; Hoe vol voelt $\mathrm{u}$ zich?; Hoe verzadigd voelt $\mathrm{u}$ zich?; Hoe groot is uw wens om te eten?; Hoeveel dorst heeft $u$ ?; Hoeveel trek heeft $\mathrm{u}$ in iets zoets?; Hoeveel trek heeft $u$ in iets hartigs?"(26).

All rating scales were provided on separate sheets that were collected after each rating.

\section{Actual beverage intake}

To measure the effect of the type of aroma stimulation on actual food consumption, 5 min after the subjects had been aroma stimulated, they were offered 1 litre of sweetened strawberry-flavoured milk drink, served with a straw in a jar covered with aluminium foil at $7 \pm 1^{\circ} \mathrm{C}$, from which they could drink ad libitum. The amount offered was such that there were always leftovers. After consumption the amount of beverage consumed was measured for each subject (Mettler-Toledo balance; Greifensee, Switzerland).

\section{Pleasantness of flavour rating}

To determine possible sensory-specific satiety effects, defined as the decrease in pleasantness of a food after it is eaten compared with the decrease in pleasantness of foods that were tasted but not eaten to satiation ${ }^{(35)}$, two different kinds of dairy products were used: a sweetened strawberry-flavoured milk drink and chocolate milk drink. The sweetened strawberry-flavoured milk drink was the same drink as used for the actual beverage intake measurements. Before and after the aroma stimulation, subjects received $10 \mathrm{~mL}$ of both sweetened strawberry-flavoured milk drink and chocolate milk drink. Samples were served at $7 \pm 1^{\circ} \mathrm{C}$. After drinking the sweetened strawberry flavoured milk drink sample, subjects were asked to scale their hedonic rating (100-mm VAS anchored with "not pleasant at all" and "very pleasant") and their desire to drink this sweetened strawberry-flavoured milk drink (100-mm VAS anchored with "not at all" and "very much") (see $\mathrm{VAS}_{\text {liking }}$ - Figure 3.4). Subsequently, the same measures for the chocolate milk drink were recorded.

Data analysis of short-term appetite profile, actual beverage intake and pleasantness of flavour

VAS ratings were measured in millimetres from the left ("not at all") end of the scale. Since there were no significant differences in VAS rating at baseline measurement, delta VAS ratings, i.e. changes in VAS ratings, were calculated by subtracting the ratings at the time-point before aroma stimulation took place VAS $_{\text {AP-ref }}$ for appetite profile ratings and $\mathrm{VAS}_{\text {liking-ref }}$ for hedonic ratings) from the ratings at the different time-points after aroma stimulation VAS $_{\mathrm{AP}-1}$ to $\mathrm{VAS}_{\mathrm{AP}-7}$ for appetite profile ratings and $\mathrm{VAS}_{\text {liking-1 }}$ for hedonic 
ratings). All data are presented as means with their standard errors of the mean. Actual beverage intake and the different VAS ratings were compared between the two aroma stimulations by using paired t-tests and also ANOVA with repeated measures. Post hoc, for each comparison separately, ANOVA with repeated measures was also used. For all data analyses the statistical packages SAS, release 9.1 (SAS Institute Inc., Cary, NC, USA) were used. $\mathrm{P}<0.05$ was considered statistically significant.

\section{RESULTS}

Sensory evaluation of the aroma profiles

From the 100 triangles that were carried out in the triangle test, seventy-three correct responses were counted. This implies that subjects were able to evaluate the two aroma release profiles as significantly different $(P<0.001)$; thus most of them were able to discriminate between the liquid (profile A) and (soft) solid (profile B) aroma release profile. Among the responses, it was not possible to identify sensitive and insensitive subjects. In the satiation experiments, the timing for each sip of sweetened milk drink while an aroma profile was delivered did not vary between the two aroma profiles $\mathrm{A}$ and $B$. The only difference in sensory experience that was perceived by the subjects was a lingering of aroma (i.e. aftertaste) after swallowing the sweetened milk sample when aroma profile B was administered. By interviewing subjects afterwards, it appeared that they were completely unaware that the strawberry-flavoured sweetened milk drink consisted of separately delivered aroma and taste/mouth feel stimuli.

\section{Short-term appetite profile}

Before, during and after the sensory stimulation, appetite profile measurements were performed. Figures 3.5 and 3.6 show, respectively, the results of the different types of aroma stimulation on the change in VAS ratings of satiation and the effect of aroma stimulation in general on the change in desire to eat sweet and savoury products VAS rating. A significant difference was demonstrated in perceived satiation between an olfactometer delivery of a classical beverage aroma profile (profile A; delta mean response at $\mathrm{VAS}_{2} 3.0$ (SEM 5.3) mm) compared to an olfactometer delivery of a (soft) solid aroma profile (profile B; delta mean response at VAS 214.5 (SEM 5.3) mm). From Figure 3.5 it can be concluded that during aroma stimulation $\left(\mathrm{VAS}_{2}\right.$ ) subjects felt more satiated if they were aroma stimulated with profile $B\left(F_{(1,390)} 4.24 ; \mathrm{P}=0.04\right)$. In addition, with regard to desire to eat sweet and savoury products ratings, there was a decrease in desire to eat sweet products after stimulation with the sweet strawberry aroma, irrespective of the type of aroma stimulation (delta mean -14.6 (SEM 4.4) mm). Overall, after stimulation with the strawberry aroma, the desire to eat sweet products

decreased significantly $\left(\mathrm{F}_{(1,390)} 8.17 ; \mathrm{P}=0.0001\right)$. As expected, no significant change in desire to eat savoury products after aroma stimulation with the sweet strawberry 


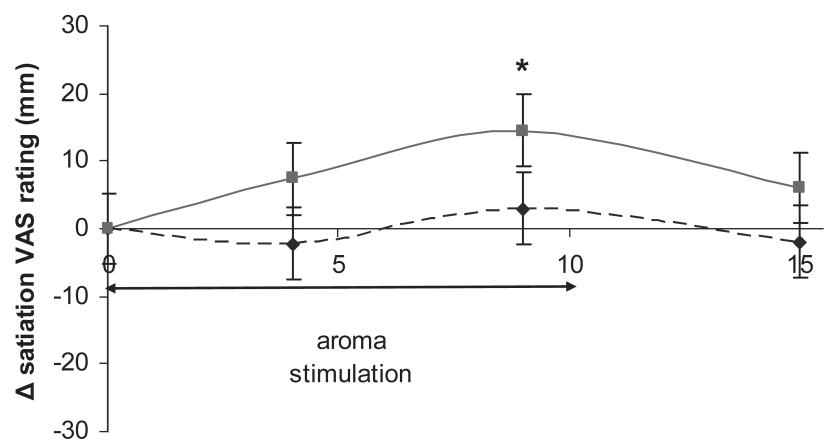

Time after start trial (min)

$\longrightarrow--$ short stimulation profile $\mathrm{A} \longrightarrow$ long stimulation profile $\mathrm{B}$

Figure 3.5 Change $(\Delta)$ in satiation visual analogue scale (VAS) rating after stimulation with aroma profile A $(\downarrow) v$. aroma profile B $(\boldsymbol{\bullet})$. Values are means with their standard errors depicted by vertical bars. ${ }^{*}$ Effect of type of aroma stimulation (profile A or B) on $\Delta$ satiation VAS rating $(\mathrm{P}<0.05)$.

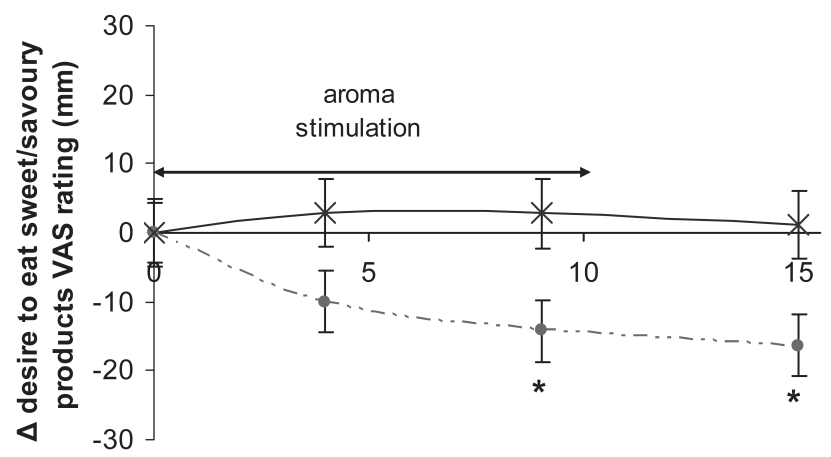

Time after start trial (min)

- - - - delta desire for sw eet products $\quad \longrightarrow$ delta desire for savoury products

Figure 3.6 Change $(\Delta)$ in desire to eat sweet $(\bullet)$ or savoury $(\mathrm{x})$ products visual analogue scale (VAS) rating after stimulation with sweet strawberry aroma. Since there were no significant differences in VAS ratings after stimulation with aroma profile $\mathrm{A} v$. aroma profile $\mathrm{B}$, data from aroma profile $\mathrm{A}$ and $\mathrm{B}$ were averaged. Values are means with their standard errors depicted by vertical bars. * Effect of aroma stimulation on $\Delta$ desire to eat sweet products VAS rating $(\mathrm{P}<0.05)$.

aroma was observed (delta mean 0.7 (SEM 4.9) mm; $\mathrm{F}_{(1,390)} 0.54 ; \mathrm{P}=0 \cdot 80$; Figure 3.6). Post hoc, after aroma stimulation a significant age effect was observed; i.e. older people (age $\geq 45$ years) felt on average less satiated (peak values for delta satiation VAS rating $=3$ and $13 \mathrm{~mm}$ for older and younger people, respectively) and had less decrease in desire to eat sweet products (delta desire to eat sweet products VAS rating $=-8$ and -18 $\mathrm{mm}$ for older and younger people, respectively; $\mathrm{P}<0.05$; data not shown). 


\section{Actual beverage intake}

After sensory stimulation actual beverage intake of sweetened strawberry-flavoured milk drink was measured. The amount of sweetened strawberry-flavoured milk drink consumed ad libitum did not differ significantly between the two aroma stimulations (respectively, 187 (SEM 16) $\mathrm{mL}$ (range 3.7-526.2 $\mathrm{mL}$ ) after aroma stimulation with profile A and 185 (SEM 16) $\mathrm{mL}$ (range 10.8-600.8 mL) after aroma stimulation with profile $\mathrm{B})\left(\mathrm{F}_{(1,25)} 0.01 ; \mathrm{P}=0 \cdot 94\right.$; Figure 3.7$)$. Since there was no gender effect in the actual beverage intake data $\left(\mathrm{F}_{(1,25)} 0.18, \mathrm{P}=0.68\right)$, males and females were analysed together. After calculating to what extent energy consumed ad libitum contributed to the daily dietary energy requirements, it appeared that overweight subjects (BMI $>25 \mathrm{~kg} \mathrm{~m}^{-2}$ ) consumed more compared to the normal-weight subjects (BMI $\leq 25 \mathrm{~kg} \mathrm{~m}^{-2}$ ). Actual beverage intake, expressed as a percentage of the daily dietary energy requirements, was positively related to BMI after aroma stimulation with both profile A and profile $\mathrm{B}$ (for aroma stimulation with profile $\mathrm{A}: \mathrm{R}^{2} 0.17 ; \mathrm{P}=0.03$; and for aroma stimulation with profile $B: R^{2}$ 0.34; $P=0.001$, respectively).

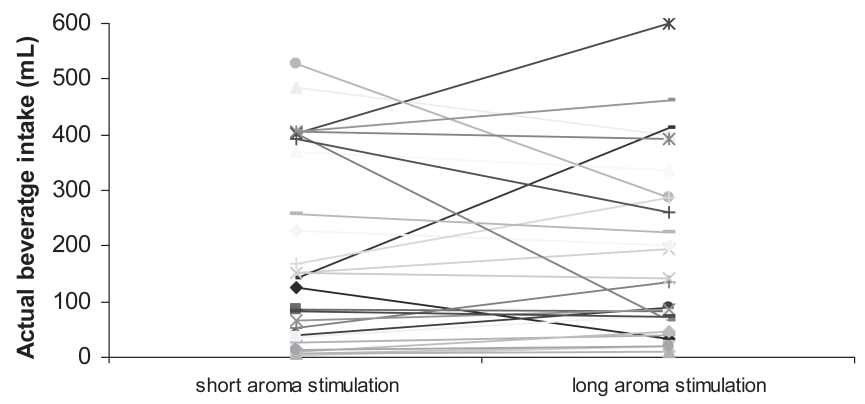

Figure 3.7 The amount of sweetened strawberry-flavoured milk drink consumed ad libitum after the two aroma stimulations by the twenty-seven subjects. There was no significant difference in actual beverage consumption between the two aroma stimulations $\left(\mathrm{F}_{(1,25)} 0.01 ; \mathrm{P}=0.94\right)$.

\section{Pleasantness of flavour rating}

Even though after aroma stimulation the pleasantness of flavour decreased for both the sweetened strawberry-flavoured milk (delta mean -1.4 (SEM 2.2) mm) and the chocolate milk drink (delta mean -3.4 (SEM 1.7) $\mathrm{mm}$ ), no significant effect upon the pleasantness of flavour was observed $\left(\mathrm{F}_{(1,25)}<1.59 ; \mathrm{P}>.0 .21\right)$. Subjects perceived no decrease in pleasantness of flavour or desire to drink the sweetened strawberryflavoured milk drink compared to the chocolate milk drink.

\section{DISCUSSION}

Using a triangle test, differences with respect to duration of the olfactory stimulation were determined using the (untrained) consumer subjects. Subjects were able to 
distinguish the two different aroma profiles as significantly different when they were delivered to them in a consecutive order. However, it has to be noted that during the satiation measurements, which were 1 week apart, the subjects were not consciously aware of the differences in delivered aroma release profiles A and B. By interviewing subjects afterwards, it appeared that subjects may be aware to some extent of the delivery of aroma, but they did not perceive any difference in the type of aroma stimulation they received when visiting the laboratory the second time 1 week later compared to the first time. This indicates that there was no response bias. In conclusion, a significant difference demonstrated in perceived satiation between olfactometer delivery A and B can be perceived, but during the satiation experiments, subjects were not consciously aware of the differences.

The demonstrated difference in perceived satiation between an olfactometer delivery of a classical beverage aroma profile A compared to an olfactometer delivery of a (soft) solid aroma profile $B$ is a meaningful result. To our knowledge, this is the first time that such a result has been observed. A beverage with an aroma release profile similar to a (soft) solid food (profile B) is able to increase the subject's feeling of satiation significantly (Figure 3.5). Since the transit time in the oral cavity is relatively short with consumption of beverages, consumption of beverages usually results in relatively short and spiked aroma release patterns ${ }^{(22,24)}$. This limited retro-nasal aroma release efficiency may result in less sensory stimulation. The difference in the extent of retronasal aroma release between (soft) solid and liquid foods is most likely one of the reasons why people perceive to be more satiated by a (soft) solid food compared to a beverage.

It appeared that after stimulation with the strawberry aroma a significant decrease in desire to eat sweet products is observed, irrespective of the type of aroma stimulation (Figure 3.6). This is due to sensory-related satiation. Apparently, the difference in aroma profiles $\mathrm{A}$ and $\mathrm{B}$ did not result in a difference in decrease in desire to eat sweet products. This may be due to a difference too small between both aroma profiles. Based on the results regarding desire to eat sweet products, it is in line with expectations that no significant change in desire to eat savoury products after aroma stimulation with the sweet strawberry aroma was observed (Figure 3.6).

The fact that no significant difference was observed in actual beverage intake after an olfactometer delivery of a classical beverage aroma profile (A) compared to an olfactometer delivery of a (soft) solid aroma profile (B) was not unexpected. Energy intake during a meal was not related to pre-prandial satiety, similar to previous observations ${ }^{(7,36-38)}$. In fact, energy intake during a meal is related to the various parameters after the meal, i.e. postprandial satiety and intermeal interval ${ }^{(39)}$. Furthermore, no significant difference in pleasantness of flavour rating of a sweetened strawberry-flavoured milk drink $v$. a chocolate milk drink after olfactometer delivery A or $\mathrm{B}$ appeared. A possible explanation could be that aroma was not the only determinative 
factor responsible for the outcome of the pleasantness of flavour ratings. It might be that congruency between sweet taste and aroma perception for both the strawberry and the chocolate drink plays a role ${ }^{(40)}$. Since the chocolate milk drink had a sweet taste too, this may be the sensory driver for pleasantness of flavour ratings and therefore there is limited difference between chocolate and strawberry-flavoured milk. This would indicate a generalization over sweet products, thus a larger band-width, after aroma stimulation with sweet foods in general.

In addition, the higher satiation response after the (soft) solid aroma profile (profile B) compared to the liquid aroma profile (profile A) might be contributing to a learned response (i.e. conditioned satiation, cf. Booth et al. ${ }^{(41)}$ and Gibson and Brunstrom ${ }^{(42)}$ ). In real life people may gradually learn that (soft) solid foods have a higher satiating capacity/energy content than liquid foods. The higher satiating effect of the (soft) solid aroma profile may be explained in terms of a longer nasal monitoring of odour release which is usually associated with a higher subsequent ingestion of energy.

An alternative explanation for the observed difference in appetite rating is a higher sensory-specific satiety effect of the (soft) solid aroma profile compared to the liquid aroma profile. The lack of significant differences in the pleasantness of the exposed relative to the unexposed flavour and in ad libitum intake makes this explanation less probable. However, it may be difficult to distinguish between a sensory-related satiation effect and sensory-specific satiety.

To summarise, by using this novel approach, i.e. delivering aroma stimuli separately from taste and mouthfeel, the relative importance of aroma stimuli on the short-term appetite profile and subsequent energy intake can indeed be determined. The present study demonstrates that a beverage is perceived as more satiating than the original beverage when the retro-nasal aroma release profile during consumption coincides with the profile of a (soft) solid food. Perceived satiation can thus be increased by altering the extent of aroma release. Despite changes in subjective experience, there is no impact on ad libitum amount consumed. This dissociation is a common observation in the field and similar to previous studies ${ }^{(7,36-38)}$. However, in a follow-up study it would be a great challenge to obtain also a significant effect on actual food intake. The results of the present study are interesting for the development of foods that contain triggers that are able to induce or increase the feeling of satiation, for instance foods with an increase of aftertaste by lingering aroma, or long chewable food structures that evoke lots of oral processing and an increase in transit time in the oral cavity, resulting in a higher retro-nasal aroma release efficiency. These applications may lead to a higher quality or quantity of sensory stimulation, which in turn may lead to enhanced feelings of satiation. For example, people who are participating in a weight loss programme may benefit with these foods. 


\section{ACKNOWLEDGEMENTS}

We acknowledge Marc Jacobs, Annereinou Dijkstra, Denise Jonker and Iris van Swam for their skilful assistance with the experimental design and measurements. We also thank Meike te Giffel for critical reading of the manuscript.

This work was done within DiOGenes. DiOGenes is the acronym of the project 'Diet, Obesity and Genes' supported by the European Community (contract no. FOODCT-2005-513946). The parties of the project are listed on the website of the project: http://www.diogenes-eu.org/. Special acknowledgement is made to the Dutch Dairy Association for co-financing this project.

\section{REFERENCES}

1. Sorensen, L.B., Moller, P., Flint, A., Martens, M., \& Raben, A. (2003) Effect on sensory perception of foods on appetite and food intake: a review of studies on humans. Int. J. Obes. Relat. Metab. Disord. 27: 1152-1166.

2. Vickers, Z., \& Holton, E.A. (1998) A comparison of taste test ratings, repeated consumption, and postconsumption ratings of different strengths of iced tea. $J$. Sensory Stud. 13: 199-212.

3. Zandstra, E.H., \& de Graaf, C. (1998) Sensory perception and pleasantness of orange beverages from childhood to old age. Food Qual. Pref. 9: 5-12.

4. Haber, G.B., Heaton, K.W., Murphy, D., \& Burroughs, L.F. (1977) Depletion and disruption of dietary fibre. Effects on satiety, plasma-glucose, and serum-insulin. Lancet ii: 679-682.

5. Mattes, R.D., \& Rothacker, D. (2001) Beverage viscosity is inversely related to postprandial hunger in humans. Physiol. Behav. 74: 551-557.

6. Mattes, R. (2005) Soup and satiety. Physiol. Behav. 83: 739-747.

7. Tsuchiya, A., Almiron-Roig, E., Lluch, A., Guyonnet, D., \& Drewnowski, A. (2006) Higher satiety ratings following yoghurt consumption relative to fruit drink or dairy fruit drink. J. Am. Diet. Assoc. 106: 550-557.

8. Hirsch, A.R., \& Gomez, R. (1995) Weight reduction through inhalation of odorants. J. Neurol. Orthop. Med. Surg. 16: 28-31.

9. Mayer, S.N., Davidson, R.S., \& Hensley, C.B. (1999) The role of specific olfactory stimulation in appetite suppression and weight loss. J. Adv. Med. 12: 13.

10. Murphy, C., Cain, W.S., \& Bathoshuk, L.M. (1977) Mutual action of taste and olfaction. Sens. Processes 1: 204-211.

11. Rozin, P. (1982) Taste-smell confusions and the duality of the olfactory sense. Percept. Psychophys. 31: 397-401.

12. Small, D.M., Gerber, J.C., Mak, Y.E., \& Hummel, T. (2005) Differential neural responses evoked by orthonasal versus retro-nasal odorant perception in humans. Neuron 47: 593-605. 
13. Linforth, R.S.T., Baek, I., \& Taylor, A.J. (1999) Simultaneous instrumental and sensory analysis of volatile release from gelatine and pectin/gelatine gels. Food Chem. 65: 77-83.

14. Cook, D.J., Linforth, R.S.T., \& Taylor, A. (2003) Effects on hydrocolloid thickeners on the perception of savoury flavors. J. Agric. Food Chem. 51: 3067-3072.

15. Lethuaut, L., Weel, K.G., Boelrijk, A.E., \& Brossard, C.D. (2004) Flavour perception and aroma release from model dairy desserts. J. Agric. Food Chem. 52: 3478-3485.

16. van Ruth, S.M., de Witte, L. \& Uriarte, A.R. (2004) Volatile flavour analysis and sensory evaluation of custard desserts varying in type and concentration of carboxymethyl cellulose. J. Agric. Food Chem. 52: 8105-8110.

17. Brown, W.E., Dauchel, C., \& Wakeling, I. (1996) Influence of chewing efficiency on texture and flavour perceptions of food. J. Texture Stud. 27: 433-450.

18. Buettner, A., Beer, A., Hanning, C., \& Settles, M. (2001) Observation of the swallowing process by application of videofluoroscopy and real-time magnetic resonance imaging - consequences for retro-nasal aroma stimulation. Chem. Senses 26: 1211-1219.

19. Buettner, A., Beer, A., Hanning, C., Settles, M., \& Schieberle, P. (2002) Physiological and analytical studies on flavour perception dynamics as induced by eating and swallowing process. Food Qual. Pref. 13: 497-504.

20. Wright, K.M., Sprunt, J., Smith, A.C., \& Hills, B.P. (2003) Modelling flavour release from a chewed bolus in the mouth. Part 1. Mastication. Int. J. Food Sci. Technol. 38: 351-360.

21. Pionnier, E., Chabanet, C., Mioche, L., Le Quere, J.L., \& Salles, C. (2004) 1. In vivo aroma release during eating of a model cheese: relationships with oral parameters. J. Agric. Food Chem. 52: 557-564.

22. Ruijschop, R.M.A.J., Burgering, M.J.M., Jacobs, M.A, \& Boelrijk, A.E.M. (2009) Retro-nasal aroma release depends on both subject and product differences: A link to food intake regulation? Chem. Senses doi:10.1093/chemse/bjp011.

23. Brauss, M.S., Balders, B., Linforth, R.S.T., Avison, S., \& Taylor, A.J. (1999) Fat content, baking time, hydration and temperature affect flavour release from biscuits in model-mouth and real systems. Flavour Fragr. J. 14: 351-357.

24. Weel, K.G.C., Boelrijk, A.E.M., Burger, J.J., Gruppen, H., Voragen, A.G.J., \& Smit, G. (2003) A protocol for measurement of in vivo aroma release from beverages. $J$. Food Sci. 68: 1123-1128.

25. Taylor, A.J., Linforth, R.S.T., Harvey, B.A., \& Blake, A. (2000) Atmospheric pressure chemical ionisation mass spectroscopy for in vivo analysis of volatile flavour release. Food Chem. 71: 327-338. 
Retro-nasal aroma release and satiation

26. Westerterp-Plantenga, M.S., Rolland, V., Wilson, S.A.J., \&Westerterp, K.R. (1999) Satiety related to $24 \mathrm{~h}$ diet-induced thermogenesis during high protein/carbohydrate versus high fat diets, measured in a respiration chamber. Eur. J. Clin. Nutr. 53: 495-502.

27. COST 921 action. Retrieved 08-08-2006, from http://www.cost921.uni-wuppertal. de.

28. Visschers, R.W., Jacobs, M.A., Frasnelli, J., Hummel, T., Burgering, M., \& Boelrijk, A.E.M. (2006) Cross-modality of texture and aroma perception is independent of orthonasal or retro-nasal stimulation. J. Agric. Food Chem. 54: 5509-5515.

29. Weel, K.G.C., Boelrijk, A.E.M., Burger, J.J., Verschueren, M., Gruppen, H., Voragen, A.G., \& Smit, G. (2004) New device to simulate swallowing and in vivo aroma release in the throat from liquid and semi-liquid food systems. J. Agric. Food Chem. 52: 6564-6571.

30. van Loon, W.A., Linssen, J.P., Boelrijk, A.E., Burgering, M.J., \& Voragen, A.G. (2005) Real-time flavour release from French fries using atmospheric pressure chemical ionization-mass spectrometry. J. Agric. Food Chem. 53: 6438-6442.

31. de Kok, P.M.T., Boelrijk, A.E.M., de Jong, C., Burgering, M.J.M., \& Jacobs, M.A. (2006) MS-nose flavour release profile mimic using an olfactometer. In: Bredie, W., \& Petersen, M.A. (Eds.), Developments in Food Science; Flavour Science, Recent Advances and Trends. London: Elsevier 43: 585-599.

32. Harris, J.A., \& Benedict, F.G. (1919) A Biometric Study of Basal Metabolism in Man (Publication no. 279). Washington, DC: Carnegie Institute of Washington.

33. Lawless, H.T., \& Heymann, H. (1998) Sensory Evaluation of Food: Principles and Practices (pp. 121-139). New York: Chapman \& Hall.

34. Meilgaard, M., Civille, G.V., \& Carr, B.T. (1999) Sensory Evaluation Techniques (pp. 61-68). $3^{\text {rd }}$ ed. Boca Raton, FL: CRC Press.

35. Snoek, H.M., Huntjens, L., van Gemert, L.J., de Graaf, C., \& Weenen, H. (2004) Sensory-specific satiety in obese and normal-weight women. Am. J. Clin. Nutr. 80: 823-831.

36. Mattes, R. (1990) Hunger ratings are not a valid proxy measure of reported food intake in humans. Appetite 15: 103-113.

37. de Graaf, C., Blom, W.A.M., Smeets, P.A.M., Stafleu, A., \& Hendriks, H.F.J. (2004) Biomarkers of satiation and satiety. Am. J. Clin. Nutr. 79: 946-961.

38. Harper, A., James, A., Flint, A., \& Astrup, A. (2007) Increased satiety after intake of a chocolate milk drink compared with a carbonated beverage, but no difference in subsequent ad libitum lunch intake. Br. J. Nutr. 97: 579-583.

39. Schilstra, A.J. (1981) Meal-interval correlations: what can they tell us? Physiol. Behav. 27: 299-304. 
40. de Graaf, C., Schreurs, A., \& Blauw, Y.H. (1993) Short-term effects of different amounts of sweet and nonsweet carbohydrates on satiety and energy intake. Physiol. Behav. 54: 833-843.

41. Booth, D.A., Lee, M., \& McAleavey, C. (1976) Acquired sensory control of satiation in man. Br. J. Psychol. 67: 137-147.

42. Gibson, E.L., \& Brunstrom, J.M. (2007) Learned influences on appetite, food choice and intake: evidence in human beings. In: Cooper, S.J., \& Kirkham, T.C. (Eds.), Progress in Brain Research: Appetite and Body Weight - Integrative Systems and the Development of Anti-obesity Drugs (pp. 271-300). London: Elsevier. 


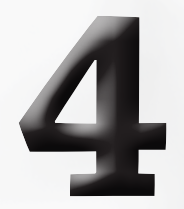

\title{
Effects of ingredient-related aroma cues on satiation and food intake
}

\author{
Ruijschop, R.M.A.J., Boelrijk, A.E.M., \\ Burgering, M.J.M., de Graaf, C., \\ \& Westerterp-Plantenga, M.S.
}

Submitted for publication 


\section{ABSTRACT}

In a within-subject repeated-measures design the effect of ingredient-related aroma cues at sensory detection threshold on short-term appetite profile and energy intake was investigated in 45 young, healthy, and normal-weight men. The men consumed ad libitum four custard products. To each product a different cueing aroma stimulus was added (i.e. lactones, maltol, 'animalic', and water (placebo)). These stimuli were expected to cue unconsciously for the energy content of fat, carbohydrate, and protein, respectively, while water served as placebo. The relatively high and corresponding palatability of all the custard products demonstrated that the subjects were unable to consciously recognise the ingredient-related aroma cues. Before, during, and after the ad libitum consumption, appetite profile measurements were performed. Compared to placebo, subjects felt significantly fuller during consumption of the custard product with addition of maltol aroma and after consumption of the custard product with addition of 'animalic' aroma. However, there was no effect on actual custard product consumption.

In conclusion, addition of specific cueing aroma stimuli to custard at sensory detection threshold led to increased perceived fullness, yet did not affect energy intake.

Key words: Satiation; Aroma cue; Sensory detection threshold; Appetite profile; Energy intake; Palatability; Macronutrients; Conditioned satiation 


\section{INTRODUCTION}

Sensory signals that are not perceived consciously, like quickly flashing single words in advertisements on a television screen or quiet background music in a shop or restaurant, may affect a human's emotional state and/or behaviour. Unconscious processes are important for decision making processes ${ }^{(1-5)}$. For example, in relation to unconscious odour cues, Holland et al. ${ }^{(3)}$ revealed that the mere exposure to the scent of all-purpose cleaner caused subjects to keep their direct environment more clean during an eating task. Awareness checks showed that subjects were unaware of this influence.

To a large extent, satiation and satiety are conditioned (learned) responses. Sensory signals are mostly unconsciously learned to be associated with the metabolic consequences of food products ${ }^{(\text {(e.g. } 6)}$. These associations develop during lifetime by repeated exposure to food. With high energy dense foods sensory cues are suggested to anticipate the energy or macronutrient content ${ }^{(c .6-8)}$. In a recent study we were able to show that a retro-nasally delivered aroma stimulus (strawberry) was capable of inducing perceived satiation ${ }^{(9)}$.

The present study investigates whether specific aroma stimuli, which subjects do not consciously recognise, are able to cue for satiation. We hypothesised that the addition of specific cueing aroma stimuli at sensory detection threshold might unconsciously trigger a person to stop eating. We tested three sensory cueing stimuli, which were conceived to be related to fat content (i.e. lactones), carbohydrate content (i.e. maltol), and to the breakdown of protein content (a non-food odour, i.e. 'animalic').

In order to study these hypotheses, in a double-blind, placebo-controlled, randomised cross-over study the effect of ingredient-related aroma cues at sensory detection threshold on short-term appetite profile and energy intake was investigated in normalweight men through an ad libitum eating experiment. The aim of this study was to determine whether ingredient-related aroma cues at sensory detection threshold may contribute to satiation, because of unconsciously perceiving different levels of congruency in sensory perception, or due to unconsciously perceiving the aroma stimuli cueing for the energy content of specific macronutrients.

\section{SUBJECTS AND METHODS}

The effect of ingredient-related aroma cues at sensory detection threshold on satiation and food intake was investigated in men, every time testing a different custard product (i.e. with addition of lactones, with addition of maltol, with addition of 'animalic', and without addition of cueing aroma stimuli (i.e. placebo product)).

\section{Subjects}

Forty-five healthy male subjects aged 20-40 years living in Ede, The Netherlands, and surroundings were recruited through the local newspapers. The subjects included 
normal-weight subjects, with a body mass index (BMI) of 20 to $25 \mathrm{~kg} \mathrm{~m}^{-2}$.

Subjects' degrees of dietary restraint were determined using the Dutch translation of the Three-Factor Eating Questionnaire (TFEQ) ${ }^{(10)}$. Based on the outcome of the TFEQ subjects were selected with low scores on dietary restraint (i.e. scores $\leq 9$ ). In addition, based on self-report, subjects were not allergic to, nor did they have an aversion to, any of the food ingredients used in the present study. Subject characteristics, including TFEQ, scores are summarised in Table 4.1. Subjects were fully informed about the course of the test day and gave their written, informed consent. To prevent responsebias the participants were given no information about the hypotheses and nature of the predictions of the experiment. They were only aware of the original nature of the study, i.e. the contribution of aroma to satiety. The study was approved by the Medical Ethical Committee (MEC) of Wageningen University.

Table 4.1 Characteristics of the 45 male subjects who participated in this study ${ }^{a}$

\begin{tabular}{lcc}
\hline & Mean & SD \\
\hline Age (years) & 28 & 6 \\
BMI $\left(\mathrm{kg} \mathrm{m}^{-2}\right)$ & 23 & 2 \\
TFEQ $^{\mathrm{b}}$ & & \\
$\quad$ Factor 1 (cognitive restraint) & 4 & 2 \\
$\quad$ Factor 2 (disinhibition) & 3 & 1 \\
$\quad$ Factor 3 (hunger) & 3 & 2 \\
\hline
\end{tabular}

${ }^{a}$ Mean values and standard deviations;

${ }^{\mathrm{b}}$ TFEQ: Three-Factor Eating Questionnaire. The value of factors 1, 2 and 3 is in the range of 0 to 18 ; 0 to 13 , and 0 to 14 , respectively. A higher value indicates more restraint, disinhibition or physiological hunger. All values are below medians that are usual.

Origin and sensory qualitative description of cueing aroma stimuli

Lactones, maltol, and 'animalic', which were the cueing aroma stimuli that were used in the present study, find their origin in specific macronutrients through Maillard and enzymatic reactions ${ }^{(11)}$. Lactones are breakdown products from the macronutrient fat due to auto-oxidation (12). Important lactones are gamma-decalactone, deltadecalactone, and gamma-dodecalactone. Cis- 4-heptenal is an important aldehyde formed in fat oxidation. The sensory quality of lactones can be described as varying from sweet, fruity (peach like) to coconut. The flavour thresholds of lactones in water differ from 88 to $1000 \mu \mathrm{g} / \mathrm{kg}^{(13-14)}$. Maltol was used as a cueing aroma stimulus originating from carbohydrates and is effective in the Maillard reaction (i.e. nonenzymatic browning) ${ }^{(15)}$. Maltol has a warm, sweet, fruity aroma, and in solution it has a jam-like aroma. This component is also reported to have a characteristic caramelbutterscotch aroma and suggestive of fruity-strawberry aroma in dilute solution. The 
flavour threshold of maltol in water varies from 7.1 to $13 \mathrm{mg} / \mathrm{kg}$ (13-14). 'Animalic' was applied as cueing aroma stimulus relating to a non-food aroma. Perceiving 'animalic', although unconsciously, is in a dairy matrix rather unnatural. Therefore, 'animalic' was suggested as positive control in the development of satiation, because of incongruency in sensory perception. Dimethyldisulfide, benzaldehyde, 2,5-dimethylpyrazine, and 3-methylbutanal are important components in 'animalic', which are breakdown products from protein as a result of the Maillard reaction ${ }^{(15)}$. 'Animalic', a named sensory attribute, is associated with living animal including its hair, nauseating, and cattle barn ${ }^{(16)}$. The flavour thresholds of the different components in 'animalic' in water vary from 0.03 to $1500 \mu \mathrm{g} / \mathrm{kg}{ }^{(13-14)}$.

All the aroma components used occur naturally in food and were added in low dosages (200-7500 $\mu \mathrm{g} / \mathrm{kg}$, depending on the type of component), avoiding any safety concerns.

\section{Assessment of ingredient-related associations for aroma stimuli}

We hypothesised that lactones were related to fat content, maltol to carbohydrate content and 'animalic' to the breakdown of protein content. To check for these ingredient-related associations, a 4-Alternative Forced Choice (4-AFC) test was performed in-house, with 48 employees not involved in flavour research. Besides the cueing aroma stimuli, lavender was included as additional aroma to reduce the probability of chance. Subjects evaluated aqueous solutions of lactones $(500 \mu \mathrm{g} / \mathrm{kg})$, maltol (750 mg/kg), 'animalic' (200 $\mu \mathrm{g} / \mathrm{kg}$ ) and lavender (2,6-dimethyl-2-heptanol (Sigma-Aldrich Chemie GmbH, Germany); $20 \mathrm{mg} / \mathrm{kg}$ ) for their level of congruency with ingredient-related pictures representing butter (cueing for fat content), cotton candy (cueing for carbohydrate content), egg white (cueing for breakdown of protein content) and lavender (non-food), respectively. Aroma stimuli were presented orthonasally to the subjects in a randomised order. Subjects had to assign an ingredient-related picture to each of the four different aroma stimuli ("which picture belongs to this smell?") after smelling each aroma stimulus separately. It was not allowed to choose an ingredientrelated picture twice.

\section{Data analysis of 4-AFC test}

The number of correct responses (i.e. a correctly identified association between an aroma stimulus and its ingredient-related picture) was counted per aroma stimulus. Applying a binomial distribution, it was calculated whether the result of the 4-AFC test for each aroma stimulus was due to chance alone (i.e. null hypothesis $\left(\mathrm{H}_{0}\right)=0.25$ ) or whether the subjects actually perceived an association between the aroma stimulus and the corresponding ingredient-related picture (alternative hypothesis $\left(\mathrm{H}_{1}\right)>$ 0.25 ) at a significance level of $\alpha=0.05$. To this end, z-scores were calculated for each 
aroma stimulus according to $z=(k-1 / 2-n \cdot \pi) / \sqrt{ }(n \cdot \pi(1-\pi))$, i.e. $k=$ number of correct responses, $1 / 2=$ continuity correction, $n=$ number of subjects $(48), \pi=$ chance level $(1 / 4) . H_{0}$ was rejected when the one-tailed table value for the calculated $z$-score did not exceed $\alpha=5 \%{ }^{(17-18)}$.

Determination of sensory detection thresholds for cueing aroma stimuli

Initially, an in-house trained sensory panel was used to assess the detection threshold for the three cueing aroma stimuli in custard. Panellists did not have any previous experience with the cueing aroma stimuli in custard. The panel consisted of 12 subjects (11 women and 1 man) varying in age between 32 and 53 years. The panel was originally selected based on the Dutch odour identification test (GITU = Geur Identificatie Test Utrecht) and basic taste test; a texture, ranking, and triangle test; and a personal interview $^{(17,19-20)}$.

Individual Best Estimate Thresholds (BET) were determined for each trained subject for each cueing aroma stimulus. The BET for each subject is the geometric mean of the highest concentration missed and the next higher concentration. In addition, the group BET, i.e. the geometric mean of the individual BETs, was determined for the panel for each cueing aroma stimulus ${ }^{(19)}$.

Table 4.2 Concentration ranges, and group BETs ${ }^{c}$ for cueing aroma stimuli in custard in favour of the assessment of sensory detection thresholds applied in satiation experiments

\begin{tabular}{lccc}
\hline Level of cueing aroma addition & $\begin{array}{c}\text { Lactones } \\
(\mu \mathrm{g} / \mathrm{kg})\end{array}$ & $\begin{array}{c}\text { Maltol } \\
(\mu \mathrm{g} / \mathrm{kg})\end{array}$ & $\begin{array}{c}\text { 'Animalic' } \\
(\mu \mathrm{g} / \mathrm{kg})\end{array}$ \\
\hline 1 (i.e. low) & 100 & 100 & 25 \\
2 & 200 & 500 & 50 \\
3 & 300 & 1000 & 100 \\
4 & 400 & 5000 & 150 \\
5 (i.e. high) & 500 & 7500 & 200 \\
\hline & & 4500 & 150 \\
Concentration used in satiation experiments & 500 & 7500 & 200 \\
\hline
\end{tabular}

cBest Estimate Threshold.

The test was performed by presenting the panel with a single presentation of a range of cueing aroma stimuli concentrations from high to low dilution order. The initial aroma concentrations chosen were estimated based on data available in literature, i.e. always in other food matrices than custard ${ }^{(13-14)}$, and in-house testing by flavour experts. In comparison with the reference sample, i.e. custard with addition of water instead of aroma, the panellists individually determined for each sample the taste quality and 
subsequently the taste intensity on a scale from 0 to 5 (i.e. 0 : no taste difference; ?: taste difference present, but not recognisable; 1 : very weak recognisable taste difference; 2 : weak recognisable taste difference; 3 : distinct recognisable taste difference; 4: strong recognisable taste difference; 5: very strong recognisable taste difference). Table 4.2 summarises the concentration ranges that were evaluated for each stimulus. Panellists were offered $10 \mathrm{~mL}$ of sample in plastic cups. In between the samples they were instructed to rinse their mouths with tap water.

The group BET obtained for the sensory panel for each cueing aroma stimulus represented the aroma concentration between the detection threshold (i.e. the level of a stimulus at which the specific stimulus can be detected by $50 \%$ of the subjects in a population) and recognition threshold (i.e. the level of a stimulus at which the specific stimulus can be recognised and identified) (19) (see marked box Figure 4.1). Since the sensory panel was very experienced in performing this type of sensory testing, the assumption was made that the expert's recognition threshold was approximately comparable to the average consumer's detection threshold. Subsequently, to ascertain that the majority of the subjects that participated in the satiation experiments would be able to detect the cueing aroma stimuli, slightly higher concentrations were tested in-house, with employees not involved in flavour research, both on the ability to discriminate and to evaluate the pleasantness of taste of the test products (i.e. custard with addition of cueing aroma stimuli) vs. the placebo product (i.e. custard with addition of water).

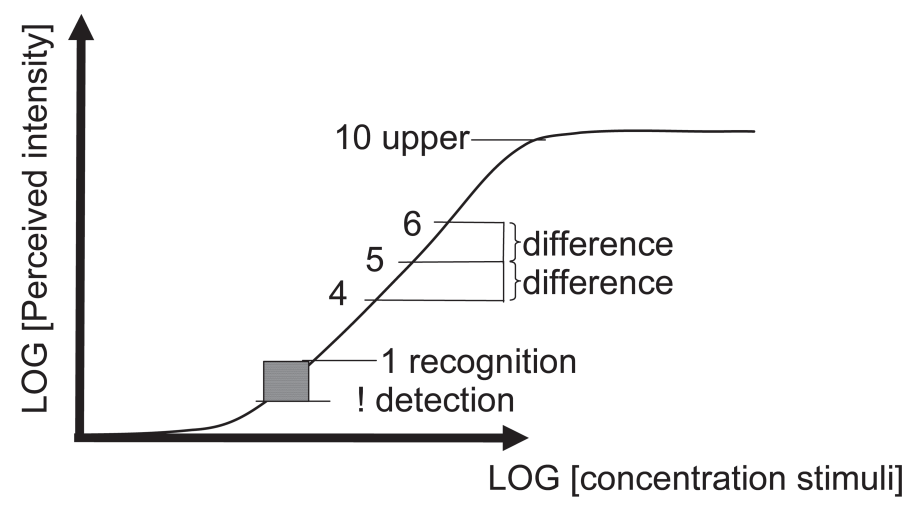

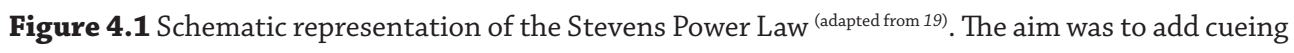
aroma stimuli at the concentration level between detection and recognition (marked box).

Preparation of products for satiation experiments

Custard with addition of lactones

The aqueous lactone solution used was designed in-house, and contained four components: gamma-decalactone $(64 \mathrm{mg} / \mathrm{kg})$, delta-decalactone (313 mg/kg), gammadodecalactone (128 mg/kg), cis-4-heptenal $(0.25 \mathrm{mg} / \mathrm{kg})$, and food-grade propylene glycol $(49.4 \mathrm{mg} / \mathrm{g}$ ) (private label from a local pharmacy in Ede, The Netherlands) 
as solvent. The ratio of lactones and cis- 4-heptenal applied was derived from the occurrence of the lactones in butter. All aroma components were supplied by SigmaAldrich Chemie GmbH, Germany.

In order to prepare the custard with addition of lactones, $1.0 \mathrm{~mL}$ of lactone solution with a concentration of $500 \mathrm{mg} / \mathrm{kg}$ was added to $1 \mathrm{~L}$ pasteurized custard (3.0\% fat) (private label Albert Heijn Zaandam, The Netherlands) following a standardised procedure of continuous stirring. The lactone concentration in the custard was $500 \mu \mathrm{g} / \mathrm{kg}$, including gamma-decalactone $(64 \mu \mathrm{g} / \mathrm{kg})$, delta-decalactone $(313 \mu \mathrm{g} / \mathrm{kg})$, gamma-dodecalactone $(128 \mu \mathrm{g} / \mathrm{kg})$, and cis-4-heptenal $(0.25 \mu \mathrm{g} / \mathrm{kg})$. The custard test products were left 1.5 days at $4^{\circ} \mathrm{C}$ to allow a good equilibration of the aroma in the product. The metabolisable energy of $1 \mathrm{~L}$ of the resulting custard test product was $4.1 \mathrm{MJ}$ (27.1\% of energy as fat, $62.2 \%$ as carbohydrate, and $10.4 \%$ as protein).

\section{Custard with addition of maltol}

For the preparation of the custard with addition of maltol, $1.0 \mathrm{~mL}$ of aqueous maltol solution with a concentration of $7.5 \mathrm{~g} / \mathrm{kg}$ was added to $1 \mathrm{~L}$ pasteurized custard $(3.0 \%$ fat) (private label Albert Heijn Zaandam, The Netherlands) following a standardised procedure of continuous stirring. The maltol concentration in the custard was $7.5 \mathrm{mg} /$ kg. Maltol was supplied by Sigma-Aldrich Chemie GmbH, Germany. The custard test products were left 1.5 days at $4^{\circ} \mathrm{C}$ to allow a good equilibration of the aroma in the product. The metabolisable energy of $1 \mathrm{~L}$ of the resulting custard test product was 4.1 MJ (27.1\% of energy as fat, $62.2 \%$ as carbohydrate, and $10.4 \%$ as protein).

\section{Custard with addition of 'animalic'}

The aqueous 'animalic' solution used was designed in-house ${ }^{(16)}$, and contained four components: dimethyldisulfide (57 mg/kg), benzaldehyde (29 mg/kg), 2,5-dimethylpyrazine $(60 \mathrm{mg} / \mathrm{kg})$, 3-methylbutanal $(56 \mathrm{mg} / \mathrm{kg})$, and food-grade propylene glycol (33.3 mg/g) (private label from a local pharmacy in Ede, The Netherlands) as solvent. All aroma components were supplied by Sigma-Aldrich Chemie $\mathrm{GmbH}$, Germany.

In order to prepare the custard with addition of 'animalic', $1.0 \mathrm{~mL}$ of 'animalic' solution with a concentration of $200 \mathrm{mg} / \mathrm{kg}$ was added to $1 \mathrm{~L}$ pasteurized custard (3.0\% fat) (private label Albert Heijn Zaandam, The Netherlands) following a standardised procedure of continuous stirring. The 'animalic' concentration in the custard was $200 \mu \mathrm{g} / \mathrm{kg}$, including dimethyldisulfide (57 $\mu \mathrm{g} / \mathrm{kg})$, benzaldehyde (29 $\mu \mathrm{g} / \mathrm{kg})$, 2,5-dimethylpyrazine $(60 \mu \mathrm{g} / \mathrm{kg})$, and 3-methylbutanal $(56 \mu \mathrm{g} / \mathrm{kg})$. The custard test products were left 1.5 days at $4^{\circ} \mathrm{C}$ to allow a good equilibration of the aroma in the product. The metabolisable energy of $1 \mathrm{~L}$ of the resulting custard test product was 4.1 MJ (27.1\% of energy as fat, $62.2 \%$ as carbohydrate, and $10.4 \%$ as protein). 
Custard without addition of cueing aroma stimuli

To check for differences in viscosity, $1.0 \mathrm{~mL}$ of tap water was added to $1 \mathrm{~L}$ pasteurized custard (3.0\% fat) (private label Albert Heijn Zaandam, The Netherlands) following a standardised procedure of continuous stirring. Ensuing from the preparation of the custard test products, the custard placebo products were also left 1.5 days at $4^{\circ} \mathrm{C}$. The metabolisable energy of $1 \mathrm{~L}$ of the resulting custard test product was $4.1 \mathrm{MJ}(27.1 \%$ of energy as fat, $62.2 \%$ as carbohydrate, and $10.4 \%$ as protein).

\section{Experimental design}

Sensory data were obtained to assess whether subjects actually perceived an association between the cueing aroma stimuli and specific macronutrients. Therefore, a 4-AFC test was performed in-house with employees not involved in flavour research. Based on these results, it could be checked whether the suggested ingredient-related associations for lactones, maltol and 'animalic', i.e. fat content, carbohydrate content and the breakdown of protein content, respectively were valid.

Sensory detection thresholds were assessed separately for the cueing aroma stimuli in custard using an in-house trained sensory panel at first. This part of the experimental design was determinative for a successful intervention. It had to be ascertained that the majority of the subjects that would participate in the satiation experiments would be able to detect the cueing aroma stimuli, however, not to recognise them. If this would be the case, it would not have been possible to test the rationale behind the present study, i.e. unconscious perception of specific aroma stimuli are able to cue for satiation.

For the satiation experiments, each subject visited the test location four times in the morning, every time testing a different custard product (i.e. with addition of lactones, with addition of maltol, with addition of 'animalic', and without addition of cueing aroma stimuli (i.e. placebo product)). Treatment order was counterbalanced across both test days and subjects. Between each visit there was a time-interval of 1 week. Before starting the experiment, daily dietary energy requirements were calculated individually by multiplying the basal metabolic rate (BMR) by an activity index of 1.60. The BMR was calculated according to the equation of Harris and Benedict (21). Subjects were asked to consume $10 \%$ of the daily dietary energy requirements for breakfast at home, which varied per person from 1045 to $1463 \mathrm{~kJ}$ (from 250 to 350 $\mathrm{kcal})$. In addition, the subjects were requested to consume the same type and amount of breakfast when visiting the laboratory the next times. Based on this individually standardised breakfast, subjects visited the laboratory every time with comparable feelings of hunger and satiety. This was confirmed by a baseline measurement before the start of the ad libitum consumption of the custard products.

In a double-blind placebo-controlled randomised cross-over full-factorial design 
subjects were served four different custard products from which they could eat ad libitum. Before, during and after the ad libitum consumption of custard product, appetite profile measurements were performed. The design of a test day is represented schematically in Figure 4.2.

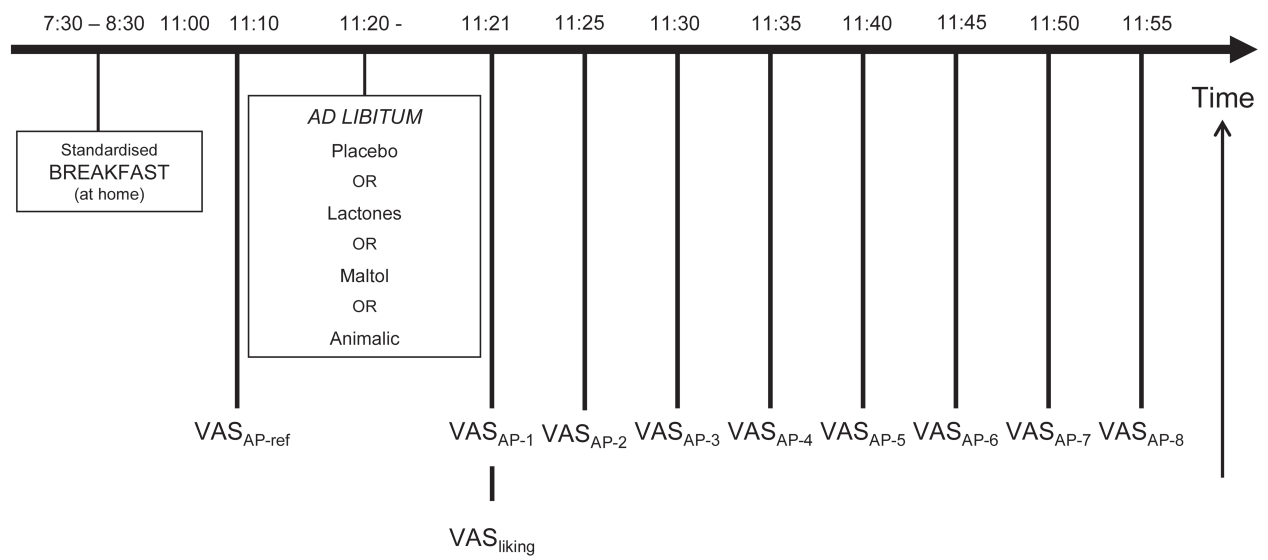

Figure 4.2 Overview of the test day protocol. Subjects came four times to the laboratory, a week apart, and received either the custard placebo product (without addition of cueing aroma stimuli) or the custard test products (with addition of lactones; with addition of maltol; and with addition of 'animalic') in a fully randomised order. Appetite profiles were recorded on a 100-mm visual analogue scale (VAS) at regular time-points $\left(\mathrm{VAS}_{\text {AP-ref }}\right.$ to $\left.\mathrm{VAS}_{\mathrm{AP}-8}\right)$. Hedonic ratings were recorded for the ad libitum consumed custard product on a 100-mm VAS $\left(\mathrm{VAS}_{\text {liking }}\right.$ ). In addition, the amount of custard product consumed ad libitum was measured.

\section{Measurements}

\section{Short-term appetite profile}

The appetite profile, i.e. ratings of hunger, fullness, satiation, desire to eat, and thirst were recorded on a 100-mm visual analogue scale (VAS) (anchored for each with "not at all" and "very much") at regular time-points before, during, and after the ad libitum consumption of the custard products (see VAS ${ }_{\mathrm{AP}}$ Figure 4.2). In addition, at the same time-points desire to eat sweet products and desire to eat savoury products were recorded on 100-mm VAS anchored with "not at all" and "very much". All rating scales were provided on separate sheets that were collected after each rating.

\section{Actual custard product consumption}

To measure the effect of the type of cueing aroma stimulus on actual custard product consumption, subjects were offered $2 \mathrm{~L}$ of custard product, served in an opaque bowl with a tablespoon at $7 \pm 1^{\circ} \mathrm{C}$, from which they could eat ad libitum. The amount offered 
was such that there were always leftovers. After consumption the amount of custard product consumed was measured for each subject (Mettler-Toledo balance, Greifensee, Switzerland).

\section{Pleasantness of flavour rating}

Immediately after the start of the ad libitum custard product consumption, pleasantness of taste of the ad libitum consumed custard product was measured. Subjects were asked to scale their hedonic rating (100-mm VAS anchored with "not pleasant at all" and "very pleasant") (see $\mathrm{VAS}_{\text {liking }}$ Figure 4.2).

Data analysis of short-term appetite profile, actual custard product consumption, and pleasantness of flavour

VAS ratings were measured in millimeters from the left ("not at all") end of the scale. Since there were no significant differences in VAS rating at baseline measurement, delta VAS ratings, i.e. changes in VAS ratings, were calculated by subtracting the ratings at

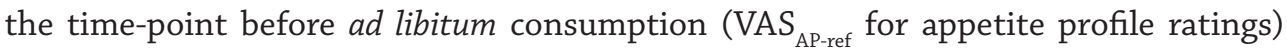
from the ratings at the different time-points during and after ad libitum consumption (VAS $_{\mathrm{AP}-1}$ to $\mathrm{VAS}_{\mathrm{AP}-8}$ for appetite profile ratings). Area under the curve (AUC) delta VAS ratings were determined using the trapezoidal method. As a composite measure for the appetite profile, desire to eat and fullness scores were used, while hunger and satiation were scored similarly. All data are presented as means with their standard errors of the mean (SEM). Actual custard product consumption and the different AUC delta VAS ratings were compared between the four different custard products by using the General Linear Model (GLM) procedure for repeated measures, with participant and type of custard product as independent variables. Least Squares Means were used for post-hoc comparisons. With the use of a mixed-model analysis of variance (ANOVA) for repeated measures, differences in delta VAS appetite profile ratings were investigated per time-point. Least Squares Means were used for post-hoc comparisons.

Simple regression analyses $(\mathrm{f}(\mathrm{x})$ ) were performed for actual custard product consumption and short-term appetite profile (y) and palatability of the custard products ( $\mathrm{x}$ ). Additionally, to investigate whether there were differences in simple regression analysis between the specific cueing aroma stimuli, ratings for placebo were subtracted from the ratings for the different cueing aroma stimuli for actual custard product consumption and short-term appetite profile (y) and palatability of the custard products (x). For all data analyses the statistical packages SAS (release 9.1, SAS Institute Inc., Cary, NC, USA) were used. P-values $<0.05$ were considered statistically significant. 


\section{RESULTS}

Ingredient-related associations for aroma stimuli

From the 48 4-AFC tests that were carries out, 30 correct responses were counted for lactones $(P(z \geq 5.83)<<0.13 \%$ (i.e. $z$-score $=3.0)$, 43 correct responses were counted for maltol ( $\mathrm{P}(\mathrm{z} \geq 10.17)<<0.13 \%), 32$ correct responses were counted for 'animalic' $(\mathrm{P}(\mathrm{z} \geq 6.5)<<0.13 \%)$ and 42 correct responses were counted for lavender ( $\mathrm{P}(\mathrm{z} \geq$ $9.83)<0.13 \%)$. For each of the four different aroma stimuli the one-tailed table value for the calculated $z$-score did not exceed $\alpha=5 \%$. This provided enough evidence to reject the null hypothesis for each of the four different aroma stimuli. The 4-AFC tests demonstrated that subjects actually perceived an association between the aroma stimuli and the corresponding ingredient-related pictures.

\section{Concentrations of cueing aroma stimuli used in satiation experiments}

From the 12 individual Best Estimate Thresholds (BET) for each cueing aroma stimulus in custard, the sensory panel group BET was determined. Table 4.2 shows these threshold values. All values are in the $\mu \mathrm{g} / \mathrm{kg}$ range. Slightly higher concentrations of the cueing aroma stimuli in custard (see Table 4.2: concentration used in satiation experiments), tested in-house, were perceived as slightly different compared to the custard without addition of cueing aroma stimuli. However, employees were not able to describe the difference they perceived; neither did they observe any difference in palatability of the custard products.

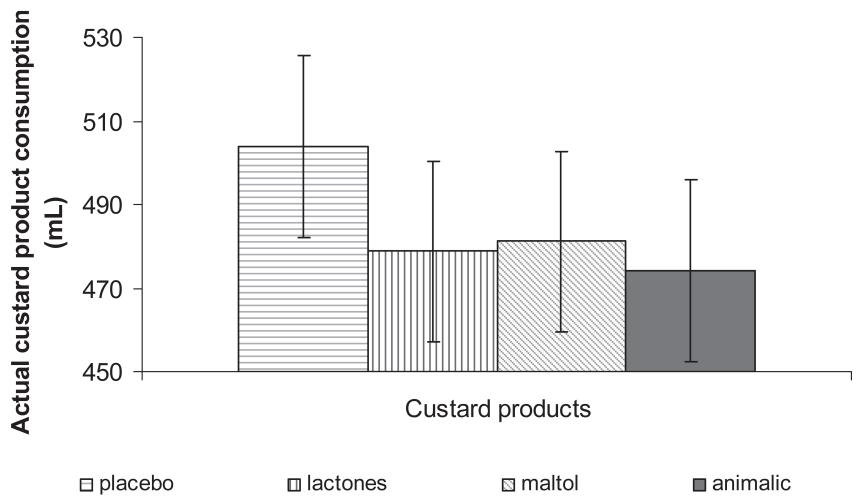

Figure 4.3 The amount of custard product consumed ad libitum for the four custard products (placebo and custard test products with addition of cueing aroma stimuli; i.e. lactones, maltol, and 'animalic') by the 45 subjects. Values are means with their standard errors depicted by vertical bars. There was no significant difference in actual custard product consumption between the four custard products $\left(\mathrm{F}_{(3,44)}=0.37 ; \mathrm{P}=0.77\right)$. 
Actual custard product consumption

The amount of custard product consumed ad libitum did not differ significantly between the four custard products (respectively, $504 \pm 22 \mathrm{~mL}$ (range $31.0-1425.0 \mathrm{~mL}$ ) for custard placebo product; $479 \pm 22 \mathrm{~mL}$ (range $36.2-1585.0 \mathrm{~mL}$ ) for custard product with addition of lactones; $481 \pm 22 \mathrm{~mL}$ (range $0.9-1809.1 \mathrm{~mL}$ ) for custard product with addition of maltol; and $474 \pm 22 \mathrm{~mL}$ (range $1.4-1879.0 \mathrm{~mL}$ ) for custard product with addition of 'animalic' $\left(\mathrm{F}_{(3,44)}=0.37 ; \mathrm{P}=0.77\right.$ ) (Figure 4.3).

\section{Short-term appetite profile}

Before, during, and after the ad libitum custard product consumption, appetite profile measurements were performed. At baseline hunger, fullness, satiation, desire to eat, and thirst VAS ratings $\left(V_{\text {VAS }}\right.$ ) were $58.0 \pm 3.2 \mathrm{~mm}, 35.6 \pm 3.5 \mathrm{~mm}, 33.2 \pm 3.5 \mathrm{~mm}$, $59.4 \pm 3.4 \mathrm{~mm}$, and $44.4 \pm 4.1 \mathrm{~mm}$ for custard placebo product; $58.7 \pm 3.2 \mathrm{~mm}, 35.8$ $\pm 3.5 \mathrm{~mm}, 35.4 \pm 3.5 \mathrm{~mm}, 58.5 \pm 3.4 \mathrm{~mm}$, and $48.0 \pm 4.1 \mathrm{~mm}$ for custard product with addition of lactones; $53.3 \pm 3.2 \mathrm{~mm}, 29.3 \pm 3.5 \mathrm{~mm}, 34.6 \pm 3.5 \mathrm{~mm}, 56.9 \pm 3.4 \mathrm{~mm}$, and $51.2 \pm 4.1 \mathrm{~mm}$ for custard product with addition of maltol; and $56.8 \pm 3.2 \mathrm{~mm}$, $30.9 \pm 3.5 \mathrm{~mm}, 33.3 \pm 3.5 \mathrm{~mm}, 62.9 \pm 3.4 \mathrm{~mm}$, and $45.2 \pm 4.1 \mathrm{~mm}$ for custard product with addition of 'animalic', respectively. Since there was no significant difference in the amount of custard product consumed ad libitum, no additional adjustments were made for the effect of amount consumed on recorded appetite profile ratings. Figures 4.4 and 4.5 show the results of the different types of cueing aroma stimuli on the (AUC) change in VAS ratings of fullness, and desire to eat, respectively. Compared to placebo, a significant difference was demonstrated in perceived fullness during consumption of the custard product with addition of maltol (Figure 4.4; AUC delta fullness VAS rating during consumption $=86.4 \pm 7.7 \mathrm{~mm}\left(\mathrm{~F}_{(3,179)}=2.25 ; \mathrm{P}=0.02\right)$ and after consumption of the custard product with addition of 'animalic' (Figure 4.4; AUC delta fullness VAS rating after consumption $=171.7 \pm 13.9 \mathrm{~mm}\left(\mathrm{~F}_{(3,179)}=3.16 ; \mathrm{P}=0.05\right)$. During consumption of the custard product with addition of maltol and after consumption of the custard product with addition of 'animalic', subjects felt fuller than during or after consumption of the custard placebo product, respectively (Figure 4.4; AUC delta fullness VAS rating during consumption $=60.1 \pm 7.7 \mathrm{~mm}$ and AUC delta fullness VAS rating after consumption $=132.3 \pm 13.9 \mathrm{~mm}$, respectively). In addition, compared to the custard product with addition of lactones (Figure 4.4; AUC delta fullness VAS rating after consumption $=132.3 \pm 13.9 \mathrm{~mm}$ ), subjects felt significantly fuller after consumption of the custard product with addition of 'animalic' (Figure 4.4; AUC delta fullness VAS rating after consumption $=171.7 \pm 13.9 \mathrm{~mm}\left(\mathrm{~F}_{(3,179)}=3.16 ; \mathrm{P}=0.01\right)$ as well as after consumption of the custard product with addition of maltol (Figure 4.4; AUC delta fullness VAS rating after consumption $=162.8 \pm 13.9 \mathrm{~mm}\left(\mathrm{~F}_{(3,179)}=2.25 ; \mathrm{P}\right.$ $=0.03)$. 
Furthermore, a significant difference in perceived desire to eat was shown after consumption of the custard product with addition of 'animalic' (Figure 4.5; AUC delta desire to eat VAS rating after consumption $=-159.8 \pm 11.0 \mathrm{~mm}$ ) compared to the custard product with addition of lactones (Figure 4.5; AUC delta desire to eat VAS rating after consumption $=-114.2 \pm 11.0 \mathrm{~mm}$ ) as well as the custard product with addition of maltol (Figure 4.5; AUC delta desire to eat VAS rating after consumption $=-116.0 \pm 11.0 \mathrm{~mm}$ ). After consumption of the custard product with addition of 'animalic', subjects had less desire to eat than after consumption of the custard placebo product with addition of lactones $\left(\mathrm{F}_{(3,179)}=3.67 ; \mathrm{P}=0.01\right)$ or the custard product with addition of maltol $\left(\mathrm{F}_{(3,179)}\right.$ = 3.67; $\mathrm{P}=0.01$ ).

In addition, ad libitum consumption affected desire to eat sweet and savoury products ratings. There was a decrease in desire to eat sweet products during the ad libitum consumption of the (sweet) custard products, irrespective of the type of custard product consumed ad libitum (Figure 4.6; AUC delta desire to eat sweet products VAS rating during consumption $=-34.9 \pm 6.1 \mathrm{~mm}$ and AUC delta desire to eat sweet products VAS rating after consumption $=-95.4 \pm 12.4 \mathrm{~mm}$ ). Overall, during and after ad libitum consumption of the (sweet) custard products, the desire to eat sweet products decreased significantly $\left(\mathrm{F}_{(3,660)}=3.95 ; \mathrm{P}=0.0083\right.$ and $\mathrm{F}_{(3,836)}=4.13 ; \mathrm{P}=0.0064$, respectively $)$. As expected, no significant change in desire to eat savoury products during and after the ad libitum consumption of the (sweet) custard products was observed (Figure 4.6; AUC delta desire to eat savoury products VAS rating during consumption $=-18.6 \pm 6.5 \mathrm{~mm}$ and AUC delta desire to eat savoury products VAS rating after consumption $=-43.7 \pm$ $12.6 \mathrm{~mm})\left(\mathrm{F}_{(3,660)}=1.94 ; \mathrm{P}=0.12\right.$ and $\mathrm{F}_{(3,836)}=1.62 ; \mathrm{P}=0.18$, respectively $)$.

Furthermore, it was shown that appetite-regulating effects were involved in both intraand inter-meal satiety (Figures 4.4 -4.6). For example, perceived fullness was elevated during ad libitum consumption up to 20 minutes after ad libitum consumption.

\section{Palatability of the custard products}

Subjects evaluated the pleasantness of taste for all four custard products, measured at the start of ad libitum consumption, on average $61.9 \pm 1.7 \mathrm{~mm}$ (Figure 4.7). No significant differences in palatability were observed between the custard products $\left(\mathrm{F}_{(3,43)}=0.55 ; \mathrm{P}=0.65\right)$. In general, it appeared that the amount eaten was a function of palatability of taste of the custard products $\left(y=7.5 x+20.4 ; R^{2}=0.14 ; P<0.001\right.$, in which $y$ and $x$ denote amount of custard product consumed ad libitum and pleasantness of taste of the custard products, respectively). After subtracting the ratings for placebo from the ratings for the different cueing aroma stimuli, simple regression analysis showed no effect of palatability of the different custard test products (x), measured immediately after the start of actual consumption, on the amount consumed ad libitum (y) or on the appetite profile ratings (y). This result was equal for all cueing aroma 

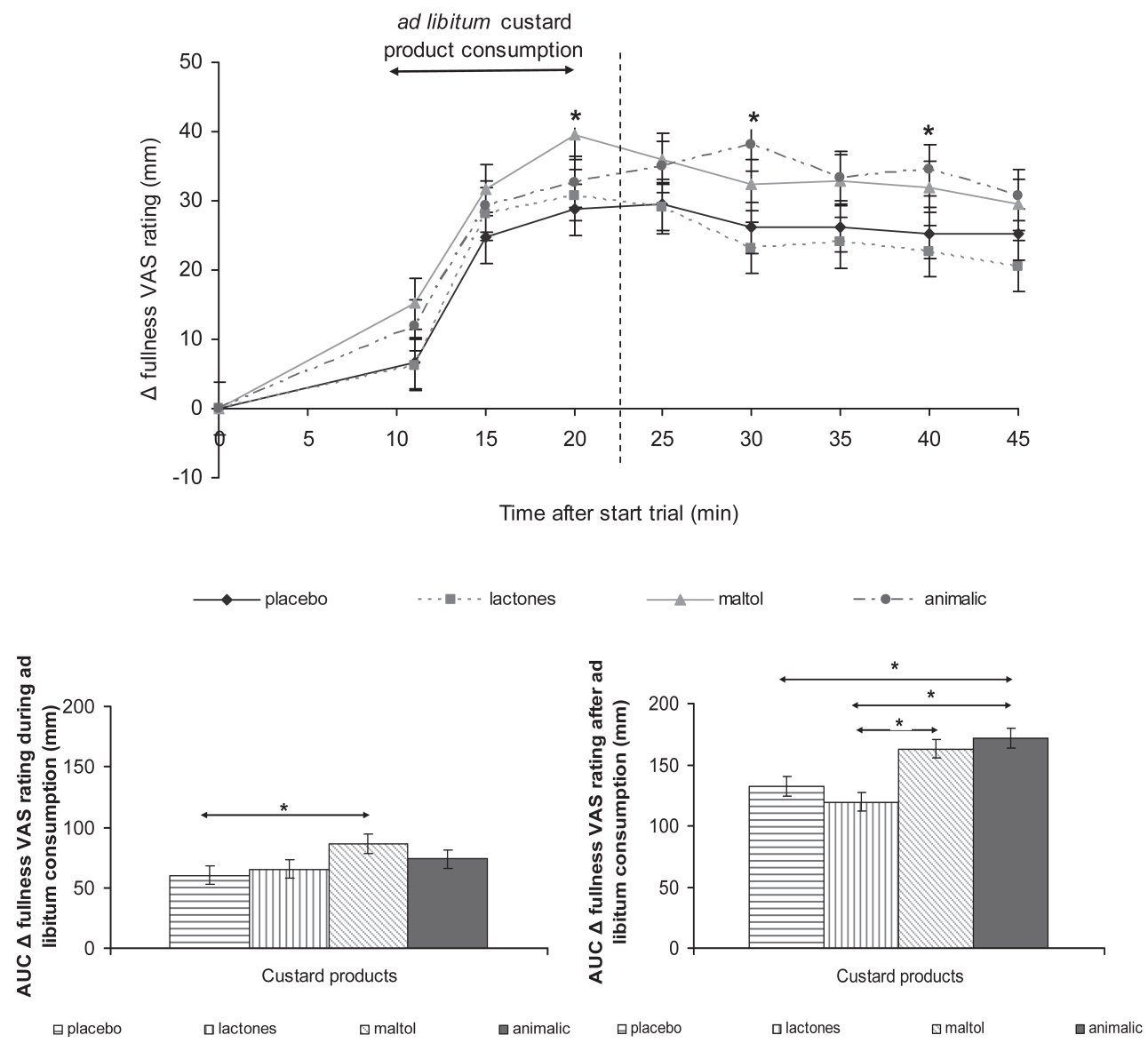

Figure 4.4 Upper graph: Change $(\Delta)$ in fullness VAS rating during and after consumption of the four custard products (placebo; with addition of lactones; with addition of maltol; and with addition of 'animalic'). Lower graphs: Area under curve (AUC) $\Delta$ fullness VAS rating during (left) and after (right) consumption of the four custard products. Values are means with their standard errors depicted by vertical bars. * denotes effect of type of custard product on (AUC) change in fullness VAS rating at the designated time point with $\mathrm{p} \leq 0.05$.

stimuli. Compared to placebo, palatability of the cueing aroma stimuli did not affect the amount consumed ad libitum or the appetite profile ratings.

\section{DISCUSSION}

No significant difference was observed in the actual custard product consumption, despite addition of cueing aroma stimuli (Figure 4.3). The absence of significant differences in the amount of custard product consumed ad libitum could not be explained by the palatability of the custard products, since subjects evaluated the taste of the custard products as acceptable pleasant and not different from the placebo (Figure 4.7). 

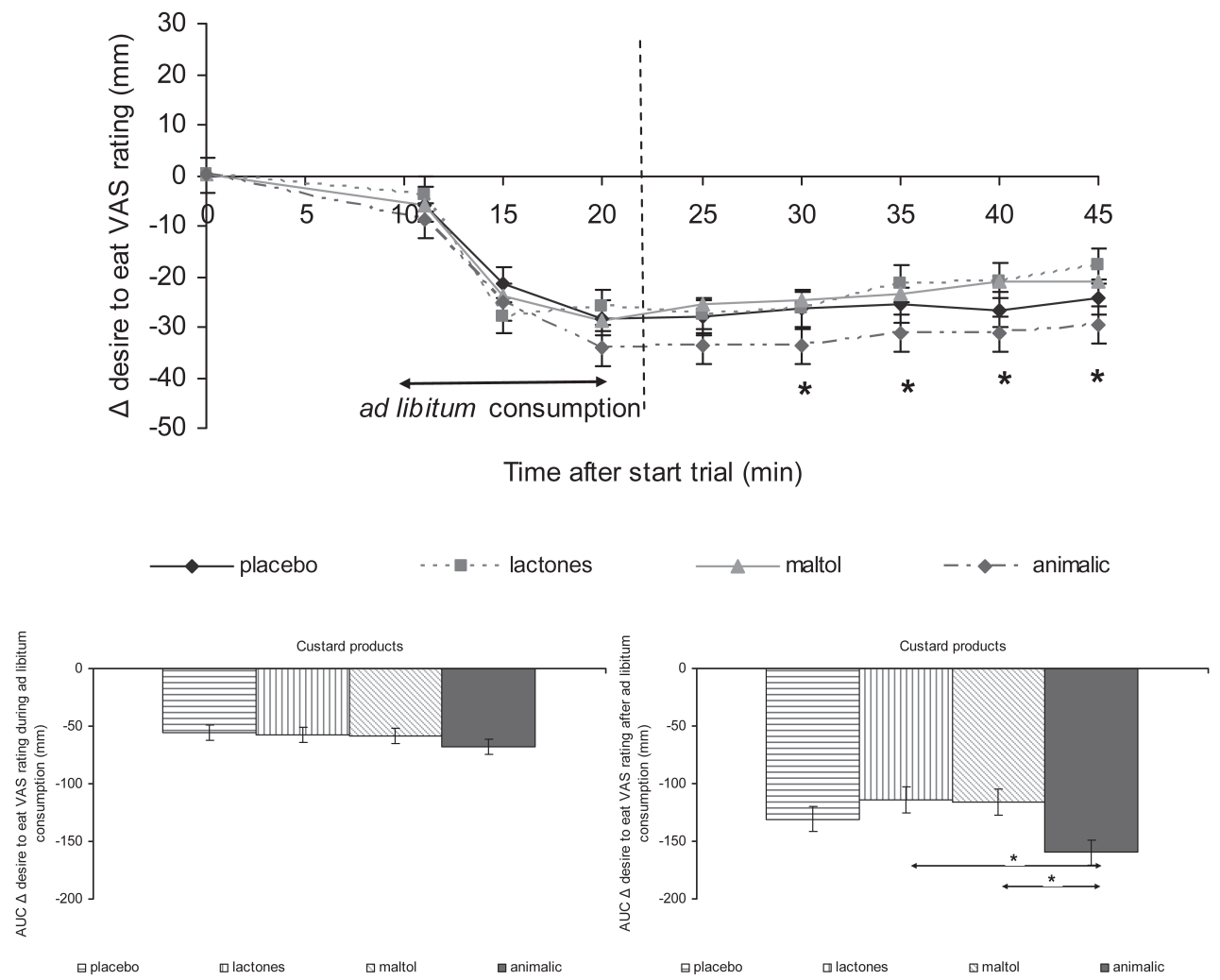

Figure 4.5 Upper graph: Change $(\Delta)$ in desire to eat VAS rating during and after consumption of the four custard products (placebo; with addition of lactones; with addition of maltol; and with addition of 'animalic'). Lower graphs: Area under curve (AUC) $\Delta$ desire to eat VAS rating during (left) and after (right) consumption of the four custard products. Values are means with their standard errors depicted by vertical bars. * denotes effect of type of custard product on (AUC) change in desire to eat VAS rating at the designated time point with $\mathrm{p} \leq 0.05$.

Generally, amount eaten was a function of palatability of taste of the custard products. Amount eaten being positively related to palatability has been shown in various studies (22). The question remains whether this is caused by unpalatability related to a small amount of intake or high palatability related to a larger intake. However compared to placebo, no differences were observed in palatability between the cueing aroma stimuli (lactones, maltol, and 'animalic') that might have affected the amount eaten. The higher the pleasantness of taste a subject scored, the higher ad libitum intake was of this subject, irrespective of the type of cueing aroma stimulus.

Apparently, the concentrations used for the cueing aroma stimuli (i.e. sensory detection thresholds) in custard may not be intense enough to create a significant difference in actual custard consumption. Nevertheless, it was the intention of the experiment 


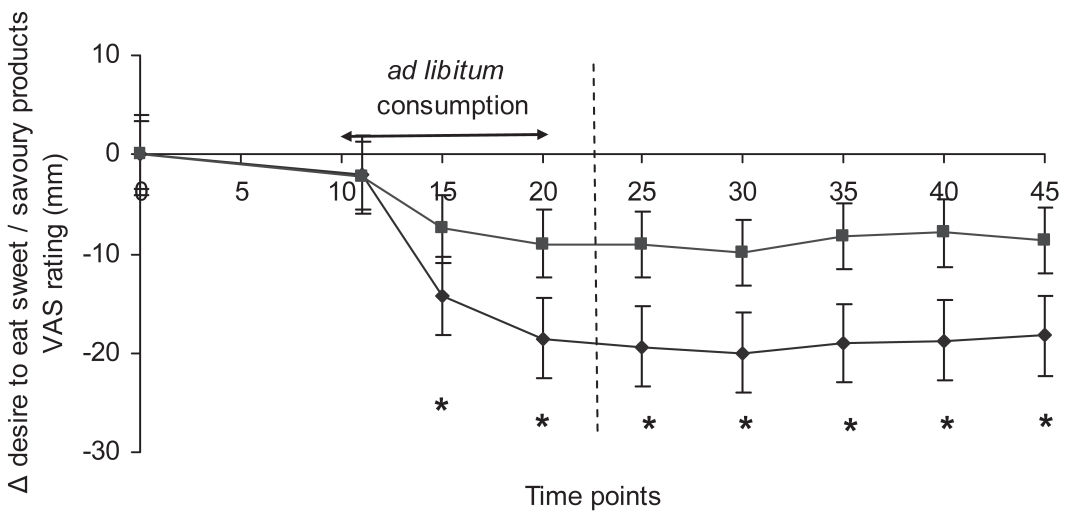

$\longrightarrow$ delta desire to eat sweet products $\rightarrow-$ delta desire to eat savoury products
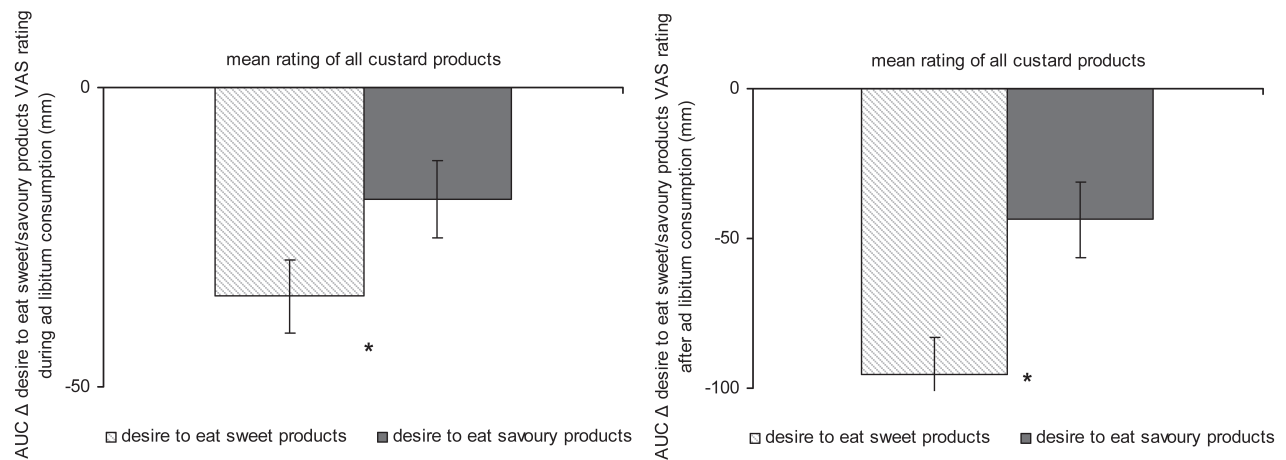

Figure 4.6 Upper graph: Change $(\Delta)$ in desire to eat sweet or savoury VAS rating during and after consumption of the four custard products (placebo; with addition of lactones; with addition of maltol; and with addition of 'animalic'). Lower graphs: Area under curve (AUC) $\Delta$ desire to eat sweet or savoury VAS rating during (left) and after (right) consumption of the four custard products. Values are means with their standard errors depicted by vertical bars. * denotes effect of type of custard product on (AUC) change in desire to eat sweet or savoury VAS rating at the designated time point with $\mathrm{p} \leq 0.05$.

to have sensory detection threshold intensities; thus increasing the intensity of the cueing aroma stimuli used would affect palatability, consequently leading to subjects who might stop eating due to aversion instead of satiation. Alternatively, the cueing aroma stimuli used, may not be effective in decreasing actual food consumption, implying that the hypothesis that the applied ingredient-related aroma cues may affect food intake, is not valid.

It was demonstrated that compared to placebo and custard product with addition of lactones, custard products with addition of maltol or 'animalic' at sensory detection threshold were able to increase subjects' feeling of fullness significantly (Figure 4.4). 


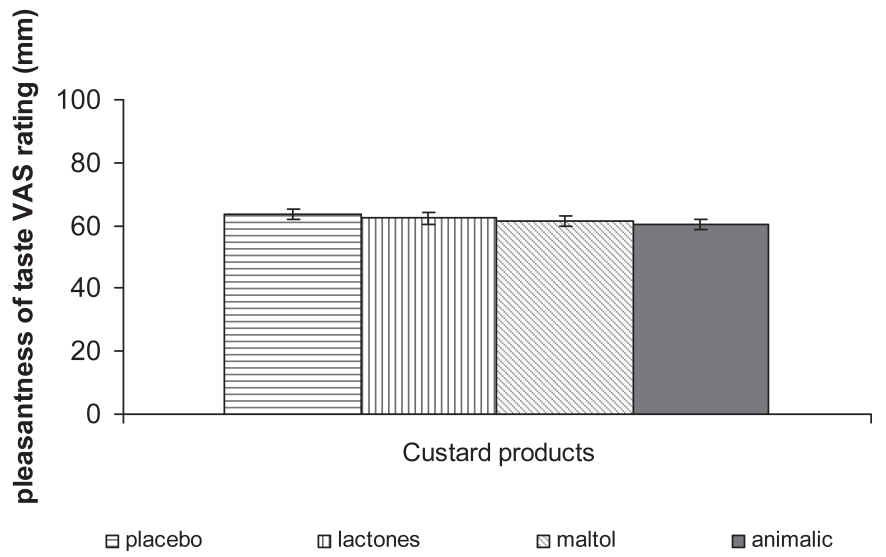

Figure 4.7 Pleasantness of taste VAS rating for the four custard products (placebo and custard test products with addition of cueing aroma stimuli; i.e. lactones, maltol, and 'animalic'). Values are means with their standard errors depicted by vertical bars. There was no significant difference in type of custard product on pleasantness of taste VAS rating $\left(\mathrm{F}_{(3,43)}=0.55 ; \mathrm{P}=0.65\right)$.

Besides increasing perceived fullness, custard products with addition of 'animalic' were also able to decrease the subjects' desire to eat significantly compared to the custard product with addition of maltol or lactones (Figure 4.5). Taking into account the effect of amount consumed ad libitum on appetite profile ratings, similar trends were observed. The lack of significance in appetite profile ratings per liter consumed ad libitum may be explained by effects in either the numerator or the denominator, i.e. related to a rapid translation to fullness (low fraction) or a small amount of intake (high fraction), respectively.

The results obtained regarding the short-term appetite profile were expected, since it was hypothesised that 'animalic', used as aroma stimulus relating to a non-food aroma, would be cueing for incongruence between the actual flavour and the flavour expectation attributable to the consumed food product, consequently unconsciously triggering satiation (i.e. perceived fullness). Besides possible incongruence in flavour perception, alternatively, the response to the cueing aroma stimuli may be a learned response, i.e. conditioned satiation (i.e. perceived fullness) possibly due to flavournutrient learning (FNL; ${ }^{c f}{ }^{6-8}$ ). According to our hypothesis, subjects may associate the aroma stimuli 'animalic' and maltol cueing for the energy content (i.e. postingestive consequences) of protein and carbohydrate, respectively. This assumption was confirmed by the results of the 4-AFC tests. Subjects were able to associate the cueing aroma stimuli with the corresponding ingredient-related pictures, representing specific macronutrients. The present result regarding the short-term appetite profile is in line with observations that macronutrients have different satiating efficiencies, in which protein is more satiating, followed by carbohydrate, and fat as least satiating (2326). Nevertheless, 'animalic' is a proposed example of a possible aroma stimulus cueing 
for the energy content of protein. It is doubtful whether this aroma stimulus is the ultimate aroma stimulus cueing for protein. It is possible that other aroma stimuli (relating to food instead of non-food) cueing for the energy content of protein would provide even more powerful results.

Moreover, during the ad libitum consumption of the custard products a significant decrease in desire to eat sweet products was observed, irrespective of the type of custard (Figure 4.6). This is due to sensory-related satiation ${ }^{(27)}$. Our subjects were sensorily satiated with respect to the sweet taste of foods in general after consumption of all (sweet) custard products. In line with expectations, no significant change in desire to eat savoury products during the ad libitum consumption of the (sweet) custard products was observed (Figure 4.7).

To summarise, the present study demonstrates that ingredient-related aroma cues at sensory detection threshold are able to contribute to perceived fullness. From this study, it can, however, not be concluded whether this is due to incongruence between the actual flavour and the flavour expectation attributable to the consumed food product or to perceiving the aroma stimuli cueing for the energy content of specific macronutrients.

The concept that exposure to specific cueing aroma stimuli at sensory detection threshold is able to affect perceived fullness may be valuable for the development of foods that contain triggers that are able to induce or increase the feeling of fullness. While active ingredients may induce satiety at later stages in the food intake cycle, sensory triggers operating at early stages have a consumer benefit that is immediately noticeable, thus leading more quickly to an increased feeling of fullness. Although there was no effect on actual food consumption, increased feelings of fullness may still be useful to affect consumer's motivational state. When a product is perceived as inducing a feeling of fullness, the consumer feels good just by consumption of the product. Specific food product application might even strengthen the impact of the concept by researching other aroma cues or different products (e.g. savoury (soup) vs. creamy, sweet (custard) food matrices).

\section{ACKNOWLEDGEMENTS}

We acknowledge Annereinou Dijkstra, Wim van Ginkel, Ineke Klok, Egbert Metz, Jan van Riel, Margreet Rippen, Saskia van Schalkwijk, Suzanne van Steenis, Marja Twigt, Nico Willigenburg for their skilful assistance with the measurements. We also thank Meike te Giffel for critical reading of the manuscript.

This work was done within DiOGenes. DiOGenes is the acronym of the project "Diet, Obesity and Genes" supported by the European Community (Contract no. FOODCT-2005-513946). The Parties of the project are listed on the web-site of the project: http://www.diogenes-eu.org/. 
Special acknowledgement is made to the Dutch Dairy Association for co-financing this project.

\section{REFERENCES}

1. Packard, V. (1957) The Hidden Persuaders. New York: David McKay Co., Inc.

2. Wilson, T.D. (2002) Strangers to ourselves: discovering the adaptive unconscious. Cambridge Massachusetts: The Belknap Press of Harvard University Press.

3. Holland, R.W., Hendriks, M., \& Aarts, H. (2005) Smells like clean spirit. Nonconscious effects of scent on cognition and behavior. Psychol. Sci., 16: 689-693.

4. Dijksterhuis, A., Bos, M.W., Nordgren, L.F., \& van Baaren, R.B. (2006) On making the right choice: The deliberation-without-attention effect. Science 311: 10051007.

5. Wen Li, Howard, J.D., Parrish, T.B., \& Gottfried, J.A. (2008) Aversive learning enhances perceptual and cortical discrimination of indiscriminable odor cues. Science 319: 1842-1845.

6. Gibson, E.L., \& Brunstrom, J.M. (2007) Learned influences on appetite, food choice and intake: evidence in human beings. In: Cooper, S.J., \& Kirkham, T.C. (Eds.), Progress in Brain Research: Appetite and Body Weight - Integrative Systems and the Development of Anti-obesity Drugs (pp. 271-300). London: Elsevier.

7. Booth, D.A., Lee, M., \& McAleavey, C. (1976) Acquired sensory control of satiation in man. Br. J. Psychol. 67: 137-147.

8. Mobini, S., Chambers, L.C., \& Yeomans, M.R. (2007) Effects of hunger state on flavour pleasantness conditioning at home: flavour-nutrient learning vs. flavourflavour learning. Appetite, 48: 20-28.

9. Ruijschop, R.M.A.J., Boelrijk, A.E.M., de Ru, J.A., de Graaf, C., \& WesterterpPlantenga, M.S. (2008) Effects of retro-nasal aroma release on satiation. Br. J. Nutr. 99: 1140-1148.

10. Westerterp-Plantenga, M.S., Rolland, V., Wilson, S.A.J., \& Westerterp, K.R. (1999) Satiety related to $24 \mathrm{~h}$ diet-induced thermogenesis during high protein/ carbohydrate versus high fat diets, measured in a respiration chamber. Eur. J. Clin. Nutr. 53: 495-502.

11. Hamilton, R.J. (2001) Rancidity of animal fats and a comparison with that of vegetable oils. In: Rossell, J.B. (Ed.), Oils and Fats, Animal carcass fats (pp. 123-146). Leatherhead: Leatherhead Food Research Association.

12. Hamilton, R.J. (2003) Oxidative rancidity as a source of off-flavours. In: Baigrie, B. (Ed.), Taints and off-flavours in food (pp. 140-149). Cambridge: Woodhead Publishing Ltd \& CRC Press LLC.

13. Flavor Database by Leffingwell \& Associates. (2004) Retrieved 10-01-2007, from http://www.leffingwell.com. 
14. Burdock, G.A. (2005) Fenaroli's handbook of flavor ingredients (pp. 132-133, 390392, 486-487, 513-514, 762-763, 1051-1052, 1148-1149, 1339-1340, 12931294). Boca Raton, FL: CRC Press.

15. Arnoldi, A. (2003) The Maillard reaction as a source of off-flavours. In: Baigrie, B. (Ed.), Taints and off-flavours in food (pp. 162-166). Cambridge: Woodhead Publishing Ltd \& CRC Press LLC.

16. Boelrijk, A.E., \& de Jong, C. (2003) Relating analytical and sensory data to predict flavor quality in dairy products. In: Cadwallader, K.R., \& Weenen, H. (Eds.), Freshness and shelf life of foods (pp. 95-107). Washington: American Chemical Society.

17. Brinkman, J.H.M. (2006) Proeven van succes - sensorisch onderzoek: technieken, procedures en toepassingen (pp. 83-108). Houten: Keesing Noordervliet BV.

18. Lawless, H.T., \& Heymann, H. (1998) Sensory evaluation of food: principles and practices (pp. 129-131; 795-796). New York: Chapman \& Hall.

19. Meilgaard, M., Civille G.V., \& Carr B.T. (1999) Sensory evaluation techniques (pp. 7-8, 123-132, 133-159). $3^{\text {rd }}$ ed. Boca Raton, FL: CRC Press.

20. Hendriks, A.P. (1988) Olfactory dysfunction. Rhinology 26: 229-251.

21. Harris, J.A., \& Benedict, F.G. (1919) A Biometric Study of Basal Metabolism in Man (Publication no. 279). Washington, DC: Carnegie Institute of Washington.

22. De Graaf, C., de Jong, L.S., \& Lambers, A.C. (1999) Palatability affects satiation but not satiety. Physiol. Behav. 66: 681-688.

23. De Castro, J.M. (1987) Macronutrient relationships with meal patterns and mood in the spontaneous feeding behaviour of humans. Physiol. Behav. 39: 561-569.

24. De Graaf, C., Hulshof, T., Westrate, J.A., \& Jas, P. (1992) Sort-term effects of different amounts of protein, fats and carbohydrates on satiety. Am. J. Clin. Nutr. 55: 33-38.

25. Stubbs, R.J. (1995) Macronutrient effects on appetite. Int. J. Obes. 19: S11-S19.

26. Westerterp-Plantenga, M.S., Ijedema, M.J.W., \& Wijckmans-Duijsens, N.E.G. (1996) The role of macronutrient selection in determining patterns of food intake in obese and non-obese women. Eur. J. Clin. Nutr. 50: 580-591.

27. Snoek, H.M., Huntjens, L., van Gemert, L.J., de Graaf, C., \& Weenen, H. (2004) Sensory-specific satiety in obese and normal-weight women. Am. J. Clin. Nutr. 80: 823-831. 


\title{
Acute effects of complexity in aroma composition on satiation and food intake
}

\author{
Ruijschop, R.M.A.J., Boelrijk, A.E.M., \\ Burgering, M.J.M., de Graaf, C., \\ \& Westerterp-Plantenga, M.S.
}

Submitted for publication 


\section{ABSTRACT}

In a within-subject repeated-measures design, the acute effect of complexity in aroma composition on satiation and food intake was investigated in 41 young, healthy, and normal-weight subjects. Subjects consumed two different strawberry-aromatised sweetened yoghurt products (i.e. test and placebo product) in either an olfactometeraided or an ad libitum eating experimental design. The test product was aromatised with a multi-component strawberry aroma, while the placebo product was aromatised with a single-component strawberry aroma. Before, during and after the olfactometeraided sensory stimulation and ad libitum consumption, appetite profile measurements were performed.

Compared to placebo, perceived satiation was significantly increased during aroma stimulation with the multi-component strawberry aroma in the olfactometer-aided setting. Additionally, perceived satiation was significantly increased 10-15 minutes after consumption of the multi-component strawberry-aromatised sweetened yoghurt product in the ad libitum eating setting. There was no effect on actual strawberryaromatised sweetened yoghurt product consumption. Apart from the differences in timing of the appetite-regulating effects, both experimental settings demonstrated that the multi-component strawberry aroma, which was perceived as being more complex, yet of similar aroma quality, intensity and pleasantness compared to the single-component strawberry aroma, was able to enhance perceived satiation. The methodology of the olfactometer-aided aroma stimulation proved to be representative of a real-life setting with regard to aroma exposure and satiation.

Food products, which are perceived as being more complex, have been suggested to delay the development of sensory satiation as a result of implicitly cueing for variation. The present results may be explained by increased sensory stimulation, due to concurrent exposure to multiple aroma components cueing for sensorily similar strawberry perception.

Key words: Arousal potential level; Satiation; Appetite profile; Energy intake; Flavour; Olfactometer 


\section{INTRODUCTION}

Sensory perception during food consumption is a complex process, in which olfaction, taste, mouth feel, vision, the trigeminal system and auditory signals contribute to the total appreciation of a food product ${ }^{(1-3)}$. Repeated consumption across time may affect appreciation, in either a positive or negative direction, depending on the so-called arousal level of a sensory stimulus ${ }^{(4-9)}$. The arousal level of a sensory stimulus, which is a combination of intensity, complexity and novelty, is an intrinsic factor of a sensory stimulus, which is subject-specific and reduced by learning and experience. A singlepeaked inverted U-shape relationship exists between the preference and perceived arousal level of a sensory stimulus ${ }^{(4-6)}$, which notably includes perceived complexity (6). For each subject there is an optimal arousal potential level below and above which sensory stimuli are less preferred ${ }^{(4-7)}$. Mere exposure to food products, which are initially perceived on the right side of the optimum arousal potential level (i.e. perceived as being slightly more complex, and consequently less preferred than the optimum), is able to shift perception towards the optimum upon learning and experience (longerterm food appreciation). In contrast, repeated exposure to food products that are initially perceived at the optimum, or on the left side of the optimum arousal potential level, will only lead to diminished interest or even to boredom ${ }^{(4-9)}$.

A number of studies have revealed that repeated consumption of food products, which were perceived as being more complex, delayed the development of sensory satiation (7, 9-10). A possible explanation may be that perceived complexity implicitly cued for variation in sensory properties. Increasing the variation of sensorily distinct foods slows the decline in desire to eat the food and increases meal size ${ }^{(11-13)}$.

In the present study, the focus was on aroma. Recently, we were able to show that a retro-nasally delivered aroma (strawberry) was capable of inducing satiation ${ }^{(14)}$. The current study investigates whether two different strawberry aroma compositions, which are expected to vary only in the perceived level of complexity, are able to show a difference in resulting satiation. Assuming that the total amount of exposure to a food's sensory properties determines the total decline in desire to eat, we hypothesised that an enhancement of sensory properties by increased sensory stimulation from a more complex aroma would further reduce the desire to eat and enhance satiation. This is suggested to be due to concurrent exposure to multiple sensory attributes cueing for similar sensory perception.

In order to study this hypothesis, a single-blind, placebo-controlled, randomised crossover design was performed, to investigate the acute effect of complexity in aroma composition on satiation and food intake in human subjects. Two different strawberryaromatised sweetened yoghurt products (i.e. aromatised with a multi-component (test product, hypothesised to be perceived as being more complex) or single-component (placebo product, hypothesised to be perceived as less complex) strawberry aroma) were tested in both an olfactometer-aided and an ad libitum eating experimental 
design. The aim of this study was to determine whether effects of a single exposure to a multi-component strawberry aroma may contribute to satiation, because of increased sensory stimulation, due to concurrent exposure to multiple aroma components cueing for strawberry perception. In addition, the results served to validate the methodology of olfactometer-aided aroma stimulation as representative of a real-life setting.

\section{SUBJECTS AND METHODS}

\section{Subjects}

Forty-one healthy subjects (twenty-one women and twenty men) aged 20-40 years living in Ede, The Netherlands, and surroundings were recruited through advertisements in the local newspapers. The subjects included normal-weight subjects, with a body mass index (BMI) of 20 to $25 \mathrm{~kg} \mathrm{~m}^{-2}$. Subjects' mean age ( \pm standard deviation) was $29 \pm 7$ years and mean BMI ( \pm standard deviation) was $23 \pm 3 \mathrm{~kg} \mathrm{~m}^{-2}$.

Subjects' degrees of dietary restraint were determined using the Dutch translation of the Three-Factor Eating Questionnaire (TFEQ) ${ }^{(15)}$. Based on the outcome of the TFEQ subjects were selected with low scores $(\leq 9)$ on dietary restraint. In addition, based on self-report, subjects were not allergic to, nor did they have an aversion to, any of the food ingredients used in the present study. Subjects also reported a normal sense of smell.

Subjects were fully informed about the course of the test day and gave their written, informed consent. To prevent response-bias, the participants were given no information about the hypotheses and nature of the predictions of the experiment. They were only aware of the original nature of the study, i.e. the contribution of aroma to satiety. The study was approved by the Medical Ethical Committee (MEC) of Wageningen University.

\section{Preparation of products}

\section{Sweetened yoghurt products}

Batches of non-aromatised skimmed ( $0.5 \%$ fat) pasteurized yoghurt were produced in NIZO food research's food-grade pilot plant (The Netherlands) and contained 90\% milk (Friesland Foods, The Netherlands), 1.0\% starch (Roquette, France), and 8.4\% sugar (CSM, The Netherlands). Microbiological safety was checked for each yoghurt production. The viscosity of the produced yoghurt products was $61 \pm 14 \mathrm{~s}$, as measured with a Posthumus funnel and the $\mathrm{pH}$ was $4.03 \pm 0.1$.

\section{Strawberry-aromatised sweetened yoghurt products}

In order to prepare the strawberry-aromatised sweetened yoghurt products, $1.0 \mathrm{~mL}$ strawberry solution with a concentration of $100 \mathrm{~g} / \mathrm{kg}$, i.e. diluted 10 fold in propylene glycol (private label from a local pharmacy in Ede, The Netherlands), was added to 
$1 \mathrm{~L}$ sweetened yoghurt product (NIZO food research, The Netherlands) following a standardised procedure of continuous stirring. The strawberry concentration in the sweetened yoghurt product was $100 \mathrm{mg} / \mathrm{kg}$. The strawberry-aromatised sweetened yoghurt products were left 1.5 days at $4^{\circ} \mathrm{C}$ to allow a good equilibration of the aroma in the product. No colour was added to the strawberry-aromatised sweetened yoghurt products to prevent any unwanted cross-modal effect from a pink- or red-coloured yoghurt product with respect to the two different strawberry aroma compositions.

\section{Strawberry aroma}

Ethyl butyrate (Sigma-Aldrich Chemie GmbH, Germany) was used as single-component strawberry aroma. Ethyl butyrate is one of the key components of a generic strawberry aroma quality. The sensory quality of ethyl butyrate can be described as ethereal, fruity, ripe fruit notes ${ }^{(16)}$. The multi-component strawberry aroma used was the standard aroma of the COST 921 action, designed and supplied by Givaudan (Geneva, Switzerland), which contains 15 components, including ethyl butyrate ${ }^{(17)}$.

Prior to use in the olfactometer, the strawberry aroma was diluted 10000 fold in propylene glycol (private label from a local pharmacy in Ede, The Netherlands).

\section{Validation of aroma stimulation via olfactometer as representative of a real-life setting}

\section{Olfactometer-aided aroma stimulation}

On the one hand, the contribution of strawberry aroma was investigated apart from other stimuli from the yoghurt matrix (associated with other ingredients, textures and tastes). For this, the strawberry aroma was decoupled from the taste and mouth feel of the sweetened yoghurt product and delivered separately to the subjects by means of a tailored computer-controlled four-channel olfactometer based on airdilution olfactometry (OM4, Burghart, Germany). Using atmospheric pressure chemical ionization-mass spectrometry (APcI-MS) in combination with olfactometer methodology complete strawberry aroma release profiles were designed that mimic those obtained in vivo during the consumption of strawberry-aromatised sweetened yoghurt product ${ }^{(c .3,3,14,18)}$.

In the current set-up, the air flow out of the olfactometer was kept constant at $8 \mathrm{~L} / \mathrm{min}$ so as to be as close as possible to natural aroma release conditions during consumption. A complete aroma time-intensity release profile was administered by the olfactometer, consisting of multiple aroma pulses. The aroma release curve, resembling the consumption of the strawberry-aromatised sweetened yoghurt product, was delivered as a profile of ten consecutive pulses, each lasting $3 \mathrm{~s}$, with inter-pulse intervals of $1 \mathrm{~s}$ (Figure 5.1). 


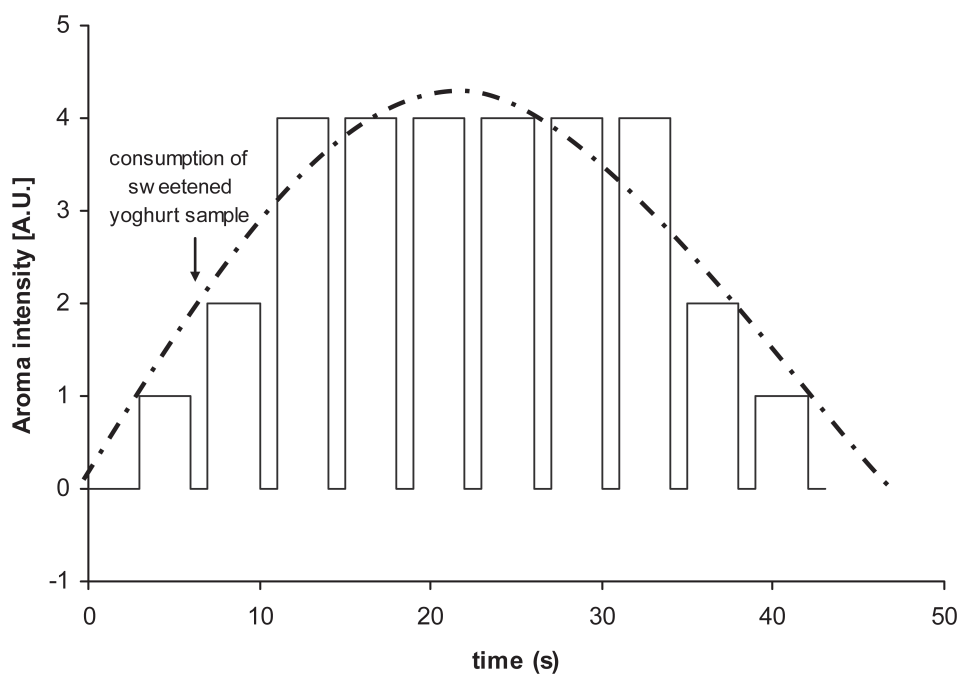

Figure 5.1 Aroma release profile delivered by olfactometer in both the single-component and multicomponent strawberry aroma stimulation. Since this study is comparison-wise, expression of the flavour intensity in arbitrary units (A.U.) is sufficient to analyse differences ${ }^{(19)}$. The smoothed line indicates the perceived aroma intensity, which is a continuous envelope. Due to the length of the aroma profile, the start of the aroma delivery was $3 \mathrm{~s}$ before the instruction to consume the sweetened yoghurt sample.

The odourized-dilution air flow ratios, i.e. the amount of odour-enriched air vs. the amount of odourless air for the ten pulses within the profile, were 1:7, 2:6, 4:4, 4:4, $4: 4,4: 4,4: 4,4: 4,2: 6,1: 7$, with a total odour + dilution air flow of $8 \mathrm{~L} / \mathrm{min}$. The aroma concentration in the delivered air corresponds linearly to the fraction of the total flow for flow rates up to $4 \mathrm{~L} / \mathrm{min}$ in each aroma vessel. The aroma profile was designed in such a way that the envelope of the aroma pulses mimicked the reflux of air that occurs during and after swallowing. Each subject received both aroma compositions via the same aroma profile with the same concentration of the strawberry aroma in a fully randomised order. For retro-nasal aroma delivery, approximately $9 \mathrm{~cm}$ in length of a silicon tube (suction catheter CH 10, D-Care B.V., The Netherlands) was placed into the lower meatus of the right nasal cavity. Anterior rhinoscopy was performed to exclude major pathology. Introduction of the tubing to the nose was tolerated well by all subjects without causing congestion, epistaxis or mucus discharge. Subjects waited for 15 minutes, in which they could relax and become familiar with the tubing. The extent to which a subject felt comfortable was recorded. The silicon tube was connected to the olfactometer while the subject was sitting straight up in a chair, enabling concurrent consumption of sweetened yoghurt product.

Subjects were connected to the olfactometer for 15 minutes. The aroma stimulation 
consisted of 15 aroma release profiles, starting every minute. All 15 aroma release profiles, which were retro-nasally delivered in the nose, were combined with the taste and mouth feel sensation of the sweetened yoghurt product (15 g) in the mouth. During one complete aroma stimulation experiment, every subject received 15 such sweetened yoghurt samples (225 g in total), which were served at $7 \pm 1^{\circ} \mathrm{C}$. A specific protocol was established for the timing of aroma delivery. As $15 \mathrm{~g}$ is a normal quantity to be consumed in one mouthful, subjects were instructed to consume the entire sweetened yoghurt sample in one mouthful using a spoon. Due to the length of the aroma profile, the start of the aroma delivery was $3 \mathrm{~s}$ before the instruction to consume the sweetened yoghurt sample, while the subjects were putting the spoon with the mouthful of sweetened yoghurt sample into their mouth. No specific instruction with regard to breathing was given. With the exception of strong breath intake through the nose, the total air flow of $8 \mathrm{~L} / \mathrm{min}$ from the olfactometer ensures delivery of the aroma to the olfactory epithelium. During the experiments, the subjects were closely observed in order to verify compliance with the protocol.

To prevent adaptation to the delivered aroma, the delay between the measurements amounted to a minimum of $17 \mathrm{~s}$ (i.e. the time interval between two successive aroma release profiles). Within this time interval, a continuous constant flow of clean air was maintained. After aroma stimulation, the silicon tube was removed and subjects went to another room for the remaining part of the experiment.

\section{Ad libitum consumption}

Alternatively, in the more real-life setting, the contribution of strawberry aroma to satiation and food intake was investigated in an ad libitum eating experimental design. For this, the strawberry aroma was coupled to the taste and mouth feel of the sweetened yoghurt product. Subjects were simultaneously exposed to the strawberry aroma, taste and mouth feel of the yoghurt product. Prior to consumption, the strawberry aroma was added to the sweetened yoghurt product in a concentration comparable to the olfactometer-aided aroma stimulation, as measured in vivo using APcI-MS.

\section{Experimental design}

Separately, in order to prevent response-bias, sensory data were obtained to investigate whether the difference in the two strawberry aroma compositions was large enough to be perceived as being different with respect to the level of complexity. Therefore, after the satiation experiments, a sensory evaluation was performed with the subjects who participated in this study. Based on these results, it could be checked whether the intervention was successful.

For the satiation experiments, each subject visited the test location four times in the morning, testing the two strawberry-aromatised sweetened yoghurt products (i.e. 
aromatised with a multi-component (test product) or single-component (placebo product) strawberry aroma) in either an olfactometer-aided or an ad libitum eating setting. Treatment order was counterbalanced across both test days and subjects. Between each visit there was a time-interval of 1 week. Based on the results of the different technological approaches it could be checked whether the olfactometer-aided aroma stimulation is representative of a real-life setting with regard to aroma exposure and satiation. Therefore, timings of the two experimental designs were kept the same as much as possible. However, due to practical feasibility, both experimental settings could not start at the same time of the morning. The olfactometer-aided setting only allowed one subject at the time.

Before starting the experiment, daily dietary energy requirements were calculated individually by multiplying the basal metabolic rate (BMR) by an activity index of 1.60. The BMR was calculated according to the equation of Harris and Benedict ${ }^{(20)}$. Subjects were asked to consume $10 \%$ of the daily dietary energy requirements for breakfast at home, which varied per person from 836 to $1463 \mathrm{~kJ}$ (from 200 to 350 $\mathrm{kcal})$. In addition, the subjects were requested to consume the same type and amount of breakfast when visiting the laboratory the next times. Based on this individually standardised breakfast, subjects visited the laboratory every time with comparable feelings of hunger and satiety. This was confirmed by a baseline measurement before the start of the olfactometer-aided aroma stimulation or ad libitum consumption of the strawberry-aromatised sweetened yoghurt products.

In a single-blind, placebo-controlled, randomised cross-over design, subjects were either administered two different strawberry aroma compositions using an olfactometer-aided setting as described above, or served two different strawberry-aromatised sweetened yoghurt products, from which they could eat ad libitum. Before, during and after the olfactometer-aided sensory stimulation and ad libitum consumption, appetite profile measurements were performed. The design of a test day is represented schematically in Figure 5.2 A (olfactometer-aided setting) and Figure 5.2 B (ad libitum eating setting).

\section{Measurements}

Sensory evaluation of the strawberry-aromatised sweetened yoghurt products

Sensory attribute evaluation for the appearance, smell, taste, mouth feel and aftertaste of the different strawberry-aromatised sweetened yoghurt products was performed by the subjects on a 100-mm visual analogue scale (VAS) (anchored for each with "not at all attractive" and "very much attractive") ${ }^{(21)}$. Intensities of smell, taste and aftertaste were recorded on a 100-mm just-about-right scale (JAR) (anchored for each with "much too weak" and "much too strong") (e.g. 22).

Perceived levels of complexity, familiarity/novelty and boredom were assessed for the different strawberry-aromatised sweetened yoghurt products by questionnaire ${ }^{(c f}$. 


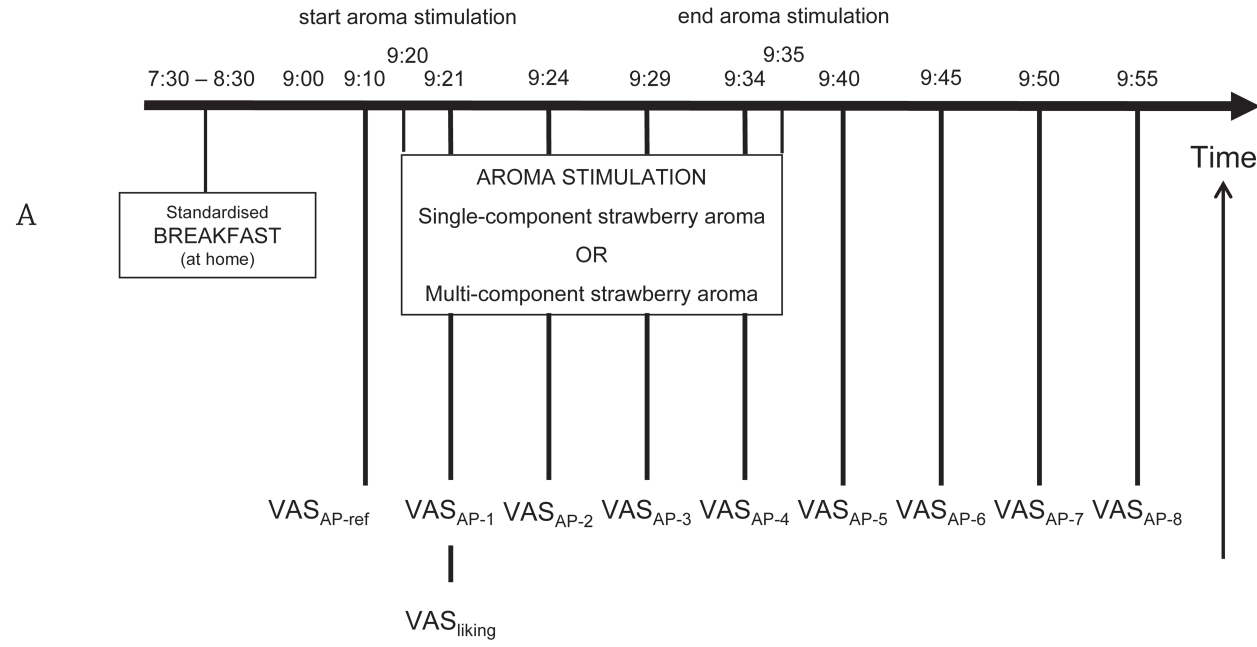

start ad libitum consumption

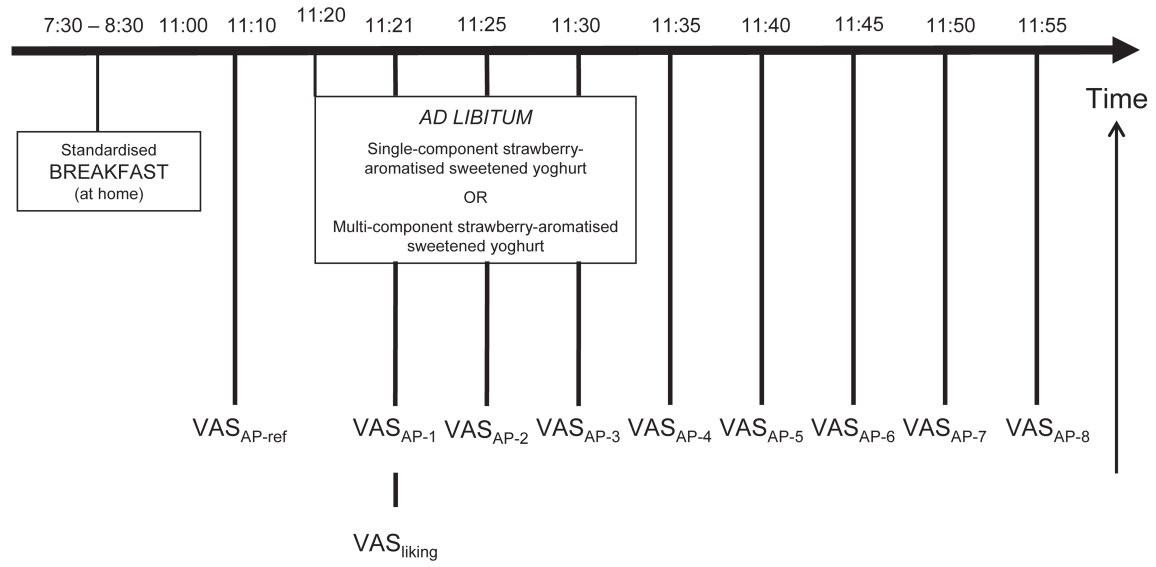

Figure 5.2 Overview of the test day protocol. Subjects came four times to the laboratory, a week apart, and received either the single- or multi-component strawberry olfactometer-aided aroma stimulation (A) or the single- or multi-component strawberry-aromatised sweetened yoghurt product (B) in a fully randomised order. Appetite profiles were recorded on a $100-\mathrm{mm}$ visual analogue scale (VAS) repeatedly (A and B: $\mathrm{VAS}_{\mathrm{AP}-\mathrm{ref}}$ to $\mathrm{VAS}_{\mathrm{AP}-8}$ ). Hedonic ratings were recorded for the strawberry-

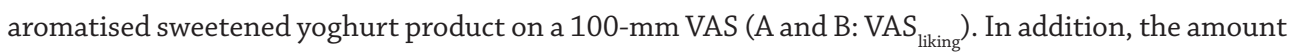
of strawberry-aromatised sweetened yoghurt product consumed ad libitum was measured (B).

9). Subjects recorded ratings for the items "difficulty to describe the taste", "perceived number of ingredients" and "perceived level of complexity" (i.e. the dimension complexity); "familiarity"; "perceived boredom", "desire to eat", "appropriateness to eat every day" and "probability of personal choice" (i.e. the dimension boredom) (100-mm VAS anchored for each with "not at all" and "very much"). 


\section{Short-term appetite profile}

The appetite profile, i.e. ratings of hunger, fullness, satiation, desire to eat and thirst were recorded on a 100-mm VAS (anchored for each with "not at all" and "very much") repeatedly before, during, and after the olfactometer-aided sensory stimulation and ad libitum consumption of the strawberry-aromatised sweetened yoghurt products (see $\mathrm{VAS}_{\mathrm{AP}}$ Figure 5.2). In addition, at the same time-points desire to eat sweet products and desire to eat savory products were recorded on 100-mm VAS anchored with "not at all" and "very much". All rating scales were provided on separate sheets that were collected after each rating.

\section{Actual strawberry-aromatised sweetened yoghurt product consumption}

To measure the effect of the two different strawberry aroma compositions on actual yoghurt product consumption, subjects were offered $2 \mathrm{~L}$ of strawberry-aromatised sweetened yoghurt product, served in an opaque bowl with a tablespoon at $7 \pm 1^{\circ} \mathrm{C}$, from which they could eat ad libitum. The amount offered was such that there were always leftovers. After consumption the amount of strawberry-aromatised sweetened yoghurt product consumed was measured for each subject (Mettler-Toledo balance, Switzerland).

\section{Pleasantness of flavour rating}

Immediately after the start of the olfactometer-aided aroma stimulation or ad libitum strawberry-aromatised sweetened yoghurt product consumption, pleasantness of taste of the consumed yoghurt product was measured. Subjects were asked to scale their hedonic rating (100-mm VAS anchored with "not pleasant at all" and "very pleasant") (see $\mathrm{VAS}_{\text {liking }}$ Figure 5.2).

\section{Data analysis}

VAS and JAR ratings were measured in millimeters from the left (respectively, "not at all" and "much too weak") end of the scale. The set of sensory data obtained was evaluated by regular statistical means (e.g. descriptive statistics), regular Principal Components Analysis (PCA) (FIZZ Calculations, release 2.30c, Biosystemes, France), and a General Linear Model (GLM) procedure for repeated measures with participant and type of strawberry aroma as independent variables (SAS, release 9.1, SAS Institute Inc., USA).

Since there were no significant differences in VAS rating for the appetite profile at baseline measurement, delta VAS ratings, i.e. changes in VAS ratings, were calculated by subtracting the ratings at the time-point before olfactometer-aided aroma stimulation or ad libitum consumption (VAS ${ }_{\text {AP-ref }}$ for appetite profile ratings) from the ratings at the different time-points during and after olfactometer-aided aroma stimulation or ad 
libitum consumption $\left(\mathrm{VAS}_{\mathrm{AP}-1}\right.$ to $\mathrm{VAS}_{\mathrm{AP}-8}$ for appetite profile ratings). Area under the curve (AUC) delta VAS ratings were determined using the trapezoidal method. As a composite measure for the appetite profile, hunger and satiation scores were used, while desire to eat and fullness were scored similarly. All data are presented as means with their standard errors of the mean (SEM). Actual strawberry-aromatised sweetened yoghurt product consumption and the different AUC delta VAS ratings were compared between the two different strawberry aroma compositions, in either the olfactometeraided or ad libitum eating setting, by using the GLM procedure for repeated measures, with participant and type of strawberry aroma as independent variables. Least Squares Means were used for post-hoc comparisons. With the use of a mixed-model analysis of variance (ANOVA) for repeated measures, differences in delta VAS appetite profile ratings were investigated per time-point. Least Squares Means were used for post-hoc comparisons.

Simple regression analyses $(\mathrm{f}(\mathrm{x})$ ) were performed for actual strawberry-aromatised sweetened yoghurt product consumption and short-term appetite profile (y), and pleasantness of taste and perceived levels of the dimensions complexity, familiarity and boredom for the strawberry-aromatised sweetened yoghurt products (x). For all data analyses the statistical packages SAS (release 9.1, SAS Institute Inc., USA) were used. P-values $<0.05$ were considered statistically significant.

\section{RESULTS}

Sensory evaluation of the strawberry-aromatised sweetened yoghurt products

Subjects evaluated the appearance, (intensity of) smell, (intensity of) taste, mouth feel and (intensity of) after taste of both strawberry-aromatised sweetened yoghurt products as acceptable attractive and just about right (Table 5.1). However, subjects rated the mouth feel of the single-component strawberry-aromatised sweetened yoghurt as more attractive compared to the multi-component strawberry-aromatised sweetened yoghurt $\left(\mathrm{F}_{(1,41)}=7.71 ; \mathrm{P}=0.01\right)$. Apart from mouth feel, sensory attribute evaluation did not differ significantly between the single- and multi-component strawberry-aromatised sweetened yoghurt products.

The multi-component strawberry-aromatised sweetened yoghurt product yielded significantly higher scores compared to the single-component strawberry-aromatised sweetened yoghurt product on the dimension complexity for the items difficulty to describe the taste $(49.8 \pm 3.3 \mathrm{~mm}$ and $62.9 \pm 3.3 \mathrm{~mm}$ for the single- and multicomponent strawberry-aromatised sweetened yoghurt product, respectively; $\mathrm{F}_{(1,41)}=$ 7.53; $\mathrm{P}=0.01)$ and perceived level of complexity $(38.8 \pm 2.6 \mathrm{~mm}$ and $47.3 \pm 2.6 \mathrm{~mm}$ for the single- and multi-component strawberry-aromatised sweetened yoghurt product, respectively; $F_{(1,41)}=5.23 ; \mathrm{P}=0.03$ ) (Figure 5.3). Subjects evaluated the dimensions familiarity and boredom for both strawberry-aromatised sweetened yoghurt products not significantly different. 
Table 5.1 Sensory attribute evaluation of the different strawberry-aromatised sweetened yoghurt products, as performed after the satiation experiments by the 41 subjects ${ }^{a}$

\begin{tabular}{|c|c|c|c|c|}
\hline & \multicolumn{2}{|c|}{$\begin{array}{l}\text { Single-component } \\
\text { strawberry aroma }\end{array}$} & \multicolumn{2}{|c|}{$\begin{array}{l}\text { Multi-component } \\
\text { strawberry aroma }\end{array}$} \\
\hline & Mean & SEM & Mean & SEM \\
\hline Appearance $(\mathrm{mm})^{b}$ & 60.4 & 1.6 & 61.9 & 1.6 \\
\hline Smell $(\mathrm{mm})^{b}$ & 52.8 & 2.6 & 51.1 & 2.5 \\
\hline Intensity of smell $(\mathrm{mm})^{c}$ & 48.4 & 2.5 & 49.1 & 2.5 \\
\hline Taste $(\mathrm{mm})^{b}$ & 55.3 & 2.5 & 54.1 & 2.5 \\
\hline Intensity of taste $(\mathrm{mm})^{c}$ & 56.5 & 1.4 & 55.2 & 1.4 \\
\hline Mouth feel $(\mathrm{mm})^{b^{*}}$ & 69.9 & 1.6 & 63.5 & 1.6 \\
\hline After taste $(\mathrm{mm})^{b}$ & 45.6 & 3.4 & 48.8 & 3.4 \\
\hline Intensity of after taste $(\mathrm{mm})^{c}$ & 60.6 & 2.5 & 59.1 & 2.5 \\
\hline
\end{tabular}

${ }^{a}$ Mean values and standard errors;

${ }^{\mathrm{b}} 100-\mathrm{mm}$ VAS scale;

'100-mm JAR scale;

* Significantly different between the two yoghurt products.

Pleasantness of taste of the strawberry-aromatised sweetened yoghurt product

Subjects evaluated the pleasantness of taste for the single- and multi-component strawberry-aromatised sweetened yoghurt product, as on average $59.4 \pm 1.8 \mathrm{~mm}$ and $58.6 \pm 1.9 \mathrm{~mm}$, respectively. No significant differences in pleasantness of taste were observed between the strawberry-aromatised sweetened yoghurt products in either the olfactometer-aided or the ad libitum eating setting $\left(\mathrm{F}_{(1,38)}=1.02 ; \mathrm{P}=0.32\right.$; and $\mathrm{F}_{(1,40)}$ $=3.12 ; \mathrm{P}=0.09$, respectively).

In general, it appeared that the amount of strawberry-aromatised sweetened yoghurt product consumed ad libitum ( $\mathrm{y}$ ) was a function of personal pleasantness of taste of the strawberry-aromatised sweetened yoghurt products $(x)\left(y=3.1 x+175.8 ; R^{2}=0.07 ; P\right.$ $=0.02$ ). Correspondingly, personal pleasantness of taste of the strawberry-aromatised sweetened yoghurt products ( $\mathrm{x}$ ) was related to the appetite profile ratings (y); either positively for perceived satiation and perceived fullness, or negatively for perceived hunger and desire to eat.

In addition, pleasantness of taste and perceived level of complexity for the two different strawberry-aromatised sweetened yoghurt products were not linearly related, but could be related to the theoretical inverted U-shape between pleasantness of taste and perceived level of complexity (Figure 5.4). The pleasantness of taste, as measured during ad libitum consumption was equal for both strawberry-aromatised sweetened yoghurt products. However, subjects perceived a significantly higher level of complexity for the multi-component strawberry aromatised sweetened yoghurt product compared to the single-component strawberry aromatised sweetened yoghurt product. Current 


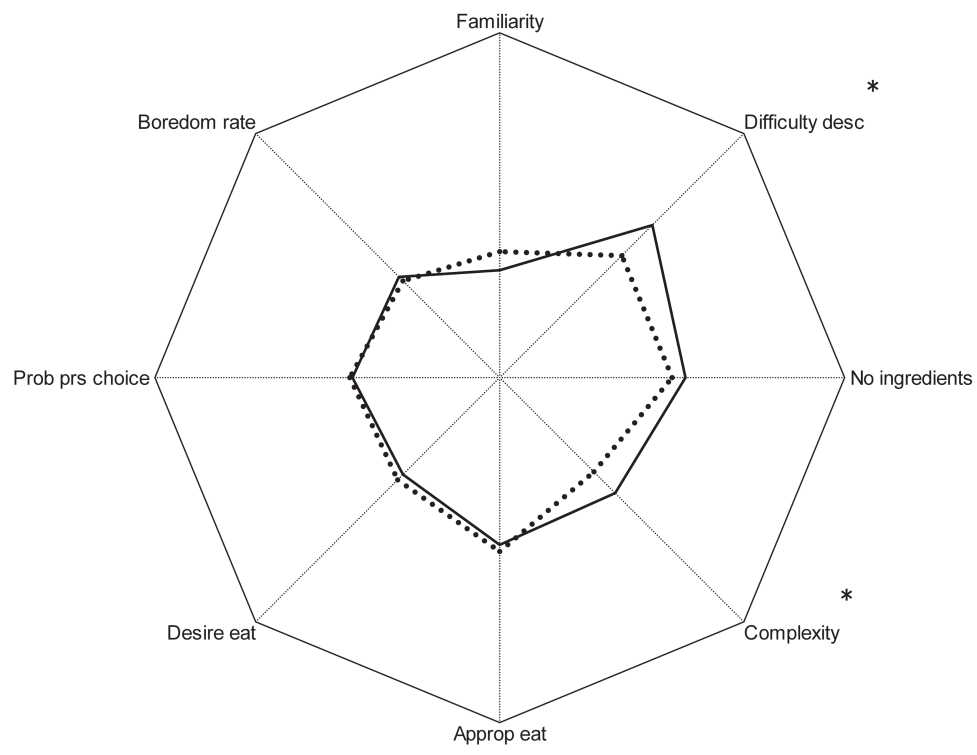

Figure 5.3 Star (spider) graph (100-mm scale) representing the ratings for the dimensions perceived complexity (i.e. the items "difficulty to describe the taste (difficulty desc)", "perceived number of ingredients (no ingredients)" and "perceived level of complexity (complexity)"), "familiarity" and boredom (items "perceived boredom (boredom rate)", "desire to eat (desire eat)", "appropriateness to eat every day (approp eat)" and "probability of personal choice (prob prs choice)") for the singlecomponent (dot line) and multi-component (solid line) strawberry-aromatised sweetened yoghurt product. Parameters with a ${ }^{*}$ denote that subjects evaluated the dimension complexity significantly higher for the multi-component strawberry-aromatised sweetened yoghurt product with respect to the items difficulty to describe the taste and perceived level of complexity.

strawberry-aromatised sweetened yoghurt products are likely positioned either on the left side of the optimum arousal potential level (Figure 5.4 A) or on both the left and right side of the optimum arousal potential level (Figure $5.4 \mathrm{~B}$ ) for the single- (placebo product) and multi-component (test product) strawberry-aromatised sweetened yoghurt product, respectively.

\section{Actual strawberry-aromatised sweetened yoghurt product consumption}

The amount of strawberry-aromatised sweetened yoghurt product consumed ad libitum did not differ significantly between the two strawberry aroma compositions (respectively, $347 \pm 19 \mathrm{~mL}$ (range 51.4 - $1101.3 \mathrm{~mL}$ ) for the single-component strawberry-aromatised sweetened yoghurt product (placebo product) and $360 \pm 19 \mathrm{~mL}$ (range 58.5 - $945.2 \mathrm{~mL}$ ) for the multi-component strawberry-aromatised sweetened yoghurt product (test product) $\left(\mathrm{F}_{(1,40)}=0.24 ; \mathrm{P}=0.63\right)$ (data not shown).

In general, it appeared that the amount of strawberry-aromatised sweetened yoghurt 


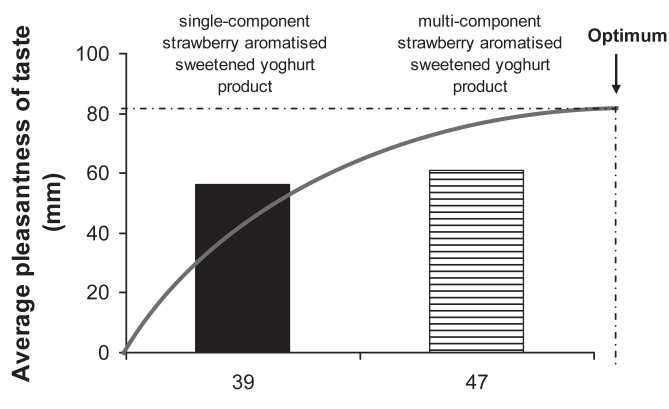

Average perceived level of complexity $(\mathrm{mm})$

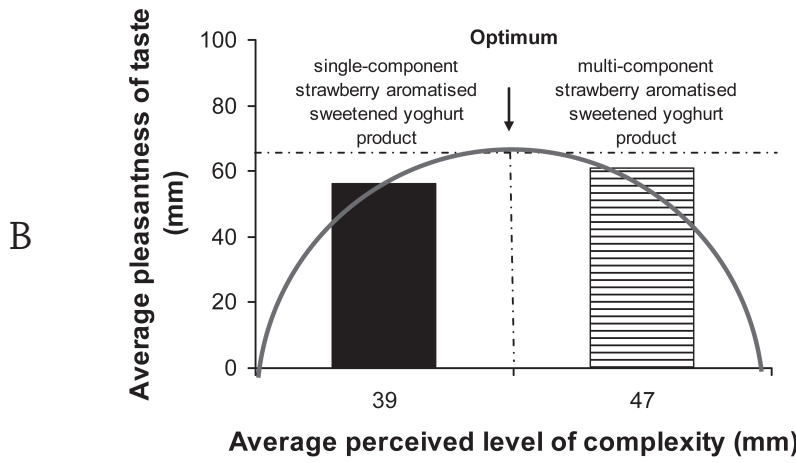

Figure 5.4 Illustration of the theoretical likely left side (A) or both left and right side (B) of the inverted U-shape relationship between pleasantness of taste and the arousal potential for the single- (placebo product) and multi-component (test product) strawberry-aromatised sweetened yoghurt product. The pleasantness of taste, as measured during ad libitum consumption, was equal for both strawberryaromatised sweetened yoghurt products; however, subjects significantly perceived a higher level of complexity for the multi-component strawberry aromatised sweetened yoghurt product.

product consumed ad libitum (y) was a function of the perceived level of complexity for the strawberry-aromatised sweetened yoghurt product $(\mathrm{x})\left(\mathrm{y}=-4.1 \mathrm{x}+528.1 ; \mathrm{R}^{2}=0.10\right.$; $\mathrm{P}=0.004)$.

\section{Short-term appetite profile}

Since the amount of sweetened-yoghurt product consumed during olfactometer-aided sensory stimulation was fixed, no additional adjustments were made for the effect of amount consumed on recorded appetite profile ratings in the olfactometer-aided setting. Although the amount of strawberry-aromatised sweetened yoghurt product consumed ad libitum was not equal for the two strawberry-aromatised sweetened yoghurt products in the ad libitum eating setting, this difference was not significant between the two different strawberry aroma compositions. Also no additional adjustments were made 
for the effect of amount consumed on recorded appetite profile ratings in the ad libitum eating setting.

Figures 5.5 and 5.6 show the results of the two different strawberry-aromatised sweetened yoghurt products, in either an olfactometer-aided or an ad libitum eating setting, on the change in VAS ratings of hunger, and satiation, respectively. Compared to placebo, a significant difference was demonstrated in perceived hunger during olfactometer-aided sensory stimulation with the multi-component strawberry aroma $\left(\mathrm{F}_{(1,342)}=5.31 ; \mathrm{P}=0.02\right)$. Subjects felt less hungry during olfactometer-aided sensory stimulation with the multi-component strawberry aroma (Figure 5.5; delta mean response at $\mathrm{VAS}_{\mathrm{AP}-3} \pm \mathrm{SEM}:-11.1 \pm 2.6 \mathrm{~mm}$ ) than during olfactometer-aided sensory stimulation with the single-component strawberry aroma (Figure 5.5; delta mean response at $\left.\mathrm{VAS}_{\mathrm{AP}-3} \pm \mathrm{SEM}:-4.4 \pm 2.6 \mathrm{~mm}\right)$.

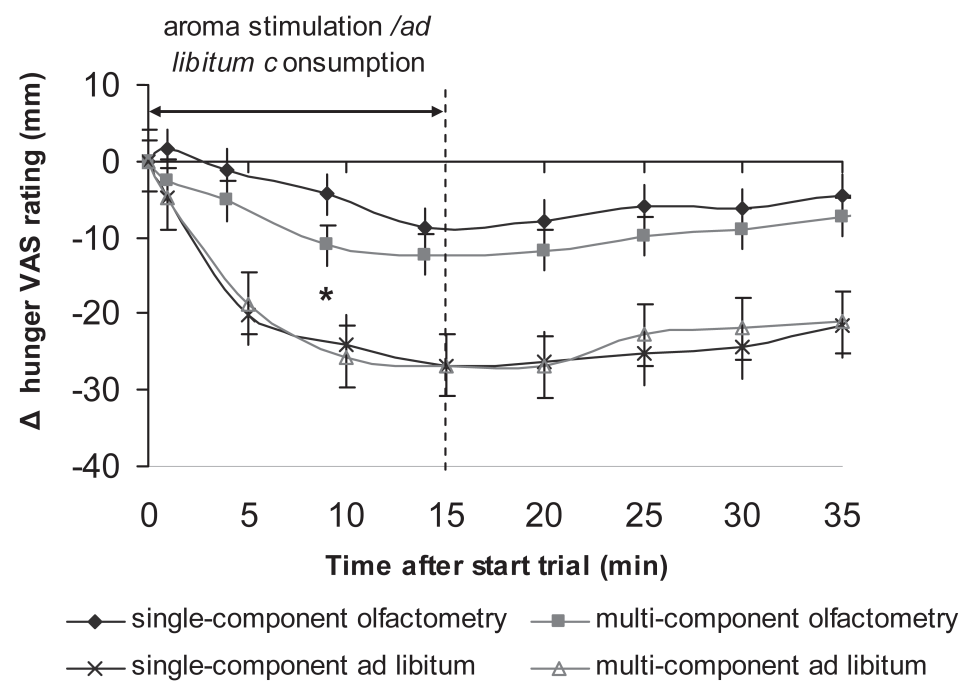

Figure 5.5 Change $(\Delta)$ in hunger VAS rating during and after the olfactometer-aided sensory stimulation (upper two data series; single- and multi-component olfactometer-aided) and ad libitum consumption of the strawberry-aromatised sweetened yoghurt products (lower two data series; single- and multi-component ad libitum), respectively. Values are means with their standard errors depicted by vertical bars. ${ }^{*}$ denotes significant effect of type of strawberry aroma on change in hunger VAS rating at the designated time point with $\mathrm{P}<0.05$.

In addition, subjects felt more satiated if they were aroma stimulated with the multicomponent strawberry aroma (Figure 5.6; delta mean response at $\mathrm{VAS}_{\mathrm{AP}-3} \pm \mathrm{SEM}: 12.8 \pm$ $2.5 \mathrm{~mm}$ ) compared to the single-component strawberry aroma (Figure 5.6; delta mean response at $\left.\mathrm{VAS}_{\mathrm{AP}-3} \pm \mathrm{SEM}: 7.4 \pm 2.5 \mathrm{~mm}\right)\left(\mathrm{F}_{(1,342)}=4.07 ; \mathrm{P}=0.05\right)$. Furthermore, $\mathrm{a}$ 
significant difference in perceived fullness was found during olfactometer-aided aroma stimulation with the multi-component strawberry aroma (delta mean response at $\left.\mathrm{VAS}_{\mathrm{AP}-3} \pm \mathrm{SEM}: 15.6 \pm 2.7 \mathrm{~mm}\right)$ compared to the single-component strawberry aroma (delta mean response at $\left.\mathrm{VAS}_{\mathrm{AP}-3} \pm \mathrm{SEM}: 8.4 \pm 2.7 \mathrm{~mm}\right)\left(\mathrm{F}_{(1,342)}=5.78 ; \mathrm{P}=0.02\right)$ (data not shown, but similar to Figure 5.6).

In the ad libitum eating setting, a significant difference in perceived satiation was observed after consumption of the multi-component strawberry-aromatised sweetened yoghurt product (Figure 5.6; delta mean response at $\mathrm{VAS}_{\mathrm{AP}-4-6} \pm \mathrm{SEM}: 35.2 \pm 4.0 \mathrm{~mm}$ ) compared to the single-component strawberry-aromatised sweetened yoghurt product (Figure 5.6; delta mean response at VAS $\mathrm{AP}-4-6 \pm \mathrm{SEM}$ : $29.1 \pm 4.0 \mathrm{~mm}$ ). After consumption of the multi-component strawberry-aromatised sweetened yoghurt product, subjects felt more satiated than after consumption of the single-component strawberryaromatised sweetened yoghurt product $\left(5.03 \geq \mathrm{F}_{(1,359)}>3.90 ; 0.03 \leq \mathrm{P}<0.05\right)$. In contrast, a decrease in perceived hunger was not observed after ad libitum consumption of the multi-component strawberry-aromatised sweetened yoghurt product.

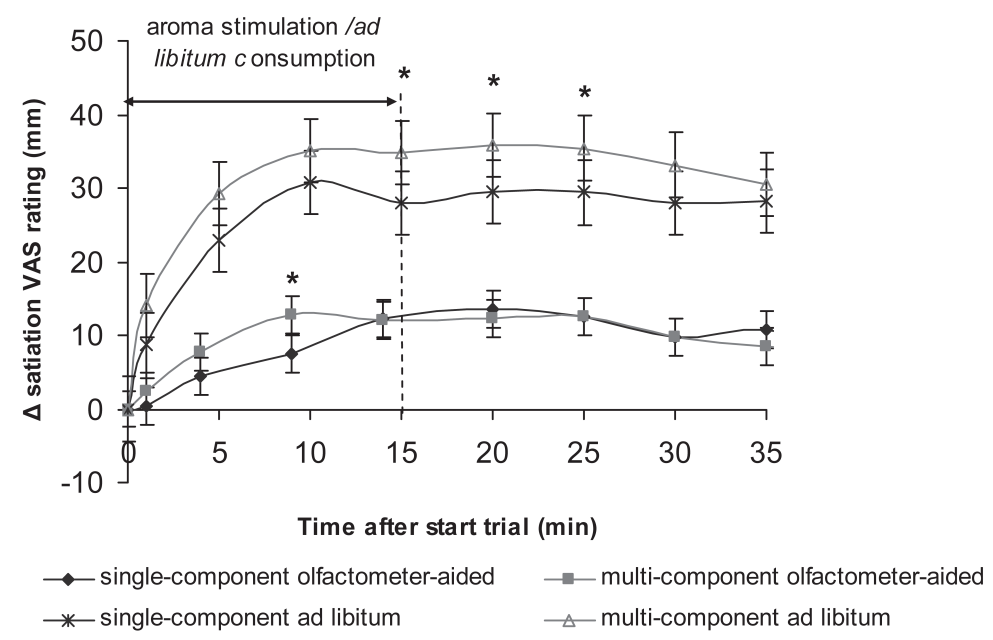

Figure 5.6 Change $(\Delta)$ in satiation VAS rating during and after the olfactometer-aided sensory stimulation (lower two data series; single- and multi-component olfactometer-aided) and ad libitum consumption of the strawberry-aromatised sweetened yoghurt products (upper two data series; single- and multi-component ad libitum), respectively. Values are means with their standard errors depicted by vertical bars. ${ }^{*}$ denotes significant effect of type of strawberry aroma on change in satiation VAS rating at the designated time point with $\mathrm{P}<0.05$.

\section{DISCUSSION}

The present study demonstrates that a multi-component strawberry aroma, which was perceived as being more complex, yet of similar aroma quality, intensity and pleasantness 
compared to a single-component strawberry aroma, is able to enhance satiation. Satiation-enhancing effects may be explained by increased sensory stimulation. This is suggested to be due to concurrent exposure to multiple aroma components cueing for sensorily similar strawberry perception.

The subjects in the current study perceived no differences in appearance, (intensity of) smell, (intensity of) taste and (intensity of) after taste between the single- and multicomponent strawberry-aromatised sweetened yoghurt products, apart from mouth feel. There are no indications that the perceived difference in mouth feel affected the present results. This unexpected distinction could not be related to batch differences in yoghurt production or cross-modal sensory effects, such as differences in the perceived level of complexity. Based on the smell and taste ratings, it can be concluded that subjects were not consciously aware of the difference in strawberry aroma composition between the two different strawberry-aromatised sweetened yoghurt products. However, subjects did perceive the multi-component strawberry-aromatised sweetened yoghurt product as being more complex and more difficult to describe the taste compared to the singlecomponent strawberry-aromatised sweetened yoghurt product (Figure 5.3). Hence, the positioning of the single- and multi-component strawberry-aromatised sweetened yoghurt product as placebo product and test product, respectively, turned out to be valid. This was the most unforeseeable part of the experimental design, since it was not possible to define a priori the subjects' perceived level of complexity for the two different strawberry-aromatised sweetened yoghurt products ${ }^{(c f .9)}$.

Although differences in the perceived level of complexity between the two strawberryaromatised sweetened yoghurt products could be engineered, the average pleasantness of taste was equal for both yoghurt products (Figure 5.4). The theoretical inverted U-shape relationship between pleasantness of taste and the arousal potential for the single- (placebo product) and multi-component (test product) strawberry-aromatised sweetened yoghurt product is a result of a trade-off between the engineering of a maximum perceived level of complexity and preservation of a maximum pleasantness of taste. If strawberry-aromatised sweetened yoghurt products, which would have been perceived as being more complex, had been used, pleasantness of taste might have been negatively affected, consequently leading to subjects who might stop eating, due to aversion instead of satiation. The positioning of the current strawberry-aromatised sweetened yoghurt products on the theoretical inverted U-curve was successful for the present intervention with a single exposure (Figure 5.4). Thus, probably both yoghurt products were perceived as a single 'body / gestalt' without cueing for variation.

The result that the multi-component strawberry aroma, which only varied in perceived level of complexity was able to enhance satiation was in line with our expectations (Figure 5.6). We hypothesised that the multi-component strawberry aroma would lead to increased sensory stimulation, due to concurrent exposure to multiple aroma components cueing for strawberry perception. To our knowledge, this result has not 
been shown before in the literature. Food products, which are perceived as being more complex, are usually reported to delay the development of sensory satiation ${ }^{(7,9-10)}$. However, in those observations perceived complexity might implicitly cue for variation, leading to increased meal size ${ }^{(11-13)}$, while in the present study perceived complexity did not result in consciously perceived sensory differences between the two different strawberry-aromatised sweetened yoghurt products. The absence of a significant effect on hunger ratings after ad libitum consumption of the multi-component strawberryaromatised sweetened yoghurt product was not expected. Subjects likely interpreted hunger differently than the opposite of satiation.

In addition, the results served to validate the methodology of the olfactometeraided aroma stimulation as representative of a real-life setting with regard to aroma exposure and satiation. Although timings of the two experimental designs were kept the same as much as possible, differences in timing of the appetite-regulating effects were nevertheless observed between the olfactometer-aided and ad libitum eating setting. However, both experimental settings demonstrated that the multicomponent strawberry aroma was able to enhance perceived satiation. Compared to the olfactometer-aided setting, appetite-regulating effects were observed later in the ad libitum eating setting. For example, compared to placebo, perceived satiation was significantly increased during aroma stimulation with the multi-component strawberry aroma in the olfactometer-aided setting, while perceived satiation was significantly increased 10-15 minutes after consumption of the multi-component strawberryaromatised sweetened yoghurt product in the ad libitum eating setting (Figure 5.6). These timing differences are likely to be ascribed to a controlled vs. uncontrolled way of yoghurt product consumption in the olfactometer-aided vs. ad libitum eating setting, respectively. For example, eating rate and bite size are hypothesised to be different in the two experimental settings. In addition, the satiating power of food per $\mathrm{kJ}$ consumed is known to decrease slowly during the day ${ }^{(23)}$. By starting the ad libitum eating experiment in the beginning of the morning, satiating effects of the multicomponent strawberry-aromatised sweetened yoghurt product even could have been observed during ad libitum consumption.

Although significant changes in appetite profile ratings were demonstrated between the two different strawberry aroma compositions, no significant difference between ad libitum consumption of the two different strawberry-aromatised sweetened yoghurt products was observed. As discussed by Veldhorst et al. ${ }^{(24)}$, it is likely that the magnitude of the effect in perceived satiation was too small to have an effect on the amount consumed ad libitum. Veldhorst et al. ${ }^{(24)}$ showed that differences in appetite ratings in a preload-ad libitum meal design need to be at least larger than $15 \mathrm{~mm}$ VAS in order to have a significant effect on subsequent energy intake. Although in the present study no preload-ad libitum meal design was applied, differences in VAS between the two different strawberry aroma compositions in both the olfactometer-aided and 
ad libitum eating setting were rather small. The change in perceived satiation during olfactometer-aided aroma stimulation and after consumption of the yoghurt products in the ad libitum eating setting was on average $73 \%$, corresponding to $5.4 \mathrm{~mm}$ VAS and $22 \%$, corresponding to $6.4 \mathrm{~mm}$ VAS, respectively. Alternatively, the magnitude of the appetite-regulating effect might have been bigger if the yoghurt products had been pink coloured. Although subjects were not told that they were going to consume a strawberry-aromatised yoghurt product, addition of pink colour to the yoghurt products would likely have been better to meet consumers' expectations towards the consumption of the strawberry-aromatised yoghurt products.

The present study tested the acute effects on satiation and food intake of a single exposure to two different strawberry aroma compositions, which only varied in the perceived level of complexity. Since subjects were not able to make a distinction between the two strawberry aroma compositions based on sensory attribute evaluation, it would be interesting to investigate whether the present appetite-regulating effects are also observed after repeated exposure.

The concept that exposure to a more complex aroma stimulus is able to affect satiation may be valuable for the development of foods containing triggers that are able to induce or increase the feeling of satiation. A possible food application could be for instance, the engineering of multi-component aroma compositions, which provide more 'body / gestalt' to food products. Other specific food product applications might even strengthen the impact of the concept by the inclusion of other sensory attributes, such as texture complexity (e.g. cross-modal complexity interactions between aroma (perceived as complex in aroma composition) and texture (perceived as complex in aroma release profile, due to longer oral processing as a result of texture), as long as all those sensory attributes (e.g. texture maybe also colour, taste) together add only to the complexity of a single 'body / gestalt' of the food product and do not implicitly cue for variation.

\section{ACKNOWLEDGEMENTS}

We acknowledge Severine Bordet and Leonie Hermans for their skilful assistance with the preparations for this study.

This work was supported by DiOGenes. DiOGenes is the acronym of the project "Diet, Obesity and Genes" supported by the European Community (Contract no. FOODCT-2005-513946). The Parties of the project are listed on the web-site of the project: http://www.diogenes-eu.org/. Special acknowledgement is made to the Dutch Dairy Association for co-financing this project. 


\section{REFERENCES}

1. Shepherd, R. (1995) Psychological aspects of food choice. Food Sci. Technol. Today 9: 178-182.

2. Meiselman, H.L. (1996) The contextual basis for food acceptance, food choice and food intake: the food, the situation and the individual. In: Meiselman, H.L., \& MacFie, H.J.H. (Eds.), Food choice, acceptance and consumption (pp. 239-263). London: Blackie Academic \& Professional.

3. Visschers, R.W., Jacobs, M.A., Frasnelli, J., Hummel, T., Burgering, M., \& Boelrijk, A.E.M. (2006) Cross-modality of texture and aroma perception is independent of orthonasal or retro-nasal stimulation. J. Agric. Food Chem. 54: 5509-5515.

4. Berlyne, D.E. (Ed.) (1960) Conflict, Arousal and Curiosity. New York: McGraw-Hill.

5. Berlyne, D.E. (1970) Novelty, complexity, and hedonic value. Percept. Psychophys. 8: 279-286.

6. Dember, W.N., \& Earl, R.W. (1957) Analysis of exploratory, manipulatory and curiosity behaviors. Psychol. Rev. 64: 91-96.

7. Lévy, C.M., MacRae, A., \& Köster, E.P. (2006) Perceived stimulus complexity and food preference development. Acta Psychol. 123: 394-413.

8. Köster, E.P. (2003) The psychology of food choice: some often encountered fallacies. Food Qual. Pref. 14: 359-373.

9. Weijzen, P.L.G., Zandstra, E.H., Alfieri, C., \& de Graaf, C. (2008) Effects of complexity and intensity on sensory-specific satiety and food acceptance after repeated consumption. Food Qual. Pref. 19: 349-359.

10. Johnson, J., \& Vickers, Z. (1992) Factors influencing sensory-specific satiety. Appetite 19: 15-31.

11. Hetherington, M.M., Foster, R., Newman, T., Anderson, A.S., \& Norton, G. (2006) Understanding variety: tasting different foods delays satiation. Physiol. Behav. 87: 263-271.

12. Romer, M., Lehrner, J., van Wymelbeke, V., Jiang, T., Deecke, L., \& Brondel, L. (2006) Does modification of olfacto-gustatory stimulation diminish sensoryspecific satiety in humans? Physiol. Behav. 87: 469-477.

13. Harthoorn, L.F., Ruijschop, R.M.A.J., Weinbreck, F., Burgering, M.J.M., de Wijk, R.A., Ponne, C.T., \& Bult, J.H.F. (2008) Effects of aroma-texture congruency within dairy custard on satiation and food intake. Food Qual. Pref. 19: 644-650.

14. Ruijschop, R.M.A.J., Boelrijk, A.E.M., de Ru, J.A., de Graaf, C., \& WesterterpPlantenga, M.S. (2008) Effects of retro-nasal aroma release on satiation. Br. J. Nutr. 99: 1140-1148.

15. Westerterp-Plantenga, M.S., Rolland, V., Wilson, S.A.J., \& Westerterp, K.R. (1999) Satiety related to $24 \mathrm{~h}$ diet-induced thermogenesis during high protein/ carbohydrate versus high fat diets, measured in a respiration chamber. Eur. J. Clin. Nutr. 53: 495-502. 
16. Flavor Database by Leffingwell \& Associates. (2004) Retrieved 18-12-2007, from http://www.leffingwell.com.

17. COST 921 action. Retrieved 31-10-2008, from http://www.cost921.uni-wuppertal. de.

18. de Kok, P.M.T., Boelrijk, A.E.M., de Jong, C., Burgering, M.J.M., \& Jacobs, M.A. (2006) MS-nose flavour release profile mimic using an olfactometer. In: Bredie, W., \& Petersen, M.A. (Eds.), Developments in Food Science; Flavour Science, Recent Advances and Trends. London: Elsevier 43: 585-599.

19. Taylor, A.J., Linforth, R.S.T., Harvey, B.A., \& Blake, A. (2000) Atmospheric pressure chemical ionization mass spectroscopy for in vivo analysis of volatile flavor release. Food Chem. 71: 327-338.

20. Harris, J.A., \& Benedict, F.G. (1919) A Biometric Study of Basal Metabolism in Man (Publication no. 279). Washington, DC: Carnegie Institute of Washington.

21. Aitken, R.C. (1969) Measurement of feelings using visual analogue scales. Proc. Roy. Soc. Med. 62: 989-993.

22. Shepherd, R., Farleigh, C.A., \& van Wharf, S.G. (1991) Effect of quantity consumed on measures of liking for salt concentrations in soup. J. Sens. Stud. 6: 227-238.

23. Schilstra, A.J. (1981) Meal-interval correlations: what can they tell us? Physiol. Behav. 27: 299-304.

24. Veldhorst, M.A.B., Nieuwenhuizen, A.G., Hochstenbach-Waelen, A., Westerterp, K.R., Engelen, M.P.K.J., Brummer, R.J.M., Deutz, N.E.P., \& Westerterp-Plantenga, M.S. 2009. Comparison of the effects of a high- and normal- casein breakfast on satiety, 'satiety' hormones, plasma amino acids and subsequent energy intake. $\mathrm{Br}$. J. Nutr. 101: 295-303. 


\title{
Effects of aroma-texture congruency within dairy custard on satiation and food intake
}

\author{
Rianne M.A.J. Ruijschop
}

Adapted from:

Harthoorn, L.F., Ruijschop, R.M.A.J., Weinbreck, F., Burgering, M.J., de Wijk, R.A., Ponne, C.T., \& Bult, J.H.F. Food Quality \& Preference (2008) 19: 644-650 doi:10.1016/j.foodqual.2008.05.004 


\section{ABSTRACT}

This study investigated if congruency in different aroma-texture combinations within a dairy product influences satiation and food consumption in humans. Among seven different aromas, vanilla was rated as congruent and lemon as incongruent aroma in the context of creamy texture, while both aromas were highly liked and familiar. Creamy custard, either vanilla- or lemon-aromatised, was given to 32 subjects in a preload-ad libitum regimen. Satiation was measured on visual analogue scales. Finally, the amount of ad libitum intake was determined. No effects of congruency were found on ad libitum consumption and perceived satiation. Subjects felt significantly more satiated when preload and ad libitum intakes shared the identical aroma compared to varied aromas. In conclusion, there was no relation between congruency in aroma and texture in dairy custard and food intake, but aroma perception possibly modulates perceived satiation.

Keywords: Appetite; Aroma; Congruency; Custard; Energy intake; Texture 


\section{INTRODUCTION}

As food is eaten, continued exposure to its appearance, taste, mouth feel and smell, may result in reduced pleasantness and desire to eat that specific food. This phenomenon is called "sensory-specific satiety" because it occurs in the relatively short-term before a meal is digested and absorbed ${ }^{(1-3)}$. Taste-, aroma-, texture- and appearance-specific satieties have been identified (e.g. 1, 4-10). Factors that interrupt continued exposure, i.e. distractors introduced during a meal or variety in food and sensory properties, delay the expected decrease in appetite ${ }^{(11-12)}$. This implies that, when a food is eaten, introducing another food with different sensory properties slows the decline in desire to eat the food and increases meal size.

Previous studies have shown that aromas may enhance perceived taste intensity ${ }^{(13-}$ 14), and even perceived properties like thickness and creaminess ${ }^{(15)}$, provided that the aroma matches the sensory property that is enhanced. The perceptual match between aroma on the one hand and taste and texture on the other hand is referred to as aromataste and aroma-texture congruency. Aroma-taste and aroma-texture congruency may be exploited to influence the perceived taste- and texture properties of a food without changing its macronutrient composition. Assuming that the total amount of exposure to a food's sensory properties defines the total decline in desire to eat, it is expected that an enhancement of sensory properties by a congruent aroma will further reduce desire to eat. Hence, two determinants of meal size may be distinguished, i.e. congruency of taste, mouth feel and aroma within one stimulus and variation in successive exposure to taste, mouth feel or aroma. Meal sizes may then be reduced by increasing the congruency of combinations of aroma, texture and taste or by reducing the sensory variation in successively presented foods.

The present study was designed to determine if the level of congruency and temporal variation in sensory input of aroma-texture combinations influence satiation and subsequent food intake. It was hypothesised that satiation and food intake are affected by the level of congruency as well as by variation of successive exposure to aromatexture combinations. Using a regimen of a fixed preload followed by an ad libitum meal of the creamy custard, the effects of four possible aroma combinations (either congruent or incongruent with creamy texture) on the amount of ad libitum food intake were tested in a two-by-two full-factorial design.

\section{SUBJECTS AND METHODS}

\section{Subjects}

Thirty-two healthy women, aged between 20 and 40 years, participated in this study. They were recruited and screened for dietary restraint, eating disinhibition and hunger using a validated Dutch translation of the three-factor eating questionnaire ${ }^{(16-17)}$. Smokers and subjects with prescribed medication, except for contraceptives, were 
excluded from participating in the study. Subjects were paid for their involvement, and gave informed consent. Testing took place at NIZO Food Research (Ede, The Netherlands) in a laboratory setting by trained staff on four consecutive morning sessions of $1 \frac{1}{2} \mathrm{~h}$ each, from 8:15 a.m. to 9:45 a.m., with a minimum interval of 1 week between each session. All subjects arrived in a fasting state. Individual weight and height were measured while subjects wore indoor clothing and no shoes. The subjects were normal-weight subjects with a body mass index (BMI) varying between 20 and 25 $\mathrm{kg} \mathrm{m}^{-2}$, calculated as weight $(\mathrm{kg})$ divided by height $(\mathrm{m})$ squared.

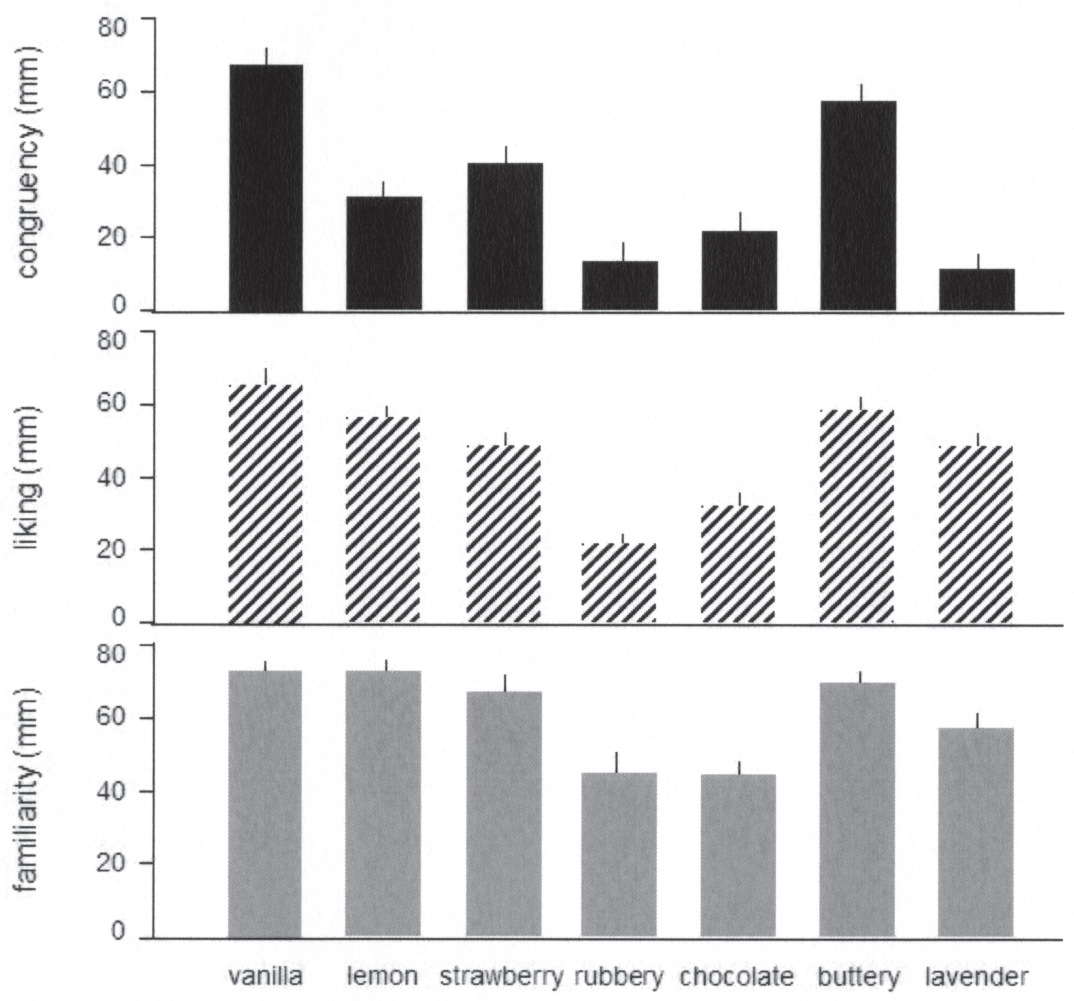

Figure 6.1 Ratings of congruency to creamy texture, liking and familiarity of seven different aromas measured during intake of non-aromatised creamy custard. Values are means with their standard errors depicted by vertical bars.

\section{Aromas}

Five food-related aromas, i.e. vanilla (vanillin; $5 \mathrm{~g} / \mathrm{L}$ ), lemon (citral; $2.5 \mathrm{~mL} / \mathrm{L}$ ), strawberry (European COST 921 action; $2.5 \mathrm{~mL} / \mathrm{L}$ ), chocolate (3-methylbutanal; 2.5 $\mathrm{mL} / \mathrm{L}$ ) and buttery (2,3-butanedione; $2.5 \mathrm{~mL} / \mathrm{L})$, and two non-food related aromas, i.e. rubbery (benzothiazol; $2.5 \mathrm{~mL} / \mathrm{L}$ ) and lavender (2,6-dimethyl-2-heptanol; $12.5 \mathrm{~mL} / \mathrm{L}$ ), were evaluated for their level of congruency with creamy texture as well as for liking and 
familiarity. Hereto, fifty-one panellists took a spoon full of the non-aromatised creamy custard while smelling the seven different aromas separately using dedicated flavour test strips (Aldrich, Zwijndrecht, The Netherlands). Subjects rated the congruency ("how well does this aroma fit with the custard?") of each aroma with the creamy texture of the custard and aroma-liking ("how much do you like this aroma?") and familiarity ("how familiar are you with this aroma?") using a 100-mm visual analogue scales (VAS) labelled with "not at all" and "very much" at their ends. To control for possible effects of familiarity or liking of the used aromas with intake measures, aromas were used that had received different congruency ratings with respect to the product in which they were used, but similar liking and familiarity ratings. Of the aromas associated with foods, vanilla aroma was perceived as most congruent with respect to a creamy texture (Figure 6.1) (2A02405, $2000 \mathrm{ppm})$ and lemon aroma was perceived as incongruent with respect to creamy texture (Figure 6.1) (DU64668, $1000 \mathrm{ppm}$ ). Aroma concentrations were matched with regard to their subjective intensities in the custard.

\section{Product preparation}

Batches of non-aromatised creamy custard of $566 \mathrm{~kJ} / 100 \mathrm{~g}$ were produced by Friesland Foods (Deventer, The Netherlands) and contained 90\% milk, 3.1\% starch, and 6.5\% sugar, which corresponds to $7.6(\mathrm{w} / \mathrm{w}) \%$ fat, $14.1(\mathrm{w} / \mathrm{w}) \%$ carbohydrates, and 3.2 $(\mathrm{w} / \mathrm{w}) \%$ protein. Each batch was surveyed for microbiological safety and approved if appropriate according to the guidelines of the Dutch Food and Drug Act (VWS/VWA) and the European Directive 2073/2005. The two aromas were added to the creamy custard following a standard procedure of continuous stirring. Then the custards were left at $5^{\circ} \mathrm{C}$ for at least $36 \mathrm{~h}$ before testing by the panellists, to allow a good equilibration of the aroma within the product.

\section{Design and procedure}

The subjects firstly consumed the fixed preload consisting of a $150 \mathrm{~g}$ portion $(850 \mathrm{~kJ})$ of either the vanilla- or the lemon-aromatised custard within $5 \mathrm{~min}$, as illustrated in Figure 6.2. The amount of preload was fixed and not individually standardised, since we had to ascertain that all subjects had a similar sensory exposure to the preload. Possible effects on satiation and food intake were thought to be sensory-related. Then, 15 min after finishing the preload intake, subjects were offered an ad libitum meal of $900 \mathrm{~g}$ of either the vanilla- or the lemon-aromatised custard, and were asked to eat of this portion as much as they would like until they felt pleasantly full. Congruency (high vs. low) and sensory variety in time of aroma-texture combinations were manipulated in a two-by-two full factorial design. After ad libitum consumption, the left-over of the custards were weighed, and the amount of custard eaten was calculated. At eight specific time points during the test session, subjects were asked to rate their perceived 
satiation ("how satiated are you?") on 100-mm VAS, anchored at their ends by the descriptors "not at all" and "very much" (Figure 6.2), as previously described ${ }^{(18)}$. In addition, after preload and after ad libitum consumption, subjects rated their liking for the product consumed ("how much do you like the product?") using 100-mm VAS with the descriptors "not at all" and "very much" at their ends (Figure 6.2).

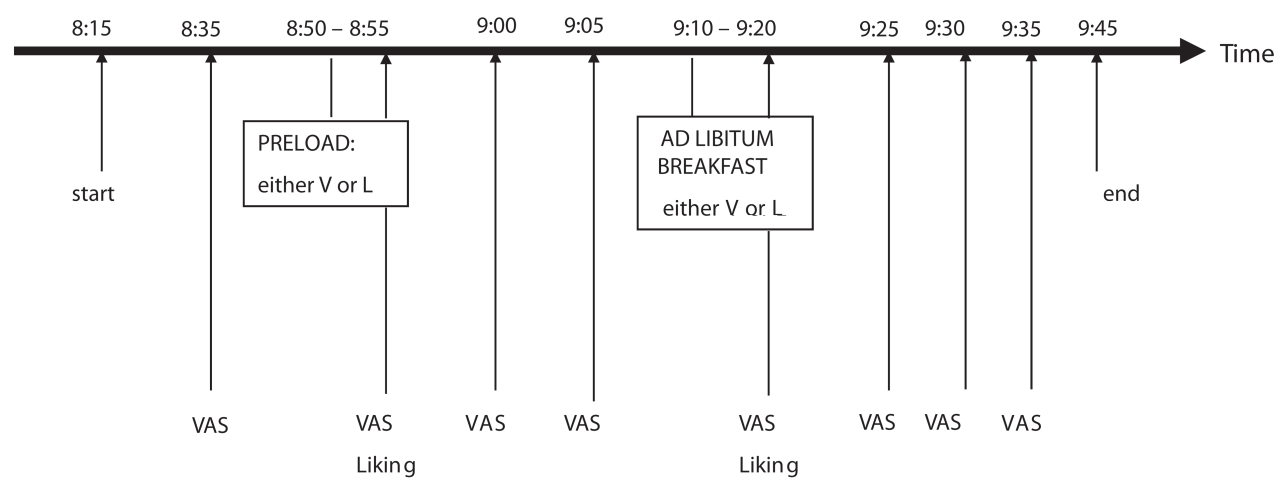

Figure 6.2 Experimental setup with a preload-ad libitum regimen of four possible aroma ( $\mathrm{V}=$ vanilla, L=lemon) combinations.

\section{Data analysis}

Data are expressed as mean \pm SEM, unless otherwise specified. VAS ratings on congruency, liking, familiarity, and satiation were measured in $\mathrm{mm}$ from the "not at all" end. Changes (delta) in satiation ratings were calculated by subtracting the rating at the time point before preload consumption from the ratings at the different time points after preload and ad libitum intake. Effects of aroma-texture congruency and variation of successive exposure of aroma-texture combinations were tested on the amount of different aromatised custards consumed ad libitum and delta satiation rating. Liking ratings were compared between the two aromatised custards at the two time points, i.e. after preload and ad libitum intake. Effect of time was tested for delta satiation ratings. Also the effect of aroma type of the ad libitum meal was tested for the amount of ad libitum intake and for delta satiation ratings after the ad libitum intake. All effects were tested by repeated measures analysis of variance (ANOVA) by either using the GLM procedure (i.e. excluding an effect of time) and a mixed-model ANOVA (i.e. including an effect of time) for repeated measures, with participant and type of aroma (or aroma combination) as independent variables. For example, the effect of type of aroma combination on ad libitum intake was tested by the GLM procedure, while the effect of type of aroma combination on differences in delta satiation ratings per timepoint was analysed by using a mixed-model ANOVA. Least Squares Means were used for post-hoc comparisons. Differences with P-values of 0.05 or less were considered to be statistically significant. All data were analysed by using the statistical packages SAS (version 9.1; SAS Institute, Cary, NC, USA). 


\section{RESULTS}

For all 32 subjects mean age $( \pm$ SD) was $29.3 \pm 6.2$ years and mean BMI $( \pm$ SD) was 23.4 $\pm 1.9 \mathrm{~kg} \mathrm{~m}^{-2}$.

Congruency, liking and familiarity ratings

Congruency scores of aromas with respect to the creamy custard were highest for vanilla $(67 \pm 3 \mathrm{~mm})$, followed by buttery $(57 \pm 3 \mathrm{~mm})$ and strawberry $(40 \pm 3 \mathrm{~mm})$ aroma (Figure 6.1). Figure 6.1 further shows that lemon $(31 \pm 3 \mathrm{~mm}$ ) and chocolate (22 $\pm 3 \mathrm{~mm})$ scored considerably less on congruency, whereas rubbery $(13 \pm 3 \mathrm{~mm})$ and lavender (11 $\pm 3 \mathrm{~mm}$ ) were very incongruent aromas with respect to the creamy custard $\left(\mathrm{F}_{(6,50)}=47.69 ; \mathrm{P}<0.01\right)$. Liking scores for vanilla $(65 \pm 3 \mathrm{~mm})$, buttery $(59 \pm 3$ $\mathrm{mm}$ ) and lemon (56 $\pm 3 \mathrm{~mm}$ ) aromas were highest, whereas liking scores for strawberry $(48 \pm 3 \mathrm{~mm})$ and lavender $(48 \pm 3 \mathrm{~mm})$ aroma were lower, and chocolate $(32 \pm 3 \mathrm{~mm})$ and rubbery $(21 \pm 3 \mathrm{~mm})$ were lowest $\left(\mathrm{F}_{(6,50)}=22.12 ; \mathrm{P}<0.01\right)$. Furthermore, aromas of lemon (73 $\pm 3 \mathrm{~mm})$, vanilla $(72 \pm 3 \mathrm{~mm})$, buttery $(69 \pm 3 \mathrm{~mm})$ and strawberry (67 $\pm 3 \mathrm{~mm}$ ) were rated as highly familiar, while aromas of lavender (57 $\pm 3 \mathrm{~mm})$, rubbery $(45 \pm 3 \mathrm{~mm})$ and chocolate $(44 \pm 3 \mathrm{~mm})$ were rated lower for familiarity $\left(\mathrm{F}_{(6,50)}=14.30\right.$; $\mathrm{P}<0.01)$.

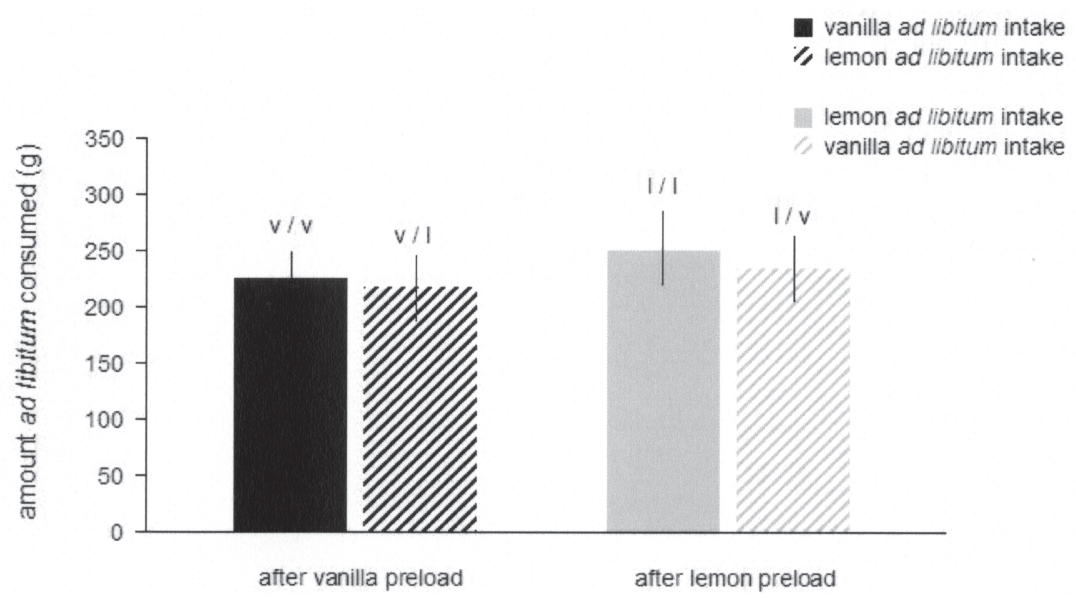

Figure 6.3 Intake of the different aromatised creamy custards after preload consumption. Values are means with their standard errors depicted by vertical bars.

\section{Ad libitum intake}

After vanilla-aromatised preload intake, the amount of vanilla- and lemon-aromatised custard consumed ad libitum was $228 \pm 31 \mathrm{~g}$ and $220 \pm 33 \mathrm{~g}$, respectively, while after lemon-aromatised preload intake, the amount of lemon- and vanilla-aromatised custard eaten ad libitum was $250 \pm 35 \mathrm{~g}$ and $237 \pm 33 \mathrm{~g}$, respectively (Figure 6.3). These 
amounts did not differ significantly between the two preload conditions, so no effect of congruency was found with respect to the food intake amount $\left(\mathrm{F}_{(1,31)}=0.85 ; \mathrm{P}=0.36\right)$. Also, no effects were found for variety of aroma combinations $\left(F_{(1,31)}=0.26 ; P=0.61\right)$ and aroma type of the ad libitum meal $\left(\mathrm{F}_{(1,31)}=0.01 ; \mathrm{P}=0.93\right)$ on the ad libitum amount eaten. The averaged amount of custard consumed ad libitum was $241 \pm 16 \mathrm{~g}$ (1365 \pm 92 $\mathrm{kJ})$, irrespectively of preload.

\section{Satiation ratings}

Immediately after preload consumption and 5 and 10 min after preload intake, delta satiation VAS ratings was $21 \pm 3 \mathrm{~mm}$ for vanilla-aromatised custard and $21 \pm 3 \mathrm{~mm}$ for lemon-aromatised custard. No effect of aroma-texture congruency was found on delta perceived satiation for the two differently aromatised intakes as measured at 5 min after preload intake $\left(\mathrm{F}_{(1,977)}=0.17 ; \mathrm{P}=0.69\right)$. After ad libitum consumption, the averaged delta satiation VAS rating was $39 \pm 3 \mathrm{~mm}$ as compared to before preload intake. An effect of variety in aroma-texture combinations on successive intakes was demonstrated for the delta satiation VAS ratings measured at $5 \mathrm{~min}$ after the ad libitum meal $\left(\mathrm{F}_{(1,31)}=5.30 ; \mathrm{P}=0.03\right)$ (Figure 6.4), whereas no effect of last aroma type was found $\left(\mathrm{F}_{(1,31)}=0.46 ; \mathrm{P}=0.50\right)$. Thus, consumption of identically aromatised preload and ad libitum meals resulted in higher delta satiation ratings than varied aromatised successive meals.

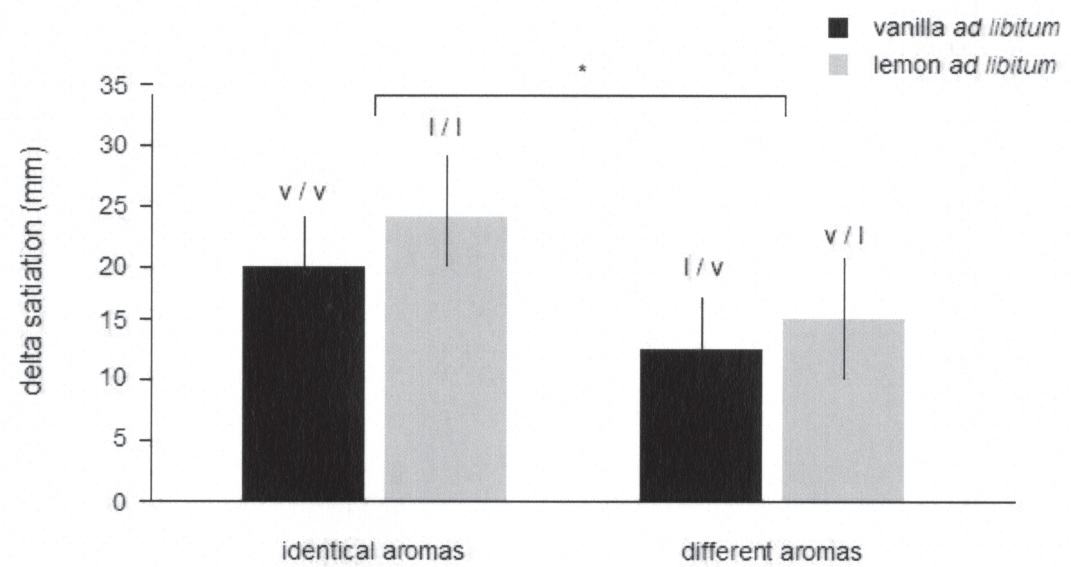

Figure 6.4 Change (delta) in satiation VAS ratings after ad libitum consumption as compared to before ad libitum intake for the different aroma combinations. Values are means with their standard errors depicted by vertical bars. ${ }^{*}$ denotes effect of variety in aroma-texture combinations on successive intakes on change in satiation VAS rating with $\mathrm{P}<0.05$.

\section{Liking ratings}

With respect to liking of the vanilla- and lemon-aromatised custards rated after 
consumption of preload and ad libitum meal, subjects evaluated these two aromatised custards significantly different (Figure 6.5), which is in line with the previous results on liking (Figure 6.1). After preload intake, in one occasion, lemon-aromatised was less liked than vanilla-aromatised custard $\left(\mathrm{F}_{(3,31)}=4.97 ; \mathrm{P}=0.047\right)$. After ad libitum consumption, also in one occasion, the liking of lemon-aromatised custard was lower than the vanilla-aromatised custard $\left(\mathrm{F}_{(3,31)}=4.51 ; \mathrm{P}=0.049\right)$. Adjusting the statistical analysis for the difference in liking between the lemon- and vanilla-aromatised custards, aforementioned results regarding ad libitum intake and delta satiation VAS ratings were not significantly affected.

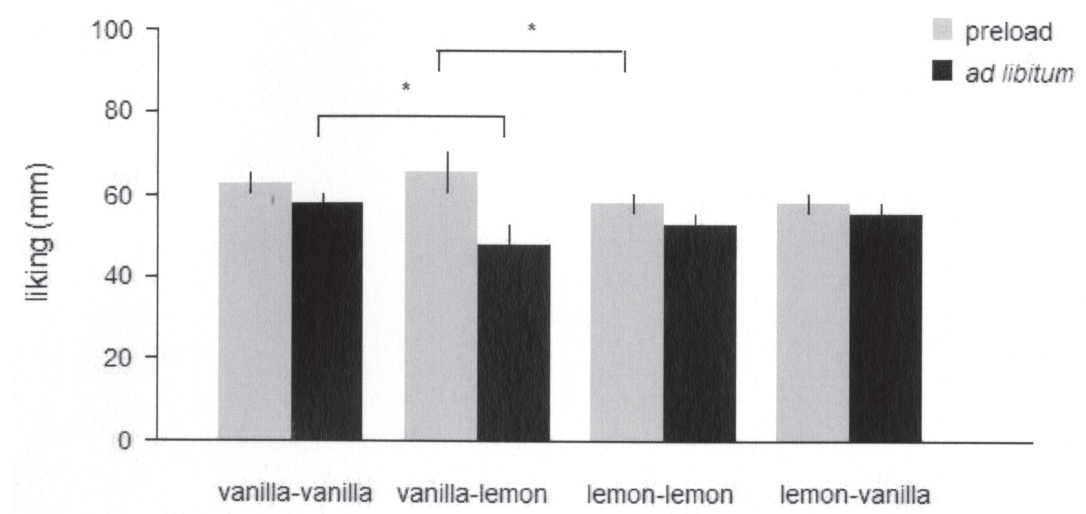

Figure 6.5 Liking VAS ratings for the two aromatised custards measured after preload and ad libitum intake at all four combinations were slightly different. Values are means with their standard errors depicted by vertical bars. * denotes effect of type of aromatised custards on liking VAS rating with $\mathrm{P}$ $<0.05$.

\section{DISCUSSION}

In the present study, effects of congruency level of aroma-texture combinations within dairy custard and the effects of successive aroma variation of dairy custards were evaluated on satiation and the amount of food intake in humans. A preload-ad libitum intake regimen of creamy custards, aromatised with either a vanilla or a lemon aroma, congruent or incongruent to creamy texture, respectively, resulted in four possible combinations of aromatised custard consumption. In spite of the different congruency scores of these two aromas with respect to the custard, their liking and familiarity are more or less the same indicating that both aromas are well-recognised and congruency scores do not depend on familiarity scores. This gave the opportunity to study not only the amount of ad libitum intake possibly influenced by aroma-texture congruency and different successive aroma-texture combinations, but also to follow satiation patterns, that possibly influence the amount of a subsequent ad libitum meal in a fixed time period. 
The presence of different aromas within custards did not influence the amounts of ad libitum intake, which shows that there was no effect of aroma-texture congruency of dairy custard on ad libitum food consumption. While the amount eaten ad libitum is a direct inverse measure for satiation for the custard, this finding is further substantiated by unchanged satiation during the different intakes. However, it is questionable whether the applied experimental setup of a preload-ad libitum intake regimen was appropriate to demonstrate an effect of aroma-texture congruency on satiation and food intake (i.e. meal termination). A follow-up study with ad libitum intake only, i.e. not preceded by a preload, is hypothesised to be more appropriate to determine the effect of aroma-texture congruency on meal termination.

With regard to variation in successive exposure to aroma-texture combinations within dairy custard, subjects did not differ in their amount of ad libitum consumed custard between similarly-aromatised custards in succession and varied-aromatised custard combinations. However, the increase in perceived satiation VAS ratings was significantly less after consuming custards accompanied by different aromas in varied compared to identical combinations. As discussed by Veldhorst et al. ${ }^{(19)}$, it is likely that the magnitude of the effect in perceived satiation was too small to have an effect on the amount consumed ad libitum. Veldhorst et al. ${ }^{(19)}$ showed that differences in appetite ratings in a preload-ad libitum meal design need to be at least larger than $15 \mathrm{~mm}$ VAS in order to have a significant effect on subsequent energy intake. In the present study, the difference in satiation VAS ratings between similar- and varied-aromatised custards combinations in succession was on average $7.5 \mathrm{~mm}$ VAS (Figure 6.4). Although the vanilla-and lemon-aromatised custards were expected to contrast considerably, it may be that the difference between both custards still remained within the band-width of sensory-specific satiety. Comparably, Rolls et al. ${ }^{(20)}$ could neither demonstrate an enhancement of food intake when a variety of yoghurt was offered which differed only in taste (i.e. strawberry, raspberry and cherry). Albeit possible effects on satiation and food intake were thought to be sensory-specific, the fixed preload provided a considerable amount of energy that might have also affected metabolic satiety. Since the amount of preload was fixed and not individually standardised, the amount consumed in proportion to a subject's daily dietary energy requirement was different among the subjects. Therefore, different starting-point in the subjects' relative energy intake after preload consumption might also have affected the amount consumed ad libitum.

Although, not attributed to differences in the ad libitum food consumption, the lower increase in perceived satiation VAS ratings after consuming varied-aromatised custard combinations might point to a 'seeking for variety' principle in ad libitum meal situations, which has been reported previously on subjects eating sandwiches or yoghurts distinctive in taste, texture, and appearance ${ }^{(20)}$. Interestingly, in the present study feelings of variety-seeking were induced by merely changing the aroma type of the product, while other food characteristics like appearance and ingredient composition, 
which largely determines texture, remained the same.

In this study subjects evaluated liking of the vanilla- and lemon-aromatised custards differently. First, liking of vanilla-aromatised custard was slightly higher compared to lemon-aromatised custard after preload intake. Second, after vanilla-aromatised preload consumption subjects liked the lemon-aromatised custard in the ad libitum meal less than the vanilla-aromatised one. Whether this is due to a difference in liking only or also to changes in perceived satiation is unclear. Liking assessments are complex, since different psychological or functional components of pleasure of eating can be distinguished as separate neural substrates mostly driven without conscious awareness ${ }^{(21)}$.

To summarise, the present study demonstrates that feelings of variety-seeking were induced by merely changing the aroma type of dairy custard in successive exposure to aroma-texture combinations, while aroma-texture congruency within dairy custard did not affect satiation and food intake.

\section{ACKNOWLEDGEMENTS}

Ms. Corine van Geffen (Givaudan, Naarden, The Netherlands) and Ms. Renske Asma (Friesland Foods, Deventer, The Netherlands) are gratefully acknowledged for providing the aromas and the custards, respectively.

\section{REFERENCES}

1. Rolls, B.J., Rowe, E.A., \& Rolls, E.T. (1982). How sensory properties of food affect human feeding behaviour. Physiol. Behav. 29: 409-417.

2. Hetherington, M.M. (1996). Sensory-specific satiety and its importance in meal termination. Neurosci. Biobehav. Rev. 20: 113-117.

3. Sorensen, L.B., Moller, P., Flint, A., Martens, M., \& Raben, A. (2003) Effect on sensory perception of foods on appetite and food intake: a review of studies on humans. Int. J. Obes. Relat. Metab. Disord. 27: 1152-1166.

4. Hirsch, A.R., \& Gomez, R. (1995) Weight reduction through inhalation of odorants. J. Neurol. Orthop. Med. Surg. 16: 28-31.

5. Mayer, S.N., Davidson, R.S., \& Hensley, C.B. (1999) The role of specific olfactory stimulation in appetite suppression and weight loss. J. Adv. Med. 12: 13.

6. O’Doherty, J., Rolls, E.T., Francis, S., Bowtell, R., McGlone, F., Kobal, G., Renner, B., \& Ahne, G. (2000). Sensory-specific satiety related olfactory activation of the human orbitofrontal cortex. Neuroreport 11: 893-897.

7. Ruijschop, R.M.A.J., Boelrijk, A.E.M., de Ru, J.A., de Graaf, C., \& WesterterpPlantenga, M.S. (2008) Effects of retro-nasal aroma release on satiation. Br. J. Nutr. 99: 1140-1148. 
8. De Graaf, C., Shreurs, A., \& Blauw, Y.H. (1993). Short-term effects of different amounts of sweet and non-sweet carbohydrates on satiety and energy intake. Physiol. Behav. 54: 833-843.

9. Guinard, J., \& Brun, P. (1998). Sensory-specific satiety: comparison of taste and texture effects. Appetite 31: 141-157.

10. Maier, A., Vickers, Z., \& Jeffrey Inman, J. (2007). Sensory-specific satiety, its crossovers, and subsequent choice of potato chip flavours. Appetite 49: 419-428.

11. Brunstrom, J.M., \& Mitchell, G.L. (2006) Effects of distraction on the development of satiety. Br. J. Nutr. 96: 761-769.

12. Romer, M., Lehrner, J., van Wymelbeke, V., Jiang, T., Deecke, L., \& Brondel, L. (2006) Does modification of olfacto-gustatory stimulation diminish sensoryspecific satiety in humans? Physiol. Behav. 87: 469-477.

13. Schifferstein, H.N.J., \& Verlegh, P.W.J. (1995). The role of congruency and pleasantness in odor-induced taste enhancement. Acta Psychol. 94: 87-105.

14. Frank, R.A., \& Byram, J. (1988). Taste-smell interactions are tastant and odorant dependent. Chem. Senses 13: 445-455.

15. Bult, J.H.F., de Wijk, R.A., \& Hummel, T. (2007) Investigations on multimodal sensory integration: texture, taste, and ortho- and retronasal olfactory stimuli in concert. Neurosci. Lett. 411: 6-10.

16. Stunkard, A.J., \& Messick, S. (1985). The three-factor eating questionnaire to measure dietary restraint, disinhibition and hunger. J. Psychosom. Res., 29: 71-83.

17. Westerterp-Plantenga, M.S., Rolland, V., Wilson, S.A.J., \& Westerterp, K.R. (1999) Satiety related to $24 \mathrm{~h}$ diet-induced thermogenesis during high protein/ carbohydrate versus high fat diets, measured in a respiration chamber. Eur. J. Clin. Nutr. 53: 495-502.

18. Flint, A., Raben, A., Blundell, J.E., \& Astrup, A. (2000). Reproducibility, power and validity of visual analogue scales in assessment of appetite sensations in single test meal studies. Int. J. Obes. Relat. Metab. Disord. 24: 38-48.

19. Veldhorst, M.A.B., Nieuwenhuizen, A.G., Hochstenbach-Waelen, A., Westerterp, K.R., Engelen, M.P.K.J., Brummer, R.J.M., Deutz, N.E.P., \& Westerterp-Plantenga, M.S. 2009. Comparison of the effects of a high- and normal- casein breakfast on satiety, 'satiety' hormones, plasma amino acids and subsequent energy intake. $\mathrm{Br}$. J. Nutr. 101: 295-303.

20. Rolls, B.J., Rowe, E.A., Rolls, E.T., Kingston, B., Megson, A., \& Gunary, R. (1981). Variety in meal enhances food intake in man. Physiol. Behav. 26: 215-221.

21. Berridge, K.C. (1996) Food reward: brain substrates of wanting and liking. Neurosci. Biobehav. Rev. 20: 1-25. 


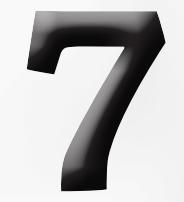

Effects of bite size and duration of oral processing on retro-nasal aroma release - features contributing to meal termination

Ruijschop, R.M.A.J., Zijlstra, N., Boelrijk, A.E.M.,

Dijkstra, A., Burgering, M.J.M., de Graaf, C., \& Westerterp-Plantenga, M.S.

Submitted for publication 


\section{ABSTRACT}

The brain response to a retro-nasally sensed food odour signals the perception of food and is suggested to be related to satiation. It is hypothesised that consuming food either in multiple small bite sizes or with a longer duration of oral processing may evoke substantial oral processing per gram consumed and an increase in transit time in the oral cavity. This is expected to result in a higher cumulative retro-nasal aroma stimulation, which in turn may lead to increased feelings of satiation and decreased food intake.

Using real-time atmospheric pressure chemical ionization-mass spectrometry (APcIMS), in vivo retro-nasal aroma release was assessed for 21 young, healthy, and normalweight subjects consuming dark chocolate-flavoured custard. Subjects were exposed to both free or fixed bite size ( $5 \mathrm{~g}$ and $15 \mathrm{~g}$ ) and duration of oral processing before swallowing ( $3 \mathrm{~s}$ and $9 \mathrm{~s}$ ) in a cross-over design. For a fixed amount of dark chocolateflavoured custard, consumption in multiple small bite sizes resulted in a significantly higher cumulative extent of retro-nasal aroma release per gram consumed compared to a smaller amount of large bite sizes. In addition, a longer duration of oral processing tended to result in a higher cumulative extent of retro-nasal aroma release per gram consumed compared to a short duration of oral processing. An interaction effect of bite size and duration of oral processing was not observed.

In conclusion, decreasing bite size or increasing duration of oral processing led to a higher cumulative retro-nasal aroma stimulation per gram consumed. Hence, adapting bite size or duration of oral processing indicates that meal termination can be accelerated by increasing the extent of retro-nasal aroma release and subsequently, satiation.

Key words: APcI-MS; MS-Nose; Retro-nasal aroma stimulation; Flavour; Satiation; Energy intake 
Bite size, oral processing time and retro-nasal aroma release |

\section{INTRODUCTION}

During the consumption of a meal, aroma molecules reach the olfactory epithelium retro-nasally (perceived as arising from the mouth) ${ }^{(1,2)}$. The brain response, i.e. neural brain activation, to a retro-nasally sensed food odour signals the perception of food and is suggested to be related to satiation ${ }^{(3)}$. The extent of retro-nasal aroma release during consumption depends on both product (i.e. the physical structure of a food, which has an influence on the breakdown and oral processing in the mouth $\left.{ }^{(4-7)}\right)$ and interpersonal differences ${ }^{(8)}$. Interpersonal differences are factors that are likely to be uncontrolled by a person, e.g. saliva production, nasal anatomy, and oral processing habits ${ }^{(9-13)}$. In addition to product and (uncontrolled) interpersonal features, bite size and duration of oral processing may also be of importance for the extent of retro-nasal aroma release.

Recently, Zijlstra et al. ${ }^{(14-15)}$ investigated the effect of bite size (i.e. either free or fixed $(5 \mathrm{~g}$ and $15 \mathrm{~g})$ ) and duration of oral processing (i.e. either free or fixed (3 $\mathrm{s}$ and $9 \mathrm{~s}$ )) for a semi-liquid food product (i.e. dark chocolate-flavoured custard) on satiation / ad libitum food intake. In the fixed eating conditions, subjects consumed significantly less when bite sizes were small ( $5 \mathrm{~g}$ for both short and longer duration of oral processing) compared to large ( $15 \mathrm{~g}$ for both short and longer duration of oral processing (bite size effect $\mathrm{P}<0.05$ ) and when duration of oral processing was $9 \mathrm{~s}$ compared to $3 \mathrm{~s}$ (oral processing time effect $\mathrm{P}<0.05)$. Ad libitum consumption in the free eating condition (without any chewing protocol) was comparable to the ad libitum consumption with large bite sizes. According to Zijlstra et al. ${ }^{(15)}$, the lower ad libitum food intake when consuming the custard in small bite sizes or with a longer duration of oral processing was likely explained by a longer oro-sensory exposure from the dark chocolate-flavoured custard to the sensory tactile and taste receptors in the oral cavity ${ }^{(16)}$. Longer orosensory exposure may accelerate sensory satiation, which in turn may lead to earlier meal termination ${ }^{(17-18)}$.

In this context, differences in the extent of retro-nasal aroma release may also be (partly) responsible for this effect, stimulating olfactory receptors. We hypothesise that differences in the extent of retro-nasal aroma release during consumption may be one of the reasons that people vary in their satiation characteristics, due to differences in perceived intensity, duration or quality of retro-nasal aroma stimulation. In a recent study we were able to show that a retro-nasally delivered aroma stimulus was capable of inducing satiation ${ }^{(19)}$. Therefore, the aim of this study was to provide an additional, possibly complementary, explanation for the ad libitum intake results obtained by Zijlstra et al. ${ }^{(15)}$ from a retro-nasal aroma release perspective. In addition, the results from the free eating condition served to determine whether interpersonal differences in the extent of retro-nasal aroma release can be linked to interpersonal differences in ad libitum food intake, as previously reported ${ }^{(8)}$. 


\section{SUBJECTS AND METHODS}

Subjects

Twenty-one healthy subjects (nine men and twelve women) aged $27 \pm 9$ years (mean \pm standard deviation) living in Ede, The Netherlands, and surroundings participated in this study. Initially, subjects were recruited from the subject population that participated in the study of Zijlstra et al. ${ }^{(14-15)}$. To prevent a lack of statistical power nine subjects were recruited in-house. Subjects did not have any previous experience with atmospheric pressure chemical ionization-mass spectrometry (APcI-MS) measurements. The subjects were of normal-weight, with a body mass index (BMI) varying between 19 and $25 \mathrm{~kg} \mathrm{~m}^{-2}$. BMI was calculated as body weight $(\mathrm{kg})$ divided by height $(\mathrm{m})$ squared. Subjects were fully informed about the course of the APcI-MS measurement and gave their written, informed consent. To prevent response-bias the participants were given no information about the hypothesis and nature of the predictions of the experiment. They were only aware of the fact that the study was about in vivo retro-nasal aroma release assessment.

\section{Food product}

Subjects consumed dark chocolate-flavoured custard (Royal FrieslandCampina, The Netherlands). The physical structure of the custard can be characterised as semi-liquid with a viscosity of $43 \pm 11 \mathrm{~s}$, as measured with a Posthumus funnel.

To check for a clear aroma signal in the APcI-MS measurement, the dark chocolateflavoured custard was spiked with methyl acetate. Methyl acetate (Sigma-Aldrich Chemie $\mathrm{GmbH}$, Germany) was applied as a volatile marker aroma molecule, which was rapidly and easily released from the food product matrix during consumption. The sensory quality of methyl acetate can be described as fruity and sweet. In finished consumer products methyl acetate concentrations vary from 0.1 to $30 \mathrm{mg} / \mathrm{kg}{ }^{(20)} .0 .1$ $\mathrm{mL}$ methyl acetate solution with a concentration of $100 \mathrm{~g} / \mathrm{kg}$, i.e. diluted 10 fold in propylene glycol (private label from a local pharmacy in Ede, The Netherlands), was added to $1 \mathrm{~L}$ dark chocolate-flavoured custard following a standardised procedure of 10 times gently stirring. The methyl acetate concentration in the dark chocolate-flavoured custard was $10 \mathrm{mg} / \mathrm{kg}$. The dark chocolate-flavoured custard product was left overnight at $4^{\circ} \mathrm{C}$ to allow a good equilibration of the aroma in the product.

The viscosity of the dark chocolate-flavoured custard product was not affected by the addition of methyl acetate. Nor were sensory differences perceived between the dark chocolate-flavoured custards with or without addition of methyl acetate $(P=0.12)$. This was evaluated by an in-house trained sensory panel (11 panelists), which performed a triangle test. 
Bite size, oral processing time and retro-nasal aroma release |

Measurement of the extent of retro-nasal aroma release with APCI-MS technology

To detect the aroma compounds with the highest response in retro-nasal aroma release, the dynamic headspace of the dark chocolate-flavoured custard product was measured. Aroma compounds in the air released from the artificial mouth ${ }^{(21)}$ were monitored by on-line sampling by an atmospheric pressure chemical ionization gas-phase analyzer (APcI-GPA) attached to a VG Quattro II mass spectrometer (MS-Nose; Micromass UK Ltd., Manchester, UK) ${ }^{(22-25)}$.

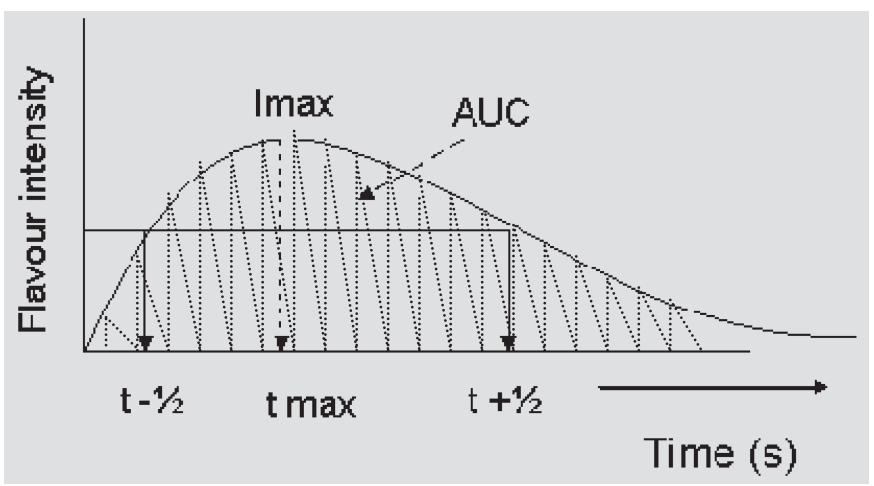

Figure 7.1 Schematic representation of a retro-nasal aroma release curve and its characteristic parameters ( $I_{\max }$ : maximum intensity [A.U.], $T_{\text {max }}$ : time at which maximal intensity occurs [min], AUC: total area under the curve [A.U.], $T_{-1 / 2}$ : time at which half of the maximal intensity occurs, before reaching maximum intensity [min], $T_{+1 / 2}$ : time at which half of the maximal intensity occurs, after reaching maximum intensity [min]).

Compounds were ionized by a $3.0 \mathrm{kV}$ discharge (source and probe temperature were $80^{\circ} \mathrm{C}$ ) and scanned for $\mathrm{m} / \mathrm{z} 50-250 . \mathrm{m} / \mathrm{z}$ values with the highest response were selected, i.e. $\mathrm{m} / \mathrm{z} 69, \mathrm{~m} / \mathrm{z} 75$ and $\mathrm{m} / \mathrm{z} 87$. Both $\mathrm{m} / \mathrm{z} 69$ and $\mathrm{m} / \mathrm{z} 87$ were originally present in the dark chocolate-flavoured custard, while $\mathrm{m} / \mathrm{z} 75$ represented the marker aroma molecule methyl acetate. In vivo retro-nasal aroma release was assessed in exhaled breath of the subjects. Subjects breathed in and out through the nose. One nostril was placed over a small disposable plastic tube, allowing them to breathe and eat normally. Aroma compounds in the air released from the breath of subjects were monitored by on-line sampling of part of the exhaled air directly into the APcI-MS. The air was sampled (75 $\mathrm{mL} / \mathrm{min})$ through a capillary tube $\left(0.53 \mathrm{~mm}\right.$ internal diameter, heated to $\left.100^{\circ} \mathrm{C}\right)$. The compounds were monitored in selected ion mode ( $0.08 \mathrm{~s}$ dwell on each ion). The cone voltage used was $20 \mathrm{~V}$.

Acetone, present in human breath, was measured at $\mathrm{m} / \mathrm{z} 59(19 \mathrm{~V})$ as an indicator of the breathing pattern ${ }^{(26)}$. The area of the resulting breath peaks in the aroma signal was taken as a measure of in vivo retro-nasal aroma release. Different parameters could be extracted from each individual retro-nasal aroma release curve, characterising the 
extent of retro-nasal aroma release, i.e. $\mathrm{T}_{-1 / 2}, \mathrm{~T}_{\max }, \mathrm{T}_{+1 / 2}, \mathrm{I}_{\max }$ and area under curve (AUC) (Figure 7.1). Since we were interested in comparative retro-nasal aroma release between subjects, expression of the extent of retro-nasal aroma release in arbitrary units (A.U.) was sufficient to analyze differences ${ }^{(22)}$.

\section{Experimental design}

In vivo retro-nasal aroma release was assessed in exhaled breath of the 21 subjects for the dark chocolate-flavoured custard product in quintuplicate according to a specific protocol established to determine the effect of bite size and oral processing time before swallowing on the extent of retro-nasal aroma release ${ }^{(14-15)}$. To this end, subjects were exposed to 5 different eating conditions in a cross-over design, in which bite size was either small (5 g) or large (15 g) and oral processing time before swallowing was either short (3s) or long (9s), or subjects were free to use their own natural eating habits, including free bite size and free oral processing time before swallowing. Treatment order for the fixed eating conditions was counterbalanced across both test days and subjects. In the free eating condition subjects consumed five times one mouthful of dark chocolate-flavoured custard product by means of a soup spoon without any chewing protocol. It has to be noticed that the size of the soup spoon may have affected the bite size in the free eating condition. In the fixed eating conditions subjects were instructed to put the dark chocolate-flavoured custard product (either 5 or $15 \mathrm{~g}$, presented in a syringe) in the mouth, to close the mouth, and to actively move the custard product in the mouth with the tongue for either 3 or $9 \mathrm{~s}$, thereby simulating oral processing in the mouth, and then to swallow the entire bolus. After consumption the syringe was weighed to determine the precise bite size of custard product per serving (MettlerToledo balance, Switzerland).

Between the different eating conditions the mouth was rinsed with water. Blank experiments with water were recorded before consuming the dark chocolate-flavoured custard product in the different eating conditions, following the same protocol as for the first fixed eating condition. These experiments served as a baseline measurement. The protocol for either the free or fixed eating conditions is represented schematically in Figure 7.2. During the measurements, the subjects were closely observed in order to verify compliance with the protocol.

\section{Measurement of ad libitum food intake}

For a subset of 12 subjects ( 5 men and 7 women; aged $21 \pm 3$ years (mean \pm standard deviation); BMI $22 \pm 1 \mathrm{~kg} \mathrm{~m}^{-2}$ (mean \pm standard deviation)), showing no dietary restraint (i.e. men: score $\leq 2.89$, women: score $\leq 3.40$ on Dutch Eating Behaviour Questionnaire), ad libitum food intake data of dark chocolate-flavoured custard product was available from a study of Zijlstra et al. ${ }^{(14-15)}$. In this study the effect of bite size and oral processing time for dark chocolate-flavoured custard on satiation / ad libitum food 
Bite size, oral processing time and retro-nasal aroma release |

APcI-MS measurement:

$1 \mathrm{~min}$ approximately until retro-nasal aroma Break (1 min

release intensity has again reached baseline approximately)

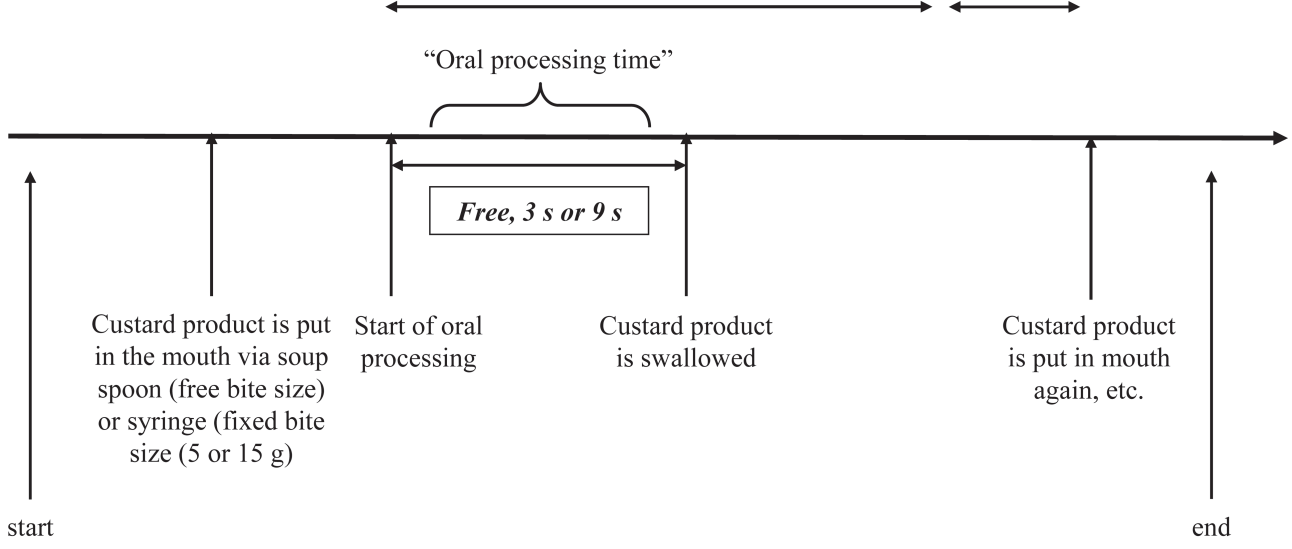

Figure 7.2 Overview of the protocol for in vivo retro-nasal aroma release assessment in either the free or different fixed eating conditions for the dark chocolate-flavoured custard product.

intake was determined. To assess whether interpersonal differences in the extent of retro-nasal aroma release can be linked to interpersonal differences in ad libitum food intake, the amount of dark chocolate-flavoured custard consumed ad libitum in the free eating condition in the satiation experiment performed by Zijlstra et al. ${ }^{(15)}$ was related to the extent of retro-nasal aroma release per gram consumed for these subjects in the free eating condition.

\section{Data analysis}

The quintuplicate measurements of the characteristic retro-nasal aroma release parameters $\left(\mathrm{T}_{\max }, \mathrm{I}_{\max }\right.$ and $\left.\mathrm{AUC}\right)$ for each subject per eating condition were averaged. This is allowed, since subjects are reproducible in their extent of retro-nasal aroma release during consumption of a specific food product ${ }^{(8,10)}$. Due to the lower signalto-noise ratio for the custard-specific $\mathrm{m} / \mathrm{z}$ values 69 and 87 compared to the marker aroma molecule with $\mathrm{m} / \mathrm{z}$ value 75 , the background noise, as measured with the blank experiments, was subtracted from the measurements with the dark chocolate-flavoured custard product in the different eating conditions per subject for all $\mathrm{m} / \mathrm{z}$ values.

All data are presented as means with their standard errors of the mean (SEM). The different characteristic retro-nasal aroma release parameters were compared between the five different eating conditions per bite size or per gram consumed by using the GLM procedure for repeated measures, with participant and type of eating condition as independent variables. Least squares means were used for post-hoc comparisons. Multiple regression analysis $(\mathrm{f}(\mathrm{x})$ ) was performed for the characteristic retro-nasal aroma release parameters $(y)$, and bite size $(x)$ and oral processing time before 
swallowing (x).

Additionally, the extent of retro-nasal aroma release (y) was linked to subject characteristics, such as age (x) and BMI (x), and ad libitum food intake (x), applying simple regression analysis $(\mathrm{f}(\mathrm{x}))$. For all data analyses the statistical packages SAS (release 9.1, SAS Institute Inc., USA) were used. P-values < 0.05 were considered statistically significant.

\section{RESULTS}

Bite size differences affecting the extent of retro-nasal aroma release

Bite size was $13.6 \pm 0.4 \mathrm{~g}$ per mouthful (range 6.7 - $18.2 \mathrm{~g}$ ) in the free eating condition.

\section{Consumption of a small vs. large bite size}

In the fixed eating conditions subjects consumed $5.7 \pm 0.4 \mathrm{~g}$ and $15.7 \pm 0.4 \mathrm{~g}$ for the small and large bite size, respectively. Subjects differed in the extent of retro-nasal aroma release regarding intensity $\left(\mathrm{I}_{\max }\right)$ and AUC of the retro-nasal aroma release profile during the consumption of either small or large bite sizes of dark chocolate-flavoured custard product in the fixed eating conditions $\left(\mathrm{F}_{(1,41)}=16.88 ; \mathrm{P}<0.01\right.$ and $\mathrm{F}_{(1,41)}=$ 27.50; $\mathrm{P}<0.01$ for $\mathrm{I}_{\max }$ and AUC, respectively). As illustrated by Figure 7.3 small bite sizes resulted in a significantly less intense retro-nasal aroma release characteristic for dark chocolate-flavoured custard product (Figure 7.3 A; mean $\mathrm{I}_{\max } \pm$ SEM: 3.62E+05 $\pm 2.77 \mathrm{E}+04$ A.U., and Figure $7.3 \mathrm{~B}$; mean AUC \pm SEM: $2.51 \mathrm{E}+06 \pm 1.73 \mathrm{E}+05$ A.U.) compared to large bite sizes (Figure 7.3 A; mean $\mathrm{I}_{\max } \pm$ SEM: 5.23E+05 $\pm 2.77 \mathrm{E}+04$ A.U., and Figure $7.3 \mathrm{~B}$; mean AUC \pm SEM: 3.79E+06 $\pm 1.73 \mathrm{E}+05$ A.U.). Bite size in the free eating condition showed comparable retro-nasal aroma release characteristics to small bite sizes for AUC and to large bite sizes for $\mathrm{I}_{\max }$ in the fixed eating conditions (Figure 7.3 A; mean $\mathrm{I}_{\max } \pm$ SEM: 4.82E+05 $\pm 3.54 \mathrm{E}+04$ A.U., and Figure 7.3 B; mean AUC \pm SEM: $2.75 \mathrm{E}+06 \pm 2.07 \mathrm{E}+05$ A.U.).

\section{Consumption of a fixed amount in a small or large bite size}

By expressing the effect of bite size on the extent of retro-nasal aroma release per gram consumed, a different view of the results was obtained. As shown in Figure 7.4 small bite sizes resulted in a significantly more intense retro-nasal aroma release characteristic for dark chocolate-flavoured custard product per gram consumed (Figure 7.4 A; mean $\mathrm{I}_{\max } \pm$ SEM: 6.34E+04 $\pm 3.10 \mathrm{E}+03$ A.U. per gram consumed, and Figure 7.4 B; mean AUC \pm SEM: $4.38 \mathrm{E}+05 \pm 1.77 \mathrm{E}+04$ A.U. per gram consumed) compared to large bite sizes (Figure 7.4 A; mean $\mathrm{I}_{\max } \pm$ SEM: $3.33 \mathrm{E}+04 \pm 3.10 \mathrm{E}+03$ A.U. per gram consumed, and Figure $7.4 \mathrm{~B}$; mean AUC \pm SEM: $2.40 \mathrm{E}+05 \pm 1.77 \mathrm{E}+04 \mathrm{~A} . \mathrm{U}$. per gram consumed) ( $\mathrm{F}_{(1,}$ ${ }_{41)}=47.33 ; \mathrm{P}<0.01$ and $\mathrm{F}_{(1,41)}=62.01 ; \mathrm{P}<0.01$ for $\mathrm{I}_{\max }$ and $\mathrm{AUC}$, respectively). There is almost a factor 2 of difference in retro-nasal aroma release $\mathrm{I}_{\max }$ and AUC per gram 
Bite size, oral processing time and retro-nasal aroma release |

A
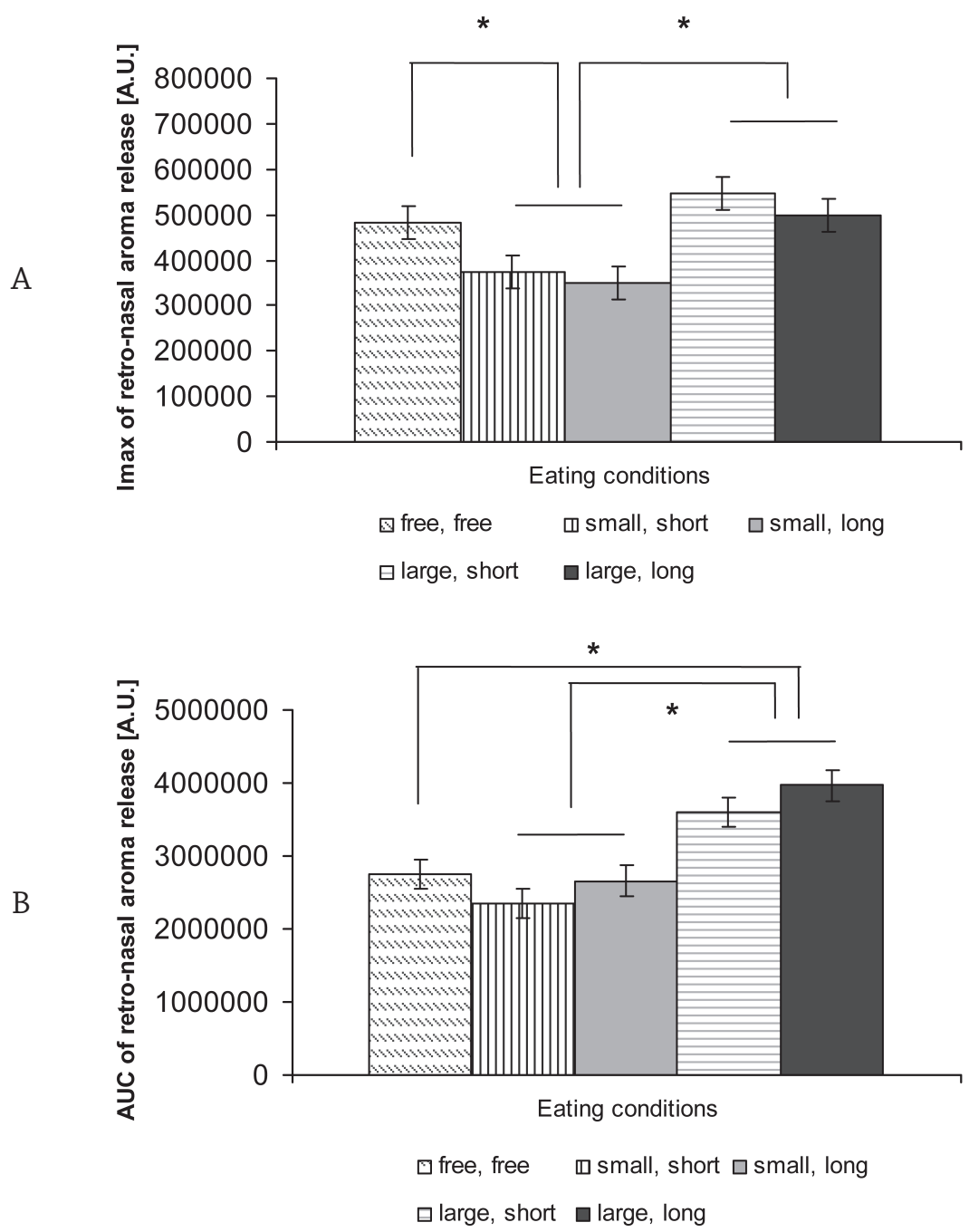

Figure 7.3 Illustration of the differences in retro-nasal aroma release intensity ( $\mathrm{I}_{\max }$-Figure 7.3 $\mathrm{A}$ and AUC-Figure 7.3 B) between the consumption of dark chocolate-flavoured custard product in either the free (free bite size and free oral processing time before swallowing (free, free)) or different fixed (small bite size and short oral processing time (small, short); small bite size and long oral processing time (small, long); large bite size and short oral processing time (large, short); and large bite size and long oral processing time (large, long)) eating conditions. Values are means with their standard errors depicted by vertical bars. ${ }^{*}$ denotes effect of bite size on retro-nasal aroma release intensity with $\mathrm{P}<$ 0.05 .

consumed between the small and large bite sizes. Bite size in the free eating condition showed comparable retro-nasal aroma release characteristics per gram consumed to the large bite sizes in the fixed eating conditions (Figure 7.4 A; mean $\mathrm{I}_{\max } \pm$ SEM: 4.12E+04 
A

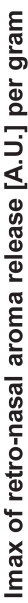

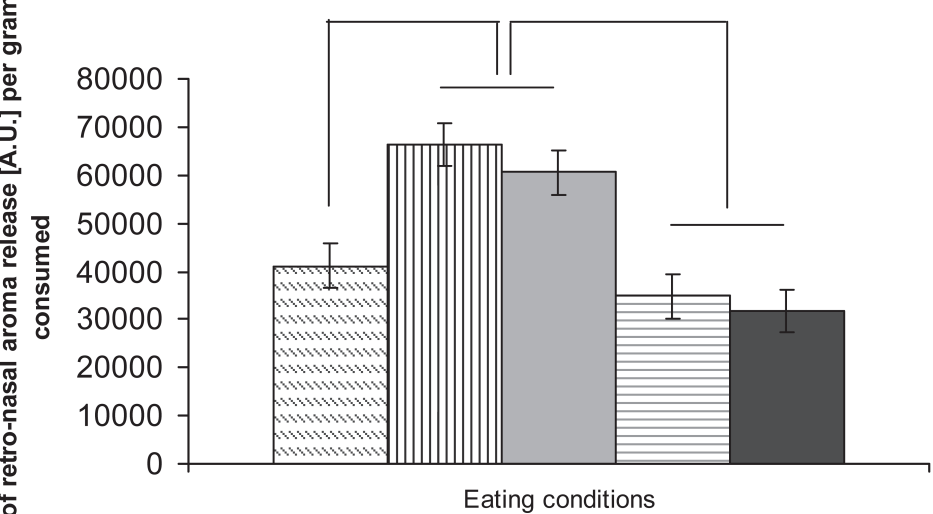
$\square$ free, free 凹small, short $\square$ small, long

alarge, short alarge, long

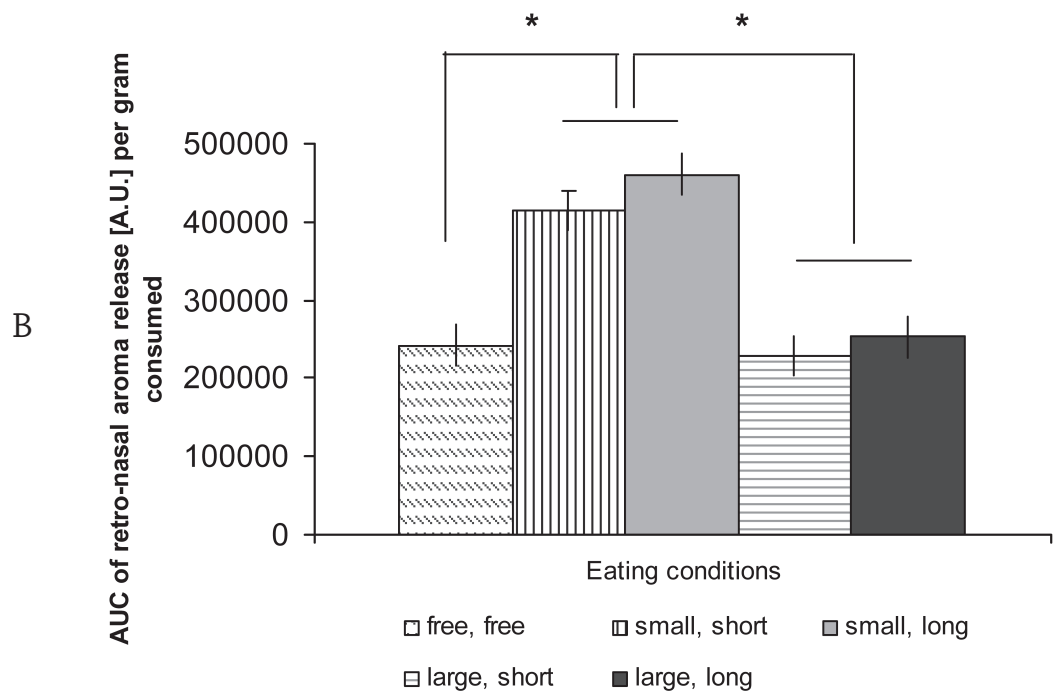

Figure 7.4 Illustration of the differences in retro-nasal aroma release intensity ( $\mathrm{I}_{\max }$-Figure 7.4 $\mathrm{A}$ and AUC-Figure 7.4 B) between the consumption of dark chocolate-flavoured custard product per gram consumed in either the free (free bite size and free oral processing time before swallowing (free, free)) or different fixed (small bite size and short oral processing time (small, short); small bite size and long oral processing time (small, long); large bite size and short oral processing time (large, short); and large bite size and long oral processing time (large, long)) eating conditions. Values are means with their standard errors depicted by vertical bars. ${ }^{*}$ denotes effect of bite size on retro-nasal aroma release intensity with $\mathrm{P}<0.05$. 
Bite size, oral processing time and retro-nasal aroma release |

\pm 4.56E+03 A.U. per gram consumed, and Figure 7.4 B; mean AUC \pm SEM: 2.42E+05 \pm $2.58 \mathrm{E}+04$ A.U. per gram consumed). When subjects were free to use their own natural eating habits, they consumed large bite sizes according to their extent of retro-nasal aroma release per gram consumed.

\section{Oral processing time differences affecting the extent of retro-nasal aroma release}

The morphology of the retro-nasal aroma release profile (in particular explained by $\mathrm{T}_{\max }$, i.e. time at which $\mathrm{I}_{\max }$ occurred) was different between the short ( $3 \mathrm{~s}$ ) and longer (9 s) duration of oral processing for a fixed bite size in the different fixed eating conditions (Figure 7.5; mean $\mathrm{T}_{\max } \pm \mathrm{SEM}$ for the small bite size: $0.16 \pm 0.01 \mathrm{~min}$ and $0.24 \pm 0.01$ min for the short and longer duration of oral processing, respectively; and mean $\mathrm{T}_{\max }$ \pm SEM for the large bite size: $0.16 \pm 0.01 \mathrm{~min}$ and $0.27 \pm 0.01 \mathrm{~min}$ for the short and longer duration of oral processing, respectively).

In compliance with the protocol, subjects swallowed later when they were exposed to the fixed eating condition of a given bite size and a longer duration of oral processing. Hence, a significant delay in $\mathrm{T}_{\max }$ was observed compared to the short duration of oral processing $(\mathrm{P}<0.01)$. In the free eating condition $\mathrm{T}_{\max }$ was $0.11 \pm 0.01 \mathrm{~min}$ (range $0.05-0.24 \mathrm{~min})$. Although significantly different from the fixed eating conditions $(\mathrm{P}<0.01), \mathrm{T}_{\max }$ in the free eating condition approximated the short duration of oral processing more than the longer duration of oral processing.

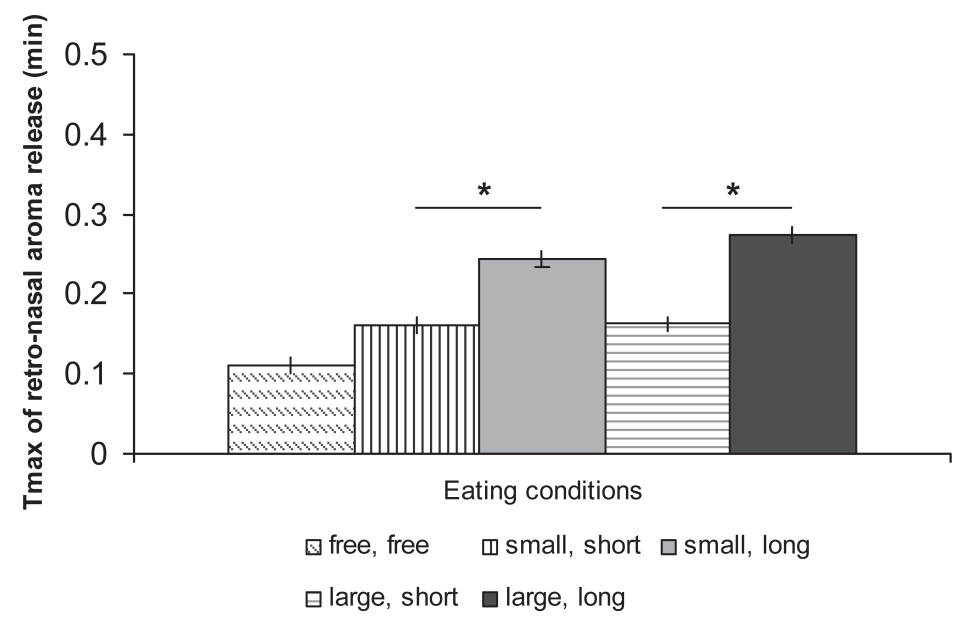

Figure 7.5 Morphology of the retro-nasal aroma release profile for the dark chocolate-flavoured custard product in the different eating conditions. There is a distinct difference in duration of oral processing for a fixed bite size in the different fixed eating conditions for $\mathrm{T}_{\max }$ (i.e. time at which maximal intensity occurs (minutes)). Values are means with their standard errors depicted by vertical bars. * denotes effect of duration of oral processing on $\mathrm{T}_{\max }$ with $\mathrm{P}<0.05$. 
Short vs. long duration of oral processing during consumption of different bite sizes Apart from differences in bite size affecting the extent of retro-nasal aroma release, differences in duration of oral processing time were also thought to be important for the extent of retro-nasal aroma release. A longer duration of oral processing resulted in a significantly higher extent of retro-nasal aroma release (AUC) for dark chocolateflavoured custard product in the fixed eating conditions (Figure 7.3 B; 2.98E+06 \pm $1.13 \mathrm{E}+05 \mathrm{~A} . \mathrm{U}$. and $3.31 \mathrm{E}+06 \pm 1.13 \mathrm{E}+05 \mathrm{~A} . \mathrm{U}$. for the short and longer duration of oral processing, respectively) $\left(\mathrm{F}_{(1,41)}=4.40 ; \mathrm{P}=0.04\right)$. The duration of oral processing in the free eating condition showed comparable retro-nasal aroma release characteristics to small bite sizes with both short and longer duration of oral processing for AUC and to large bite sizes with both short and longer duration of oral processing for $\mathrm{I}_{\max }$ in the fixed eating conditions.

Short vs. long duration of oral processing during consumption of a fixed amount

During the consumption of a fixed amount of dark chocolate-flavoured custard product, a longer duration of oral processing tended to result in a higher cumulative extent of retro-nasal aroma release (AUC) for dark chocolate-flavoured custard product per gram consumed in the fixed eating conditions (Figure 7.4 B; 3.22E+05 $\pm 1.40 \mathrm{E}+04$ A.U. per gram consumed and $3.57 \mathrm{E}+05 \pm 1.40 \mathrm{E}+04 \mathrm{~A}$.U. per gram consumed for the short and longer duration of oral processing, respectively) $\left(\mathrm{F}_{(1,41)}=3.16 ; \mathrm{P}=0.08\right)$. The duration of oral processing in the free eating condition showed comparable retro-nasal aroma release characteristics (AUC and $I_{\max }$ ) per gram consumed to both short and longer duration of oral processing of large bite sizes. The differences in bite size affected the extent of retro-nasal aroma release per gram consumed significantly compared to the difference in duration of oral processing in the fixed eating conditions $(\mathrm{y}=-1.92 \mathrm{E}+04 \mathrm{x}$ $+5.44 \mathrm{E}+05 ; \mathrm{R}^{2}=0.19 ; \mathrm{P}<0.01$ and $\mathrm{y}=5.85 \mathrm{E}+03 \mathrm{x}+3.04 \mathrm{E}+05 ; \mathrm{R}^{2}=0.01 ; \mathrm{P}=0.47$ for the effect of bite size ( $\mathrm{x}$ ) and duration of oral processing $(\mathrm{x})$ on the extent of retro-nasal aroma release per gram consumed (AUC; y), respectively). This indicates that the bite size effect presumably overwhelmed the effect of duration of oral processing. Therefore, it is likely that in the free eating condition bite size accounted for the present result rather than the duration of oral processing.

\section{DISCUSSION}

Using APcI-MS technology, in vivo retro-nasal aroma release was assessed for 21 subjects consuming dark chocolate-flavoured custard in either a free or fixed eating condition. Selected aroma compounds detected in the range of $m / z$ 20-250, i.e. aroma compounds with the highest response, showed comparable retro-nasal aroma release profiles for the dark chocolate-flavoured custard product. From previous work, it is known that aroma release data obtained for a single aroma compound (one specific $\mathrm{m} / \mathrm{z}$ value) 
Bite size, oral processing time and retro-nasal aroma release |

are a good predictor for the relative release of other aroma compounds (other $\mathrm{m} / \mathrm{z}$ values) ${ }^{(8)}$. Therefore, the same relative retro-nasal aroma release profile was measured, irrespective of the $m / z$ value taken. However, it appeared that the signal-to-noise ratio for the custard-specific $\mathrm{m} / \mathrm{z}$ values of 69 and 87 was lower compared to the marker aroma molecule with $\mathrm{m} / \mathrm{z}$ 75. The custard-specific $\mathrm{m} / \mathrm{z}$ values provided a less clear aroma signal in the APcI-MS measurements compared to the marker $m / z$ value. Although the sensory detection thresholds of both custard-specific aroma molecules were likely low enough to be detected by a human nose via the retro-nasal route, the 'MS Nose' might be less sensitive in detecting the custard-specific aroma molecules in a concentration as applied in dark chocolate-flavoured custard. After baseline correction, $m / z 75$ had the highest response for the dark chocolate-flavoured custard product and was selected for the in vivo retro-nasal aroma release measurements.

The extent of retro-nasal aroma release from small bite sizes of dark chocolate-flavoured custard product was significantly lower compared to large bite sizes (Figure 7.3). However, for a fixed amount of dark chocolate-flavoured custard product, consumption in numerous small bite sizes resulted in a significantly higher cumulative extent of retro-nasal aroma release per gram consumed compared to a smaller number of, but larger, bite sizes (Figure 7.4). These bite size effects were in line with our expectations. When subjects consumed large bite sizes, they were likely exposed to higher quantities of aroma molecules since in absolute value a larger bite size contains more aroma molecules than a smaller bite size. However, it should be mentioned that from the total amount of aroma molecules present in food, only a small fraction of the aroma is released into the nasal cavity during oral processing and swallowing. The majority of aroma molecules is swallowed together with the food matrix into the stomach and is no longer available for retro-nasal aroma perception ${ }^{(27)}$. Besides, large bite sizes presumably led to more frequent swallowing. Retro-nasal aroma stimulation is mainly related to the event of swallowing, when a small volume of air is exhaled immediately after swallowing, the so-called "swallow-breath". It is assumed that this pulse should contain the major part of food volatiles that have been released from the food product prior to swallowing, and should therefore elicit a retro-nasal aroma pulse ${ }^{(27-28)}$. Large bite sizes thus yielded a higher extent of retro-nasal aroma release, but per bite also a higher food intake compared to small bite sizes.

Alternatively, for the same amount of food intake, subjects had a higher cumulative extent of retro-nasal aroma release per gram if they consumed the custard in a multiple of small bite sizes compared to a smaller number of large bite sizes (Figure 7.4). For example, when subjects consumed a fixed amount of $15 \mathrm{~g}$ of dark chocolate-flavoured custard product in either one large or three small bite sizes, the multiple small bite sizes were hypothesised to evoke substantial oral processing per gram consumed and an increase in transit time in the oral cavity ${ }^{(8)}$. Accordingly, the three multiple small bite sizes of $5 \mathrm{~g}$ of dark chocolate-flavoured custard product were expected to lead to a 
higher cumulative retro-nasal aroma stimulation compared to the single large bite size of $15 \mathrm{~g}$.

In addition to the bite size effect, a longer duration of oral processing before swallowing tended to result in a higher cumulative extent of retro-nasal aroma release per gram consumed compared to a short duration of oral processing before swallowing (Figure 7.4). A longer duration of oral processing was thought to evoke an increase in transit time in the oral cavity and thereby result in a higher extent of retro-nasal aroma release. Besides, during a longer duration of oral processing the temperature of the dark chocolate-flavoured custard product in the mouth may further increase towards body temperature and likely more surface of the custard product is exposed to air, both resulting in a higher quantitative release of aroma molecules from the custard matrix. The effect of oral processing time was less strong than the effect of the bite size. With dark chocolate-flavoured custard as experimental food product, this result was not unexpected. The morphology of the retro-nasal aroma release curve for a custard product can be described as a relatively short and spiked retro-nasal aroma release pattern ${ }^{(8,24)}$.The more liquid food products have a relatively short transit time in the oral cavity and therefore hardly any oral processing is needed to swallow them. In the present study subjects actively moved the custard product in the mouth with the tongue for either 3 or $9 \mathrm{~s}$, thereby simulating oral processing in the mouth. However, the event of swallowing was probably not affected by varying the duration of oral processing. Therefore, the difference in duration of oral processing may not evoke a significant difference in retro-nasal aroma stimulation. The observed differences in the extent of retro-nasal aroma release between the short and longer duration of oral processing are likely to be due to intermittent opening of the connection of the oral cavity to the naso- and dorsal oropharynx. During the simulation of oral processing in the mouth, the velum was assumed to be open, which enabled air to proceed into the nasal cavity via the retro-nasal route through the velopharyngeal portal ${ }^{(10)}$. To strengthen this physiological effect, increasing the difference in duration between the short and longer duration of oral processing may enlarge the amount of air which reaches the nasal cavity via the retro-nasal route during an increased longer duration of oral processing. Alternatively, exposing subjects to a fixed protocol for swallowing, meaning that they have to swallow more frequently during the longer duration of oral processing compared to the short duration of oral processing, may increase the effect of oral processing time. It may even be more efficient than a longer duration of oral processing with respect to the extent of retro-nasal aroma release. Moreover, the choice of a more solid food product as experimental food product may strengthen the impact of a longer duration of oral processing on the extent of retro-nasal aroma release. Solid food products require considerable oral processing and swallowing, due to their firmer texture ${ }^{(8,10)}$. Since aroma pulses are generated along with each swallow-breath, solid food products generate a longer, more pronounced retro-nasal aroma release than 
Bite size, oral processing time and retro-nasal aroma release |

liquid food products ${ }^{(19)}$.

In the present study an interaction effect of bite size and duration of oral processing was not observed.

To summarise, small bite sizes contributed significantly to a higher cumulative extent of retro-nasal aroma release per gram, while a longer duration of oral processing tended to result in a higher extent of retro-nasal aroma release during consumption of a fixed amount. However, the effect of oral processing time may be significant with a more solid food product.

As reported by Zijlstra et al. ${ }^{(14-15)}$ consumption in small bite sizes or with a longer duration of oral processing resulted in a lower ad libitum food intake. The results of the present study provided an additional, possibly complementary, explanation for the ad libitum intake results obtained by Zijlstra et al. ${ }^{(15)}$ from a retro-nasal aroma release perspective, stimulating olfactory receptors. Differences in the extent of retro-nasal aroma release may thus be (partly) responsible for the decrease in food intake in certain eating conditions.

When subjects were free to use their own natural eating habits, including free bite size and free oral processing time before swallowing, the extent of retro-nasal aroma release per gram consumed reflected the extent of retro-nasal aroma release per gram consumed from large bite sizes, while duration of oral processing was more difficult to estimate. $\mathrm{T}_{\max }$ in the free eating condition approximated the short duration of oral processing more than the longer duration of oral processing (Figure 7.5). The physical structure of the custard product was likely responsible for this result. Generally, hardly any oral processing is needed under natural eating conditions to swallow (semi-)liquid food products.

In the present study for the subset of 12 subjects no significant relation was observed between the extent of retro-nasal aroma release per gram consumed in the free eating condition and the amount of dark chocolate-flavoured custard consumed ad libitum in the free eating condition in the satiation experiment done by Zijlstra et al. ${ }^{(15)}$. Nor were subject characteristics, such as gender, age and BMI, correlated with the extent of retronasal aroma release per gram consumed. This result was not unexpected, due to a lack of statistical power. The interpersonal differences in the extent of retro-nasal aroma release per gram consumed, which were hypothesised to be linked to the interpersonal differences in ad libitum food intake, were likely to be too small within the subset of 12 subjects. Subjects included were rather homogeneous, i.e. normal-weight and of similar age. A follow-up study with a larger subject population, which is more segmented with respect to age and $\mathrm{BMI}$, is needed to demonstrate a significant effect of the extent of retro-nasal aroma release on ad libitum food intake ${ }^{(8)}$.

The concept that small bite sizes or a longer duration of oral processing may lead to a higher cumulative retro-nasal aroma stimulation indicates that meal termination can be accelerated by increasing the extent of retro-nasal aroma release and subsequently, 
satiation. Bite size and duration of oral processing are features which may be subjected to behavioural changes as a result of for instance mindful eating ${ }^{(29)}$. In this context, one of the advices from dieticians when participating in a weight loss program is to consume small bite sizes and to chew properly (e.g. 10 times) on each bite before swallowing. The development of long chewable food structures that evoke substantial oral processing and an increase in transit time in the oral cavity or a reduction in bite size by tailored packaging may be product development suggestions that support the 'right' oral processing behaviour. These applications may lead to a higher extent of retro-nasal aroma release and sensory stimulation, which in turn may affect satiation and food intake behaviour.

\section{ACKNOWLEDGEMENTS}

We acknowledge Carina Ponne PhD (Royal FrieslandCampina, Deventer, The Netherlands) for providing the dark chocolate-flavoured custard.

\section{REFERENCES}

1. Murphy, C., Cain, W.S., \& Bartoshuk, L.M. (1977) Mutual action of taste and olfaction. Sens. Processes 1: 204-211.

2. Rozin, P. (1982) Taste-smell confusions and the duality of the olfactory sense. Percept. Psychophys. 31: 397-401.

3. Small, D.M., Gerber, J.C., Mak, Y.E., \& Hummel, T. (2005) Differential neural responses evoked by orthonasal versus retro-nasal odorant perception in humans. Neuron 47: 593-605.

4. Linforth, R.S.T., Baek, I., \& Taylor, A.J. (1999) Simultaneous instrumental and sensory analysis of volatile release from gelatine and pectin/gelatine gels. Food Chem. 65: 77-83.

5. Cook, D.J., Linforth, R.S.T., \& Taylor, A. (2003) Effects on hydrocolloid thickeners on the perception of savory flavors. J. Agric. Food Chem. 51: 3067-3072.

6. Lethuaut, L., Weel, K.G., Boelrijk, A.E., \& Brossard, C.D. (2004) Flavor perception and aroma release from model dairy desserts. J. Agric. Food Chem. 52: 3478-3485.

7. van Ruth, S.M., de Witte, L., \& Uriarte, A.R. (2004) Volatile flavor analysis and sensory evaluation of custard desserts varying in type and concentration of carboxymethyl cellulose. J. Agric. Food Chem. 52: 8105-8110.

8. Ruijschop, R.M.A.J., Burgering, M.J.M., Jacobs, M.A., \& Boelrijk, A.E.M. (2009) Retro-nasal aroma release depends on both subject and product differences: A link to food intake regulation? Chem. Senses doi:10.1093/chemse/bjp011.

9. Brown, W.E., Dauchel, C., \& Wakeling, I. (1996) Influence of chewing efficiency on texture and flavour perceptions of food. J. Texture Stud. 27: 433-450. 
Bite size, oral processing time and retro-nasal aroma release |

10. Buettner, A., Beer, A., Hanning, C., \& Settles, M. (2001) Observation of the swallowing process by application of videofluoroscopy and real-time magnetic resonance imaging-consequences for retro-nasal aroma stimulation. Chem. Senses 26: 1211-1219.

11. Buettner, A., Beer, A., Hanning, C., Settles, M., \& Schieberle, P. (2002) Physiological and analytical studies on flavor perception dynamics as induced by eating and swallowing process. Food Qual. Pref. 13: 497-504.

12. Wright, K.M., Sprunt, J., Smith, A.C., \& Hills, B.P. (2003) Modeling flavor release from a chewed bolus in the mouth. Part 1. Mastication. Int. J. Food Sci. Technol. 38: 351-360.

13. Pionnier, E., Chabanet, C., Mioche, L., Le Quere, J.L., \& Salles, C. (2004) 1. In vivo aroma release during eating of a model cheese: relationships with oral parameters. J. Agric. Food Chem. 52: 557-564.

14. Zijlstra, N., Mars, M., Stafleu, A., de Wijk, R.A., Prinz, J.F., Hűck, N.L., \& de Graaf, C. (2008) Effect of bite size and oral processing time of food on satiation. BFDG Abstracts. Appetite 51: 753.

15. Zijlstra, N., de Wijk, R.A., Mars, M., Stafleu, A., \& de Graaf, C. Effect of bite size and oral processing time of a semi-solid food on satiation. Submitted for publication.

16. Zijlstra, N., Mars, M., de Wijk, R.A., Westerterp-Plantenga, M.S., \& de Graaf, C. (2008) The effect of viscosity on ad libitum food intake. Int. J. Obes. 32: 676-683.

17. Hetherington, M., Rolls, B.J., \& Burley, V.J. (1989) The time course of sensoryspecific satiety. Appetite 12: 57-68.

18. Hetherington, M.M., \& Boyland, E. (2007) Short-term effects of chewing gum on snack intake and appetite. Appetite 48: 397-401.

19. Ruijschop, R.M.A.J., Boelrijk, A.E.M., de Ru, J.A., de Graaf, C., \& WesterterpPlantenga, M.S. (2008) Effects of retro-nasal aroma release on satiation. Br. J. Nutr. 99: 1140-1148.

20. Flavor Database by Leffingwell \& Associates. (2004) Retrieved 31-07-2008, from http://www.leffingwell.com.

21. van Ruth, S.M., Roozen, J.P., \& Cozijnsen, J.L. (1994). Comparison of dynamic headspace in mouth model systems for flavour release from rehydrated bell pepper cuttings. In: Maarse, H., \& van der Heij, D.G. (Eds.), Trends in flavour research (pp. 59-64). Amsterdam: Elsevier Science.

22. Taylor, A.J., Linforth, R.S.T., Harvey, B.A., \& Blake, A. (2000) Atmospheric pressure chemical ionisation mass spectrometry for in vivo analysis of volatile flavour release. Food Chem. 71: 327-338.

23. Taylor, A.J., \& Linforth, R.S.T. (1996) Flavour release in the mouth. Trends Food Sci. Tech. 7: 444-448. 
24. Weel, K.G.C., Boelrijk, A.E.M., Burger, J.J., Gruppen, H., Voragen, A.G.J., \& Smit, G. (2003) A protocol for measurement of in vivo aroma release from beverages. $J$. Food Sci. 68: 1123-1128.

25. Weel, K.G.C., Boelrijk, A.E.M., Burger, J.J., Verschueren, M., Gruppen, H., Voragen, A.G.J., \& Smit, G. (2004). New device to stimulate swallowing and in vivo aroma release in the throat from liquid and semi-liquid food systems. J. Agric. Food Chem. 52: 6564-6571.

26. Weel, K.G., Boelrijk, A.E.M., Alting, A.C., van Mil, P.J.J.M., Gruppen, H., Voragen, A.G.J., Burger, J.J., \& Smit, G. (2002) Flavor release and perception of flavored whey protein gels: perception is determined by texture rather than by release. $J$. Agric. Food Chem. 50: 5149-5155.

27. Buettner, A., \& Schieberle, P. (2000) Exhaled odorant measurement (EXOM) - a new approach to quantify the degree of in-mouth release of food aroma compounds. Lebensm-Wiss. Technol. 33: 553-559.

28. Land, D.G. (1994) Perspectives on the effects of interactions on flavor perception: an overview. In: McGorrin, R.J., \& Leland, J. (Eds.), Flavor-Food interactions (pp. 2-11). ACS Symposium Series 633. Washington: ACS.

29. Wansink, B. (2006) Mindless Eating - Why We Eat More Than We Think. New York: Bantam-Dell. 


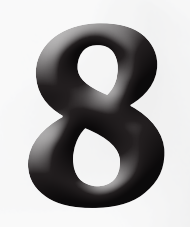

General Discussion 
In view of the epidemic of obesity, one of the aims is to develop good tasting food products that may induce an increased level of satiation, preventing consumers from overeating. This thesis focuses on the possibility of using aroma as trigger for inducing or increasing satiation. Retro-nasal aroma stimulation is hypothesised to induce sensory satiation and thereby provoke meal termination. Therefore, differences in the extent of retro-nasal aroma stimulation during consumption are hypothesised to be responsible for subject or food product differences in sensory satiation and food intake. This can be due to differences in perceived intensity, duration or quality of retro-nasal aroma stimulation. Using a novel approach of atmospheric pressure chemical ionization-mass spectrometry (APcI-MS) in combination with olfactometry, the relative importance of different aroma concepts for satiation was studied, from both the subject and food product point of view. This chapter discusses implications of this research and provides suggestions for further research.

\section{AROMA AS TRIGGER FOR SATIATION}

The subject's extent of in vivo retro-nasal aroma release is an uncontrolled characteristic that is suggested to vary across individuals. It was investigated whether subjects can be segmented based on their extent of retro-nasal aroma release using real-time APcIMS, and whether this depends on the type of food product they consume (Chapter 2). Retro-nasal aroma release intensity and profile morphology appear to be subject specific, and relatively independent of the type of food product that subjects consumed. For instance, a subject who has a relatively high retro-nasal aroma release intensity for a (semi-)liquid food product, also appears to have a relatively high retro-nasal aroma release intensity for a solid food product. This implies that the extent of retro-nasal aroma release is a physiological feature that characterises any individual. Subject differences in oral processing parameters, such as salivary flow rate, nasal anatomy, bite size and eating speed may be (partly) responsible for this finding ${ }^{(1-5)}$.

Additionally, for all subjects it is noticed that there are absolute differences between food products in the duration of retro-nasal aroma release comparing (semi-)liquid and solid food products, because of differences in oral processing. Solid food products require considerable chewing and swallowing, due to their firmer texture. Consequently, most subjects have an immediate and prolonged retro-nasal aroma release. In contrast to the consumption of solid food products, most subjects have a short and spiked retronasal aroma release pattern during the consumption of (semi-)liquid food products ${ }^{(6-7)}$. Accordingly, food product differences in the extent of retro-nasal aroma release are explained by differences in food structure and composition and the oral processing that is evoked ${ }^{(8-11)}$.

The demonstrated subject and product differences with respect to the extent of retronasal aroma release may be one of the reasons that people vary in their satiation 
characteristics and may have implications for the regulation of food intake. A higher extent of retro-nasal aroma release may therefore result in more sensory stimulation, which in turn may contribute to increased feelings of satiation and decreased food intake ${ }^{(12-14)}$. This may be one of the explanations why (soft) solid foods appear to be more satiating than liquid foods ${ }^{(15-19)}$.

Moreover, for a subset of the subjects ad libitum food intake was measured. Interestingly, a negative trend is observed between the extent of retro-nasal aroma release and the amount of ad libitum food intake. Subjects who have a higher extent of retro-nasal aroma release tend to consume less. This finding may support the hypothesis that subject differences in the extent of retro-nasal aroma release are linked to subject differences in sensory satiation and food intake behaviour. To our knowledge, this observation has not been reported before. A follow-up study with a larger subject population, which is more segmented with respect to BMI, is needed to ultimately quantify an immediate, significant effect of a contribution of the extent of retro-nasal aroma release to food intake behaviour.

Obviously, the level of aroma stimulation depends on the duration of release of the aromas and thereby differs for different food structures and compositions. In an olfactometer-aided experimental design in order to deliver aroma stimuli separately from taste and mouth feel, it was studied whether a beverage becomes more satiating when the retro-nasal aroma release profile coincides with the profile of a (soft) solid food (Chapter 3). Results show that a beverage with an aroma release profile similar to a (soft) solid food is able to increase the subject's feeling of satiation significantly. To our knowledge, this is the first time that such a result has been observed. Altering the duration of retro-nasal aroma release appears to have the potential to increase perceived satiation.

Apart from the physical structure of a food product and the extent of retro-nasal aroma release that is evoked, aroma quality is a product property that may affect retro-nasal aroma stimulation. This in turn may contribute to enhanced feelings of satiation and a decrease in food intake. To this end, the effect of ingredient-related aroma cues, complexity in aroma composition and congruency in aroma and texture on satiation and food intake was investigated.

For ingredient-related aroma cues, it was studied whether specific aroma stimuli, which subjects do not consciously recognise, are able to cue for satiation (Chapter 4). Three sensory cueing stimuli were tested, which are conceived to be related to fat content (i.e. lactones), carbohydrate content (i.e. maltol), and to the breakdown of protein content (i.e. 'animalic'). Custard products with addition of maltol or 'animalic' at sensory detection threshold were able to increase subjects' feeling of fullness significantly. This result is in line with our expectations, since it is hypothesised that 'animalic' cues for incongruence between the actual flavour and the flavour expectation attributable to the consumed food product, consequently unconsciously triggering satiation (i.e. perceived 
fullness). Alternatively, the response to the cueing aroma stimuli might be a learned response, i.e. conditioned satiation, possibly due to flavour-nutrient learning ${ }^{(c .20-22)}$. Subjects may associate the aroma stimuli 'animalic' and maltol as cueing for the energy content (i.e. post-ingestive consequences) of protein and carbohydrate, respectively. Moreover, our results are in line with observations that macronutrients have different satiating efficiencies, in which protein is more satiating, followed by carbohydrate and fat as least satiating ${ }^{(23-26)}$. Accordingly, specific cueing aroma stimuli at sensory detection threshold are able to contribute to perceived fullness. From this study, it can, however, not be concluded whether this is due to incongruence between the actual flavour and the flavour expectation attributable to the consumed food product or to perceiving the aroma stimuli cueing for the energy content of specific macronutrients. In addition, the acute effect of complexity in aroma composition on satiation and food intake was investigated in either an olfactometer-aided or an ad libitum eating experimental design (Chapter 5). Apart from the differences in timing of the appetiteregulating effects, both experimental settings demonstrate that a multi-component strawberry aroma, which is perceived as being more complex, yet of similar aroma quality, intensity and pleasantness compared to a single-component strawberry aroma, is able to enhance satiation. This observation is in line with our expectations. Assuming that the total amount of exposure to a food's sensory properties determines the total decline in desire to eat, it is hypothesised that increased sensory stimulation from a more complex aroma further reduces the desire to eat and enhance satiation. This is probably caused by concurrent exposure to multiple aroma components cueing for sensorily similar strawberry perception. To our knowledge, this result has not been described before. Food products which are perceived as being more complex are usually reported to delay the development of sensory satiation ${ }^{(27-29)}$. However, in those observations perceived complexity may implicitly cue for variation, leading to increased meal size ${ }^{(30-31)}$. In the present study, perceived complexity did not result in consciously perceived sensory differences between the two different strawberry-aromatised yoghurt products. In addition, the results of this study show that the methodology of the olfactometer-aided aroma stimulation proves to be representative of a real-life setting with regard to aroma exposure and satiation.

Comparable to the hypothesis for the concept about aroma complexity, increased sensory stimulation from a food product congruent in aroma and texture is expected to further reduce desire to eat. Also here, this is probably caused by concurrent sensory exposure to multiple sensory modalities cueing for similar sensory perception (i.e. creaminess) (Chapter 6). Satiation-enhancing effects regarding aroma-texture congruency were tested with creamy custard, either vanilla- (i.e. congruent with creamy texture) or lemon- (i.e. incongruent with creamy texture) aromatised, served in a preload-ad libitum experimental setting. It is hypothesised that satiation and food intake are affected by the level of congruency as well as by variation of successive exposure to aroma-texture 
combinations. The results show that subjects feel significantly more satiated when preload and ad libitum intakes share the identical aroma compared to varied aromas. This may point to a "seeking for variety" principle ${ }^{(32)}$. No satiation-enhancing effects of congruency were observed. However, a follow-up study with ad libitum intake only, i.e. not preceded by a preload, could be more appropriate to determine the effect of aromatexture congruency on meal termination.

In addition to (uncontrolled) subject and product features, the effect of bite size and duration of oral processing on the extent of retro-nasal aroma release was investigated (Chapter 7). Subjects consumed dark chocolate-flavoured custard, while they were exposed to both free or fixed bite size ( $5 \mathrm{~g}$ and $15 \mathrm{~g}$ ) and duration of oral processing before swallowing ( $3 \mathrm{~s}$ and $9 \mathrm{~s}$ ) in a cross-over design. It is hypothesised that consuming food either in multiple small bite sizes or with a longer duration of oral processing evokes more oral processing per gram consumed and increases transit time in the oral cavity. As expected, small bite sizes contribute significantly to a higher cumulative extent of retro-nasal aroma release per gram, while a longer duration of oral processing tends to result in more retro-nasal aroma release during consumption of a fixed amount of dark chocolate-flavoured custard. However, the effect of oral processing time may be significant with a more solid food product. As reported by Zijlstra et al. ${ }^{(33-}$ ${ }^{34)}$, consumption in small bite sizes or with a longer duration of oral processing results in a lower ad libitum food intake. The results of the present study provide an additional, possibly complementary, explanation for the ad libitum intake results obtained by Zijlstra et al. ${ }^{(33-34)}$ from a retro-nasal aroma release perspective, stimulating olfactory receptors. Differences in the extent of retro-nasal aroma release may thus contribute to the decrease in food intake in certain eating conditions.

\section{Efficacy of the different aroma concepts}

The aforementioned studies support the observation that retro-nasal aroma release is able to induce satiation. Although the extent of retro-nasal aroma release appears to be subject specific, food product properties can be tailored in such a way that these can lead to a higher quality and/or quantity of retro-nasal aroma stimulation, which in turn provokes enhanced feelings of satiation and ultimately may contribute to a decrease in food intake (Figure 8.1).

Among the proof-of-principle studies that were performed, the prolongation of the duration of retro-nasal aroma release, the addition of specific ingredient-related aroma cues, the engineering of more complex aroma compositions and the adaptation of bite size or duration of oral processing prove to be valuable aroma concepts for inducing satiation. The change in perceived satiation between the test product and placebo product varied for the different aroma concepts between $6 \mathrm{~mm}$ and $12 \mathrm{~mm}$, on a $100 \mathrm{~mm}$ visual analogue scale (VAS). This corresponds to an increase in perceived satiation of, respectively, 384\% during stimulation with a prolonged retro-nasal aroma release, 38\% 


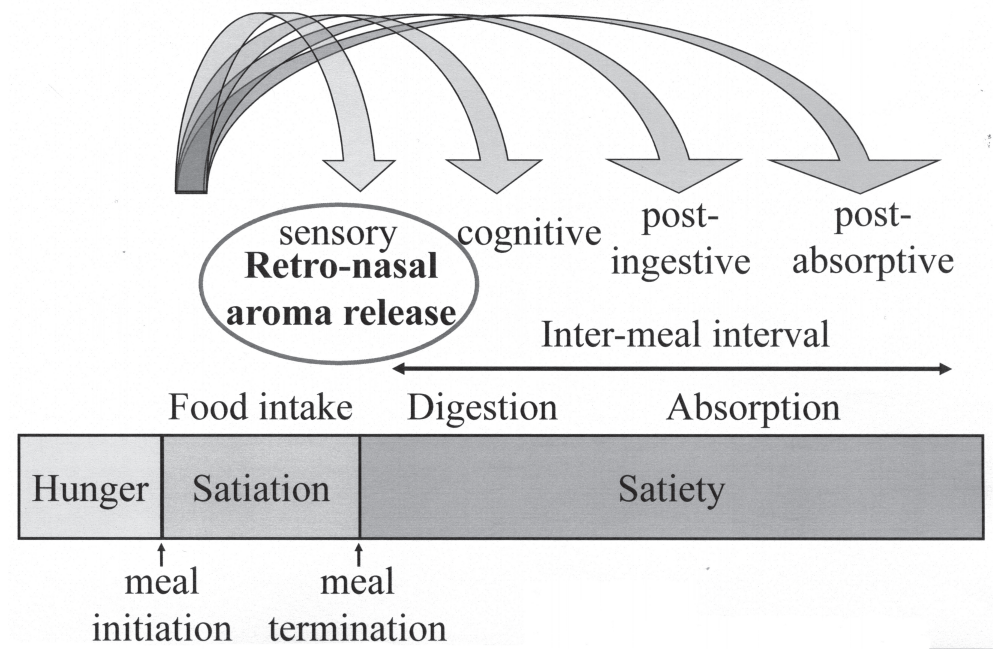

Figure 8.1 Schematic overview of the positioning of retro-nasal aroma release in a food intake cycle and satiety cascade with related terminology (adapted from 35).

during consumption of custard with addition of maltol, $42 \%$ during stimulation with a more complex aroma, $41 \%$ after consumption of custard with addition of 'animalic', and $22 \%$ after consumption of yoghurt with a more complex aroma. Apart from aromatexture congruency, all aroma concepts reveal efficacy with regard to perception.

Despite significant changes in subjective experience, no impact on ad libitum amount consumed is observed for the different aroma concepts. This dissociation is a common observation in the field and similar to previous studies ${ }^{(18,36-38)}$. As discussed by Veldhorst et al. ${ }^{(39)}$, it is likely that the magnitude of the present effect in perceived satiation is too small to have an effect on the amount consumed ad libitum. Veldhorst et al. ${ }^{(39)}$ showed that differences in appetite ratings in a preload-ad libitum meal design need to be at least larger than $35-40 \%$ in order to have a significant effect of $17-20 \%$ on subsequent energy intake. In a follow-up study, it would be a great challenge to obtain also a significant effect on actual food intake. An experimental design aiming at ad libitum consumption only is probably the most appropriate design to demonstrate aroma-induced satiation and, ultimately, accelerated meal termination ${ }^{(40)}$.

\section{Engineering food products that lead to increased retro-nasal aroma stimulation}

The combination of mass-spectrometry and olfactometry provides a unique and novel approach to investigate the role of aroma for satiation. APcI-MS technology proves again to be an appropriate tool to measure the effects of oral processing on retronasal aroma release during food consumption. In future measurements, APcI-MS technology may be applied as non-invasive biomarker to measure food oral processing efficiency from a retro-nasal aroma release perspective. Additionally, the use of tailored 
olfactometer equipment has been shown to be of great importance in mimicking aroma release during food consumption. Explicitly, in the study on aroma complexity, the results of this study validate the methodology of the olfactometer-aided aroma stimulation as representative of a real-life setting with regard to aroma exposure and satiation. The olfactometer-aided approach proves to be an appropriate tool for "fast prototyping", meaning that it is not necessary to manufacture a complete food product with inclusion of a specific aroma concept before the relative importance of that aroma concept can be investigated in vivo.

\section{Examples of food technology applications}

For prolongation of the duration of retro-nasal aroma release during food consumption, examples of applications could be the development of food products with an increase of aftertaste, an increase or lingering of aroma release via flavour delivery systems or encapsulation technology, or the development of long-chewable food structures in beverages that evoke substantially more oral processing and an increase in transit time in the oral cavity. Furthermore, a reduction in bite size by tailored packaging may support the 'right' oral processing behaviour to food products.

Other applications could be the addition of specific ingredient-related aromas at sensory detection threshold to food products, i.e. aromas cueing for the energy content of protein, or the engineering of multi-component aroma compositions, which provide more 'body/gestalt' to food products.

\section{ROLE OF AROMA IN THE ORIGIN OF OBESITY}

The human body exerts a strong defence against under-nutrition and weight loss, but applies a much weaker resistance to overconsumption and weight gain. This means that weight gain by overconsumption may occur despite efforts to prevent it ${ }^{(35)}$. Overeating is an important aspect in the complex and multifaceted origin of obesity ${ }^{(41)}$. Originally, overeating served to anticipate food insecurity. A number of ethnicities still possess this survival mechanism. In this context, for example, the off-reserve aboriginal population is reported to have a high prevalence of overweight and obesity ${ }^{(42-44)}$. Subjects may differ in their ability to apply or reduce the capacity to overeat. The extent of retronasal aroma release is suggested to play a regulating role herein.

The present studies demonstrate that retro-nasal aroma release is able to contribute to satiation induction, and possibly to meal termination. This finding supports the hypothesis that efficient retro-nasal aroma release, which is a subject specific feature, is able to reduce the capacity to overeat by triggering satiation.

In previous studies, in which for example, the effect of a specific food ingredient on satiety was investigated ${ }^{(45-46)}$, retro-nasal aroma release concurrently contributed to satiation. Because retro-nasal aroma stimulation was not the primary focus in these 
studies, aroma-induced satiation has not been described before. However, in principle, this effect should always be taken into account during food consumption, irrespective of the type of food product consumed.

Differences in the extent of retro-nasal aroma release during consumption may be one of the reasons that people vary in their satiation characteristics, which may prevent them from overeating or not. Possibly, normal-weight and obese subjects differ in the regulation of this food intake mechanism. In contrast to normal-weight subjects, obese subjects could evoke limited extent of retro-nasal aroma release during food consumption. This may result in less sensory stimulation, which in turn may lead to decreased feelings of satiation and increased food intake. To test this assumption, it is desired to design a study, in which normal-weight subjects and overweight/obese subjects are exposed to an "all you can eat" buffet. It is hypothesised that overweight/ obese subjects are capable of overeating. In a follow-up study, physiological differences during food consumption may be observed between normal-weight and obese subjects, for example, differences in oral processing or retro-nasal aroma delivery to the olfactory epithelium. The rewarding function of food for obese subjects may be limited compared to normal-weight subjects ${ }^{(c f .47)}$. It would be interesting to determine whether the in vivo retro-nasal aroma release, by using APcI-MS technology matches the subjective aroma perception by performing time-intensity measurements during food consumption.

Interestingly, in the present study (Chapter 2), a negative trend is observed between the extent of retro-nasal aroma release and the amount of ad libitum food intake. However, a relationship between the extent of retro-nasal aroma release and BMI is not shown. A larger follow-up study with a group of normal-weight subjects vs. a group of overweight/obese subjects is needed to confirm a possible effect of the extent of retro-nasal aroma release on food intake, energy intake and BMI.

\section{KEY CONCLUSIONS}

The extent of retro-nasal aroma release appears to be a physiological feature that characterises any individual. Although the extent of retro-nasal aroma release appears to be subject specific, food product properties can be tailored in such a way that these can lead to a higher quality and/or quantity of retro-nasal aroma stimulation. This in turn provokes enhanced feelings of satiation and ultimately may contribute to a decrease in food intake.

The application of aroma in food product development for inducing satiation is promising and appealing. Complementary to ingredients that focus on the post-ingestive and post-absorptive stage of the satiety cascade, retro-nasal aroma release, operating during food ingestion, has a consumer benefit that is immediately noticeable.

The current state-of-the-art in this field of research is still preliminary. The explorative research, as described in this thesis, shows that the efficacy of the different aroma concepts for inducing satiation may be relatively small. Besides, no impact on ad libitum 
amount consumed is observed.

Among the proof-of-principle studies that were performed, the prolongation of the duration of retro-nasal aroma release, the addition of specific ingredient-related aroma cues, the engineering of more complex aroma compositions and the adaptation of bite size or duration of oral processing may prove to be valuable aroma concepts for the development of foods containing triggers that induce or increase the feeling of satiation. The next challenge is to implement these concepts into real food products.

\section{FUTURE RESEARCH}

Ultimately, the aim is to use food technology for designing food products containing triggers that are able to reduce food intake. Despite significant changes in subjective experience, no impact on ad libitum amount consumed was observed for the different aroma concepts. The efficacy of the aroma concepts may be enhanced by the inclusion of other sensory modalities, such as taste, texture and mouth feel. This will probably evoke cross-modal interactions. Concurrent exposure to multiple sensory stimuli cueing for identical sensory perception is likely to enhance that perception, which may enhance satiation and decrease food intake.

In addition to the aroma concepts, which have been studied in the present work, other concepts may also be valuable for inducing satiation. For example, a number of studies report that sensory intensity of a food product is involved in satiation ${ }^{(29,48-50)}$. Apart from a longer duration of retro-nasal aroma release during food consumption, a more intense, i.e. a higher concentrated, retro-nasal aroma release during food consumption is also hypothesised to affect satiation ${ }^{(40)}$.

Retro-nasal aroma release is involved in the early phases of the satiety cascade at the interface between satiation and satiety, and may contribute to the process of meal termination. A new area of research which can be explored is the role of retro-nasal aroma release with respect to post-ingestive responses.

\section{ACKNOWLEDGEMENTS}

This chapter has been submitted for publication as: Ruijschop, R.M.A.J., Boelrijk, A.E.M., de Graaf, C., \& Westerterp-Plantenga, M.S. Retro-nasal aroma release and satiation: a review.

\section{REFERENCES}

1. Brown, W.E., Dauchel, C., \& Wakeling, I. (1996) Influence of chewing efficiency on texture and flavour perceptions of food. J. Texture Stud. 27: 433-450.

2. Buettner, A., Beer, A., Hanning, C., \& Settles, M. (2001) Observation of the swallowing process by application of videofluoroscopy and real-time magnetic resonance imaging-consequences for retro-nasal aroma stimulation. Chem. Senses 26: 1211-1219. 
3. Buettner, A., Beer, A., Hanning, C., Settles, M., \& Schieberle, P. (2002) Physiological and analytical studies on flavor perception dynamics as induced by eating and swallowing process. Food Qual. Pref. 13: 497-504.

4. Wright, K.M., Sprunt, J., Smith, A.C., \& Hills, B.P. (2003) Modeling flavor release from a chewed bolus in the mouth. Part 1. Mastication. Int. J. Food Sci. Technol. 38: 351-360.

5. Pionnier, E., Chabanet, C., Mioche, L., Le Quere, J.L., \& Salles, C. (2004) 1. In vivo aroma release during eating of a model cheese: relationships with oral parameters. J. Agric. Food Chem. 52: 557-564.

6. Brauss, M.S., Balders, B., Linforth, R.S.T., Avison, S., \& Taylor, A.J. (1999) Fat content, baking time, hydration and temperature affect flavour release from biscuits in model-mouth and real systems. Flavour Fragr. J. 14: 351-357.

7. Weel, K.G.C., Boelrijk, A.E.M., Burger, J.J., Gruppen, H., Voragen, A.G.J. \& Smit, G. (2003) A protocol for measurement of in vivo aroma release from beverages. $J$. Food Sci. 68: 1123-1128.

8. Linforth, R.S.T., Baek, I., \& Taylor, A.J. (1999) Simultaneous instrumental and sensory analysis of volatile release from gelatine and pectin/gelatine gels. Food Chem. 65: 77-83.

9. Cook, D.J., Linforth, R.S.T., \& Taylor, A. (2003) Effects on hydrocolloid thickeners on the perception of savory flavors. J. Agric. Food Chem. 51: 3067-3072.

10. Lethuaut, L., Weel, K.G., Boelrijk, A.E., \& Brossard, C.D. (2004) Flavor perception and aroma release from model dairy desserts. J. Agric. Food Chem. 52: 3478-3485.

11. van Ruth, S.M., de Witte, L., \& Uriarte, A.R. (2004) Volatile flavor analysis and sensory evaluation of custard desserts varying in type and concentration of carboxymethyl cellulose. J. Agric. Food Chem. 52: 8105-8110.

12. Small, D.M., Gerber, J.C., Mak, Y.E., \& Hummel, T. (2005) Differential neural responses evoked by orthonasal versus retro-nasal odorant perception in humans. Neuron 47: 593-605

13. Hetherington, M., Rolls, B.J., \& Burley, V.J. (1989) The time course of sensoryspecific satiety. Appetite 12: 57-68.

14. Hetherington, M.M., \& Boyland, E. (2007) Short-term effects of chewing gum on snack intake and appetite. Appetite 48: 397-401.

15. Haber, G.B., Heaton, K.W., Murphy, D., \& Burroughs, L.F. (1977) Depletion and disruption of dietary fibre. Effects on satiety, plasma-glucose, and serum-insulin. Lancet 2: 679-682.

16. Mattes, R.D., \& Rothacker, D. (2001) Beverage viscosity is inversely related to postprandial hunger in humans. Physiol. Behav. 74: 551-557.

17. Mattes, R. (2005) Soup and satiety. Physiol. Behav. 83: 739-747. 
18. Tsuchiya, A., Almiron-Roig, E., Lluch, A., Guyonnet, D., \& Drewnowski, A. (2006) Higher satiety ratings following yoghurt consumption relative to fruit drink or dairy fruit drink. J. Am. Diet. Assoc. 106: 550-557.

19. Zijlstra, N., Mars, M., de Wijk, R.A., Westerterp-Plantenga, M.S., \& de Graaf, C. (2008) The effect of viscosity on ad libitum food intake. Int. J. Obes. 32: 676-683.

20. Booth, D.A., Lee, M., \& McAleavey, C. (1976) Acquired sensory control of satiation in man. Br. J. Psychol. 67: 137-147.

21. Gibson, E.L., \& Brunstrom, J.M. (2007) Learned influences on appetite, food choice and intake: Evidence in human beings. In: Cooper, S.J., \& Kirkham, T.C. (Eds.), Progress in brain research: Appetite and body weight-- Integrative systems and the development of anti-obesity drugs (pp. 271-300). London: Elsevier.

22. Mobini, S., Chambers, L.C., \& Yeomans, M.R. (2007) Effects of hunger state on flavour pleasantness conditioning at home: flavour-nutrient learning vs. flavourflavour learning. Appetite 48: 20-28.

23. De Castro, J.M. (1987) Macronutrient relationships with meal patterns and mood in the spontaneous feeding behavior of humans. Physiol. Behav. 39: 561-569.

24. De Graaf, C., Hulshof, T., Weststrate, J.A., \& Jas, P. (1992) Short-term effects of different amounts of protein, fats, and carbohydrates on satiety. Am. J. Clin. Nutr. 55: 33-38.

25. Stubbs, R.J. (1995) Macronutrient effects on appetite. Int. J. Obes. 19: S11-S19.

26. Westerterp-Plantenga, M.S., Pasman, W.J., Yedema, M.J.W., \& Wijckmans-Duijsens, N.E.G. (1996) Energy intake adaptation of food intake to extreme energy densities of food by obese and non-obese women. Eur. J. Clin. Nutr. 50: 401-407.

27. Johnson, J., \& Vickers, Z. (1992) Factors influencing sensory-specific satiety. Appetite 19: 15-31.

28. Lévy, C.M., MacRae, A., \& Köster, E.P. (2006) Perceived stimulus complexity and food preference development. Acta Psychol. 123: 394-413.

29. Weijzen, P.L.G., Zandstra, E.H., Alfieri, C., \& de Graaf, C. (2008). Effects of complexity and intensity on sensory-specific satiety and food acceptance after repeated consumption. Food Qual. Pref. 19: 349-359.

30. Hetherington, M.M., Foster, R., Newman, T., Anderson, A.S., \& Norton, G. (2006) Understanding variety: tasting different foods delays satiation. Physiol. Behav. 87: 263-271.

31. Romer, M., Lehrner, J., van Wymelbeke, V., Jiang, T., Deecke, L., \& Brondel, L. (2006) Does modification of olfacto-gustatory stimulation diminish sensoryspecific satiety in humans? Physiol. Behav. 87: 469-477.

32. Rolls, B.J., Rowe, E.A., Rolls, E.T., Kingston, B., Megson, A., \& Gunary, R. (1981) Variety in meal enhances food intake in man. Physiol. Behav. 26: 215-221. 
33. Zijlstra, N., Mars, M., Stafleu, A., de Wijk, R.A., Prinz, J.F., Hűck, N.L., \& de Graaf, C. (2008) Effect of bite size and oral processing time of food on satiation. BFDG Abstracts. Appetite 51: 753.

34. Zijlstra, N., de Wijk, R.A., Mars, M., Stafleu, A., \& de Graaf, C. (2009) Effect of bite size and oral processing time of a semi-solid food on satiation. Submitted for publication.

35. Blundell, J.E., \& King, N.A. (1996) Overconsumption as a cause of weight gain: behavioural-physiological interactions in the control of food intake (appetite). In: James, P., Bouchard, C., \& Bray, G. (Eds.), The origins and consequences of obesity (pp. 138-158). Chichester: Wiley.

36. Mattes, R. (1990) Hunger ratings are not a valid proxy measure of reported food intake in humans. Appetite 15: 103-113.

37. de Graaf, C., Blom, W.A.M., Smeets, P.A.M., Stafleu, A., \& Hendriks, H.F.J. (2004) Biomarkers of satiation and satiety. Am. J. Clin. Nutr. 79: 946-961.

38. Harper, A., James, A., Flint, A., \& Astrup, A. (2007) Increased satiety after intake of a chocolate milk drink compared with a carbonated beverage, but no difference in subsequent ad libitum lunch intake. Br. J. Nutr. 97: 579-583.

39. Veldhorst, M.A.B., Nieuwenhuizen, A.G., Hochstenbach-Waelen, A., Westerterp, K.R., Engelen, M.P.K.J., Brummer, R.J.M., Deutz, N.E.P., \& Westerterp-Plantenga, M.S. 2009. Comparison of the effects of a high- and normal- casein breakfast on satiety, 'satiety' hormones, plasma amino acids and subsequent energy intake. $\mathrm{Br}$. J. Nutr. 101: 295-303.

40. Ramaekers, M.G., Luning, P.A., Ruijschop, R.M.A.J., \& van Boekel, M.A.J.S. (2009) Effect of aroma release profiles on ad libitum food intake. ECRO Abstracts. Chem. Senses 34: E20.

41. Hill, J.O. (2006) Understanding and addressing the epidemic of obesity: an energy balance perspective. Endocr. Rev. 27:750-761.

42. Tremblay, M.S., Pérez, C.E., Ardern, C.I., Bryan, S.N., \& Katzmarzyk, P.T. (2005) Obesity, overweight and ethnicity. Health Rep. 16: 23-34.

43. Yu, B.N., Fieldhouse, P., Hammond, G., \& Sevenhuysen, G. (2006) Differential association of food insecurity and obesity in children and youth: a Canadian population-based study. NAASO Annual Scientific Meeting abstracts. Obesity 14: 180-182.

44. Garriguet, D. (2008) Obesity and the eating habits of the Aboriginal population. Health Rep. 19: 21-35.

45. Diepvens, K., Soenen, S., Steijns, J., Arnold, M., \& Westerterp-Plantenga, M.S. (2007) Long-term effects of consumption of a novel fat emulsion in relation to body-weight management. Int. J. Obes. 31: 942-949. 
46. Hughes, G.M., Boyland, E.J., Williams, N.J., Mennen, L., Scott, C., Kirkham, T.C., Harrold, J.A., Keizer, K.G., \& Halford, J.C. (2008) The effect of Korean pine nut oil (PinnoThin) on food intake, feeding behaviour and appetite: a double-blind placebo-controlled trial. Lipids Health Dis. 7: 6.

47. Volkow, N.D., Wang, G.J., Telang, F., Fowler, J.S., Thanos, P.K., Logan, J., Alexoff, D., Ding, Y.S., Wong, C., MA, Y., \& Pradhan, K. (2008) Low dopamine striatal D2 receptors are associated with prefrontal metabolism in obese subjects: possible contributing factors. Neuroimage 42: 1537-1543.

48. Maier, A., Vickers, Z., \& Inman, J.J. (2007) Sensory-specific satiety, its crossovers, and subsequent choice of potato chip flavors. Appetite 49, 419-428.

49. Zandstra, E.H., \& de Graaf, C. (1998) Sensory perception and pleasantness of orange beverages from childhood to old age. Food Qual. Pref. 9: 5-12.

50. Vickers, Z., \& Holton, E.A. (1998) A comparison of taste test ratings, repeated consumption, and postconsumption ratings of different strengths of iced tea. $J$. Sens. Stud. 13: 199-212. 
Summary 
In view of the epidemic of obesity, one of the requirements is to develop good tasting food products that may induce an increased level of satiation, preventing consumers from overeating. This thesis focuses on the possibilities of using aroma as a trigger for inducing or increasing satiation. Retro-nasal aroma stimulation is hypothesised to induce sensory satiation and thereby provoke meal termination. Using a novel approach of mass spectrometry (atmospheric pressure chemical ionisation-mass spectrometry, APcI-MS) in combination with olfactometry, the relative importance of different aroma concepts for satiation was studied, from both a person and food product point of view.

First, the question was addressed whether subjects can be segmented based on their extent of retro-nasal aroma release, using real-time APcI-MS, and whether this depends on the type of food product they consume. Retro-nasal aroma release intensity and profile morphology appear to be subject specific, and relatively independent of the type of food product that subjects consumed. This implies that the extent of retro-nasal aroma release is a physiological feature that characterises any individual. Absolute differences between food products in the duration of retro-nasal aroma release appear when comparing (semi-)liquid (i.e. short and spiked aroma release) and solid (i.e. immediate and prolonged aroma release) food products, because of differences in oral processing.

The demonstrated subject and product differences with respect to the extent of retronasal aroma release may be one of the reasons that people vary in their satiation characteristics and may have implications for the regulation of food intake.

Obviously, the level of aroma stimulation depends on the duration of release of the aromas and thereby differs for different food structures and compositions. In an olfactometer-aided experimental design in order to deliver aroma stimuli separately from taste and mouth feel, it was studied whether a beverage becomes more satiating when the retro-nasal aroma release profile coincides with the profile of a (soft) solid food. Results show that a beverage with an aroma release profile similar to a (soft) solid food is able to increase the subject's feeling of satiation significantly. Altering the duration of retro-nasal aroma release appears to have the potential to increase perceived satiation.

For ingredient-related aroma cues, it was studied whether specific aroma stimuli, which subjects do not consciously recognise, are able to cue for satiation. Three sensory cueing stimuli were tested, which are conceived to be related to fat content (i.e. lactones), carbohydrate content (i.e. maltol), and to the breakdown of protein content (i.e. 'animalic'). Custard products with addition of maltol or 'animalic' were able to increase subjects' feeling of fullness significantly. From this study, it can, however, not be concluded whether this is due to incongruence between the actual flavour and the flavour expectation attributable to the consumed food product or to perceiving the aroma stimuli cueing for the energy content of specific macronutrients. 
In addition, the acute effect of complexity in aroma composition on satiation and food intake was investigated in either an olfactometer-aided or an ad libitum eating experimental design. Both experimental settings demonstrate that a multi-component strawberry aroma, which is perceived as being more complex, yet of similar aroma quality, intensity and pleasantness compared to a single-component strawberry aroma, is able to enhance satiation. In addition, the results of this study show that the methodology of the olfactometer-aided aroma stimulation proves to be representative of a real-life setting with regard to aroma exposure and satiation.

Satiation-enhancing effects regarding aroma-texture congruency were tested with creamy custard, either vanilla- (i.e. congruent with creamy texture) or lemon(i.e. incongruent with creamy texture) aromatised, served in a preload-ad libitum experimental setting. The results show that subjects feel significantly more satiated when preload and ad libitum intakes share the identical aroma compared to varied aromas. This may point to a 'seeking for variety' principle. No satiation-enhancing effects of congruency were observed.

In addition, the effect of bite size and duration of oral processing on the extent of retronasal aroma release was investigated. Subjects consumed dark chocolate-flavoured custard, while they were exposed to both free or fixed bite size ( $5 \mathrm{~g}$ and $15 \mathrm{~g})$ and duration of oral processing before swallowing ( $3 \mathrm{~s}$ and $9 \mathrm{~s}$ ) in a cross-over design. As expected, small bite sizes contribute significantly to a higher cumulative extent of retro-nasal aroma release per gram, while a longer duration of oral processing tends to result in more retro-nasal aroma release during consumption of a fixed amount of dark chocolate-flavoured custard. However, the effect of oral processing time may be significant with a more solid food product.

In conclusion, the extent of retro-nasal aroma release appears to be a physiological feature that characterises any individual. Although the extent of retro-nasal aroma release appears to be subject specific, food product properties can be tailored in such a way that these can lead to a higher quality and/or quantity of retro-nasal aroma stimulation. This in turn provokes enhanced feelings of satiation and ultimately may contribute to a decrease in food intake.

The current state-of-the-art in this field of research is still preliminary. The explorative research, as described in this thesis, shows that the efficacy of the different aroma concepts for inducing satiation may be relatively small. Besides, no impact on ad libitum amount consumed is observed. The efficacy of the aroma concepts may be enhanced by the inclusion of other sensory modalities, such as taste, texture and mouth feel. Further research is recommended.

Among the proof-of-principle studies that were performed, the prolongation of the duration of retro-nasal aroma release, the addition of specific ingredient-related aroma cues, the engineering of more complex aroma compositions and the adaptation of bite size or duration of oral processing may prove to be valuable aroma concepts for 
Summary

the development of foods containing triggers that induce or increase the feeling of satiation. The next challenge is to implement these concepts into real food products. 


\section{Samenvatting}


Ten behoeve van preventie of behandeling van obesitas dienen voedingsmiddelen ontwikkeld te worden die smakelijk zijn, maar waarvan minder gegeten zou kunnen worden doordat deze een langer of sterker verzadigend gevoel opwekken. In deze context beschrijft ditproefschriftonderzoeknaarderolvan aromabijverzadigingsmechanismen. Retro-nasale waarneming van het aroma van een voedingsmiddel wordt bepaald in relatie tot sensorische verzadiging en zou aldus kunnen bijdragen aan een eerdere maaltijdbeëindiging. Door gebruik te maken van een nieuwe benadering, namelijk massaspectrometrie (atmosferische druk chemische ionisatie-massaspectrometrie, APcI-MS) in combinatie met olfactometer-techniek, werd het relatieve belang van aroma bij verzadigingsmechanismen onderzocht. Hierbij werd individuele variatie in persoonskenmerken zowel als variatie in voedingsmiddelen betrokken.

Ten eerste is onderzocht of mensen gekenmerkt kunnen worden op basis van hun retro-nasale aroma-afgifte, gebruikmakend van APcI-MS. Tevens is onderzocht of dit afhankelijk is van het geconsumeerde type voedingsmiddel. De intensiteit van de retro-nasale aroma-afgifte en de morfologie van het retro-nasale aroma-afgifteprofiel blijken persoonsspecifiek te zijn, en relatief onafhankelijk van het type voedingsmiddel dat geconsumeerd wordt. Dit betekent dat de hoeveelheid aroma die vrijkomt tijdens consumptie een fysiologisch kenmerk is dat elke persoon karakteriseert. Absolute verschillen tussen voedingsmiddelen voor wat betreft de duur van retro-nasale aromaafgifte treden op wanneer (semi-)vloeibare (kort retro-nasaal aroma-afgifteprofiel met pieken) en vaste voedingsmiddelen (direct en langdurig retro-nasaal aromaafgifteprofiel) met elkaar worden vergeleken. Dit verschil is een gevolg van verschillen in orale voedselverwerking.

De aangetoonde verschillen in retro-nasale aroma-afgifte tussen personen en voedingsmiddelen kunnen verklaren waarom mensen verschillen in hun verzadigingsmechanisme. Dit draagt bij aan de voedselinnameregulatie.

De mate van aromastimulatie blijkt afhankelijk te zijn van de duur van aromaafgifte en is daardoor voor verschillende voedselstructuren en -samenstellingen verschillend. In een proefopzet waarbij gebruik wordt gemaakt van een olfactometer, die het mogelijk maakt om aromastimuli los te koppelen van smaak en mondgevoel, is onderzocht of een drank als meer verzadigend wordt ervaren wanneer deze een retronasaal aroma-afgifteprofiel heeft dat vergelijkbaar is met een vast voedingsmiddel. De deelnemers bleken zich inderdaad meer verzadigd te voelen wanneer ze sensorisch werden gestimuleerd met het aroma-afgifteprofiel dat past bij de consumptie van een vast voedingsmiddel. Het gevoel van verzadiging tijdens consumptie kan dus versterkt worden door de duur van blootstelling aan aroma tijdens consumptie te verlengen.

Daarna is onderzocht of aroma's, die met bepaalde ingrediënten geassocieerd worden, die de deelnemers niet bewust waarnemen, in staat zijn om een verzadigend gevoel op te wekken. Drie sensorische stimuli zijn onderzocht; hiervan werden associaties met vet (i.e. lactonen), koolhydraten (i.e. maltol) en afbraakproducten van eiwitten ('animalic') 
verondersteld. Vla met toevoeging van maltol of 'animalic' verhoogde het verzadigend gevoel van de deelnemers. Uit deze studie kan echter niet worden geconcludeerd of het gevonden resultaat een gevolg is van incongruentie tussen de daadwerkelijke en verwachte smaak behorend bij het voedingsmiddel, of van een associatie tussen aromastimuli en de energie-inhoud van specifieke macronutriënten.

Daarnaast is het acute effect van complexiteit van aromasamenstelling op verzadiging en voedselinname onderzocht waarbij gebruik is gemaakt van zowel een proefopzet met een olfactometer als een proefopzet met een testmaaltijd. Uit beide studies blijkt dat een aardbei-aroma, dat is opgebouwd uit meerdere componenten, in staat is om het gevoel van verzadiging te versterken. In vergelijking met een aardbei-aroma bestaande uit een enkele component, is dit uit meerdere componenten samengestelde aroma waargenomen als meer complex, maar vergelijkbaar wat betreft aroma kwaliteit, intensiteit en aangenaamheid. Deze resultaten geven ook aan dat de methodologie van aromastimulatie met behulp van een olfactometer in staat is om een representatieve setting na te bootsen voor wat betreft blootstelling aan aroma en verzadiging.

Effecten van aroma-textuur congruentie op verzadiging zijn onderzocht met behulp van een proefopzet waarin een testmaaltijd van roomvla, gearomatiseerd met vanille (i.e. congruent aan romige textuur) of citroen (i.e. incongruent aan romige textuur), vooraf werd gegaan door roomvla met hetzelfde of het andere aroma (vanille cq. citroen). De deelnemers voelden zich meer verzadigd wanneer de aroma's van de testmaaltijd en de roomvla voorafgaand aan de testmaaltijd identiek zijn in vergelijking met variërende aroma's. Dit kan duiden op een behoefte aan variatie. Er zijn geen effecten van congruentie op verzadiging waargenomen.

Daarnaast is het effect van hapgrootte (vrij, $5 \mathrm{~g}$ en $15 \mathrm{~g}$ ) en duur van orale voedselverwerking (vrij, 3 s en 9 s) op de hoeveelheid aroma die vrijkomt tijdens consumptie onderzocht. Hiertoe consumeerden de deelnemers pure chocoladevla. Zoals verwacht blijkt dat kleine happen aanzienlijk bijdragen aan een grotere cumulatieve hoeveelheid aroma die vrijkomt per geconsumeerd gewicht. Een langere orale voedselverwerking lijkt te leiden tot een hogere retro-nasale aroma-afgifte bij consumptie van een vastgestelde hoeveelheid pure chocoladevla. Het effect van de duur van orale voedselverwerking is wellicht groter met een vast voedingsmiddel.

Tot slot blijkt de mate van retro-nasale aroma-afgifte een fysiologisch kenmerk te zijn dat elk persoon karakteriseert. Hoewel de mate van retro-nasale aroma-afgifte persoonsspecifiek is, kunnen eigenschappen van voedsel zodanig aangepast worden, dat deze kunnen leiden tot een hogere kwaliteit en/of kwantiteit van retro-nasale aromastimulatie. Dit kan vervolgens leiden tot een versterkt verzadigend gevoel en zou uiteindelijk kunnen bijdragen aan verminderde voedselinname.

De huidige expertise op het gebied van aroma en verzadiging bevindt zich nog in een pril stadium. Het verkennend onderzoek, zoals in dit proefschrift is beschreven, laat zien dat de kracht van de verschillende aroma-concepten om verzadiging te 
versterken relatief gering is. Daarnaast is er geen effect op eerdere maaltijdbeëindiging waargenomen. Aanbevolen wordt meer onderzoek te doen naar het effect van andere sensorische eigenschappen (bijv. smaak, textuur, mondgevoel) in combinatie met retro-nasale aroma-afgifte op verzadiging en voedselinname.

Op basis van de uitgevoerde studies kunnen het verlengen van de duur van retronasale aroma-afgifte, het toevoegen van specifieke ingrediënt-geassocieerde aroma's, het vervaardigen van meer complexe aromasamenstellingen en het aanpassen van hapgrootte en duurvan oralevoedselverwerking waardevollearoma-concepten zijn. Deze kunnen gebruikt worden bij de ontwikkeling van voedingsmiddelen die eigenschappen bevatten die een langer of sterker verzadigend gevoel opwekken. De uitdaging is om deze aroma-concepten in commerciële voedingsmiddelen te implementeren. 


\section{Dankwoord}


“Time flies when you are having fun!" De afgelopen 4 jaar zijn werkelijk omgevlogen! Er zijn heel veel leuke en nieuwe uitdagingen op mijn pad gekomen. Hierbij waren het winnen van een prijs voor beste poster en natuurlijk vorig jaar de Unilever young scientist award of the year absoluut hoogtepunten!

Het plezier en de successen die ik de afgelopen jaren heb gehad, waren niet mogelijk geweest zonder de enorme betrokkenheid van vele mensen. Iedereen die op welke wijze dan ook heeft bijgedragen aan mijn promotieonderzoek wil ik vanaf deze plaats dan ook hartelijk bedanken! Een aantal mensen wil ik hierbij in het bijzonder noemen.

Toen ik starte met mijn promotieonderzoek was de wereld van geuren voor mij een volkomen nieuw gebied. Alexandra, jij hebt mij wegwijs gemaakt in dit veld en ik heb heel erg veel van je geleerd. Ik kon altijd bij je terecht voor wat dan ook. Het was dan ook wel even behoorlijk slikken toen je me vertelde dat je NIZO zou gaan verlaten om bij het toenmalige Numico te gaan werken. Gelukkig ben je wel mijn co-promotor gebleven! Het is super dat je enorm betrokken bent gebleven en wanneer je weer op NIZO was voor een overleg was het weer net zo gezellig als vanouds. Heel erg bedankt voor deze zeer plezierige en leerzame tijd!

Margriet en Kees, ook het verzadigingsonderzoek was voor mij een nieuwe uitdaging. Ik heb vele tips, adviezen en verbeteringen van jullie mogen krijgen ten aanzien van studieprotocollen en manuscripten, waarvoor ik jullie beiden hartelijk wil bedanken! Ondanks dat ik een 'AIO-op afstand' was, voelde dit in de praktijk absoluut niet zo. Ik waardeer het zeer dat jullie me ook hebben betrokken bij jullie AIO's van HB en de Eetclub. Hierdoor kon ik met praktische vragen over analyses (dankjewel Nicolien!) of procedures (dankjewel Astrid!) altijd bij iemand terecht en kwam ik op congressen altijd wel een bekende tegen. Jullie beide expertise was voor mij de unieke combinatie van de verzadigingscascade!

Voordat ik aan mijn promotieonderzoek begon, werkte ik al bij NIZO food research als projectleider, maar ik had zeker de ambitie om te promoveren. Meike, aan jou heb ik eigenlijk dit promotieonderzoek te danken. Toen dit project eraan zat te komen, heb je mij de gelegenheid gegeven om hieraan te beginnen. Dankjewel!! Ook wil ik je bedanken voor het kritisch lezen van alle manuscripten, je enthousiasme, betrokkenheid en het altijd bij je binnen kunnen lopen! Super dat je mijn paranimf wilt zijn!

Naast Meike, wil ik het hele NIZO management team bedanken dat ik de kans heb gekregen om op deze manier mijn promotieonderzoek te mogen doen! De combinatie met contractresearch kan ik iedereen echt aanraden.

Leden van de begeleidingscommissie, bedankt voor alle tips en adviezen tijdens onze halfjaarlijkse bijeenkomsten! De discussies waren altijd zeer zinvol. Nog steeds vind ik dat het mooie van dit project is dat het heel tastbaar en concreet is, en vrijwel direct 
toepasbaar in productontwikkeling.

The DiOGenes management, consortium partners and RTD line 5 partners I would like to thank for the excellent collaborations we had. It was nice meeting all of you and I am looking forward to working together again in another setting!

De voorbereiding en uitvoering van de beschreven studies vergt heel wat organisatie. Ik ben hierbij aan heel wat mensen veel dank verschuldigd! Maurits, dankjewel voor al je betrokkenheid bij mijn promotieonderzoek! Het was prettig om op iemand in de directe werkomgeving terug te kunnen vallen toen Alexandra NIZO verliet. Ik hoop dat je inmiddels bij TNO ook je plekje hebt gevonden!

Annereinou, Celine, Denise, Egbert, Fanny, Ineke, Iris, Jan, Kerstin, Leonie, Marc, Margreet, Marja, Marja, Nico, Peter, Severine (thank you for the extensive desk study as preparation for the complexity study), Saskia, Suzanne, Wim en collega's die ik onbedoeld misschien vergeten ben, de hulp van collega's is onmisbaar! Iedereen bedankt voor alle bijdragen en de super gezellige werksfeer!

Zonder vrijwilligers is het niet mogelijk om dit soort onderzoek te doen. Daarom alle deelnemers aan de verschillende studies heel erg bedankt voor jullie bijdrage aan de wetenschap!

Sander, Karin, Diederik, Ron, Sjaak, Ton en Willy bedankt voor het inbrengen van de neuscatheters tijdens de olfactometerstudies! Alle co-auteurs bedankt voor de prettige samenwerking! Chris thank you for checking all my manuscripts for appropriate use of English language!

De resultaten van de studies laten zien dat er veel potentie zit in het concept aromageïnduceerde verzadiging. Mariëlle, ik ben blij dat dit onderzoek via jou nu verder gaat en ik hier actief bij betrokken ben. Succes!

Hoewel ik eigenlijk steeds leefde van deadline naar deadline, zorgden de lunchpauzes, de 'even kletsen' momenten en de afdelings- en 'het is leuk om bij NIZO te werken' borrels voor een welkome onderbreking. Annemarie, Corinne, Ellen, Elles, Hendrik, Joost, Leonie, Marc, Mariëlle, Moniek, Paula, Rene, Rob, collega's van de kantoortuin (Frank, Hans, Harro, Hein, Jan, Jeroen, Maria, Marjon, Michiel en Sandra) en overige NIZO collega's dankjewel!

Tevens een dankjewel aan de Kernhemmer redactie (Ann, Barry, Cornelie, Ellen, Ellen, Gera, Hans, Marieke, Marjo, Martijn, Rita, Sander en Wilma) voor de gezellige vergaderingen!

Ook mijn Wageningen vriendinnen wil ik graag bedanken voor de vele leuke en gezellige momenten van ontspanning! Gerda, onze vriendschap begon eigenlijk pas na ons afstuderen, maar is er daarom zeker niet minder om! Behalve onze ouders die in het zuiden wonen, hebben we best veel gemeen! Jij ook succes met de laatste loodjes van je proefschrift! Super dat je mijn paranimf wilt zijn! Meiden van 'kamer 5' (Corine, 
José en Petra) het is echt weer tijd voor een weekendje weg! Ook al ben ik de enige die nu nog in Wageningen woont, ik hoop dat we waar ook ter wereld altijd vriendinnen zullen blijven! Maartje, sinds het begin van levensmiddelen spreken we 'geregeld' af om bij elkaar te eten. Dit 'geregeld' varieert van een paar keer per maand tot een paar keer per jaar. Of het nou vaak is of niet, het is altijd erg gezellig! Zo ook de laatste maanden, we waren allebei druk met het afronden van onze proefschriften en van samen eten is dan ook weinig terecht gekomen. Zullen we binnenkort weer eens afspreken? Dit geldt ook voor jullie Ruurdtje en Sylvia, we moeten binnenkort echt weer eens afspreken!

Lieve mam en pap, dank jullie wel voor alles wat ik tot dusver heb bereikt, al jullie goede zorgen, jullie nooit aflatende steun en zoveel meer! Marlies en Alex, bedankt dat jullie altijd interesse tonen in hoe het gaat! Een vraag die steevast werd gesteld was hoeveel artikelen ik nu nog moest schrijven... :)

Lieve Rob, ik ben blij dat jij het meest creatief van ons beiden bent, want anders was de kaft en de lay-out beduidend minder geweest. Super bedankt hiervoor!! Hoewel ik denk ik wel een beetje werkverslaafd ben (:), ben jij voor mij het levend bewijs dat er nog zo veel meer is! Fijn dat je er altijd voor me bent! Eindelijk tijd om samen op zoek te gaan naar ons toekomstige huis!

Op naar de volgende uitdaging!

Rianne 


\section{Personalia}




\section{CURRICULUM VITAE}

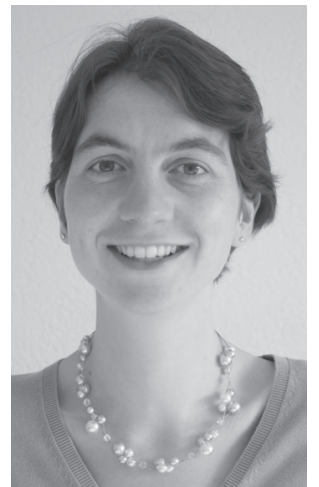

Rianne Maria Anna Josephina Ruijschop was born on January $22^{\text {nd }} 1980$ in Heerlen, The Netherlands. In 1998, she completed secondary school at the 'Catholic Grammar School Rolduc' in Kerkrade. In the same year she started her study Food Technology with main specialisation Product Design and Quality Management and second specialisation Food Quality Management at Wageningen University, where she graduated in September 2003 cum laude. In this period, she performed internships at two industrial companies, Martinair Food (Marfo) in Lelystad and Kraft Foods R\&D in Munich.

From December 2003 on, Rianne is working as a project manager at the department of Health \& Safety at NIZO food research. Besides, in January 2005 she started her PhD as part of the pan-European programme DiOGenes ("Diet, Obesity and Genes") and the Collective Research Dairy Nutrition and Health Programme carried out by NIZO food research for the Dutch dairy industry.

In October 2007, she was awarded with the Best Poster Award in the category Nutrition \& Health for her poster 'Engineering satiating liquid food products by altering the extent of flavour release' at the World Dairy Summit 2007, organized by the International Dairy Federation and held in Dublin, Ireland. In April 2008, Rianne was awarded with the prestigious Unilever Young Scientist Prize. The prize was awarded based on her ground breaking work on the role of aromas in satiation. In April 2009, she finished her thesis entitled 'Retro-nasal aroma release and satiation'. In the same month, she had the honour to participate in the $15^{\text {th }}$ European Nutrition Leadership Programme (ENLP), which is organized by a group of leading European nutritionists in close collaboration with and funded by the European food industry, held in Luxembourg.

At NIZO food research Rianne is currently involved as a project manager in multidisciplinary research projects with a focus on health. 


\section{LIST OF PUBLICATIONS}

Costa, A.I.A., \& Ruijschop, R.M.A.J. (2006) Just how convenient is convenience? An empirical study of the associations between perceived convenience, meal preparation activities and ready meals' characteristics. FCC Abstracts. Appetite 47: 261 doi: 10.1016/j.appet.2006.07.016.

Harthoorn, L.F., Ruijschop, R.M.A.J., Weinbreck, F., Burgering, M.J.M., de Wijk, R.A., Ponne, C.T., \& Bult, J.H.F. (2008) Effects of aroma-texture congruency within dairy custard on satiation and food intake. Food Qual. Pref. 19: 644-650 doi: 10.1016/j. foodqual.2008.05.004.

Ramaekers, M.G., Luning, P.A., Ruijschop, R.M.A.J., \& van Boekel, M.A.J.S. (2009) Effect of aroma release profiles on ad libitum food intake. ECRO Abstracts. Chem. Senses 34: E20 doi: 10.1093/chemse/bjn083.

Ruijschop, R.M.A.J., Boelrijk, A.E.M., Burgering, M.J.M., de Graaf, C., \& WesterterpPlantenga, M.S. Effects of ingredient-related aroma cues on satiation and food intake. Submitted for publication.

Ruijschop, R.M.A.J., Boelrijk, A.E.M., Burgering, M.J.M., de Graaf, C., \& WesterterpPlantenga, M.S. Acute effects of complexity in aroma composition on satiation and food intake. Submitted for publication.

Ruijschop, R.M.A.J., Boelrijk, A.E.M., Burgering, M.J.M., de Graaf, C., \& WesterterpPlantenga, M.S. (2009) Novel approaches to induce satiation via aroma in foods. Proceedings 12th Weurman Flavour Research Symposium, Interlaken, Switzerland. Accepted for publication.

Ruijschop, R.M.A.J., Boelrijk, A.E.M., Burgering, M.J.M., de Ru, J.A., de Graaf, C., \& Westerterp-Plantenga, M.S. (2007) Engineering satiating liquid food products by altering the extent of flavour release. SSIB Abstracts. Appetite 49: 325 doi: 10.1016/j. appet.2007.03.172.

Ruijschop, R.M.A.J., Boelrijk, A.E.M., \& te Giffel, M.C. (2008) Satiety effects of a dairy beverage fermented with propionic acid bacteria. Int. Dairy J. 18: 945-950 doi: 10.1016/j.idairyj.2008.01.004.

Ruijschop, R.M.A.J., Boelrijk, A.E.M., te Giffel, M.C., de Graaf, C., \& WesterterpPlantenga, M.S. (2009) Induction of satiation via aroma in dairy products. Aust. J. Dairy Technol. 64: 50-53.

Ruijschop, R.M.A.J., Boelrijk, A.E.M., de Graaf, C., \& Westerterp-Plantenga, M.S. Retro-nasal aroma release and satiation: a review. Submitted for publication. 
Ruijschop, R.M.A.J., Boelrijk, A.E.M., de Ru, J.A., de Graaf, C., \& WesterterpPlantenga, M.S. (2008) Effects of retro-nasal aroma release on satiation. Br. J. Nutr. 99: 1140-1148 doi: 10.1017/S0007114507837482.

Ruijschop, R.M.A.J., \& Burgering, M.J.M. (2007) Aroma induced satiation: possibilities to manage weight through aromas in food products. AgroFood Industry hitech 18: 37-39.

Ruijschop, R.M.A.J., \& Burgering, M.J.M. (2008) Mogelijk minder eetlust door geur in voedsel. Voedingsmiddelentechnologie 1/2: 20-22.

Ruijschop, R.M.A.J., Burgering, M.J.M., Jacobs, M.A., \& Boelrijk, A.E.M. (2009) Retro-nasal aroma release depends on both subject and product differences: A link to food intake regulation? Chem. Senses doi: 10.1093/chemse/bjp011.

Ruijschop, R.M.A.J., Burseg, K.M.M., Lambers, T.T., \& Overduin, J. (2009) Designing foods to induce satiation - a flavour perspective. In: McClements, D.J., \& Decker, E.D. (Eds.), Designing functional foods: Understanding, measuring and controlling food structure breakdown and nutrient absorption for the development of health-promoting foods (Chapter 24). Cambridge: Woodhead Publishing Ltd \& CRC Press LLC (in press).

Ruijschop, R.M.A.J., \& de Kok, P.M.T. (2009) Induction of satiation via aroma in foods. Food Sci. Technol. 23: 25-27.

Ruijschop, R.M.A.J., Zijlstra, N., Boelrijk, A.E.M., Dijkstra, A., Burgering, M.J.M., de Graaf, C., \& Westerterp-Plantenga, M.S. Effects of bite size and duration of oral processing on retro-nasal aroma release - features contributing to meal termination. Submitted for publication.

Van de Velde, F., de Hoog, E.H.A., \& Ruijschop, R.M.A.J. (2008) Sensorische perceptie van emulsies: het raadsel van de romigheid verder ontrafeld. Mager? Vet lekker! Voedingsmiddelentechnologie 21: 23-25.

Van de Velde, F., de Hoog, E.H.A., \& Ruijschop, R.M.A.J. (2008) Sensory perception of emulsions: translating science into products. AgroFood Industry hi-tech 19: 50-52. 



